MARCEL CAVALLINI BARBOSA

\title{
INVESTIGAÇÃO DA DISTRIBUIÇÃO DE TAMANHO DE BOLHAS EM UM SEPARADOR GÁS-LÍQUIDO DO TIPO SHROUD INVERTIDO
}

Dissertação apresentada à Escola de Engenharia de São Carlos da Universidade de São Paulo para obtenção do título de Mestre em Engenharia Mecânica.

Área de concentração: Térmica e Fluidos

Orientador: Prof. Ass. Oscar Mauricio Hernandez Rodriguez

SÃO CARLOS

2015

ESTE EXEMPLAR TRATA-SE

DA VERSÃO CORRIGIDA.

A VERSÃO ORIGINAL ENCONTRA-SE DISPONÍVEL JUNTO AO DEPARTAMENTO DE ENGENHARIA MECÂNICA DA EESC-USP. 


\section{AUTORIZO A REPRODUÇ̃̃O TOTAL OU PARCIAL DESTE TRABALHO, POR QUALQUER MEIO CONVENCIONAL OU ELETRÓNICO, PARA FINS DE ESTUDO E PESQUISA, DESDE QUE CITADA A FONTE.}

Barbosa, Marcel Cavallini

Investigação da distribuição de tamanho de bolhas em um separador gás-líquido do tipo shroud invertido / Marcel Cavallini Barbosa; orientador Oscar Mauricio Hernandez Rodriguez. São Carlos, 2015.

Dissertação (Mestrado) - Programa de Pós-Graduação em Engenharia Mecânica e Área de Concentração em Térmica e Fluídos -- Escola de Engenharia de São Carlos da Universidade de São Paulo, 2015.

1. Escoamento multifásico. 2. Separação gás-líquido. 3. Shroud invertido. 4. Duto anular. 5. Diâmetro de bolhas. 6. Aeração em canal aberto. I. Titulo. 


\section{FOLHA DE JULGAMENTO}

Candidato: Engenheiro MARCEL CAVALLINI BARBOSA.

Título da dissertação: "Investigação da distribuição de tamanho de bolhas em um separador gás-líquido do tipo shroud invertido.

Data da defesa: $13 / 11 / 2015$

Comissāo Julgadora:

Prof. Associado Oscar Mauricio Hernandez Rodriguez (Orientador)

(Escola de Engenharia de São Carlos/EESC)

Prof. Dr. Marcelo Souza de Castro

(Universidade Estadual de Campinas/UNICAMP)

Prof. Dr. Fernando Guimarães Aguiar

(Universidade Federal de São Carlos/UFSCar)
Resultado:

APROVADO

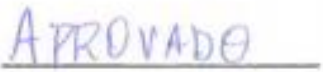

Coordenador do Programa de Pós-Graduação em Engenheira Mecânica: Prof. Associado Gherhardt Ribatski

Presidente da Comissão de Pós-Graduação:

Prof. Associado Paulo César Lima Segantine 

A meus pais Itamar e Célia, por todo o apoio em minhas decisões ao longo da vida 



\section{Agradecimentos}

A meus pais, pelo exemplo de vida e por todo o apoio dado ao longo dos tempos.

Ao meu orientador, Prof. Dr. Oscar Mauricio Hernandez Rodriguez, pela oportunidade e pela confiança a mim depositadas para a realização desse trabalho.

A todos os meus amigos e colegas do laboratório pela ajuda direta e indireta na realização deste trabalho. Seus conselhos e suas sugestões me ajudaram e me motivaram.

Aos membros do corpo técnico do LETeF, que tanto me ajudaram na realização deste trabalho. Em especial deixo meus agradecimentos a José Roberto Bogni, Jorge Nicolau dos Santos e Hélio Donizete Trebi pelo trabalho árduo e pela disposição em me auxiliarem na montagem dos experimentos.

À CAPES pelo suporte financeiro, sem o qual este trabalho não seria possível.

À PETROBRAS, financiadora do projeto, sem a qual não se poderiam realizar os experimentos aqui relatados.

Finalmente, a todos que de alguma maneira contribuíram para a conclusão deste trabalho. 



\section{Resumo}

BARBOSA, M. C. Investigação da distribuição de diâmetro de bolhas em um separador gás-líquido do tipo Shroud invertido. 2015. 166 f. Dissertação (Mestrado) - Escola de Engenharia de São Carlos da Universidade de São Paulo, São Carlos, 2015.

Operações de produção de petróleo, que utilizam sistemas de bombeamento centrífugo submerso, constantemente encontram a presença de gás livre nos poços, o que pode gerar ou agravar problemas como cavitação e falhas dinâmicas, quando o gás é succionado pela bomba. O separador gravitacional do tipo shroud invertido é uma solução possível para este problema nos casos de operação em poços direcionais de petróleo. O trabalho tem como objetivo apresentar um estudo do diâmetro das bolhas que ocorrem no interior de um separador gravitacional gás-líquido do tipo shroud invertido. A finalidade é o aprimoramento de um modelo fenomenológico do funcionamento deste tipo de separador, aplicado à indústria petrolífera, sendo que o modelo fenomenológico garante total separação de gás, fornecidas determinadas condições. O modelo prevê, através do cálculo da energia cinética turbulenta, o tamanho médio das bolhas carregadas para o seio do líquido por aeração no duto anular. Partindo de estudos anteriores, uma verificação do modelo fenomenológico foi feita utilizando um aparato experimental com misturas bifásicas ar-água e ar-óleo em três diferentes inclinações. O aparato possui dimensões radiais reais de um poço de petróleo offshore. Foi utilizado um sensor 3D ORM para a medição do tamanho médio (sauter) das bolhas arrastadas pelo líquido até a entrada do tubo de produção, em diversas combinações de vazões da mistura água-ar. Esta medição permite o ajuste das correlações que regem o modelo fenomenológico, no que diz respeito às equações dependentes do diâmetro teórico de bolhas arrastadas pela fase líquida. As descobertas provenientes deste estudo foram implementadas em um código computacional que será utilizado pela PETROBRAS, financiadora do projeto, para suas operações de bombeamento.

Palavras-chave: Escoamento multifásico; Separação gás-líquido; Shroud invertido; Duto anular; Diâmetro de bolhas; Aeração em canal aberto. 



\begin{abstract}
BARBOSA, M. C. Investigation of bubble-diameter distribution in a gas-liquid Invertedshroud separator. 2015. 166 f. MSc. Dissertation in Mechanical Engineering - São Carlos School of Engineering, University of São Paulo, São Carlos, 2015.
\end{abstract}

Oil mining operations powered by centrifugal submersible pumping systems suffer constant setbacks due to the presence of free gas in wells. Decompression in the reservoir liberates this gas in the form of bubbles that, upon reaching the suction end of the pump, cause cavitation and dynamic failures resulting in production and equipment losses. The Inverted-shroud gravitational separator is a possible solution to this problem. This work presents a study on diameters of bubbles that occur inside this separator. The goal is the improvement of the understanding of this kind of separator as well as the enhancement of a previously reported phenomenological model, which ensures total gas separation when the separator is installed in directional wells and under specific operational conditions. Empirically adjusted correlations are used to ensure that all entrained bubbles do not reach the pump. The model was tested for two-phase flows of water-air and oil-air mixtures using three different inclinations. Tests were performed with an experimental apparatus that simulates a pilot-scale well casing with an inverted-shroud separator installed. A 3D ORM particle-size sensor was employed in order to measure the average (sauter) diameter of entrained bubbles that are dragged by the liquid flow towards the end of the production tube. This investigation will be used to improve the reliability of the phenomenological model and reduce its dependency on a theoretical prediction of the bubble size. The findings were incorporated to the final version of an inhouse gas separator design software developed at the request of PETROBRAS, the project funder and Inverted-shroud patent holder, for usage on its oil mining operations.

Keywords: Multiphase flow; Gas-liquid separation; Inverted shroud; Annular duct; Bubble size; Open channel aeration. 



\section{Lista de Figuras}

Figura 2.1 - (a) Reservatório antes da descompressão. (b) Reservatório após a descompressão e subsequente liberação do gás.

Figura 2.2 - Seção de testes do separador rotativo estudado por Alhanati (1993) 33

Figura 2.3 - Mapa de eficiência do separador apresentado por Alhanati (1993) 34

Figura 2.4 - Separador de helicóide fixo (SOUZA et al., 2003).

Figura 2.5 - Seção de testes do separador proposto por Serrano (1999)......

Figura 2.6 - Separador proposto por (LIU; PRADO, 2001b), com suas três zonas de separação destacadas

Figura 2.7 - Segunda região de separação do separador de (LIU; PRADO, 2001b), com linhas críticas de trajetória das bolhas em destaque.

Figura 2.8 - Região crítica de separação de bolhas segundo (LIU; PRADO, 2001b). 38

Figura 2.9 - Separador gravitacional proposto e testado por Rondy, Cholet e Federer (1993).

Figura 2.10 - Separador gravitacional testado por Ortiz-Vidal (2010).

Figura 2.11 - Separador do tipo Inverted-Shroud com tubo perfurado (BOHORQUEZ et al., 2007).

Figura 2.12 - Tipos de variação espacial em um escoamento de superfície livre (ÇENGEL; CIMBALA, 2006)

Figura 2.13 - Distribuição de diâmetros de bolhas observada por Westende (2008), em que $d d r$ se refere aos diâmetros aferidos.

Figura 2.14 - Distribuição de diâmetros de gotas em uma solução com $10 \%$ de volume de querosene agitada com um impulsor a $450 \mathrm{rpm}$ (LOVICK et al., 2005).....47

Figura 3.1 - Distribuição das regiões de escoamento do separador de shroud invertido, retirada de Ortiz-Vidal (2010).

Figura 3.2 - Padrões de escoamento em um duto anular vertical, como identificado por Caetano, Shoham e Brill (1992)

Figura 3.3 - Geometria do escoamento em superfície livre no anular interno do separador shroud invertido (MENDES, 2012).

Figura 4.1 - Esquema do circuito experimental utilizado no LETeF-EESC-USP na primeira etapa de testes (medição da eficiência de separação de gás). 
Figura 4.2 - Esquema do circuito experimental utilizado no LETeF-EESC-USP na segunda etapa de testes (medição do diâmetro de bolhas)

Figura 4.3 - Foto da seção de testes $(\mathrm{P})$, com a viga treliçada $(\mathrm{O})$. 66

Figura 4.4 - Esquema da seção de testes. .67

Figura 4.5 - Diagrama da geometria da seção de testes. 68

Figura 4.6 - Abraçadeiras de nylon utilizadas para prender a seção de testes à viga treliçada.

Figura 4.7 - Misturador gás-líquido utilizado no aparato experimental (MENDES, 2012)...69

Figura 4.8 - Separador água-óleo de placas coalescentes instalado no NETeF-USP.

Figura 4.9 - Tanque de água com 500 litros de capacidade.

Figura 4.10 - Bombas de alimentação de água e óleo.

Figura 4.11 - Variadores de frequência. a) Variador da bomba de água, modelo WEG CFW09 e b) Variador da bomba de óleo, modelo Yaskawa VS-616PC5/P5 ... 72

Figura 4.12 - Medidores de vazão de água, a) Medidor de deslocamento positivo Oval OGT e b) Medidor tipo vortex Oval EX Delta

Figura 4.13 - Medidores de vazão de óleo, a) Medidor de deslocamento positivo Oval Flowmeter MIII e b) Medidor de deslocamento positivo Oval Flowpet EG.... 74

Figura 4.14 - Compressor de parafuso Schulz SRP-3030 Compact..................................... 74

Figura 4.15 - Reservatório de ar do sistema pneumático.................................................. 75

Figura 4.16 - Medidores de vazão volumétrica de ar, a) Oval GAL50 e b) Contech SVTG $1 / 2$,

Figura 4.17 - Transdutores de pressão utilizados no cálculo da vazão mássica de ar à montante da seção de testes.

Figura 4.18 - Barômetro e termômetro de mercúrio Princo 453.

Figura 4.19 - Medidor de vazão do tipo placa de orifício com 6,6 mm de diâmetro de furo.

Figura 4.20 - Arranjo de transdutores de pressão diferencial Smar LD301 utilizados na medição de vazão através da placa de orifício.

Figura 4.21 - Tanque de separação gás-líquido instalado à jusante da seção de testes.

Figura 4.22 - Placa de aquisição NI PCI 6224.

Figura 4.23 - Bloco conversor de sinais. 
Figura 4.24 - Interface do software supervisório implementado em LabVIEW.

Figura 4.25 - Válvulas de controle da vazão de ar à jusante da linha de testes (a) Válvula de agulha indicada em $\mathrm{T}$ e (b) Válvula de gaveta indicada em Q..... 85

Figura 4.26 - Diagrama da segunda montagem da seção de testes. 86

Figura 4.27 - Peça especial para acoplamento da sonda ORM na seção de testes. (a) Peça desmontada (b) Peça montada

Figura 4.28 - Suporte para instalação da sonda 87

Figura 4.29 - Bomba e tanque utilizados à jusante da seção de testes.

Figura 4.30 - Foto da sonda do sensor 3D ORM.

Figura 4.31 - Diâmetros de bolha esperados para a mistura ar-água a uma inclinação de 15 graus.

Figura 4.32 - Diâmetros de bolha esperados para a mistura ar-água a uma inclinação de 45 graus.

Figura 4.33 - Diâmetros de bolha esperados para a mistura ar-água a uma inclinação de 60 graus.

Figura 4.34 - Bancada usada para validação experimental do sensor ORM com câmera de alta velocidade.

Figura 4.35 - Programa em plataforma LabVIEW® para análise do diâmetro de bolhas filmadas com câmera de alta velocidade.

Figura 4.36 - Distribuição de diâmetros obtida antes da adição das microesferas de vidro, representando assim o ruído da medida.

Figura 4.37 - Distribuição de diâmetros obtida na medição das microesferas de vidro.

Figura 4.38 - Histograma comparativo da medição de partículas dispersas em água pura (em vermelho) e em água pura com microesferas de vidro (em preto).

Figura 4.39 - Fenômeno de afogamento observado na linha de testes.

Figura 4.40 - Vista frontal do tubo perfurado projetado por Bulgarelli (2014)

Figura 5.1 - Fronteira do comprimento $L N A I$ em função da vazão de líquido $Q L$ com o separador inclinado a $15^{\circ}$

Figura 5.2 - Fronteira do comprimento $L N A I$ em função da vazão de líquido $Q L$ com o separador inclinado a $45^{\circ}$

Figura 5.3 - Fronteira do comprimento $L N A I$ em função da vazão de líquido $Q L$ com o separador inclinado a $60^{\circ}$ 
Figura 5.4 - Carta de eficiência de separação em termos do comprimento LNAI pela vazão de água, para a inclinação de $15^{\circ}$, com a nova nuvem de pontos experimentais sobreposta.

Figura 5.5 - Carta de eficiência de separação em termos do comprimento LNAI pela vazão de água, para a inclinação de $45^{\circ}$, com a nova nuvem de pontos experimentais sobreposta.

Figura 5.6 - Carta de eficiência de separação em termos do comprimento LNAI pela vazão de água, para a inclinação de $60^{\circ}$, com a nova nuvem de pontos experimentais sobreposta.

Figura 5.7 - Carta de eficiência de separação em termos do comprimento LNAI adimensional pelo número de Weber ajustado $(W e *)$ do escoamento, para a inclinação de $15^{\circ}$, com a nova nuvem de pontos experimentais sobreposta

Figura 5.8 - Carta de eficiência de separação em termos do comprimento LNAI adimensional pelo número de Weber ajustado $(W e *)$ do escoamento, para a inclinação de $45^{\circ}$, com a nova nuvem de pontos experimentais sobreposta

Figura 5.9 - Carta de eficiência de separação em termos do comprimento LNAI adimensional pelo número de Weber ajustado $(W e *)$ do escoamento, para a inclinação de $60^{\circ}$, com a nova nuvem de pontos experimentais sobreposta

Figura 5.10 - Carta de eficiência de separação em termos do comprimento LNAI adimensional pelo número de Weber ajustado $(W e *)$ do escoamento arágua, para a inclinação de $15^{\circ}$, com os dados experimentais obtidos no trabalho atual e nos trabalhos de Ortiz-Vidal (2010) e Mendes (2012).......... 112

Figura 5.11 - Carta de eficiência de separação em termos do comprimento LNAI adimensional pelo número de Weber ajustado $(W e *)$ do escoamento arágua, para a inclinação de $45^{\circ}$, com os dados experimentais obtidos no trabalho atual e nos trabalhos de Ortiz-Vidal (2010) e Mendes (2012)....

Figura 5.12 - Carta de eficiência de separação em termos do comprimento LNAI adimensional pelo número de Weber ajustado $(W e *)$ do escoamento arágua, para a inclinação de $60^{\circ}$, com os dados experimentais obtidos no trabalho atual e nos trabalhos de Ortiz-Vidal (2010) e Mendes (2012)

Figura 5.13 - Carta de eficiência de separação em termos do comprimento LNAI em função da vazão de óleo $Q L$ para a inclinação de $15^{\circ}$.

Figura 5.14 - Carta de eficiência de separação em termos do comprimento LNAI em função da vazão de óleo $Q L$ com nova nuvem de pontos experimentais obtidos na inclinação de $15^{\circ}$ 
Figura 5.15 - Carta de eficiência de separação em termos do comprimento LNAI em função da vazão de óleo $Q L$ com nova nuvem de pontos experimentais obtidos na inclinação de $45^{\circ}$

Figura 5.16 - Carta de eficiência de separação em termos do comprimento LNAI em função da vazão de óleo $Q L$ com nova nuvem de pontos experimentais obtidos na inclinação de $60^{\circ}$

Figura 5.17 - Carta de eficiência de separação em termos do comprimento LNAI adimensional em função do número de Weber $W e *$ para a inclinação de $15^{\circ}$, retidada de Mendes (2012).

Figura 5.18 - Carta de eficiência de separação em termos do comprimento LNAI adimensional em função de $W e *$ para a inclinação de $15^{\circ}$ com a nuvem de pontos obtida por Mendes (2012), levando em conta a viscosidade variável.

Figura 5.19 - Carta de eficiência de separação em termos do comprimento LNAI adimensional pelo número de Weber ajustado $(W e *)$ do escoamento aróleo, para a inclinação de $15^{\circ}$, com os dados experimentais obtidos no trabalho atual e no trabalho de Mendes (2012).

Figura 5.20 - Carta de eficiência de separação em termos do comprimento LNAI adimensional pelo número de Weber ajustado $(W e *)$ do escoamento aróleo, para a inclinação de $45^{\circ}$, com os dados experimentais obtidos no trabalho atual e no trabalho de Mendes (2012).

Figura 5.21 - Carta de eficiência de separação em termos do comprimento LNAI adimensional pelo número de Weber ajustado $(W e *)$ do escoamento aróleo, para a inclinação de $60^{\circ}$, com os dados experimentais obtidos no trabalho atual e no trabalho de Mendes (2012).

Figura 5.22 - Distribuição de diâmetros de bolhas com distância Llente = 2,92 m.

Figura 5.23 - Distribuição de diâmetros de bolhas com distância Llente $=2,70 \mathrm{~m}$.

Figura 5.24 - Distribuição de diâmetros de bolhas com distância Llente $=1,43 \mathrm{~m}$.

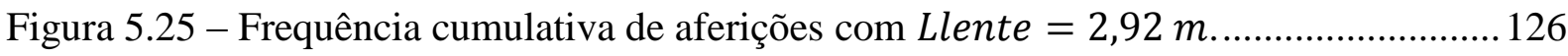

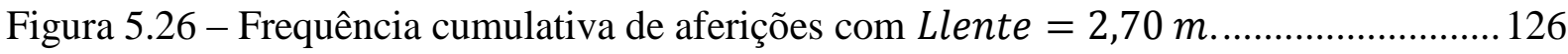

Figura 5.27 - Frequência cumulativa de aferições com Llente $=1,43 \mathrm{~m}$.

Figura 5.28 - Pontos experimentais sobrepostos à curva de diâmetros de bolha previstos pelo modelo fenomenológico.

Figura 5.29 - Eficiências de separação de gás medidas em função das vazões nos testes de afogamento.

Figura B.1 - Curva de viscosidade dinâmica do óleo Shell Vitrea 100 utilizado vs. Temperatura. 
Figura C.1 - Diagrama do software supervisório utilizado para controle da bancada experimental.

Figura E.1 - Interface do software entregue inicialmente à PETROBRAS......................... 154

Figura E.2 - Interface da última versão do software entregue à PETROBRAS.

Figura E.3 - Interface da seção do software feita para calcular o número de furos em seções do shroud ...................................................................................... 156

Figura E.4 - Fluxograma de tomada de decisões para orientação do usuário final do software de projeto de separadores tipo shroud invertido.

Figura E.5 - Dados dispostos no relatório técnico entregue à PETROBRAS para a fabricação de um separador gravitacional tipo shroud invertido a ser utilizado em condições de campo. 


\section{Lista de Tabelas}

Tabela 4.1 - Componentes do Sistema experimental. 63

Tabela 4.2 - Elementos do sistema de instrumentação. 64

Tabela 4.3 - Geometrias utilizadas na seção de testes. 68

Tabela 4.4 - Especificações do sensor 3D ORM 90

Tabela 5.1 - Pontos experimentais obtidos nas baterias de testes divididas por mistura bifásica e inclinação da seção de testes.

Tabela 5.2 - Dados obtidos através das distribuições de diâmetros de bolha 127

Tabela D.1 - Disciplinas concluídas durante o mestrado 149

Tabela F.1 - Dados experimentais obtidos com a mistura bifásica ar-água nos estudos de eficiência de separação de gás

Tabela F.2 - Dados experimentais obtidos com a mistura bifásica ar-óleo nos estudos de eficiência de separação de gás

Tabela F.2 - Dados experimentais obtidos com a mistura bifásica ar-água nos estudos de distribuições de diâmetros de bolhas 



\section{Nomenclatura e Lista de Símbolos}

$\begin{array}{lll}\text { A } & \text { área } & \mathrm{m}^{2} \\ \text { d } & \text { diâmetro de bolhas } & \mathrm{m} \\ \mathrm{D} & \text { diâmetro das tubulações } & \mathrm{m} \\ f & \text { fator de atrito } & \\ \mathrm{h} & \text { altura adimensional da interface gás-líquido } & \\ \mathrm{L} & \text { comprimento no sentido axial da tubulação } & \mathrm{m} \\ \mathrm{m}, \mathrm{n} & \text { parâmetros adimensionais de ajuste d } & \\ \dot{\mathrm{m}} & \text { vazão mássica } & \mathrm{kg} / \mathrm{s} \\ \mathrm{P} & \text { pressão } & \mathrm{Pa}, \mathrm{bar} \\ \mathrm{Q} & \text { vazão volumétrica } & \mathrm{m} / \mathrm{s} \\ \mathrm{R} & \text { constante universal dos gases } & \mathrm{J} \mathrm{kg}{ }^{-1} \mathrm{~K}^{-1} \\ \mathrm{Re} & \text { número de Reynolds } & \\ \mathrm{S} & \text { perímetro molhado ou interfacial } & \mathrm{m} \\ \mathrm{T} & \text { temperatura } & { }^{\circ} \mathrm{C} \\ \mathrm{V} & \text { velocidade } & \mathrm{m} / \mathrm{s} \\ \text { We } & \text { número de Weber } & \end{array}$

Letras gregas

$\begin{array}{llc}\beta & \text { inclinação da tubulação em relação à horizontal } & \stackrel{\text { o }}{\text { rad }} \\ \varepsilon & \text { rugosidade absoluta da tubulação } & \mathrm{m} \\ \epsilon & \text { taxa de dissipação de energia por unidade de massa } & \\ \eta & \text { eficiência de separação de gás } & \\ \mu & \text { viscosidade dinâmica } & \mathrm{Pa} . \mathrm{s} \\ \rho & \text { massa específica } & \mathrm{kg} / \mathrm{m}^{3} \\ \sigma & \text { tensão interfacial gás-líquido } & \mathrm{N} / \mathrm{m}\end{array}$

Subscritos

anular interno 

adimensional
dis
dissipação de energia
$\mathrm{L}$
fase líquida
Lente
lente da sonda óptica 3D ORM
DES
desenvolvimento do perfil de escoamento
G
fase gasosa
$\mathrm{H}$
diâmetro hidráulico
I
interno ao tubo (inner)
$\mathrm{j}$
LO
jusante do separador
$\mathrm{m}$
referente ao nível da interface gás-líquido
máximo
montante do separador
médio
diâmetro da bolha maior que $99 \%$ das amostras obtidas
média aritmética simples
NAI
nível do líquido no duto anular interno
NAE
nível do líquido no duto anular externo
$\mathrm{O}$
externo ao tubo (outer)
Sauter
média obtida através da razão entre volume e área superficial das bolhas
SEP
necessário à total separação de gás
SL superfície livre
STOKES
referente à trajetória da bolha, calculada pela Lei de Stokes
ter
terminal
Superescritos
* adimensional modificado
Siglas
BCS bomba centrífuga submersa
IS inverted-shroud
EBV escoamento bruscamente variado
EGV escoamento gradualmente variado 
escoamento uniforme

NAI

nível do líquido no duto anular interno

NAE

nível do líquido no duto anular externo

ORM optical reflectance measurement, ou medição por reflectância óptica

PDF probability density function

TGS total gas separation, ou separação total de gás 



\section{Sumário}

CAPÍTULO 1 INTRODUÇÃO 29

CAPÍTULO 2 REVISÃO DA LITERATURA …..........................................................31

$2.1 \quad$ Separadores Gás-Líquido ..............................................................................31

2.2 Escoamento em Superfície Livre e Aeração ……………………………....... 43

2.3 Análise de Distribuições de Diâmetro de Bolhas ........................................... 44

\section{CAPÍTULO 3 MODELAGEM DO SEPARADOR TIPO SHROUD INVERTIDO.....49}

$3.1 \quad$ Fenomenologia...............................................................................49

3.2 Hipóteses Adotadas ...................................................................................52

3.3 Desenvolvimento da Modelagem .................................................................52

3.3.1 Comprimento de Desenvolvimento .................................................................53

3.3.2 Comprimento de Stokes..........................................................................54

3.3.3 Velocidade terminal da bolha ..........................................................................54

CAPÍTULO 4 TRABALHO EXPERIMENTAL ...................................................................61

4.1 Instalações Experimentais ..............................................................................61

4.2 Primeira etapa experimental......................................................................65

4.2.1 Separador piloto .......................................................................................6 65

4.2.2 Suprimento de Água e Óleo ................................................................... 70

4.2.3 Suprimento de Ar ....................................................................................... 74

4.2.4 Eficiência de Separação de Gás.................................................................. 75

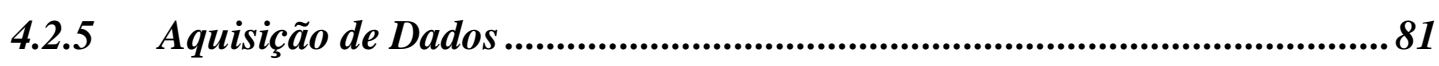

4.2.6 Operação do aparato experimental................................................................. 84

4.3 Segunda etapa experimental ......................................................................85

4.3.1 Alterações na seção de testes ..................................................................... 86

4.3.2 Alterações no sistema de alimentação de fluidos.......................................... 88

4.3.3 Alterações no sistema de instrumentação ................................................... 89

4.3.4 Medição in situ do diâmetro de bolhas......................................................... 89

4.3.5 Validação da sonda ORM - Câmera de alta velocidade ...............................92

4.3.6 Validação da sonda ORM - Partículas de diâmetro conhecido ..................94

4.4 Estudo do fenômeno de afogamento .............................................................97 
CAPÍTULO 5 RESULTADOS E DISCUSSÕES 100

Estudo da Separação de Gás ..................................................................100

5.1.1 Dados experimentais de eficiência de separação de gás........................... 100

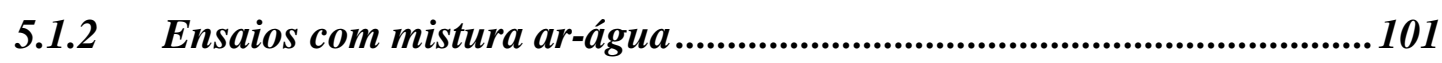

5.1.3 Ensaios com mistura ar-óleo .............................................................114

5.2 Estudo da distribuição de diâmetros de bolha .........................................122

$5.3 \quad$ Ensaios de afogamento (ar-água).............................................................. 129

5.4 Observações qualitativas e conclusões .....................................................130

5.4.1 Separação de Gás .............................................................................130

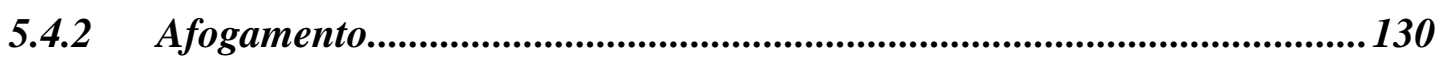

CAPÍtULOO 6 CONCLUSÕES E PERSPECTIVAS .......................................................131

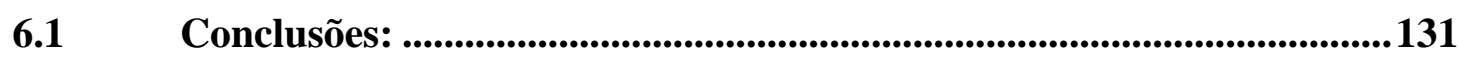

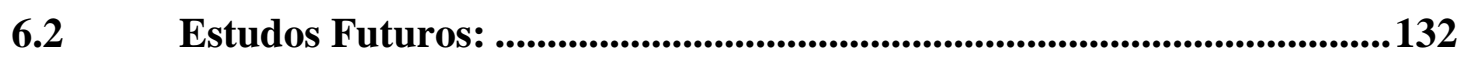

APÊNDICE A INCERTEZAS EXPERIMENTAIS .........................................................139

A.1 Incerteza do medidor de vazão do tipo Placa de Orifício........................140

A.1.1 Incerteza associada ao coeficiente de descarga ........................................ 141

A.1.2 Incerteza associada ao diâmetro interno do tubo ..................................... 141

A.1.3 Incerteza associada ao diâmetro do furo da placa .................................... 141

A.1.4 Incerteza associada ao fator isoentrópico ................................................ 141

A.1.5 Incerteza associada à pressão diferencial ...............................................142

A.2 Incerteza da vazão mássica de gás através da vazão volumétrica, pressão e temperatura .........................................................................142

A.2.1 Incerteza das densidades do ar à montante e à jusante da linha .............. 143

A.3 Incerteza da eficiência de separação de gás ................................................ 145

APÊNDICE B PROPRIEDADES FÍSICAS DO ÓLEO...................................................147

APÊNDICE C DIAGRAMA DO SOFTWARE SUPERVISÓRIO.................................. 149

APÊNDICE D DISCIPLINAS CONCLUÍDAS NO MESTRADO E PUBLICAÇÕES.........................................................................151

D.1 Publicações em anais de congressos...................................................151

APÊNDICE E TRABALHO REALIZADO COM A INDÚSTRIA.............................153

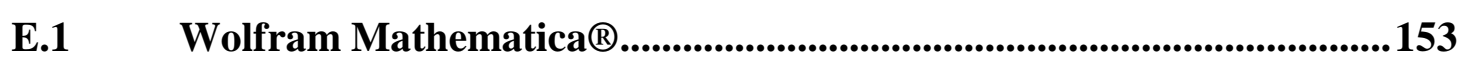

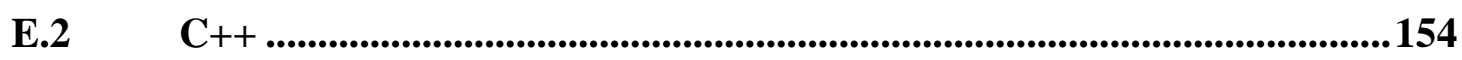


E.3 Projeto de Separador para instalação em campo......................................157 



\section{CAPÍtULOO 1 INTRODUÇÃo}

A crescente necessidade energética global motiva grandes esforços para o desenvolvimento de novas tecnologias para a extração do petróleo, desde os métodos para a detecção de reservas subterrâneas, até técnicas de bombeamento para aumentar a produtividade de um poço. Descobertas recentes de reservas petrolíferas na camada pré-sal no Brasil, em particular, têm estimulado a investigação de formas mais eficientes de extração em condições especialmente adversas.

Uma situação importante a ser estudada é a presença de gás livre nos tubos de produção. A presença de gases no fundo do poço pode ser benéfica nos casos em que se usa a técnica de extração conhecida como gas-lift, em que gas é injetado no poço para diminuir o peso da coluna hidrostática efetiva e aumentar a taxa de produção de petróleo. No entanto, tal técnica, apesar do custo relativamente baixo, nem sempre pode ser utilizada e oferece um incremento limitado da taxa de produção. O bombeamento centrífugo submerso (BCS), em contrapartida, tem maiores custos de operação e manutenção, mas maior flexibilidade operacional e altas taxas de produção, sendo indicado para poços com grandes comprimentos de linha e alta fração de água. No entanto, por depender de um sistema mecânico de bombeamento, a técnica é vulnerável a falhas dinâmicas e cavitação, quando aplicada a poços com alta razão gás-líquido. Ao longo do tempo, essas falhas reduzem a eficiência de bombeamento e a vida útil do equipamento, causando paradas para manutenção que resultam em grandes perdas de produção.

Diversas técnicas para separação do gás à montante das bombas vêm sendo propostas, principalmente a partir dos anos 90 (ALHANATI, 1993), numa tentativa de melhorar o BCS. Um estudo recente (ORTIZ-VIDAL, 2010) sobre o separador do tipo shroud invertido (IS, i.e., Inverted-shroud) foi feito para avaliar a viabilidade da separação em poços direcionais, assunto pertinente às operações da empresa petrolífera brasileira PETROBRAS. O separador IS consiste em um tubo (shroud) instalado concentricamente entre o tubo de produção e o revestimento do poço. Sendo fechado em seu fundo, ele cria uma zona de decantação na extremidade inferior do tubo de produção, de forma a evitar que a mistura bifásica que surge do fundo do poço entre em contato diretamente com a montante do sistema de BCS. Esse trabalho propôs uma mudança na forma de se prever a separação gás-líquido, sendo que até então se buscava a obtenção de curvas de eficiência de separação com a variação de parâmetros como a vazão do líquido. Partindo de um modelo fenomenológico, buscou-se 
entender o fenômeno de aeração no separador. O objetivo foi a proposição de um critério de separação total, onde garante-se certo nível de líquido no duto anular interno ao shroud (nível anular interno, ou NAI), suficiente para evitar que bolhas entranhadas no líquido alcancem a bomba.

O objetivo geral deste trabalho é compreender melhor o fenômeno de geração de bolhas devido à dissipação de energia cinética turbulenta, que ocorre no duto anular interno ao separador IS. Pretende-se verificar a validade do modelo através da medição in situ do diâmetro médio (sauter) das bolhas arrastadas pelo líquido até a entrada do tubo de produção. Ao fim e ao cabo, a separação total de gás depende fortemente da previsão do valor do diâmetro médio das bolhas. Atualmente, o modelo é dependente de um diâmetro teórico de bolha, o qual é obtido via correlações ajustadas, deduzidas através de uma abordagem por volume de controle. Essas serão substituídas por dados de diâmetro médio de bolhas. Além da verificação da validade da fenomenologia adotada, teremos como resultado um modelo mais preciso. Para lograr objetivo geral, algumas metas precisam ser alcançadas:

1. Realizar estudo da literatura relacionada aos temas: separação gás-líquido e medição in situ de bolhas e gotas dispersas em escoamentos bifásicos.

2. Estudar detalhadamente a fenomenologia do separador tipo shroud invertido, para que se possa determinar exatamente o objetivo dos ensaios experimentais.

3. Preparar o aparato experimental para coleta de dados de eficiência de separação de gás, a fim de validar ou ajustar o modelo a ser estendido.

4. Realizar medições do diâmetro médio de bolhas, analisando a influência das condições de operação do separador sobre esta variável.

5. Desenvolver correlações semi-empíricas que aumentem a robustez da modelagem fenomenológica atual, visando uma previsão mais precisa da separação total de gás. 


\section{CAPÍTULO 2 REVISÃO DA LITERATURA}

A primeira seção deste capítulo tem como objetivo situar o leitor no tema de separadores gás-líquido utilizados na indústria petrolífera. Na segunda seção será feita uma breve discussão acerca do fenômeno de aeração em canais inclinados, tema importante na compreensão da aeração que ocorre dentro do anular interno do separador do tipo InvertedShroud. A terceira seção apresenta ao leitor o conceito do diâmetro médio Sauter e a técnica de medição conhecida como 3D ORM (Three-Dimensional Optical Reflectance Measurement, ou Medição Tridimensional por Reflectância Óptica), a fim de esclarecer o método experimental central deste trabalho.

\subsection{SEPARADORES GÁS-LÍQUIDO}

Na indústria petrolífera é comum a presença de gás escoando juntamente com petróleo em um fluxo bifásico à montante dos sistemas de bombeamento. Este fenômeno ocorre devido a fatores como a descompressão repentina da fase líquida durante o bombeamento, ocasionando o surgimento de bolhas do gás previamente dissolvido no óleo (Figura 2.1). Este gás escoa em diversos padrões de escoamento ao longo do poço e pode gerar ou agravar fenômenos como a cavitação em bombas centrífugas submersas, propiciando a ocorrência de falhas mecânicas e acarretando grandes custos de reposição de peças, manutenção e, o mais grave, paradas de produção. Lea e Bearden (1982) estudaram este fenômeno experimentalmente e, de forma geral, constataram a ocorrência de falhas no bombeamento quando a fração volumétrica da fase gasosa excedia $10 \%$. 
(a)

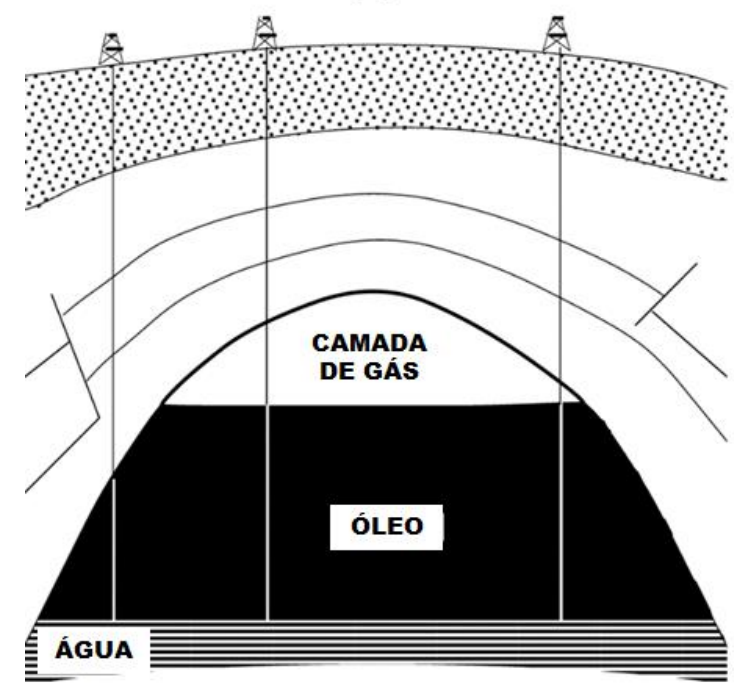

(b)

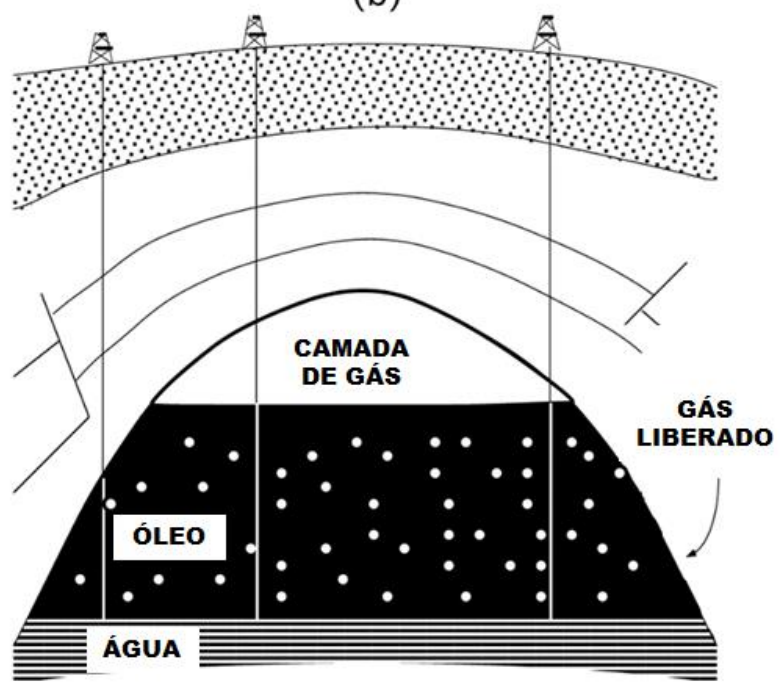

Figura 2.1 - (a) Reservatório antes da descompressão. (b) Reservatório após a descompressão e subsequente liberação do gás. ${ }^{1}$

Isto motivou o desenvolvimento de diversos tipos de separadores de gás, para que a bomba receba apenas a fase líquida da mistura. Separadores gás-líquido são, na indústria de petróleo, equipamentos específicos que recebem a mistura gás-petróleo e segregam o gás através de vários meios possíveis, como a separação gravitacional. Dada a grande profundidade de operação em poços, tais equipamentos têm suas dimensões radiais máximas limitadas ao diâmetro do poço e costumam ter forma tubular. A evolução dos separadores gáslíquido se deu, principalmente, objetivando um funcionamento simples e menos obstrutivo, com menor necessidade de manutenção de peças móveis. A vazão e o ângulo de inclinação (no caso de uso em poços direcionais) são também fatores importantes.

A eficiência de separação gás-líquido de um separador que se encontra em operação estável (regime permanente) pode, de forma geral, ser definida como a proporção de gás recuperado (i.e, que não passa pela bomba) em relação à massa total de gás fornecida pelo poço em um intervalo de tempo. Isto pode ser calculado na forma de uma razão de vazões mássicas, como pode ser visto na Equação (2.1):

$$
\eta_{\text {shroud }}=\frac{\dot{m}_{j}}{\dot{m}_{m}}
$$

\footnotetext{
${ }^{1}$ PETROWIKI. Gas Cap Drive Reservoirs. Disponível em:

<http://petrowiki.org/Gas_cap_drive_reservoirs〉. Acesso em 10 set. 2015.
} 
sendo $\eta_{\text {shroud }}$ a eficiência de separação de gás, $\dot{m}_{j}$ a vazão de gás recuperado e $\dot{m}_{m}$ a vazão mássica de gás que é fornecida pelo poço. Uma das primeiras propostas de separador gáslíquido foi o separador do tipo rotativo, estudado por Alhanati (1993). Consistindo em um helicóide móvel giratório, este separador foi apresentado para uso à montante de bombas centrífugas submersas.

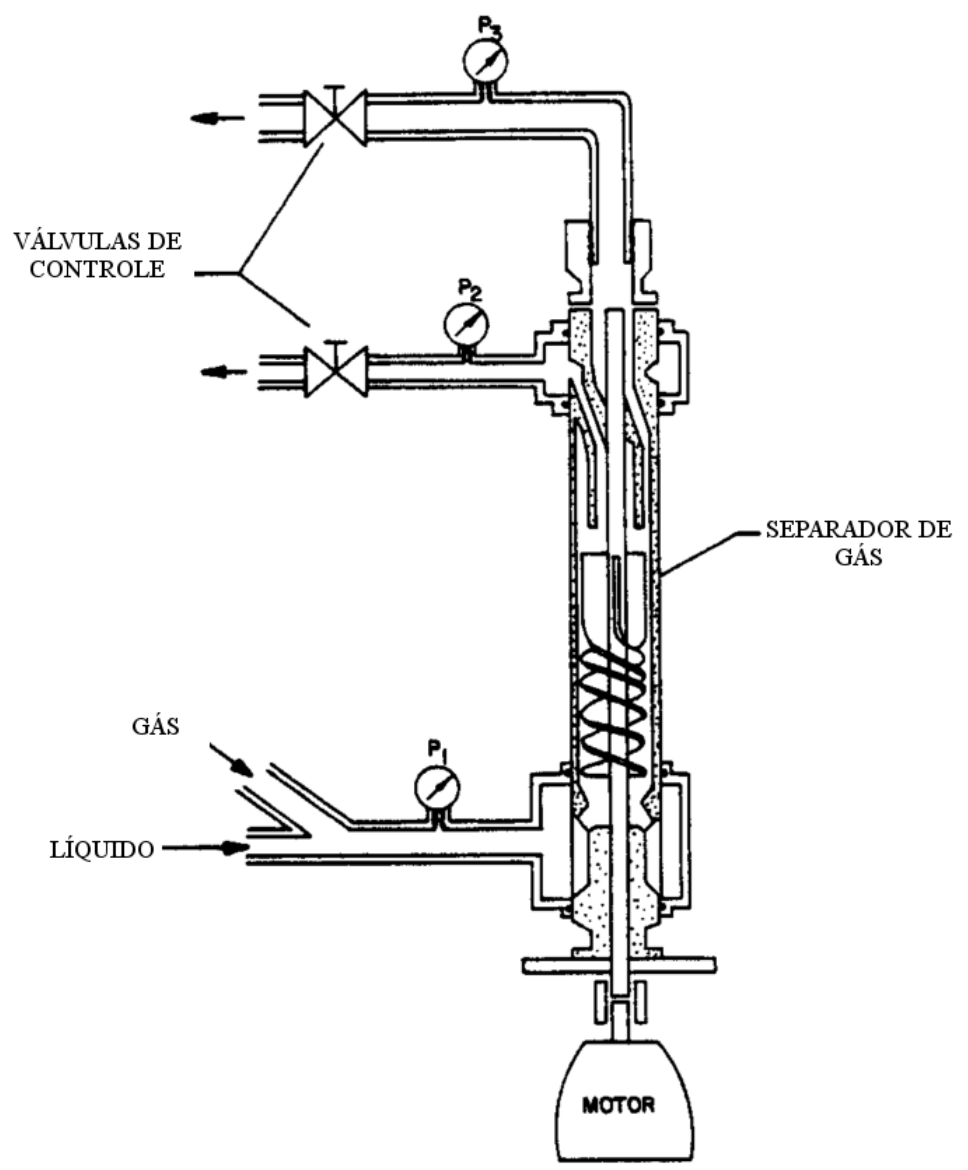

Figura 2.2 - Seção de testes do separador rotativo estudado por Alhanati (1993).

Um modelo fenomenológico foi proposto para a eficiência de separação, apresentando os resultados em mapas de eficiência (Figura 2.3) que utilizam as vazões dos fluidos, a pressão interna do separador e a velocidade de rotação do helicóide como variáveis do modelo. 


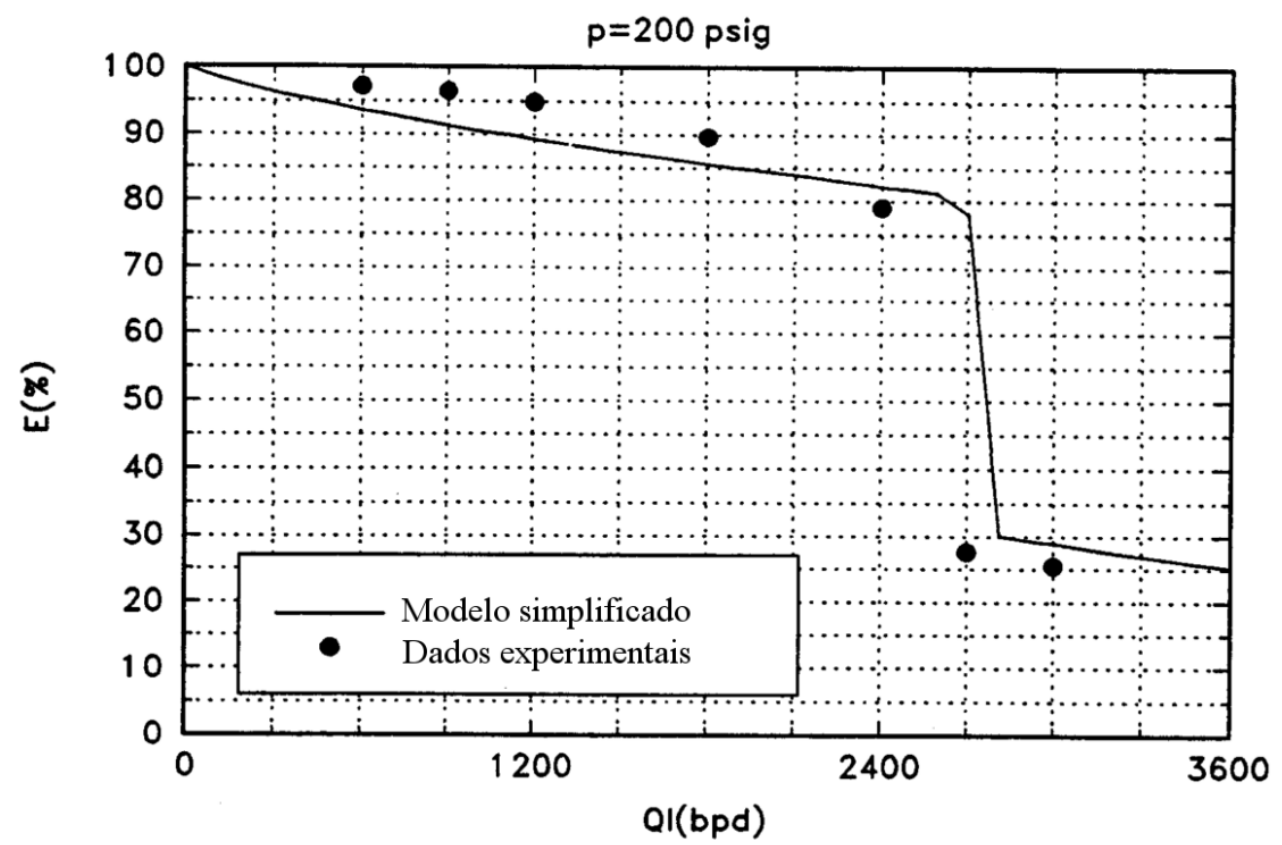

Figura 2.3 - Mapa de eficiência do separador apresentado por Alhanati (1993)

O modelo proposto prevê, no mapa de eficiência (Figura 2.3), uma zona de alta eficiência de separação e uma zona de baixa eficiência, com uma transição abrupta entre as zonas. O modelo foi testado experimentalmente e houve coerência entre os dados coletados e os dados experimentais da literatura. No entanto, apesar dos bons resultados, a presença de partes móveis traz consigo o problema de necessárias manutenções que comprometeriam a produção contínua e gerariam altos custos operacionais. Além disso, perdas transientes de eficiência de separação podem ocorrer devido à presença de bolhas de Taylor no escoamento à montante do separador. Atualmente este tipo de separador gás-líquido é o mais utilizado pela PETROBRAS em suas operações.

Uma alternativa ao problema do separador anterior foi proposta por Souza et al. (2003), que desenvolveram um separador gravitacional com um helicóide fixo (Figura 2.4) dentro de um tubo fechado no fundo, que atua como um tubo de decantação (chamado neste e em outros trabalhos de shroud invertido). Sendo esse um separador usado em poços verticais, o helicóide fixo serve para que o líquido não caia no fundo do shroud em um escoamento descendente e caótico, fazendo com que o escoamento seja segregado e inclinado. Isto ajuda também a evitar a formação de bolhas através de aeração. 


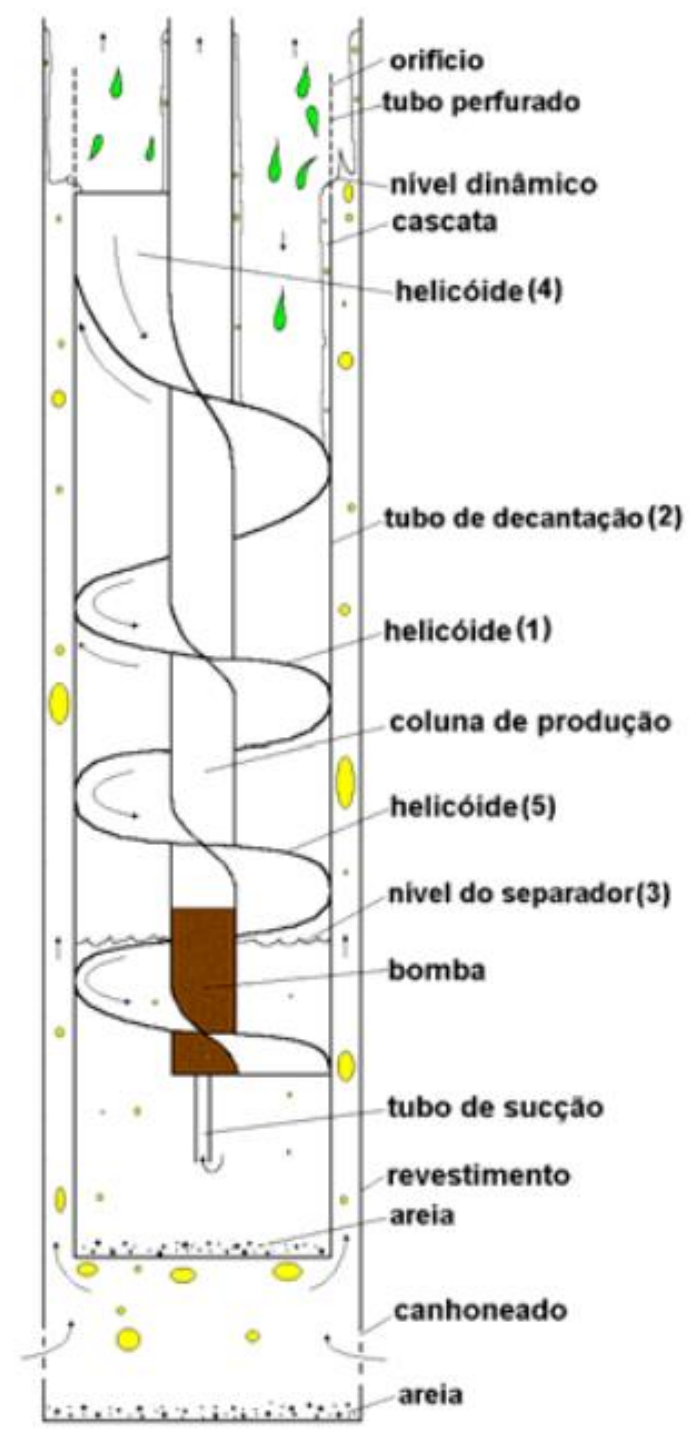

Figura 2.4 - Separador de helicóide fixo (SOUZA et al., 2003).

Apesar de não ter sido apresentada uma modelagem para o separador, ele apresenta resultados consistentes com os dados da literatura obtidos em trabalhos semelhantes anteriores. Testes experimentais geraram bons resultados, com eficiências de separação de gás acima de $90 \%$.

Os problemas de peças móveis do separador rotativo foram eliminados com a introdução do helicóide fixo, mas segundo os autores o equipamento exige vários cuidados construtivos e operacionais. A área de seção transversal do separador é parcialmente restringida pelo helicóide e, com isso, a vazão de líquidos de alta viscosidade (como é o caso de muitos tipos de petróleo) é limitada. 
Um separador sem helicóide nem tubo de decantação foi proposto por Serrano (1999), que fez uma análise do efeito do ângulo de inclinação do separador sobre sua eficiência de separação através de estudos teóricos e experimentais. Utilizando a seção de testes mostrada na Figura 2.5, o autor comprovou que a eficiência de separação aumenta para angulações maiores (a partir da vertical). Os resultados experimentais mostraram coerência com um modelo simplificado baseado no modelo de Alhanati (1993).

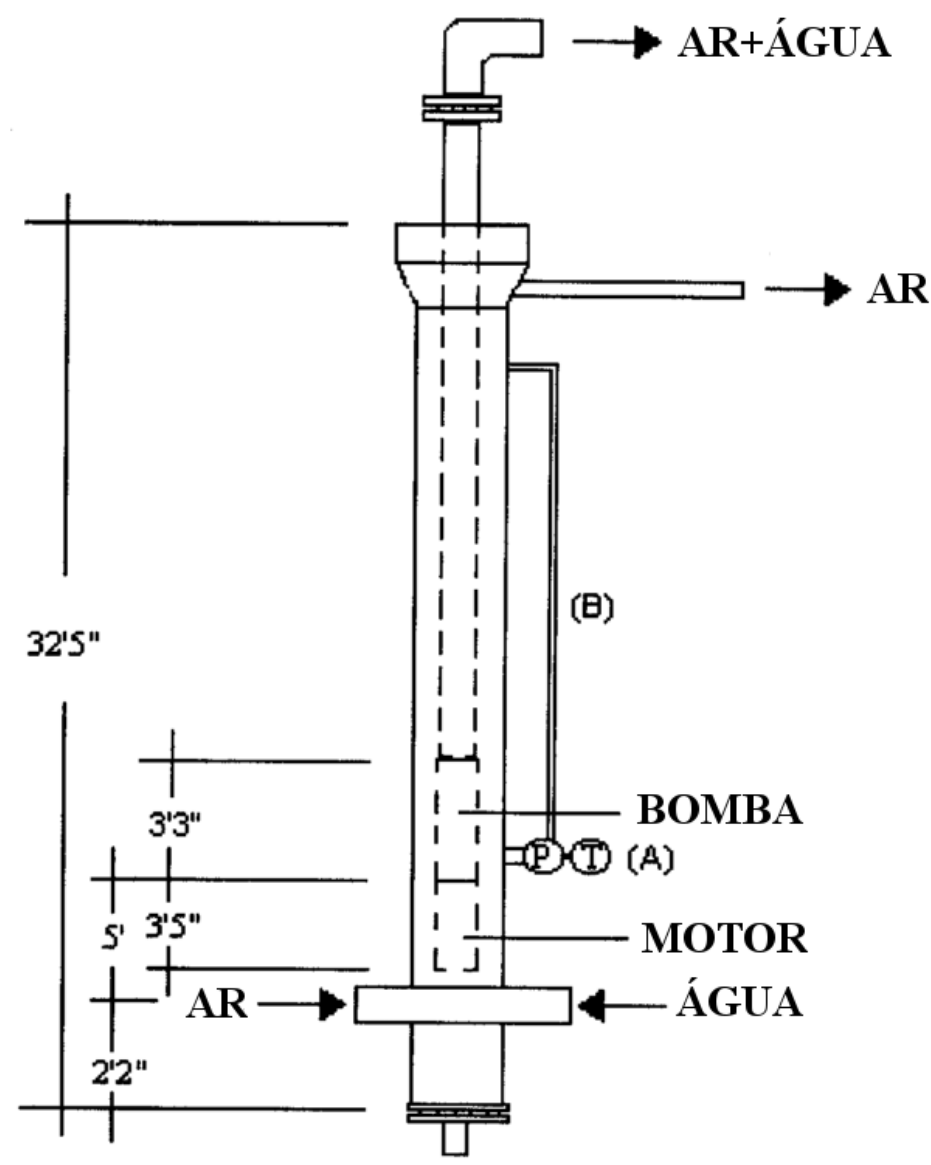

Figura 2.5 - Seção de testes do separador proposto por Serrano (1999).

O autor concluiu que a vazão do líquido e o ângulo de inclinação da seção de testes influenciam a eficiência de separação de gás. O modelo proposto serviu como parâmetro para outros separadores, apesar de não ter sido testado com fluidos altamente viscosos. Além disso, pode-se dizer que o modelo tem aplicação limitada por precisar de conhecimento prévio da fração volumétrica in situ dos fluidos à montante da bomba.

O problema da medição da fração volumétrica foi resolvido quando Harun et al. (2000, 2003) propuseram um novo modelo para este separador, utilizando desta vez as equações da quantidade de movimento das fases e uma correlação geral relacionada ao 
deslizamento entre as mesmas. Com isto, observou-se que a eficiência do separador está altamente relacionada à sua geometria e à fração de vazio do escoamento, bem como à velocidade in situ do gás. Posteriormente, outro modelo foi novamente proposto por Harun et al. (2001) quando os autores tentaram analisar a inclinação da seção de testes. Os modelos são coerentes com os dados experimentais de Serrano (1999).

Liu e Prado (2000, 2001a, 2001b) fizeram um novo estudo do separador gravitacional, desta vez analisando a trajetória de bolhas em três regiões de trabalho distintas e em torno da região de sucção da bomba, como descrito na Figura 2.6. A fim de analisar a fundo a trajetória das bolhas no escoamento na Região II (Figura 2.7), crítica à separação de gás, os autores fizeram uma extensiva revisão da literatura. Baseando-se nos trabalhos de Sambangi (1994) e Lackner (1997), Liu e Prado (2000) fizeram uma modelagem da separação de gás baseada no rastreamento da trajetória das bolhas submetidas a forças de empuxo e de sucção da bomba. Utilizando parâmetros geométricos, foi proposta uma circunferência limite para a separação de bolhas de gás (Figura 2.8).

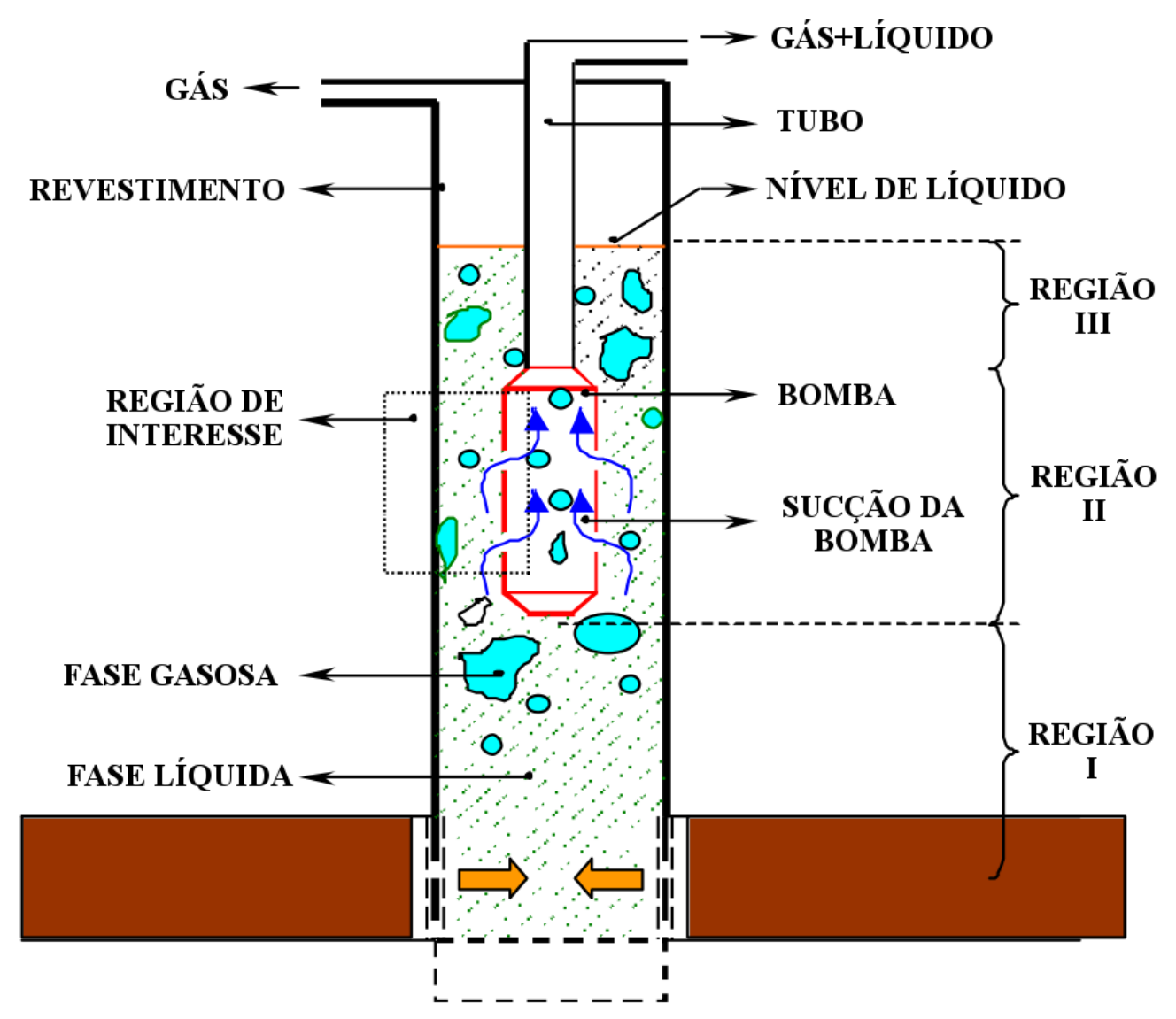

Figura 2.6 - Separador proposto por (LIU; PRADO, 2001b), com suas três zonas de separação destacadas. 


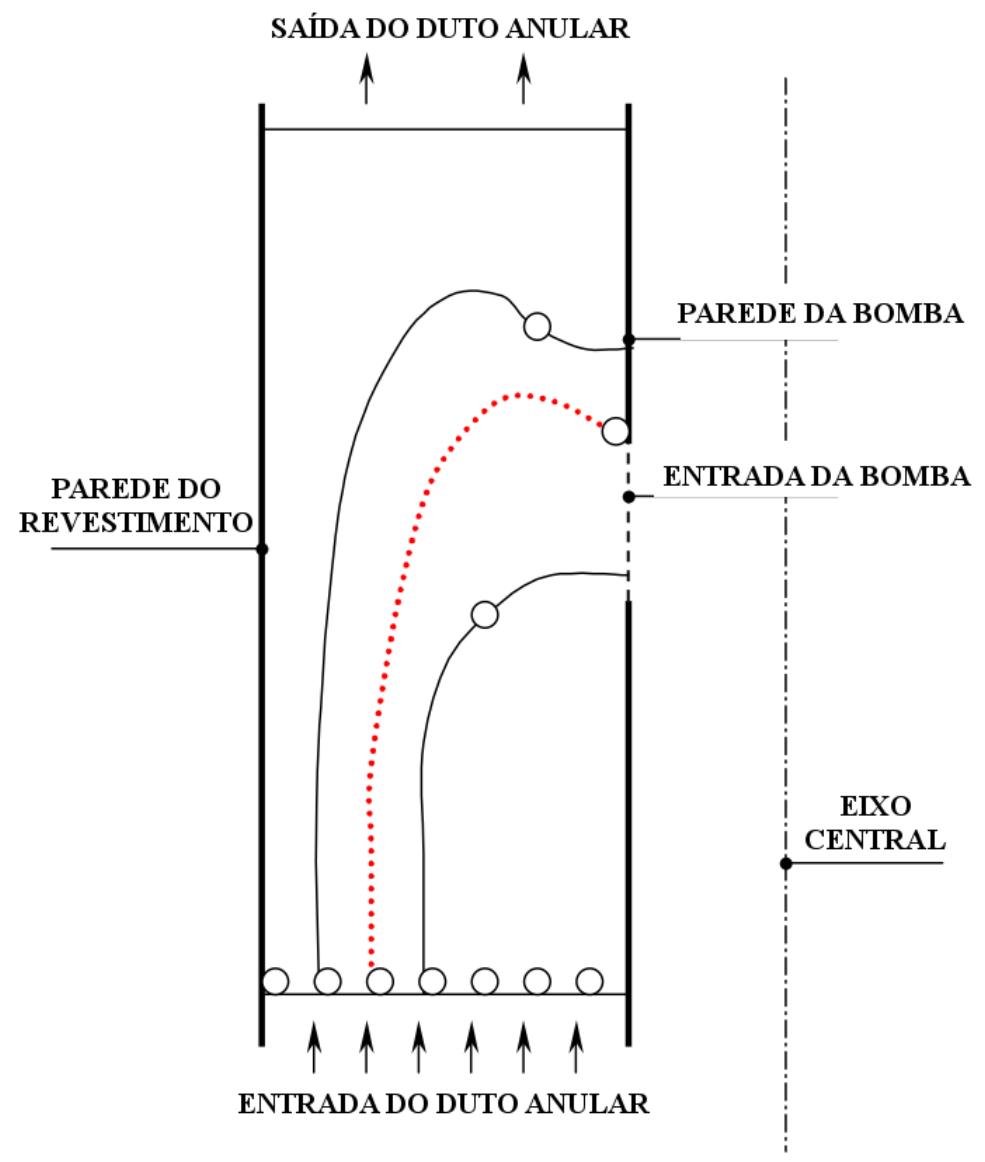

Figura 2.7 - Segunda região de separação do separador de (LIU; PRADO, 2001b), com linhas críticas de trajetória das bolhas em destaque.

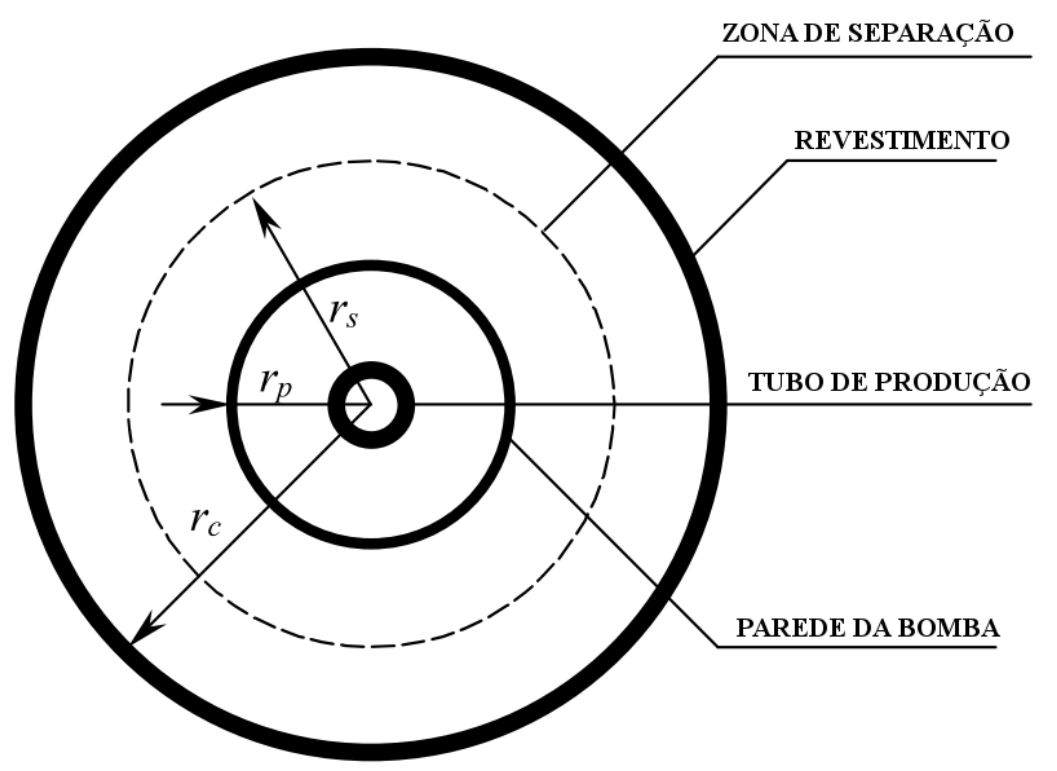

Figura 2.8 - Região crítica de separação de bolhas segundo (LIU; PRADO, 2001b). 
Posteriormente, Marquez e Prado (2002) continuaram o trabalho anterior de Liu e Prado (2000, 2001a, 2001b) levando em conta que as correlações propostas a partir de dados da literatura não eram capazes de descrever completamente os fenômenos físicos presentes na separação de gás e líquido. Partindo deste princípio, os autores realizaram um estudo aprofundado dos padrões de escoamento presentes no anular interno de separadores gáslíquido. Com base no critério proposto por Caetano, Shoham e Brill (1992) para escoamento bifásico em duto anular, foi previsto o escoamento pistonado/agitante para Alhanati (1993), Sambangi (1994) e Lackner (1997), enquanto para Serrano (1999) foi previsto o padrão bolhas. Também foi investigado o efeito da velocidade terminal de ascensão de bolhas de gás na direção axial do separador, sendo esta variável de grande importância quando se deseja evitar que tais bolhas sejam sugadas pela bomba.

Foi observado que os modelos desenvolvidos anteriormente (ALHANATI, 1993; HARUN et al., 2000, 2001, 2003; SERRANO, 1999) consideravam desprezível o efeito do deslizamento das fases na entrada da bomba. Márquez e Prado (2007b), no entanto, não faziam esta desconsideração por notarem que o deslizamento é válido devido a acelerações convectivas na entrada da bomba, pois nela havia uma considerável redução de área. Com isto, foi concluído que o novo modelo apresentava melhor confiabilidade e precisão em relação às outras modelagens.

Os trabalhos de Alhanati (1993) e Souza et al. (2003) mencionam a possibilidade do uso de separadores gravitacionais com tubo de decantação (shroud invertido) e sem helicóide. Bohorquez et al. (2007) fizeram um estudo comparativo da eficiência de separação em separadores helicoidais e gravitacionais em posição vertical concluindo que, em condições semelhantes de trabalho, o modelo helicoidal será sempre o mais eficiente. Os autores notaram nos experimentos com shroud invertido que a velocidade superficial descendente do líquido dentro do separador, quando excessiva, resulta em perdas de eficiência de separação. A operação vertical deste tipo de separador impossibilita o controle sobre a velocidade superficial do líquido nesta região, resultando em um escoamento caótico. Um trabalho mais recente (CARIOS et al., 2013) continuou o trabalho de Bohorquez et al. (2007), obtendo uma correlação ajustada experimentalmente para a eficiência de separação de gás em função da vazão das fases e da densidade do gás. Pode-se notar que a correlação proposta tem limitada aplicação prática, por precisar de conhecimento da densidade e vazão volumétrica do gás. Eficiências de separação menores que $90 \%$ foram observadas na maioria dos pontos experimentais, como era esperado devido à posição vertical do separador. 
Um trabalho experimental de Rondy, Cholet e Federer (1993) demonstrou que ao inclinar o separador de shroud invertido o escoamento do líquido rumo ao fundo do tubo de decantação torna-se inclinado e segregado em canal livre. Com isto, elimina-se o problema do escoamento caótico observado por Bohorquez et al. (2007) e é obtido um separador gravitacional sem partes móveis e de fácil construção.

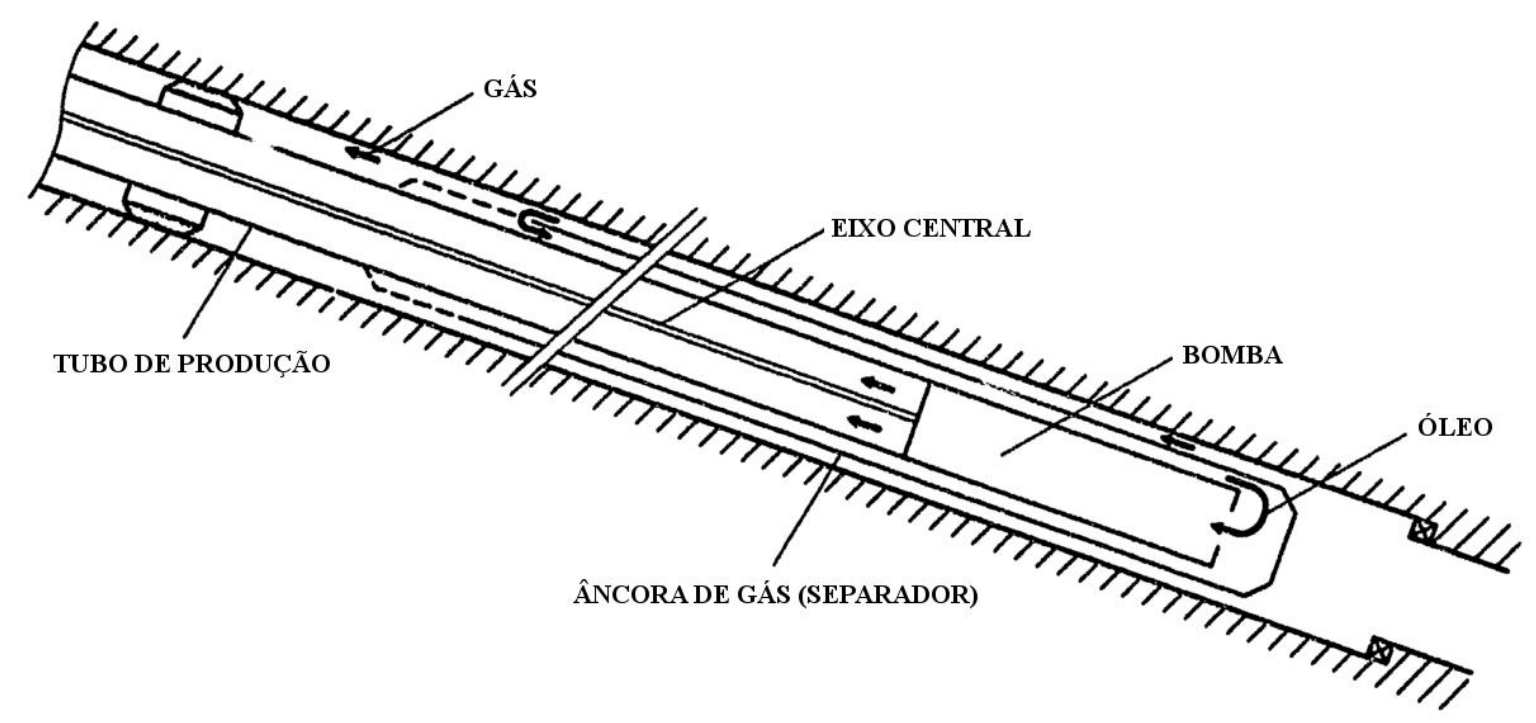

Figura 2.9 - Separador gravitacional proposto e testado por Rondy, Cholet e Federer (1993).

Dados experimentais com dois tipos de misturas bifásicas (ar/água e gás/óleo) foram obtidos por Rondy, Cholet e Federer (1993) em uma bancada experimental, mas sem apresentar uma modelagem do processo de separação. Posteriormente, outros autores (ORTIZ-VIDAL et al., 2012; ORTIZ-VIDAL, 2010) estudaram o mecanismo de separação de gás e propuseram um modelo fenomenológico consistente com os resultados previamente encontrados. Os autores levaram em conta novas variáveis, como o nível de líquido no tubo de decantação (nível do anular interno, NAI) e a pressão interna do revestimento do separador. 


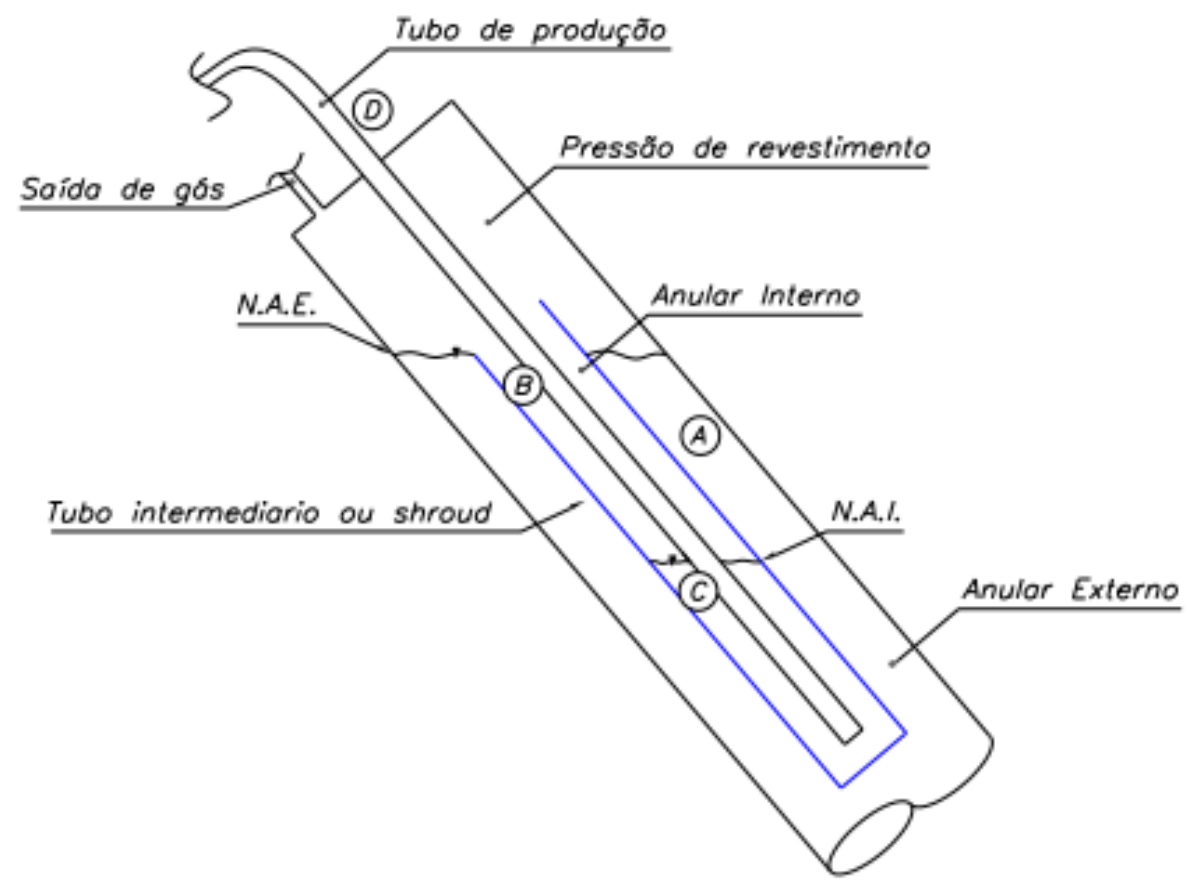

Figura 2.10 - Separador gravitacional testado por Ortiz-Vidal (2010).

Ortiz-Vidal (2010) propôs uma nova abordagem em que se visa prever a total separação do gás. Buscou-se determinar um nível mínimo de líquido decantado no anular interno (NAI) que seria suficiente para garantir a separação do gás por efeito gravitacional. A energia cinética do escoamento de superfície livre seria a fonte de energia cinética turbulenta, responsável pela quebra e manutenção das bolhas no seio líquido. Estas seriam entranhadas, pelo fenômeno de aeração, no momento do choque do escoamento em superfície livre (B) com o nível do anular interno (NAI, Fig. Figura 2.10). A taxa de dissipação da energia cinética turbulenta por unidade de massa de fluido estaria, segundo a teoria, relacionada ao diâmetro médio das bolhas. O autor testou diferentes comprimentos do NAI para um conjunto de vazões de ar e água, analisando a eficiência de separação do gás para cada ponto a fim de propôr correlações para o comprimento de dissipação $\left(L_{\text {dis }}\right)$ de energia cinética turbulenta.

Mendes (2012) expandiu o modelo proposto inicialmente por Ortiz-Vidal (2010) e, através de testes com óleo no mesmo aparato experimental, propôs alterações no modelo para fluidos de alta viscosidade. Mendes estudou de forma aprofundada os padrões de escoamento no anular externo (região entre o revestimento de um poço e o shroud) do separador, propondo cartas de fluxo e relacionando-as à eficiência de separação do gás. O autor concluiu que o padrão de escoamento não surte efeitos observáveis na eficiência do separador. 
Adicionalmente, Mendes (2012) reportou um problema operacional do separador, denominado "afogamento". Isto é observado quando se tem um excesso de vazão da fase líquida, de forma que o espaço anular entre o shroud e o tubo de produção tem área insuficiente para comportar tal vazão. Este fenômeno foi também reportado por Bohorquez et al. (2007), que sugeriram como solução o uso de uma seção perfurada na ponta superior do shroud (Figura 2.11). Isto serviria para aumentar a área pela qual a fase líquida pode entrar no anular interno, reduzindo a possibilidade de afogamento.

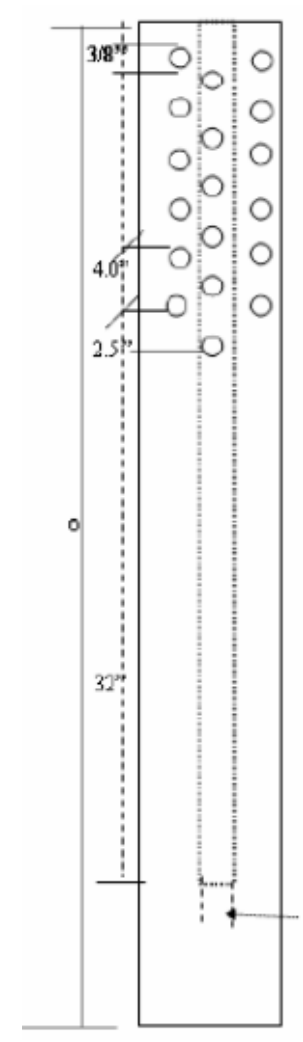

Figura 2.11 - Separador do tipo Inverted-Shroud com tubo perfurado (BOHORQUEZ et al., 2007).

Bulgarelli (2014) testou o uso de uma seção de tubos perfurados no mesmo aparato experimental reportado na presente dissertação, obtendo um incremento na vazão máxima (i.e., vazão na qual se registra o fenômeno de afogamento). Foi observado também um leve incremento na eficiência de separação nas mesmas condições registradas sem o tubo perfurado. Os procedimentos e resultados deste experimento estão também contidos nesta dissertação. 


\subsection{ESCOAMENTO EM SUPERFÍCIE LIVRE E AERAÇÃO}

O escoamento em superfície livre é uma parte fundamental no estudo da modelagem fenomenológica do separador gás-líquido tipo shroud invertido. Exemplos comuns deste tipo de escoamento são rios e calhas. No shroud invertido, este tipo de escoamento é gerado pela segregação gravitacional da mistura gás-líquido em um duto pelo qual escoa descendentemente, sendo caracterizado pela interface livre e contínua.

Considera-se, na modelagem deste tipo de escoamento, que a superfície livre está exposta a uma pressão constante ao longo do duto. A distribuição de velocidades no canal em que ocorre o escoamento é tridimensional, mas, para fins de engenharia, se pode considerá-la unidimensional. (ÇENGEL e CIMBALA, 2006).

Um escoamento em superfície livre pode ser uniforme ou variado. Um escoamento em regime permanente, i.e. em que não há variações temporais em suas características, ainda pode ser considerado variado nos casos em que há variações de profundidade ao longo do canal aberto. Quando se tem um obstáculo alterando ativamente a seção transversal do escoamento, como uma comporta parcialmente aberta ou uma cachoeira, tem-se um escoamento bruscamente variado (EBV). Nos casos em que a variação é gradativa, caracteriza-se um escoamento gradualmente variado (EGV). A Figura 2.12 exemplifica os dois fenômenos. (ÇENGEL; CIMBALA, 2006).

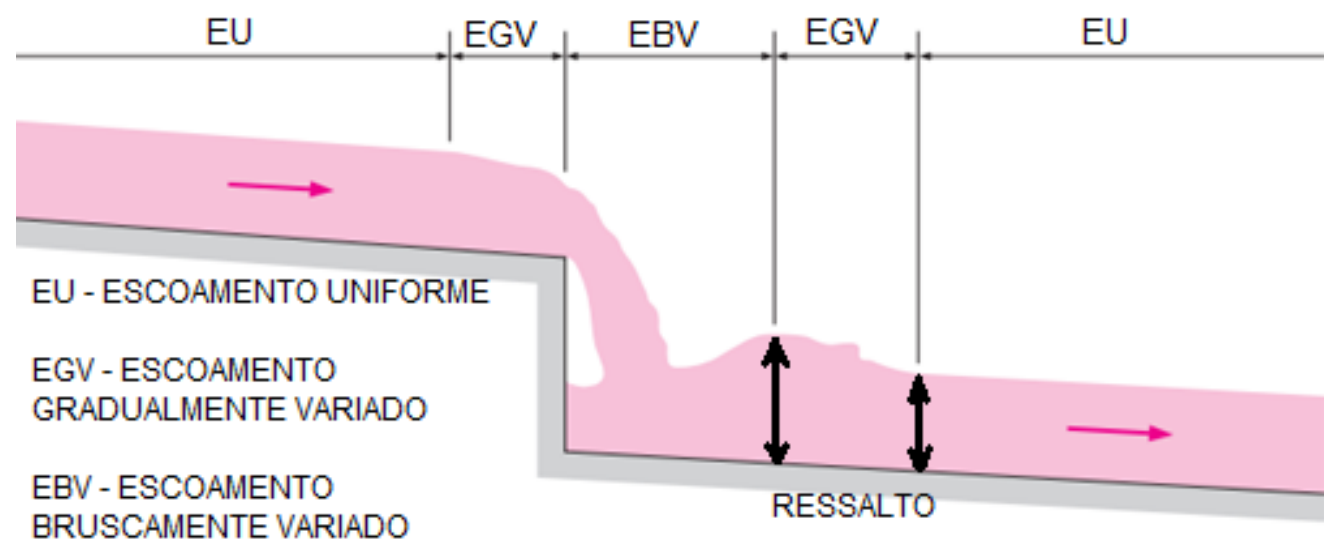

Figura 2.12 - Tipos de variação espacial em um escoamento de superfície livre (ÇENGEL; CIMBALA, 2006)

Um caso importante de EBV pode ser explicado através do número de Froude, parâmetro que representa a raiz da razão entre forças inerciais e forças gravitacionais em um 
escoamento. Ao transitar de uma situação supercrítica $(F r>1)$ para uma situação subcrítica $(F r<1)$, o escoamento sofre dissipação de energia por turbulência e com isto pode-se observar um EBV que ocorre naturalmente, como pode ser visto na Figura 2.12.

O escoamento no início do shroud é um EGV, que pode atingir o EU antes do NAI (Nível do Anular Interno). O encontro do escoamento de superfície livre com o NAI pode ser entendido como um EBV que é capaz de promover também o fenômeno de aeração. Parte da energia cinética se converte em energia cinética turbulenta, responsável pela quebra das bolhas de ar (VOLKART, 1980).

Gulliver, Thene e Rindels (1990), posteriormente, estudaram também o fenômeno da aeração por impacto em canais abertos, de forma semelhante ao que ocorre no separador tipo shroud invertido. Os autores estudaram a quebra de bolhas e sugeriram que ela ocorre devido a forças de cisalhamento do próprio escoamento, propondo utilizar o diâmetro obtido por Hinze $^{2}$ (1955 apud GULLIVER, THENE e RINDELS, 1990) para prever o tamanho das mesmas. Mendes (2012) e Ortiz-Vidal (2010) utilizaram este diâmetro no estudo de separadores de shroud invertido, sendo um dos objetivos do presente trabalho a validação dessa teoria.

\subsection{ANÁLISE DE DISTRIBUIÇÕES DE DIÂMETRO DE BOLHAS}

Devido à natureza intrinsecamente caótica do processo de geração de bolhas, sua medição costuma apresentar resultados dispersos em torno de um valor médio. A distribuição do diâmetro de bolhas ou gotas em um escoamento pode ser expressa de diversas formas, como, por exemplo, uma curva de densidade de probabilidades (Probability Density Function, ou PDF) (Figura 2.13 - Distribuição de diâmetros de bolhas observada por Westende (2008), Figura 2.13).

${ }^{2}$ HINZE, J.O. (1955) Fundamentals of the hydrodynamic mechanism of splitting in dispersion processes. AIChE Journal, v.1, n.3, p.289-295. 


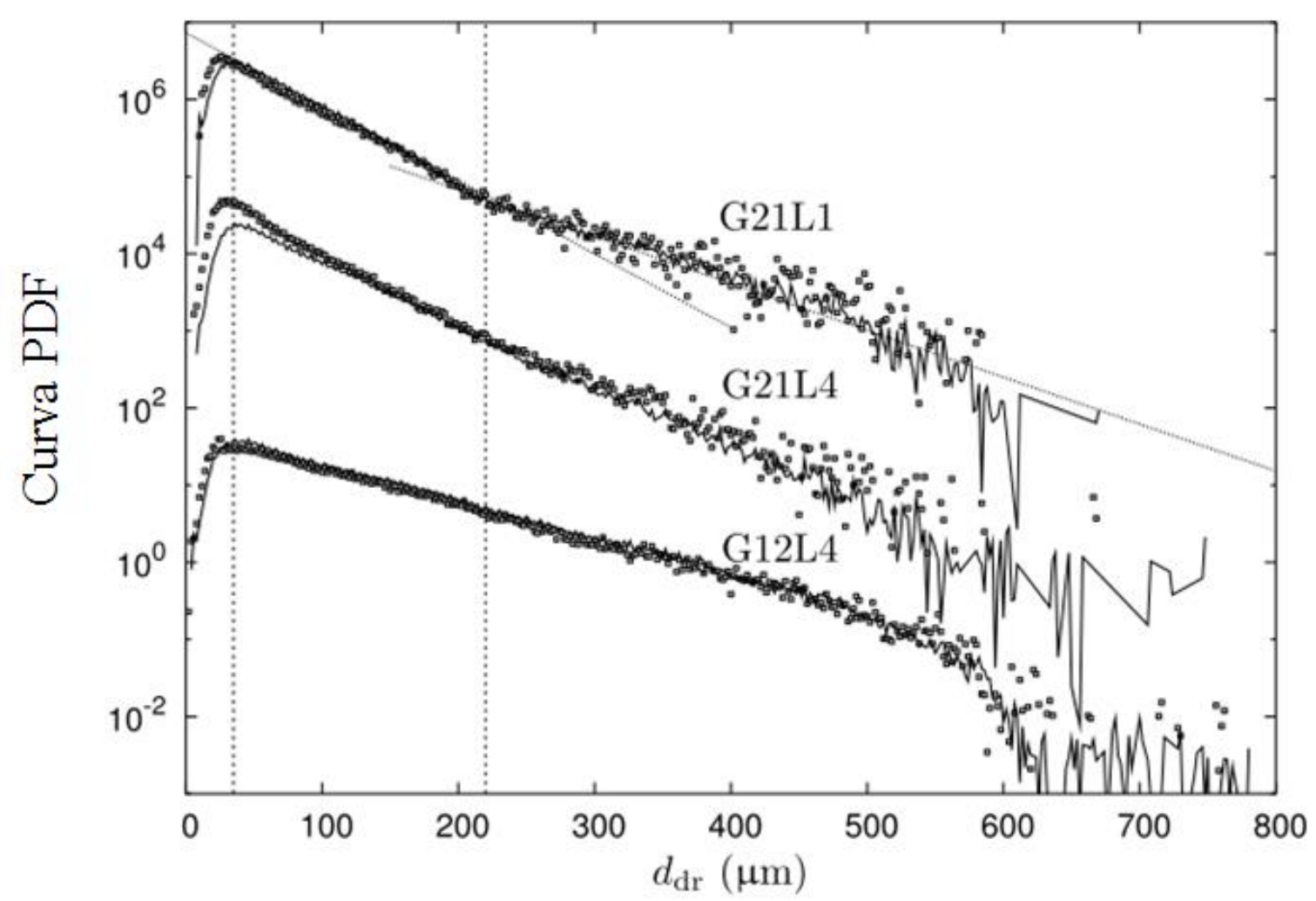

Figura 2.13 - Distribuição de diâmetros de bolhas observada por Westende (2008), em que $d_{d r}$ se refere aos diâmetros aferidos.

A fim de melhorar a visualização dos resultados da distribuição de diâmetros, pode-se utilizar diferentes formas de representar o eixo vertical em uma curva PDF. A escala logarítmica, utilizada por Westende (2008), possibilita uma melhor representação dos resultados caso o escoamento seja dominado por partículas de tamanho reduzido. Para este fim, é também possível ajustar a distribuição de acordo com o comprimento, a área ou o volume da partícula medida (SOMMER, 2012).

Em certos casos, no entanto, é necessário que esta distribuição seja caracterizada por um único valor, como um diâmetro médio. Dependendo do foco do estudo, pode-se utilizar uma mediana dos diâmetros medidos ou até mesmo uma média aritmética. Em geral, o diâmetro médio em uma distribuição qualquer pode ser descrito por uma razão entre dois somatórios, como descrito abaixo, em que $D_{i}$ são os diâmetros de uma faixa de medidas e $k_{i}$ é o número de partículas que se encontram na respectiva faixa: 


$$
D_{p q}=\left(\frac{\sum_{i=1}^{\infty} k_{i} D_{i}^{p}}{\sum_{i=1}^{\infty} k_{i} D_{i}^{q}}\right)^{\frac{1}{p-q}}
$$

Como a área superficial e o volume da bolha são respectivamente proporcionais ao quadrado e ao cubo do seu diâmetro, Sauter ${ }^{3}$ (1926 apud AZZOPARDI, 2011) propôs o uso de um diâmetro médio em que se admite $p=3$ e $q=2$. Sauter aplicou este diâmetro médio ao estudo de atomização em carburadores, a fim de desenvolver uma técnica de medição do tamanho de gotas em que se mede a absorção e o espalhamento de luz na partícula a ser medida. Autores como Evans et al. (1992), posteriormente, utilizaram o diâmetro médio Sauter aliado a outras duas formas de diâmetros médios para caracterizar a distribuição de bolhas geradas por um jato de líquido (plunging jet):

$\checkmark$ Diâmetro médio: obtido com uma média aritmética simples, ou seja, utilizando $p=1$ e $q=0$ na Equação (2.2);

$\checkmark$ Diâmetro máximo: diâmetro cujo valor é superior a $99 \%$ das medidas obtidas na distribuição. Pode ser obtido com o uso de um gráfico cumulativo da distribuição;

Evans et al. (1992) observaram que a razão entre o diâmetro médio Sauter $\left(D_{\text {Sauter }}\right)$ e o diâmetro máximo $\left(D_{\text {máximo }}\right)$ tinha pouca variação para um dado escoamento, tendo observado uma razão igual a 0,61 $\pm 0,03$ em seus experimentos.

De forma semelhante ao que foi feito nos experimentos de Sauter $^{4}$ (1926 apud AZZOPARDI, 2011) e Evans et al. (1992), em que fotografias foram utilizadas para realizar a aferição do diâmetro de bolhas, técnicas modernas de medição de partículas in situ através de sua reflectância óptica podem ser aplicadas de forma não-invasiva para este mesmo fim. Lovick et al. (2005) fizeram um estudo do diâmetro médio Sauter de gotas de querosene dispersas em uma solução agitada de água utilizando esta técnica através de um sensor 3D ORM (Threedimensional Optical Reflectance Measurement). Os dados obtidos foram validados com o uso de um endoscópio acoplado a uma câmera de alta velocidade capaz de aferir o diâmetro real

\footnotetext{
${ }^{3}$ SAUTER, J. (1926) Grössenbestimmung von Brennstoffteilchen, Forschungsarbeiten auf dem Gebiete des Ingenieurwesens, p.279.
} 
das partículas in situ, a fim de verificar a performance da técnica 3D ORM para estudos futuros. Os autores obtiveram resultados satisfatórios, como pode ser visto na Figura 2.14.

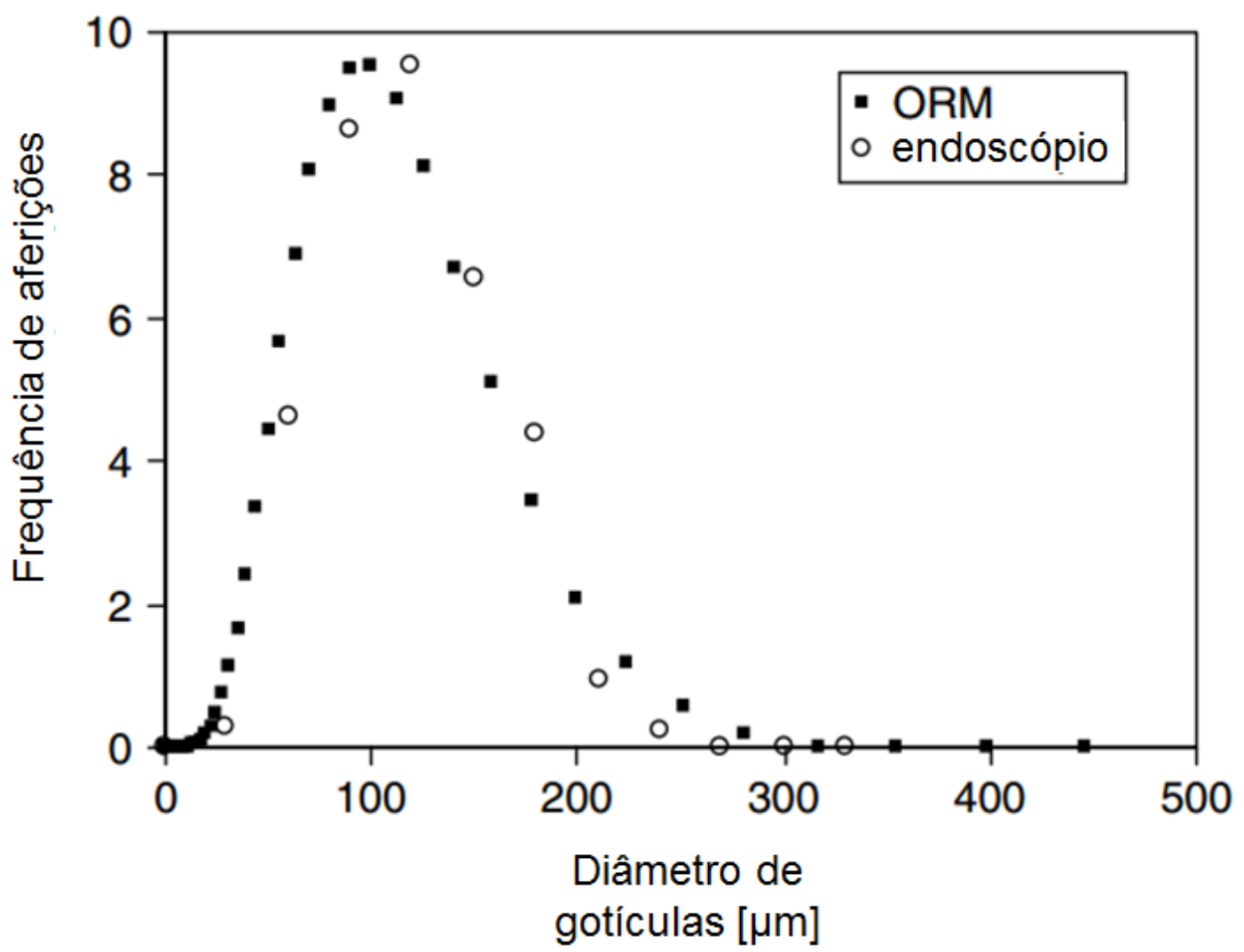

Figura 2.14 - Distribuição de diâmetros de gotas em uma solução com 10\% de volume de querosene agitada com um impulsor a $450 \mathrm{rpm}$ (LOVICK et al., 2005). 



\section{CAPÍTULO 3 MODELAGEM DO SEPARADOR TIPO SHROUD INVERTIDO}

O presente capítulo tem como objetivo descrever a modelagem fenomenológica da separação de gás em separadores gás-líquido do tipo Shroud invertido. Esta modelagem foi inicialmente proposta por Ortiz-Vidal (2010), em uma tentativa de prever a separação total do gás, i.e., uma eficiência de separação $(\eta)$ igual a 100\%, a partir de parâmetros mais facilmente mensurados em um poço de petróleo, sendo estes:

1. Vazão de líquido.

2. Pressão interna do revestimento do poço.

3. Pressão na saída do tubo de produção ou cabeça do poço.

4. Inclinação da seção do poço em que está o separador.

5. Propriedades dos fluidos de trabalho.

\subsection{FENOMENOLOGIA}

A função de um separador gravitacional é, basicamente, separar as fases de uma mistura gás-líquido de forma que apenas a fase líquida possa escoar através de um sistema de bombeamento. Estudos com separadores deste tipo instalados em poços verticais mostram que o escoamento descendente da fase líquida, observado na região entre o tubo de produção e o shroud (duto anular interno), é caótico e de alta velocidade, promovendo aeração e causando uma baixa eficiência de separação. O uso deste separador em poços inclinados, no entanto, faz com que o escoamento no anular interno seja segregado em canal livre. Com isto, se tem uma redução no efeito de aeração e, consequentemente, uma melhor eficiência.

O escoamento interno ao separador gás-líquido shroud invertido pode ser dividido em quatro zonas de propriedades distintas, como ilustra a Figura 3.1. 


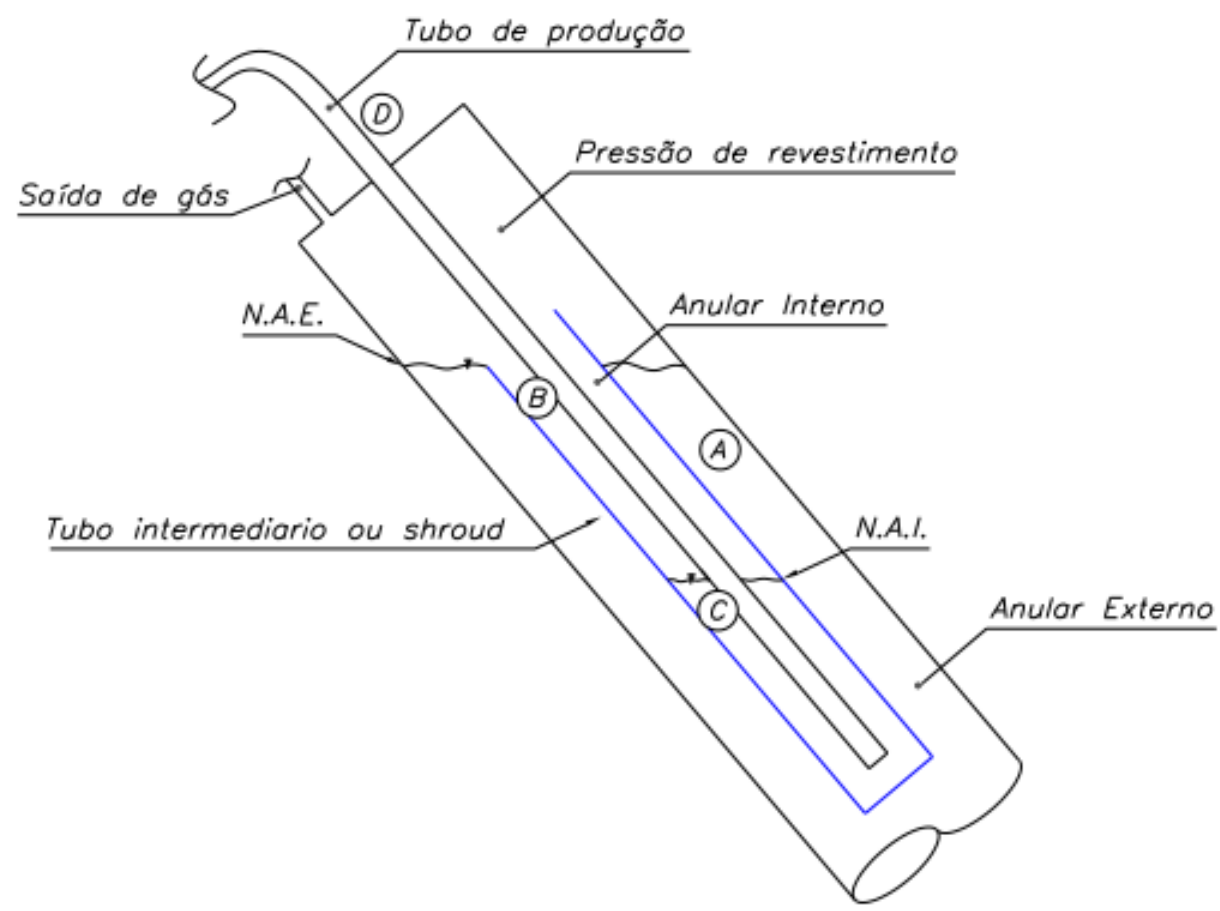

Figura 3.1 - Distribuição das regiões de escoamento do separador de shroud invertido, retirada de Ortiz-Vidal (2010).

Na Região "A” (Figura 3.1) tem-se o anular externo, área que fica entre o revestimento do poço e o tubo intermediário que compõe o shroud. Esta região conduz a mistura bifásica gás-líquido na direção ascendente em diversos padrões de escoamento (Figura 3.2), cujas propriedades foram extensivamente estudadas nos trabalhos de Caetano, Shoham e Brill (1992) e Mendes (2012) 


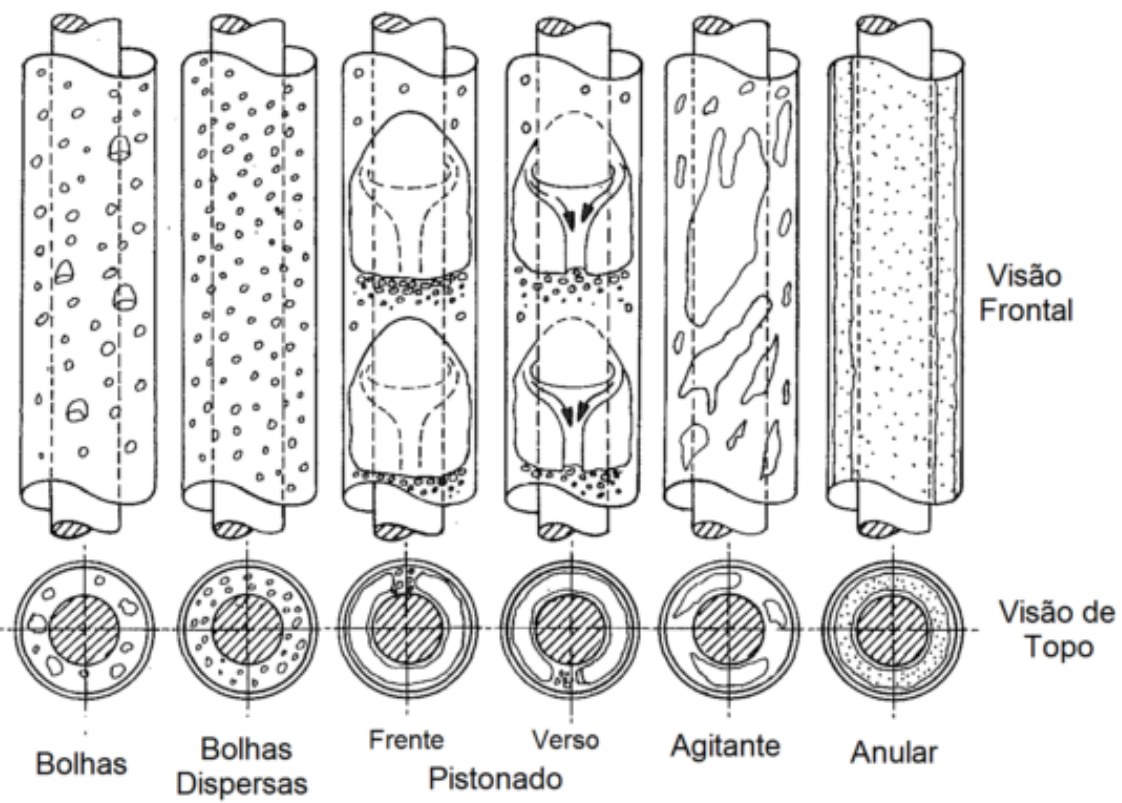

Figura 3.2 - Padrões de escoamento em um duto anular vertical, como identificado por Caetano, Shoham e Brill (1992).

Após sofrer segregação pela mudança na direção do escoamento, o gás tende a se acumular na parte superior do separador (Figura 3.1). Sujeita a forças gravitacionais, a fase líquida tende a entrar no anular interno (Região "B", localizada entre o shroud e o tubo de produção). Nesta região a fase líquida escoa de forma segregada em um canal aberto. Acima da fase líquida pode-se observar que a fase gasosa se encontra praticamente estática, com gotículas de líquido dispersas nela quando há turbulência no escoamento em superfície livre.

A fronteira entre as Regiões " $\mathrm{B}$ " e " $\mathrm{C}$ " é caracterizada por um choque entre o escoamento em superfície livre (B) e o nível dinâmico do líquido decantado no anular interno (NAI). Este choque pode ser modelado de forma semelhante a um ressalto hidráulico (ORTIZ-VIDAL, 2010), com significante aeração devido à dissipação turbulenta de energia. (ÇENGEL; CIMBALA, 2006). Após o choque, pode ser observada uma mistura bifásica descendente de bolhas dispersas em líquido.

As bolhas na Região "C" têm trajetória bem definida, sendo que, logo após o choque descrito acima, seu movimento é descendente e helicoidal, acompanhando a superfície interna do anular interno, ou seja, o tubo do shroud (ORTIZ-VIDAL, 2010). Ao longo desta trajetória, conforme a lei de Stokes, o movimento das bolhas é ascendente e em direção à parte superior do tubo do shroud, i.e., ocorre a segregação do gás. Isto deve ocorrer antes que 
as bolhas alcancem a entrada do tubo de produção, para que, assim, seja obtida a separação total do gás.

Assumindo que a separação total do gás seja alcançada, pode-se considerar que na Região " $D$ ” há apenas um escoamento monofásico de líquido em tubo.

\subsection{HIPÓTESES ADOTADAS}

Para permitir a modelagem do problema, foram adotadas as seguintes hipóteses simplificadoras:

1. O padrão de escoamento no anular externo não surte efeito algum sobre o escoamento em superfície livre, que ocorre no anular interno.

2. Não há perdas de líquido por quaisquer outras saídas, i.e., todo o líquido que percorre o anular externo também escoa pelo anular interno e, posteriormente, pelo tubo de produção.

3. O escoamento em superfície livre (Região "B”, Figura 3.1) não sofre efeitos de aeração, sendo assim monofásico. O escoamento na Região "C" também é considerado monofásico.

4. Nas regiões "B", "C" e "D”, considera-se que o escoamento é incompressível e ocorre em regime permanente.

5. O sistema comporta-se de forma isotérmica e adiabática, sendo assim desconsiderados os efeitos de troca de calor.

6. O gás que escoa pelo sistema é considerado ideal.

\subsection{DESENVOLVIMENTO DA MODELAGEM}

A modelagem do escoamento nas seções anteriores ao choque entre a superfície livre e o líquido decantado, na fronteira entre as regiões "B" e " $C$, foi descrita em detalhes por OrtizVidal (2010), não sendo necessário detalhá-la novamente. No entanto, a fim de desenvolver o modelo de separação de gás na região entre o choque e a entrada do tubo de produção, será necessário descrever a fenomenologia proposta por Ortiz-Vidal e, posteriormente, estendida por Mendes (2012). 
O modelo fenomenológico assume que o comprimento do NAI $\left(L_{N A I}\right)$ deve ser maior ou igual que um comprimento crítico do NAI para o qual se tem a separação total de gás, dado um conjunto de condições de operação do separador. O comprimento crítico, doravante denominado $L_{S E P}$ (comprimento de separação), é igual à máxima distância percorrida pelas bolhas no sentido axial dos tubos. Caso $L_{N A I}$ seja maior que $L_{S E P}$, haverá espaço suficiente para que quaisquer bolhas que escoam rumo à entrada do tubo de produção possam sofrer suficiente redução de velocidade através de forças de empuxo e arrasto. Consequentemente elas coalescem com outras bolhas e flutuam até chegarem ao NAI. Caso $L_{N A I}$ seja menor que $L_{S E P}$, haverá bolhas entrando no tubo de produção e, assim, será observada uma perda de eficiência de separação.

Ortiz-Vidal (2010) propôs que a distância $L_{S E P}$ fosse composta por duas componentes distintas. Uma delas, denominada $L_{D E S}$, é relacionada ao comprimento de desenvolvimento do perfil médio de velocidades no anular interno. A outra, denominada $L_{S T O K E S}$, é associada à projeção na direção axial da trajetória percorrida por uma bolha ao realizar um movimento helicoidal dentro do anular interno. Essa trajetória, causada pelo balanço de forças que age sobre a bolha, parte da região do choque entre a superfície livre e o líquido decantado (NAI), e segue em direção à entrada do tubo de produção. Com isto, se obtém a Equação (3.1):

$$
L_{N A I} \geq L_{S E P}=L_{D E S}+L_{S T O K E S}
$$

\subsubsection{Comprimento de Desenvolvimento}

O comprimento $L_{D E S}$, associado ao desenvolvimento do perfil de velocidades no anular interno, tem valores distintos para o escoamento laminar e para o escoamento turbulento (MENDES, 2012), de acordo com o número de Reynolds no anular interno após o choque turbulento $\left(R e_{A I}\right)$. Como nesta parte do separador o duto anular interno está totalmente ocupado pela fase líquida, temos:

$$
R e_{A I}=\frac{\rho_{L} \frac{Q_{L}}{A_{A I}} D_{H}}{\mu_{L}}
$$

Com isto, para o escoamento turbulento $L_{D E S}$ é dado por: 


$$
L_{D E S}=4,4 R e_{A I}^{1 / 6} D_{H}
$$

enquanto, para o escoamento laminar, temos:

$$
L_{D E S}=0,065 R e_{A I} D_{H}
$$

\subsubsection{Comprimento de Stokes}

O comprimento indicado por $L_{S T O K E S}$, pode ser calculado desde que se conheça o ângulo de inclinação do separador $(\beta)$, o diâmetro externo do duto anular interno $\left(D_{O_{A I}}\right)$, a velocidade terminal da bolha no meio líquido $\left(V_{t e r}\right)$ e a velocidade do líquido no anular interno $\left(V_{A I}\right)$. Como demonstrado por Ortiz-Vidal (2010), temos:

$$
L_{\text {STOKES }}=\frac{\pi}{2} D_{O_{A I}}\left(\frac{V_{A I}-V_{t e r} \operatorname{sen}(\beta)}{V_{\text {ter }} \cos (\beta)}\right)
$$

\subsubsection{Velocidade terminal da bolha}

Ao realizar uma trajetória descendente rumo à entrada do tubo de produção do separador, uma bolha tem velocidade máxima (terminal) igual a $V_{t e r}$, calculável através de um balanço entre forças gravitacionais, de empuxo e de arrasto. Este cálculo é realizado através da Lei de Stokes, como mostra a Equação (3.6) (MENDES, 2012; ORTIZ-VIDAL, 2010).

$$
V_{t e r}=\frac{\left(\rho_{L}-\rho_{G}\right) g d_{b}^{2}}{18 \mu_{L}}
$$

em que $\rho_{L}, \rho_{G}, \mu_{L}$ e $d_{b}$ são, respectivamente, a massa específica do líquido, a massa específica do gás, a viscosidade dinâmica do líquido e o diâmetro da bolha de gás. O diâmetro $d_{b}$ é considerado por Ortiz-Vidal como igual ao diâmetro proposto por Hinze ${ }^{4}$ (1955 apud GULLIVER, THENE e RINDELS, 1990) e será comparado neste trabalho com o seu valor real a partir dos dados aferidos com o aparato experimental de medição do tamanho de partículas (como será descrito no Capítulo 4).

4 HINZE, J.O. (1955) Fundamentals of the hydrodynamic mechanism of splitting in dispersion processes. AIChE Journal, v.1, n.3, p.289-295. 
O diâmetro proposto por Hinze pode ser visto na Equação (3.7),

$$
d_{b}=1,15\left(\frac{\sigma}{\rho_{L}}\right)^{0,6} \epsilon_{d i s}^{-0,4}
$$

onde $\sigma$ e $\epsilon_{d i s}$ são, respectivamente, a tensão superficial da mistura bifásica e a taxa de dissipação de energia por unidade de massa.

$\mathrm{O}$ valor de $\epsilon_{\text {dis }}$, a taxa de dissipação de energia cinética turbulenta por unidade de massa de fluido, é função da velocidade do líquido que escoa pela Região "B" (Figura 3.1) e do comprimento de dissipação da energia cinética turbulenta do fluido. Conforme demonstrado por Mendes (2012), utilizando a conservação de energia em um volume de controle que envolve a região do impacto entre " $\mathrm{B}$ " e " $\mathrm{C}$ ", temos:

$$
\epsilon_{d i s}=\frac{V_{S L}^{3}}{2 L_{d i s}}
$$

em que $L_{d i s}$ é o comprimento mínimo de percurso para que seja totalmente dissipada a energia cinética turbulenta do fluido. Para calcular este parâmetro, Mendes (2012) baseou-se nos dados experimentais de Ortiz-Vidal (2010) e propôs uma correlação experimental que utilizasse o número de Weber para caracterizar a interação entre as duas fases do escoamento gás-líquido:

$$
\frac{L_{d i s}}{D_{H_{A I}}}=m\left(\frac{W e_{S L}}{48}\right)^{-n}
$$

onde $m$ e $n$ são coeficientes ajustados experimentalmente, $D_{H_{A I}}$ é o diâmetro hidráulico do anular interno e $W e_{S L}$ é o número de Weber calculado para o escoamento em superfície livre. Mendes (2012), analisando seu banco de dados próprio, propôs que fosse utilizado $m=1500$ para o escoamento turbulento na região de superfície livre e $m=0,008$ para o escoamento laminar, enquanto para ambos os casos se tem $n=2$. O número de Weber é calculado por:

$$
W e_{S L}=\frac{\rho_{L} V_{S L}^{2} S_{i L}}{48 \sigma}
$$

em que $S_{i_{A L}}$ é o comprimento da interface entre a fase líquida e a fase gasosa na região em que ocorre o escoamento em superfície livre. 
A fim de obter a velocidade do escoamento em superfície livre $\left(V_{S L}\right)$, é necessário que se tenha conhecimento das características geométricas do escoamento em canal aberto. Admitindo uma superfície livre plana nesta região, a fim de simplificar o modelo, temos uma geometria igual à descrita pela Figura 3.3. As áreas e perímetros do escoamento são funções da profundidade da superfície livre no anular interno, denominada por $h_{L O_{A I}}$. As equações, já desenvolvidas, são apresentadas a seguir (BLANCO; ALBIERI; RODRIGUEZ, 2008):

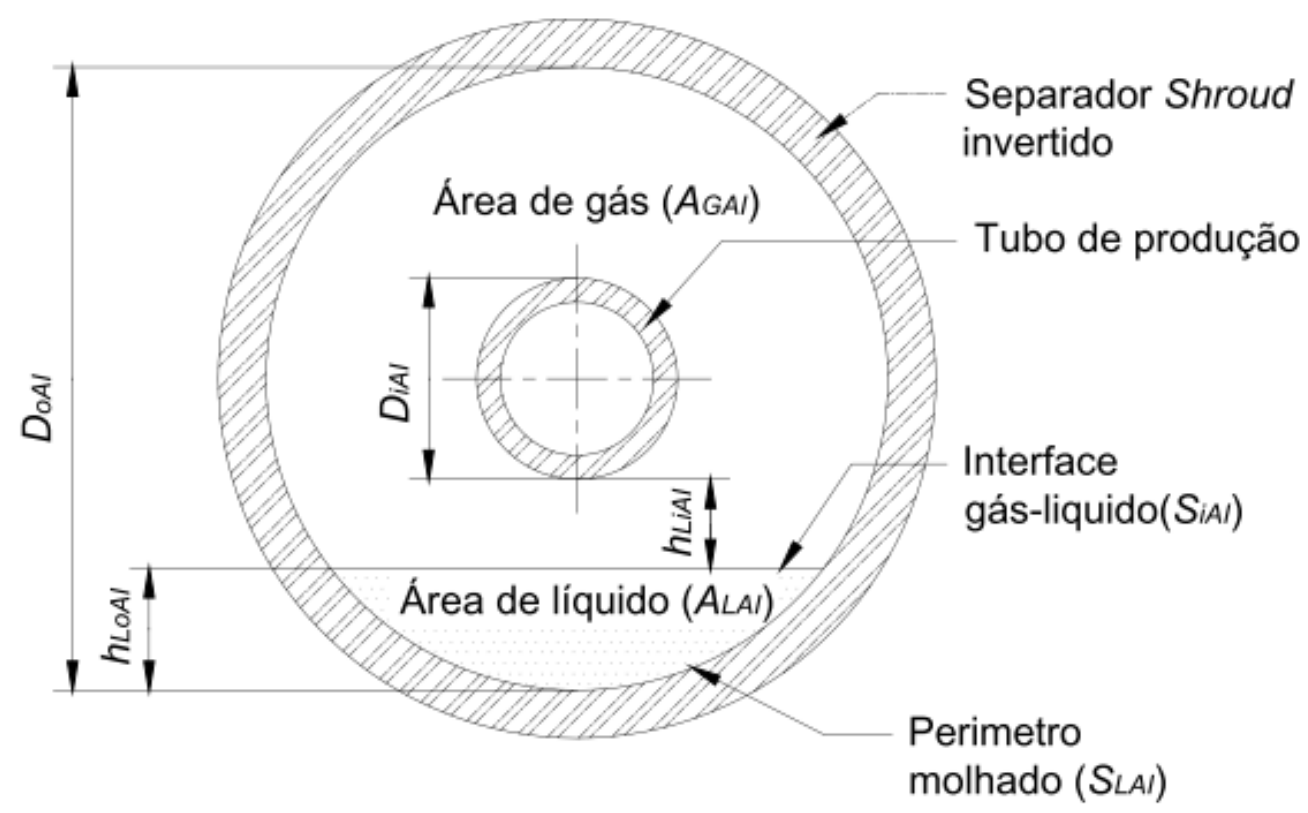

Figura 3.3 - Geometria do escoamento em superfície livre no anular interno do separador shroud invertido (MENDES, 2012)

Se $h_{L O_{A I}} \leq \frac{\left(D_{O_{A I}}-D_{I_{A I}}\right)}{2}$ 


$$
\begin{aligned}
& A_{L_{A I}}=\frac{1}{4} D_{O_{A I}}^{2}\left[\arccos \left(1-\frac{2 h_{L O_{A I}}}{D_{O_{A I}}}\right)-\sqrt{1-\left(\frac{2 h_{L O_{A I}}}{D_{O_{A I}}}-1\right)^{2}}\left(1-\frac{2 h_{L O_{A I}}}{D_{O_{A I}}}\right)\right] \\
& S_{L_{A I}}=D_{O_{A I}} \arccos \left(1-\frac{2 h_{L O_{A I}}}{D_{O_{A I}}}\right) \\
& S_{i_{A L}}=D_{O_{A I}} \sqrt{1-\left(1-\frac{2 h_{L O_{A I}}}{D_{O_{A I}}}\right)^{2}} \\
& \operatorname{Se} \frac{D_{O_{A I}}-D_{I_{A I}}}{2}<h_{L O_{A I}}<\frac{D_{O_{A I}}+D_{I_{A I}}}{2} \\
& A_{L_{A I}}=\frac{\pi\left(D_{O_{A I}^{2}}^{2}-D_{I_{A I}^{2}}^{2}\right)}{4} \\
& -\frac{1}{4} D_{O A I}^{2}\left[\arccos \left(\frac{2 h_{L O_{A I}}}{D_{O_{A I}}}-1\right)-\sqrt{1-\left(\frac{2 h_{L O_{A I}}}{D_{O_{A I}}}-1\right)^{2}}\left(\frac{2 h_{L O_{A I}}}{D_{O_{A I}}}-1\right)\right] \\
& +\frac{1}{4} D_{I_{A I}}^{2}\left[\arccos \left(\frac{2 h_{L I} A I}{D_{I_{A I}}}-1\right)-\sqrt{1-\left(\frac{2 h_{L I_{A I}}}{D_{I_{A I}}}-1\right)^{2}}\left(\frac{2 h_{L I_{A I}}}{D_{I_{A I}}}-1\right)\right] \\
& S_{L_{A I}}=\pi\left(D_{O_{A I}}+D_{I_{A I}}\right)-D_{O_{A I}} \arccos \left(\frac{2 h_{L O_{A I}}}{D_{O_{A I}}}-1\right)-D_{I_{A I}} \arccos \left(\frac{2 h_{L I} A I}{D_{I_{A I}}}-1\right) \\
& S_{i_{A I}}=D_{O_{A I}} \sqrt{1-\left(\frac{2 h_{L O_{A I}}}{D_{O_{A I}}}-1\right)^{2}-D_{I_{A I}} \sqrt{1-\left(\frac{2 h_{L I} A I}{D_{I_{A I}}}-1\right)^{2}}}
\end{aligned}
$$

Se $h_{L O_{A I}} \geq \frac{D_{O_{A I}+D_{I_{A I}}}}{2}$ 


$$
\begin{gathered}
A_{L_{A I}}=\frac{\pi\left(D_{O_{A I}}^{2}-D_{I_{A I}}^{2}\right)}{4} \\
-\frac{1}{4} D_{O_{A I}}^{2}\left[\arccos \left(\frac{2 h_{L O_{A I}}}{D_{O_{A I}}}-1\right)-\sqrt{1-\left(\frac{2 h_{L O_{A I}}}{D_{O_{A I}}}-1\right)^{2}}\left(\frac{2 h_{L O_{A I}}}{D_{O_{A I}}}-1\right)\right] \\
S_{L_{A I}}=D_{O_{A I}\left[\pi-\arccos \left(\frac{2 h_{L O_{A I}}}{D_{O_{A I}}}-1\right)\right]+\pi D_{I_{A I}}} \\
S_{i_{A I}}=D_{O_{A I}} \sqrt{\left(1-\frac{2 h_{L O_{A I}}}{D_{O_{A I}}}-1\right)^{2}}
\end{gathered}
$$

Em posse das equações descritas e da vazão da fase líquida $\left(Q_{L}\right)$, a velocidade $V_{S L}$ torna-se uma função da geometria do sistema, mais especificamente da área $A_{L_{A I}}$ :

$$
Q_{L}=V_{S L} A_{L_{A I}}
$$

Uma outra relação entre $V_{S L}$ e a geometria do sistema pode ser obtida através da equação utilizada por Chézy $^{5}$ (1775 apud MENDES, 2012)para determinar a velocidade do escoamento de superfície livre em canais abertos,

$$
V_{S L}=\sqrt{\frac{2 g D_{h_{S L}} \operatorname{sen}(\beta)}{f_{S L}}}
$$

em que $D_{h_{S L}}$ é o diâmetro hidráulico do escoamento em superfície livre, descrito por

$$
D_{h_{S L}}=4 \frac{A_{L_{A I}}}{S_{L_{A I}}}
$$

A variável $A_{L I}$ representa a área ocupada pelo líquido na seção transversal do escoamento em superfície livre, enquanto $S_{L_{A I}}$ é o perímetro molhado da fase líquida. Ambas podem ser vistas na Figura 3.3 e são calculáveis através das Equações (3.11) a (3.19)u. O fator de atrito $f_{S L}$ também se refere ao escoamento em superfície livre, sendo que neste trabalho será utilizado para escoamento laminar,

${ }^{5}$ Chézy, A. (1775). Memoire sur la vitesse de l'eau conduit dans une rigole donne. Dossier 847 (MS 


$$
f_{S L}=\frac{64}{R e_{S L}}
$$

em que $R e_{S L}$ se refere ao número de Reynolds do escoamento em superfície livre, dado por

$$
R e_{S L}=\frac{4 \rho_{L} Q_{L}}{\pi D_{h_{S L}} \mu_{L}}
$$

No caso de escoamento turbulento $\left(R e_{S L}>2000\right)$, será utilizado neste trabalho o fator proposto por Zigrang e Sylvester ${ }^{6}$ (apud MENDES, 2012):

$$
f_{S L}=\frac{1}{\left[2 \log _{10}\left(\frac{\varepsilon}{3,7 D_{h_{S L}}}-\frac{5,02}{R e_{S L}} \log _{10}\left[\frac{\varepsilon}{3,7 D_{h_{S L}}}-\frac{5,02}{R e_{S L}} \log _{10}\left[\frac{\varepsilon}{3,7 D_{h_{S L}}}-\frac{13}{R e_{S L}}\right]\right]\right)\right]^{2}}
$$

em que $\varepsilon$ é a rugosidade da parede interna do shroud.

Com o conjunto de equações apresentado, torna-se possível determinar a velocidade terminal $V_{S L}$ do escoamento em superfície livre e sua profundidade $h_{L O_{A I}}$, através de um sistema de duas incógnitas e duas variáveis. Desta forma, finalmente podemos calcular $L_{N A I}$ através apenas dos quatro parâmetros propostos inicialmente.

Uma forma de desenvolver a modelagem descrita é o ajuste experimental de um dos parâmetros, através da proposição de correlações que melhor descrevam os fenômenos documentados. A função deste trabalho é validar ou corrigir o cálculo do diâmetro de bolhas, disposto na Equação (3.7), a fim de obter um modelo mais preciso.

${ }^{6}$ ZIGRANG, D. J.; SYLVESTER, N. D. Explicit approximations to the solution of Colebrook's friction factor equation. AIChE Journal, v. 28, n. 3, p. 514-515, 1982. American Institute of Chemical Engineers. Disponível em: <http://dx.doi.org/10.1002/aic.690280323> 



\section{CAPÍTULO 4 TRABALHO EXPERIMENTAL}

Neste capítulo será descrito em detalhes o aparato experimental utilizado neste trabalho, para que se possa verificar a qualidade dos dados coletados e para ilustrar a metodologia utilizada.

O aparato descrito teve financiamento da petroleira brasileira Petróleo Brasileiro S/A, PETROBRAS. A montagem foi realizada nas instalações do Laboratório de Engenharia Térmica e Fluidos (LETeF) da Escola de Engenharia de São Carlos (EESC) da Universidade de São Paulo (USP), no ano de 2010. Desde sua concepção, realizada para a execução dos trabalhos de Ortiz-Vidal e Mendes (MENDES, 2012; ORTIZ-VIDAL, 2010), esta linha experimental passou por várias mudanças, em sua geometria e em seus equipamentos. Desta forma, faz-se necessário descrevê-la detalhadamente.

O estudo experimental deste trabalho se deu em duas partes, descritas separadamente neste capítulo. A primeira trata do separador-piloto utilizado na verificação do modelo fenomenológico proposto nos trabalhos anteriores de Ortiz-Vidal e Mendes. A segunda parte, central ao objetivo deste trabalho, descreverá em mais detalhes os equipamentos e a metodologia utilizados na aferição do diâmetro de bolhas no duto anular interno do aparato. Por fim, um estudo adicional a respeito da mitigação do fenômeno de afogamento com o uso de um shroud com tubo perfurado será discutido. A análise de incertezas experimentais será melhor detalhada no Apêndice A.

\subsection{INSTALAÇÕES EXPERIMENTAIS}

O aparato experimental instalado no LETeF-USP consiste, basicamente, em um separador-piloto feito de tubos concêntricos de vidro e PVC segundo uma geometria radial de poço em escala real especificada pela PETROBRAS. Sistemas de suprimento dos três fluidos utilizados (água, óleo e ar) e um sistema de instrumentação e controle implementado em plataforma LabVIEW® permitem que testes sejam realizados remotamente, sendo necessária a presença de apenas um operador.

O esquema apresentado na Figura 4.1 mostra os elementos utilizados no aparato experimental na primeira etapa de testes, em que foi estudada a eficiência de separação de gás. Na execução da segunda etapa de testes, em que foi estudada a distribuição do diâmetro 
de bolhas geradas por dissipação de energia cinética do escoamento, foram realizadas mudanças na posição de alguns componentes para que estes fossem melhor aproveitados após melhorias feitas durante um hiato entre as duas etapas experimentais. Um esquema da segunda instalação é apresentado na Figura 4.2. Em ambos os diagramas pode-se ver os elementos de instrumentação representados por números e os componentes do sistema representados por letras. Os aparatos são descritos detalhadamente com números e letras nas Tabelas 4.2 e 4.3 .

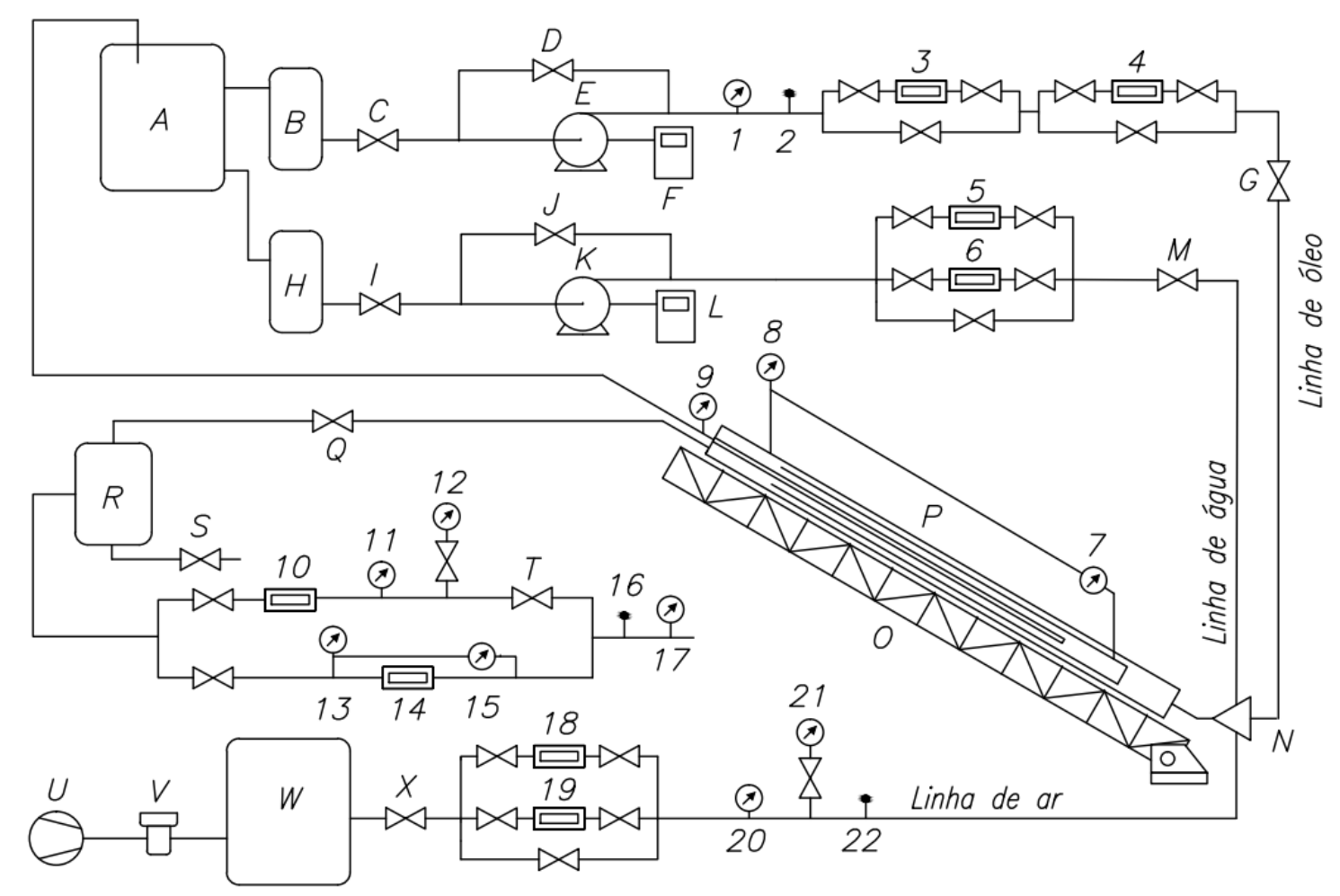

Figura 4.1 - Esquema do circuito experimental utilizado no LETeF-EESC-USP na primeira etapa de testes (medição da eficiência de separação de gás) 


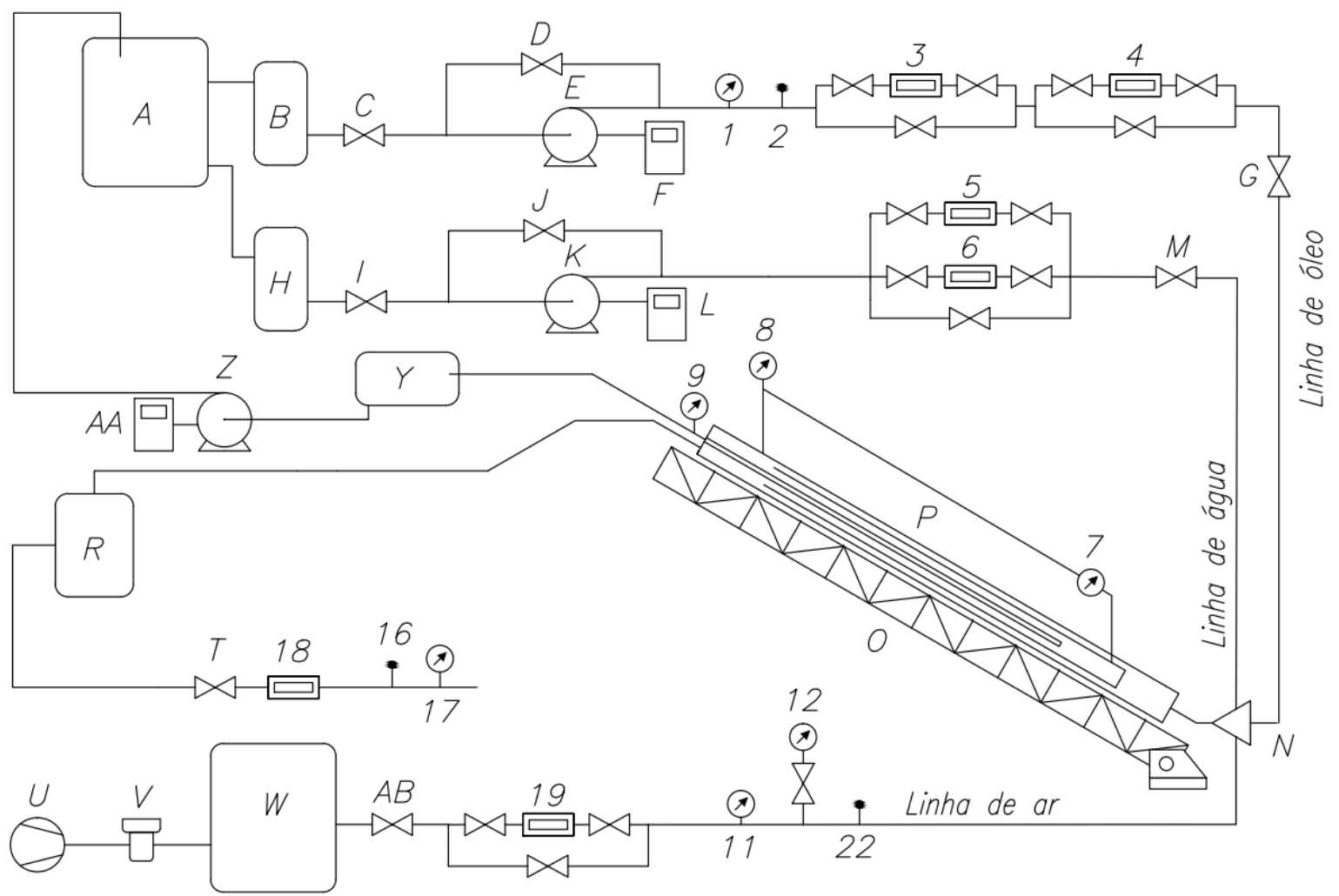

Figura 4.2 - Esquema do circuito experimental utilizado no LETeF-EESC-USP na segunda etapa de testes (medição do diâmetro de bolhas)

Tabela 4.1 - Componentes do Sistema experimental.

\begin{tabular}{ll}
\hline \hline Letra & Componente \\
\hline \hline A & Separador de placas coalescentes \\
B & Tanque de óleo \\
C & Válvula do tanque de óleo \\
D & Válvula de bypass da bomba de óleo \\
E & Bomba helicoidal de óleo \\
F & Variador de frequência da bomba de óleo \\
G & Válvula esférica \\
H & Tanque de água \\
I & Válvula do tanque de água \\
J & Válvula de bypass da bomba de água \\
K & Bomba helicoidal de água \\
L & Variador de frequência
\end{tabular}




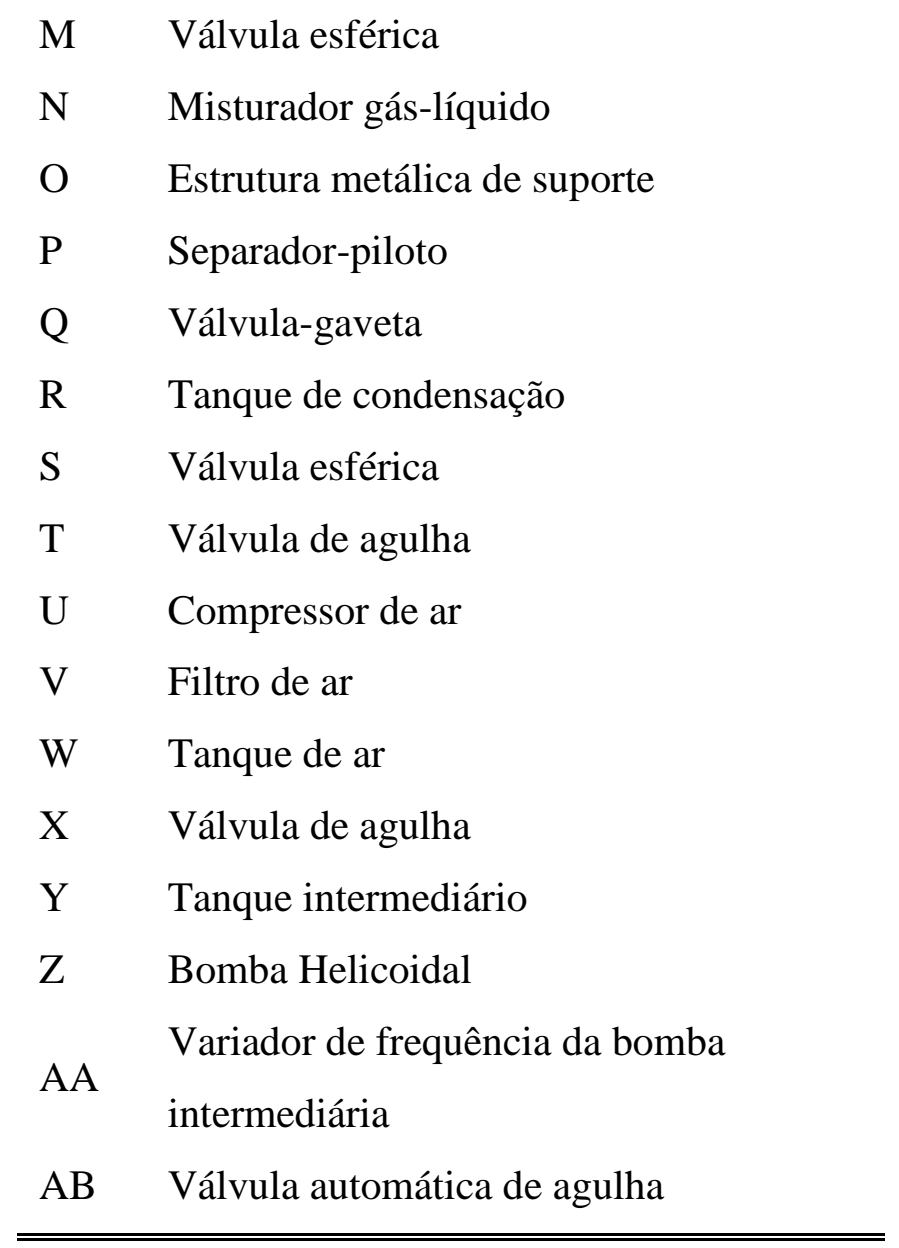

Tabela 4.2 - Elementos do sistema de instrumentação.

\begin{tabular}{clll}
\hline \hline Número & Instrumento de Medição & Range (CNTP) & Precisão \\
\hline \hline 1 & Transdutor de pressão Huba Control 510 & 0 a 5 (bar) & $0,25 \% \mathrm{FE}$ \\
2 & Transmissor de temperatura IOPE TW-TC/2 & -20 a $140\left({ }^{\circ} \mathrm{C}\right)$ & $0,5{ }^{\circ} \mathrm{C}$ \\
3 & Medidor de vazão de óleo Oval M-III 45 & 0,05 a $8(1 / \mathrm{min})$ & $1 \% \mathrm{FE}$ \\
4 & Medidor de vazão de óleo Oval Flowpet EG & 2,5 a $106,7(1 / \mathrm{min})$ & $0,5 \% \mathrm{RD}$ \\
5 & Medidor de vazão de água Oval OGT & 1 a $35(1 / \mathrm{min})$ & $0,75 \% \mathrm{RD}$ \\
6 & Medidor de vazão de água Oval EX Delta & 30 a $1300(1 / \mathrm{min})$ & $1 \% \mathrm{RD}$ \\
7 & Transdutor de Pressão Smar LD 301 & 1 a $50(\mathrm{kPa})$ & $0,075 \% \mathrm{Span}$ \\
8 & Transdutor de pressão Huba Control 510 & 0 a $5(\mathrm{bar})$ & $0,25 \% \mathrm{FE}$ \\
9 & Transdutor de pressão Huba Control 961 & -1 a $1(\mathrm{bar})$ & $0,3 \% \mathrm{FE}$ \\
10 & Medidor de vazão de gás Oval GAL 50 & 1 a $20(1 / \mathrm{min})$ & $1 \% \mathrm{FE}$ \\
11 & Transdutor de pressão Danfoss AKS 33 & 0 a $12(\mathrm{bar})$ & $0,25 \% \mathrm{FE}$
\end{tabular}


12 Transdutor de pressão Danfoss AKS 33

$\begin{array}{ll}0 \text { a } 1(\mathrm{bar}) & 0,8 \% \mathrm{FE} \\ 1,25 \text { a } 50(\mathrm{kPa}) & 0,075 \% \text { Span } \\ 120 \text { a } 360(\mathrm{l} / \mathrm{min}) & \text { Variável } \\ 1,25 \text { a } 50(\mathrm{kPa}) & 0,075 \% \text { Span } \\ 15 \text { a } 50\left({ }^{\circ} \mathrm{C}\right) & 0,5{ }^{\circ} \mathrm{C} \\ 647 \text { a } 830(\mathrm{mmHg}) & 0,5 \mathrm{mmHg} \\ 1,37 \text { a } 13,7\left(\mathrm{~m}^{3} / \mathrm{h}\right) & 1 \% \mathrm{FE} \\ 1 \text { a } 20(1 / \mathrm{min}) & 1 \% \mathrm{FE} \\ 0 \text { a } 5(\mathrm{bar}) & 0,25 \% \mathrm{FE} \\ 2 \text { a } 250(\mathrm{kPa}) & 0,075 \% \mathrm{Span} \\ -20 \text { a } 140\left({ }^{\circ} \mathrm{C}\right) & 0,5{ }^{\circ} \mathrm{C}\end{array}$

\subsection{PRIMEIRA ETAPA EXPERIMENTAL}

\subsubsection{Separador piloto}

A parte central da instalação experimental é a seção de testes indicada em P, na Figura 4.1. O aparato simula um poço de petróleo em que estão inseridos um tubo de produção e um separador shroud invertido. O poço e o shroud são compostos de vidro borosilicato, enquanto o tubo de produção é um tubo de PVC. O aparato tem comprimento total de $10,5 \mathrm{~m}$, sendo que as partes de vidro são compostas por seções de tubo com 1,5 m de comprimento e o tubo de PVC é contínuo e mede 8,5 m. Luvas de PVC, projetadas por Mendes (2012), foram utilizadas para unir as seções de tubos. A Figura 4.3 mostra a seção de testes. 


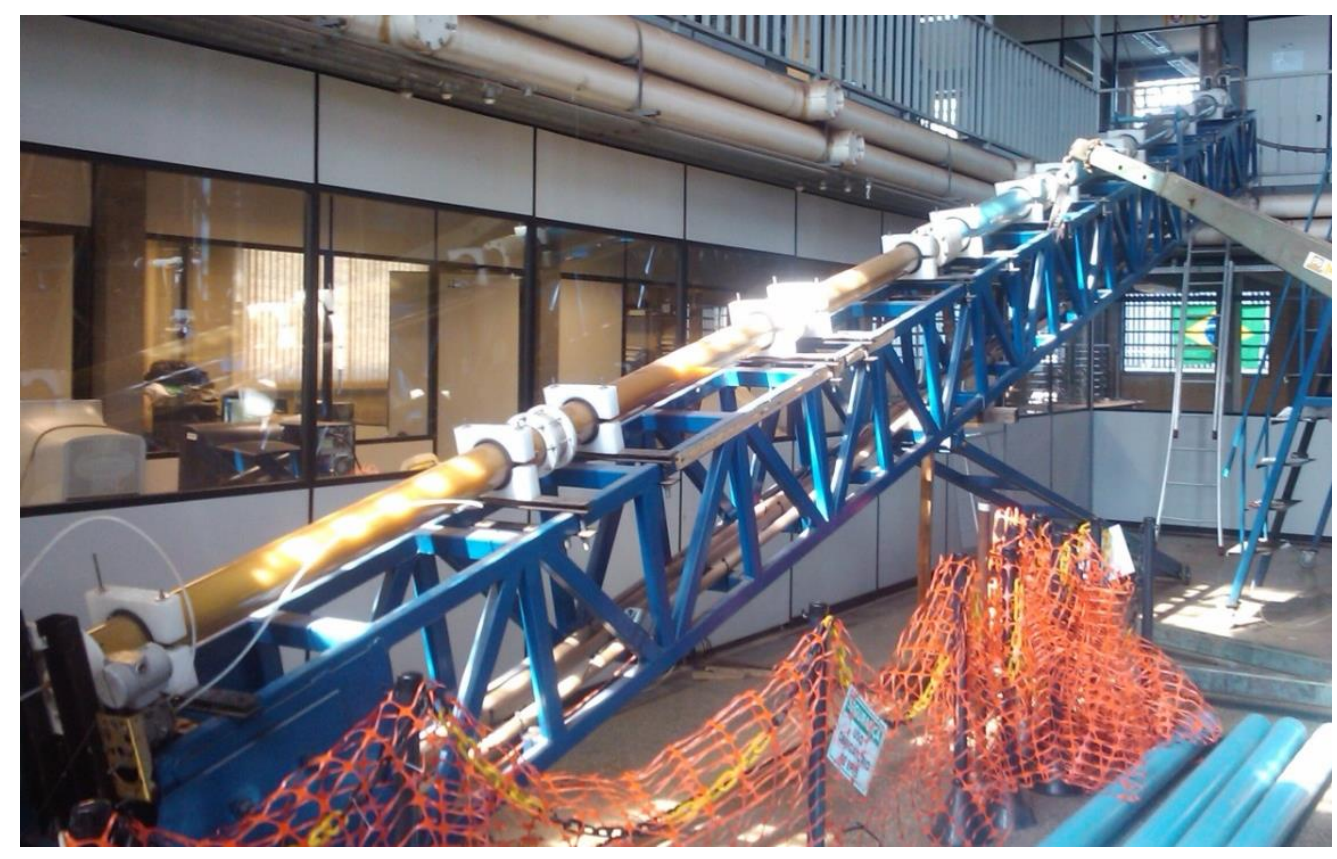

Figura 4.3 - Foto da seção de testes $(\mathrm{P})$, com a viga treliçada $(\mathrm{O})$.

A montagem usada na primeira etapa de testes, ilustrada pela Figura 4.4, difere dos trabalhos anteriores por ter uma seção externa (Revestimento do poço) mais curta. Com o estudo de Mendes (2012), sobre o escoamento bifásico no anular externo do separador-piloto, foi verificado que o padrão de escoamento nesta região não afeta a eficiência de separação. Isto possibilitou que fossem removidas as seções inferiores do tubo externo para que fosse mais fácil visualizar o escoamento no interior do shroud. 


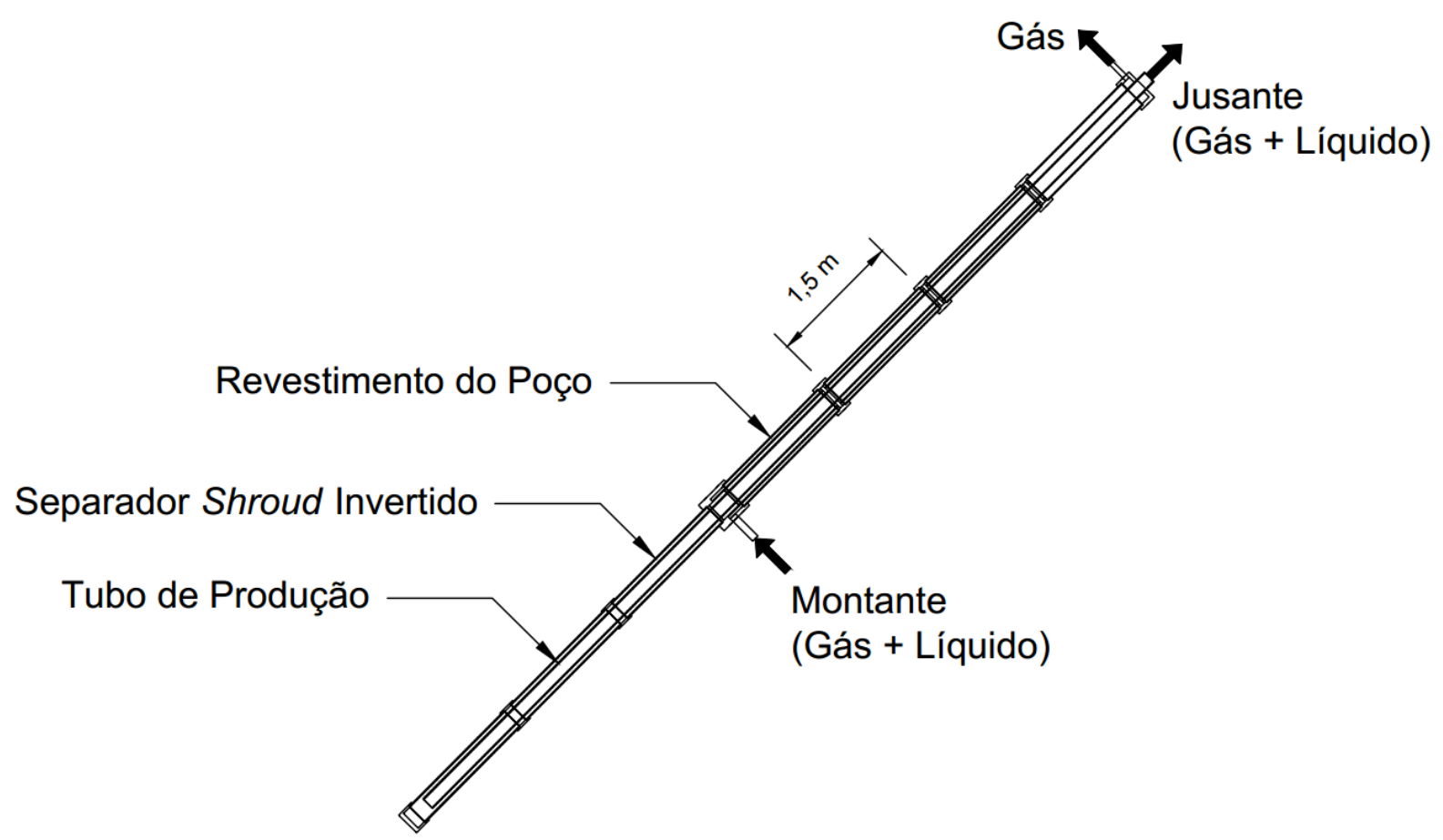

Figura 4.4 - Esquema da seção de testes.

A Figura 4.5 mostra um exemplo de secção em corte da seção de testes. Duas geometrias distintas (conjunto de diâmetros do Revestimento, Shroud e Tubo de Produção) foram utilizadas neste trabalho, como descrito na Tabela 4.3. O estudo da eficiência de separação do gás, a fim de verificar o modelo proposto inicialmente por Ortiz-Vidal (2010), foi feito com a geometria em escala real sugerida pela PETROBRAS. No estudo dos diâmetros de bolhas foi utilizada uma segunda geometria (Tabela 4.3) com dimensões reduzidas em relação à original, o que propicia uma maior dissipação de energia cinética e facilita a medição dos diâmetros de bolhas. 


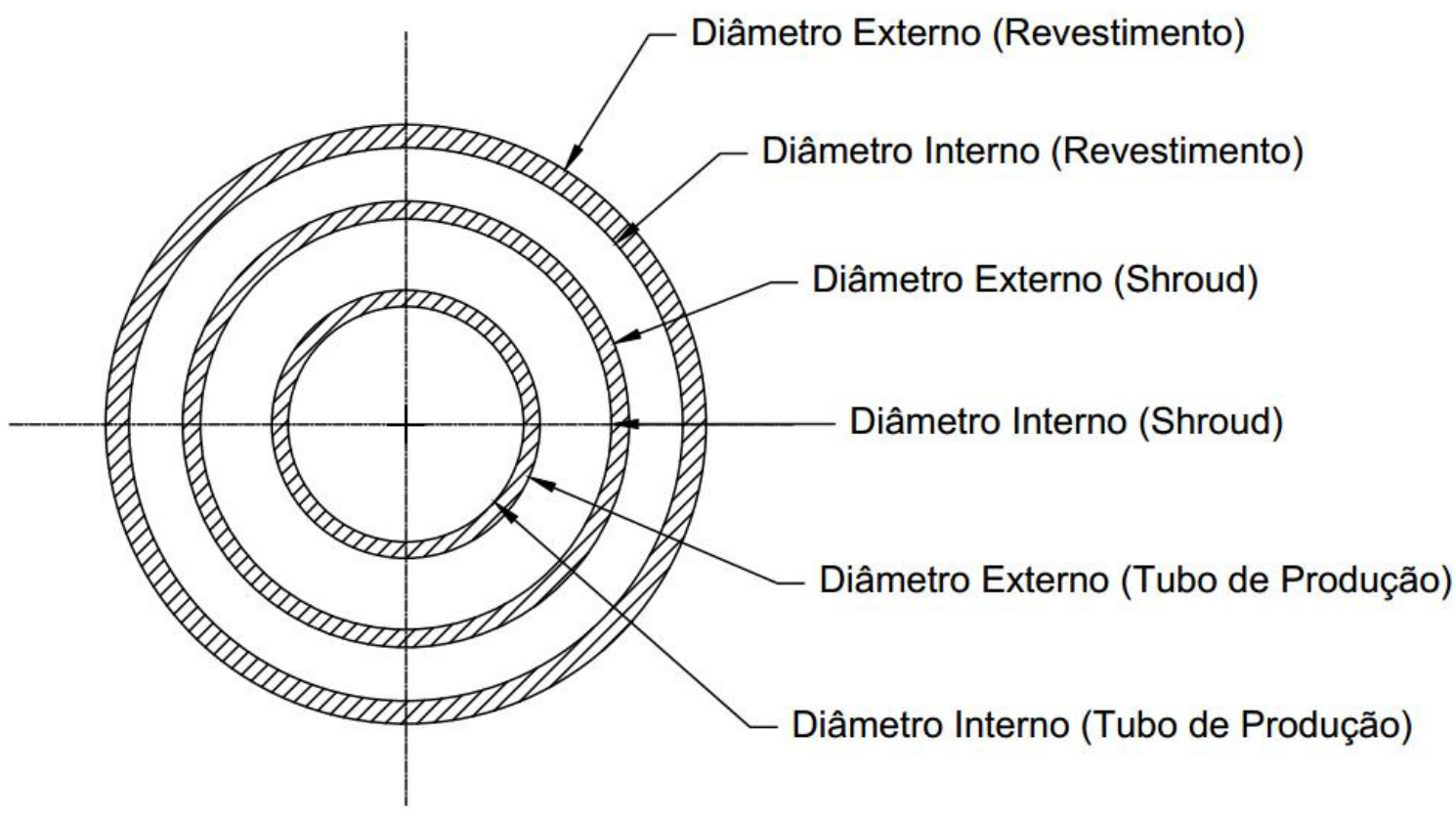

Figura 4.5 - Diagrama da geometria da seção de testes.

Tabela 4.3 - Geometrias utilizadas na seção de testes.

\begin{tabular}{ccccccc}
\hline Tipo de estudo & $\begin{array}{c}\text { Diâmetro do } \\
\text { tubo de } \\
\text { produção }(\mathrm{mm})\end{array}$ & $\begin{array}{c}\text { Diâmetro do } \\
\text { Shroud }(\mathrm{mm})\end{array}$ & $\begin{array}{c}\text { Diâmetro do } \\
\text { revestimento } \\
(\mathrm{mm})\end{array}$ \\
\hline Estudo da eficiência de separação \\
$\begin{array}{c}\text { de gás } \\
\text { Est. }\end{array}$ & 66 & 75 & 115 & 125 & 155 & 165 \\
Ext. & Int. & Ext. & Int. & Ext. \\
\hline
\end{tabular}

Uma viga treliçada $(\mathrm{O})$, cujos detalhes de construção estão dispostos em Ortiz-Vidal (2010), serve para sustentar e inclinar a seção de testes. Um guincho HiPull GT12B20T é utilizado para posicionar o aparato no ângulo desejado para cada teste, enquanto um medidor de nível Bosch DNM 60L é utilizado para verificar a inclinação com $0,2^{\circ}$ de precisão entre $1^{\circ}$ e $89^{\circ}$.

A fixação da seção de testes na viga treliçada é feita através de abraçadeiras de nylon posicionadas em torno dos tubos de vidro. Varões de aço unem as abraçadeiras e as prendem a duas chapas de aço com $5 \mathrm{~mm}$ de espessura que estão fixadas à viga, como mostra a Figura 4.6. 


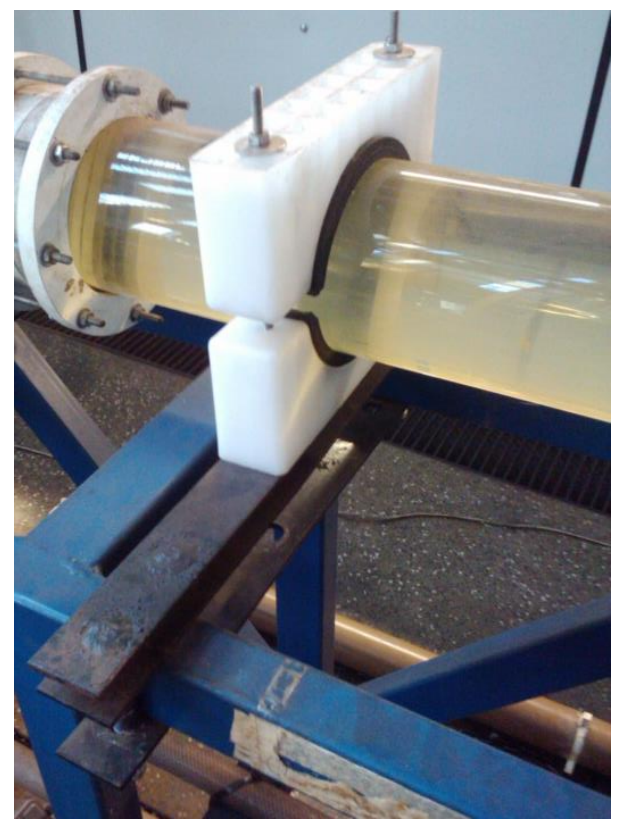

Figura 4.6 - Abraçadeiras de nylon utilizadas para prender a seção de testes à viga treliçada.

Os fluidos são injetados no anular externo do separador através de um tubo conectado a uma das luvas de PVC, após passarem pelo misturador gás-líquido (N) ilustrado na Figura 4.7 .

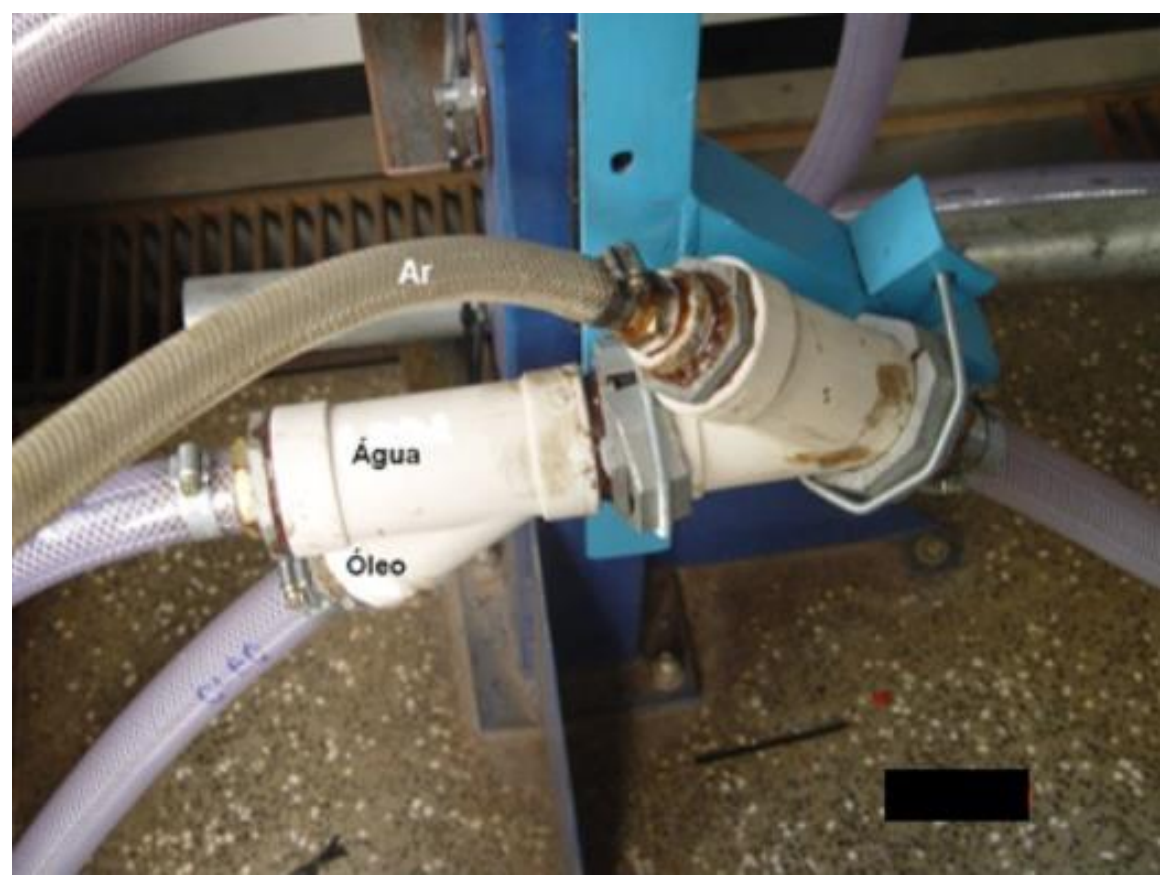

Figura 4.7 - Misturador gás-líquido utilizado no aparato experimental (MENDES, 2012). 
Duas tomadas de pressão no separador, localizadas na Figura 4.1 pelos itens 7 e 8 , medem respectivamente a pressão da coluna de líquido no anular interno e a pressão de revestimento $\left(P_{r e v}\right)$ em seu anular externo. O primeiro parâmetro mencionado é utilizado na verificação do nível de líquido no anular interno (NAI), sendo, no entanto, necessário confirmar constantemente este valor visualmente ao longo de uma bateria de testes. $\mathrm{O}$ segundo parâmetro é utilizado para o cálculo da queda de pressão $(\Delta P)$ entre a entrada do shroud e a saída do tubo de produção, como descrito na fenomenologia proposta inicialmente por Ortiz-Vidal (2010).

\subsubsection{Suprimento de Água e Óleo}

O conjunto de experimentos que são realizados no LETeF conta com um circuito fechado de linhas de água e óleo, com a capacidade de separar os dois fluidos para uso contínuo. O componente A indicado na Figura 4.1 e mostrado na Figura 4.8 representa um separador água-óleo de placas coalescentes, que é utilizado para separar esta mistura bifásica à medida que seus elementos são utilizados. Ao passarem por este separador os fluidos se encontram decantados e são despejados nos tanques idênticos B e H (óleo e água, respectivamente). As válvulas C e I servem para manter os tanques fechados caso seja necessário realizar alguma mudança ou manutenção nas linhas. A Figura 4.9 mostra um dos tanques mencionados.

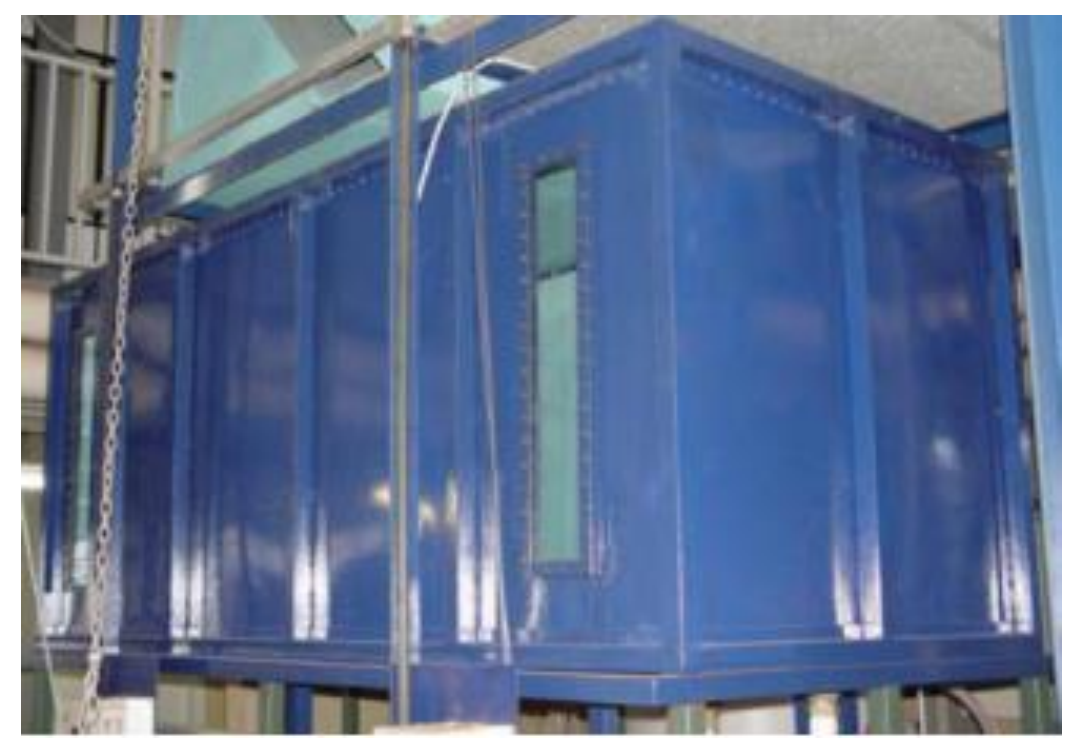

Figura 4.8 - Separador água-óleo de placas coalescentes instalado no NETeF-USP. 


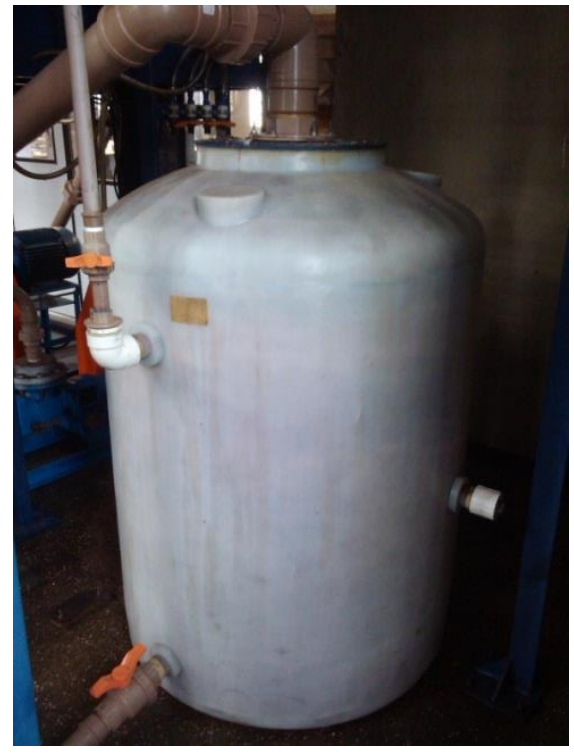

Figura 4.9 - Tanque de água com 500 litros de capacidade.

Duas bombas helicoidais de cavidades progressivas Weatherford modelo 2WHT53 com capacidade máxima de pressão de $12 \mathrm{kgf} / \mathrm{cm}^{2}$ (aproximadamente $12 \mathrm{bar}$ ), indicadas em E e K (Figura 4.1) servem para bombear cada fase independentemente. Sistemas de bypass para cada linha são controlados pelas válvulas D e J, sendo possível fechá-las para maximizar a vazão de cada bomba.

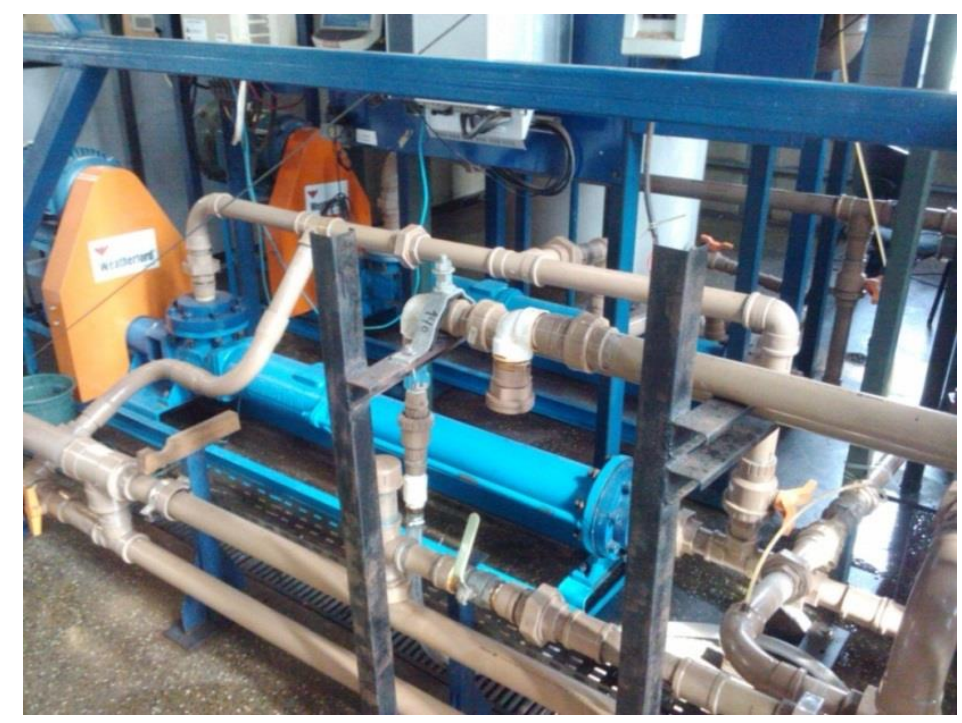

Figura 4.10 - Bombas de alimentação de água e óleo.

Cada bomba é acionada e controlada independentemente por um variador de frequência (Figura 4.11) auxiliado remotamente através do protocolo Profibus ETHERNET de comunicação, através de uma plataforma NI LabVIEW®. A bomba de água utiliza um 
variador WEG modelo CFW09 indicado em E na Tabela 4.1, enquanto a bomba de óleo utiliza um variador Yaskawa modelo VS-616PC5/P5.

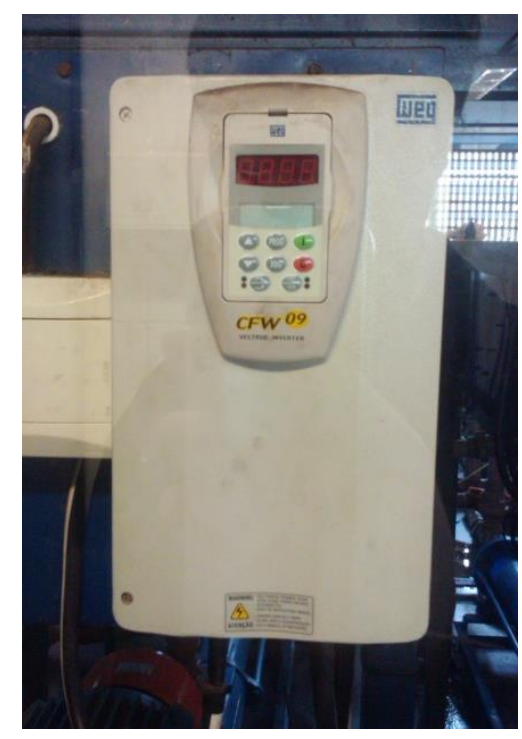

(a)

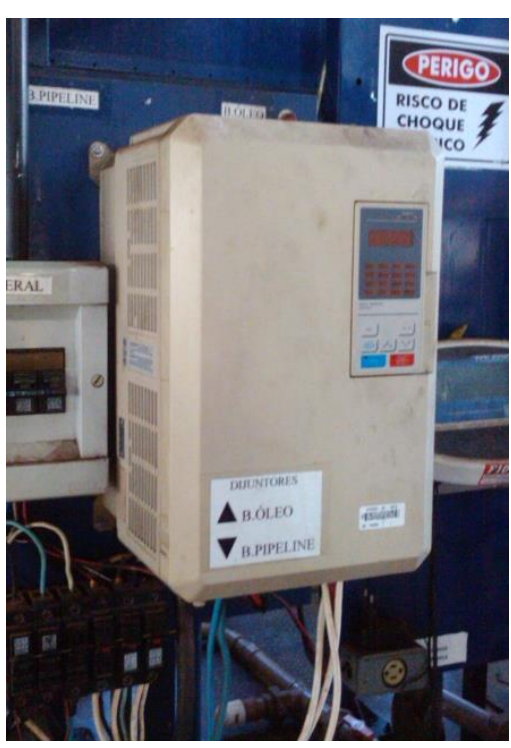

(a)

Figura 4.11 - Variadores de frequência. a) Variador da bomba de água, modelo WEG CFW09 e b) Variador da bomba de óleo, modelo Yaskawa VS-616PC5/P5

Devido à alta viscosidade do óleo utilizado (Apêndice B), é comum que a linha à jusante da bomba $E$ esteja sujeita a altas pressões. $O$ transdutor de pressão indicado em 1 (Figura 4.1) é utilizado para alertar o usuário através do sistema de instrumentação caso seja atingida uma pressão acima de 3 bar, evitando que componentes da linha de PVC sejam danificados antes que seja possível reduzir a potência da bomba para níveis seguros. Para aferir quaisquer mudanças na viscosidade do óleo com variações de temperatura utiliza-se o termopar 2. Anteriormente aos experimentos, foi aferida, em um reômetro, uma curva de Viscosidade vs. Temperatura do óleo, descrita no Apêndice B.

A vazão volumétrica de água é lida pelos sensores indicados na Tabela 4.2 e na Figura 4.1 pelos itens 5 e 6 . Para vazões baixas foi utilizado um medidor de deslocamento positivo Oval OGT Badger Meter, enquanto que para vazões altas foi utilizado um medidor tipo vortex modelo Oval EX Delta. Ambos estão indicados na Figura 4.12. 


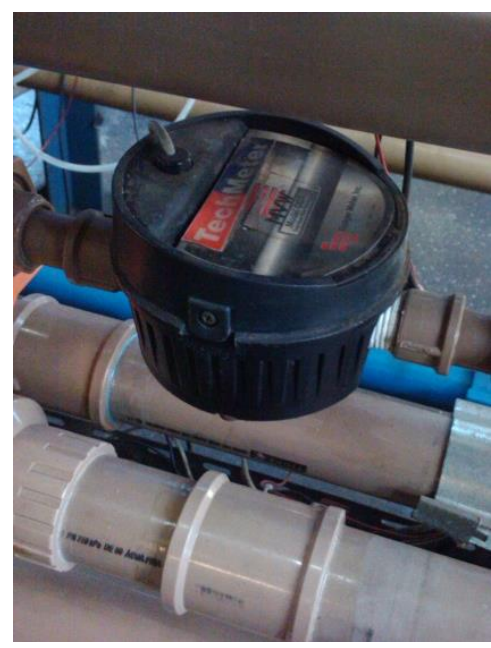

(a)

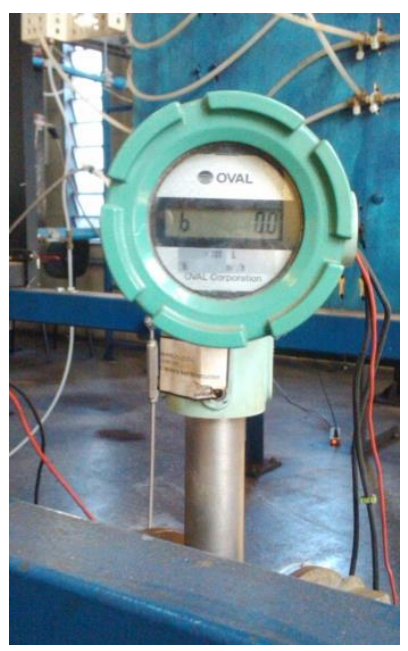

(a)

Figura 4.12 - Medidores de vazão de água, a) Medidor de deslocamento positivo Oval OGT e b) Medidor tipo vortex Oval EX Delta

Para realizar a medição da vazão de óleo foi necessário utilizar o medidor de deslocamento positivo Oval Flowmeter MIII (indicado em 3, Tabela 4.2) em vazões baixas e o medidor Oval Flowpet EG (indicado em 4) em vazões altas. Ambos podem ser vistos na Figura 4.13.

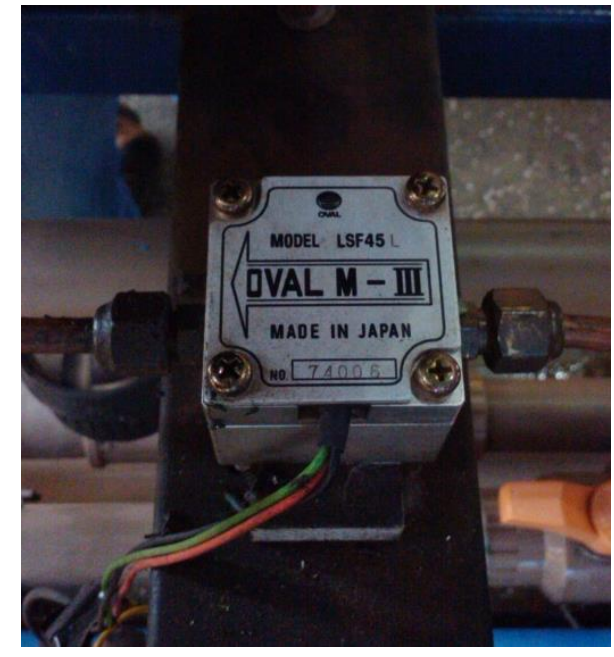

(a)

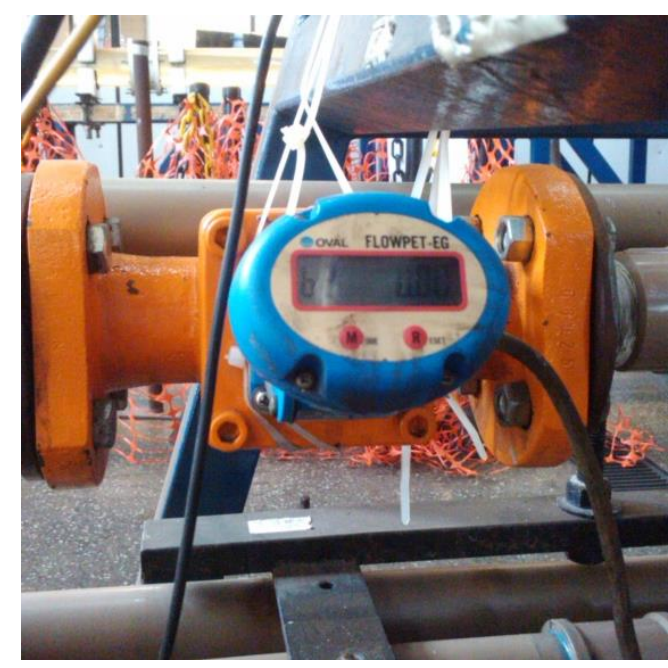

(a) 
Figura 4.13 - Medidores de vazão de óleo, a) Medidor de deslocamento positivo Oval Flowmeter MIII e b) Medidor de deslocamento positivo Oval Flowpet EG.

\subsubsection{Suprimento de Ar}

Um compressor do tipo parafuso modelo Schulz SRP-3030 Compact, ilustrado pela Figura 4.14, fornece o ar utilizado na montagem experimental. Com capacidade de fornecer ar a uma pressão de trabalho de 7,5 bar, o compressor (U, Figura 4.1) descarrega o ar em um conjunto de seis tanques pneumáticos (W) que atuam como um "pulmão" do sistema. O conjunto de tanques pode ser visto na Figura 4.15.

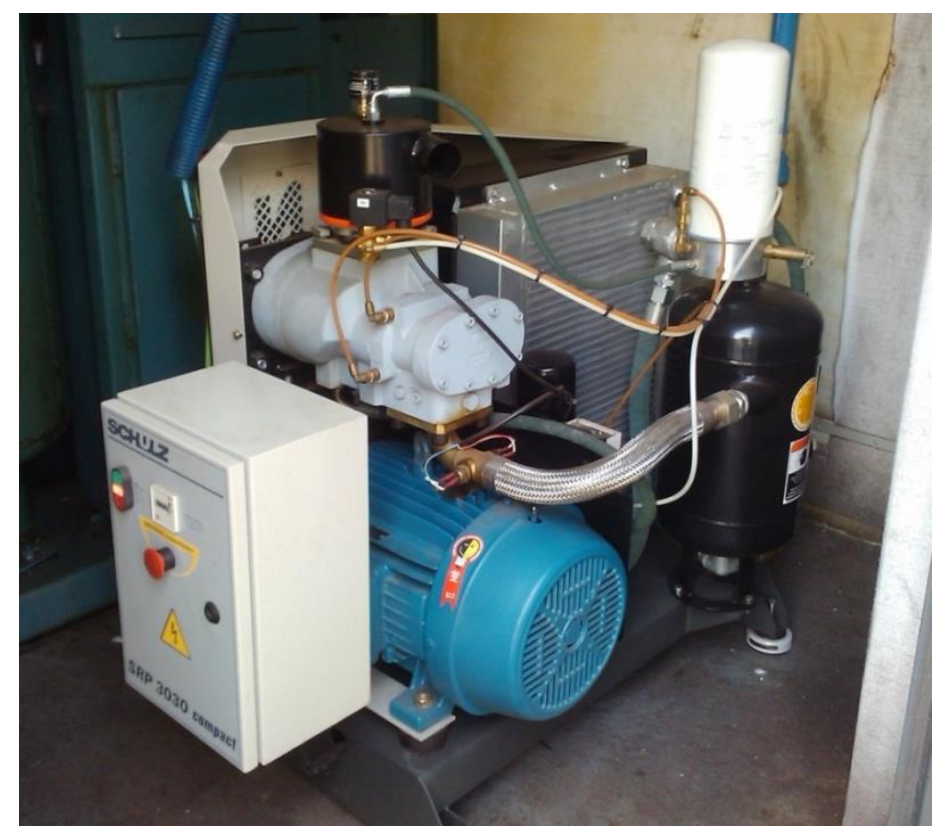

Figura 4.14 - Compressor de parafuso Schulz SRP-3030 Compact. 


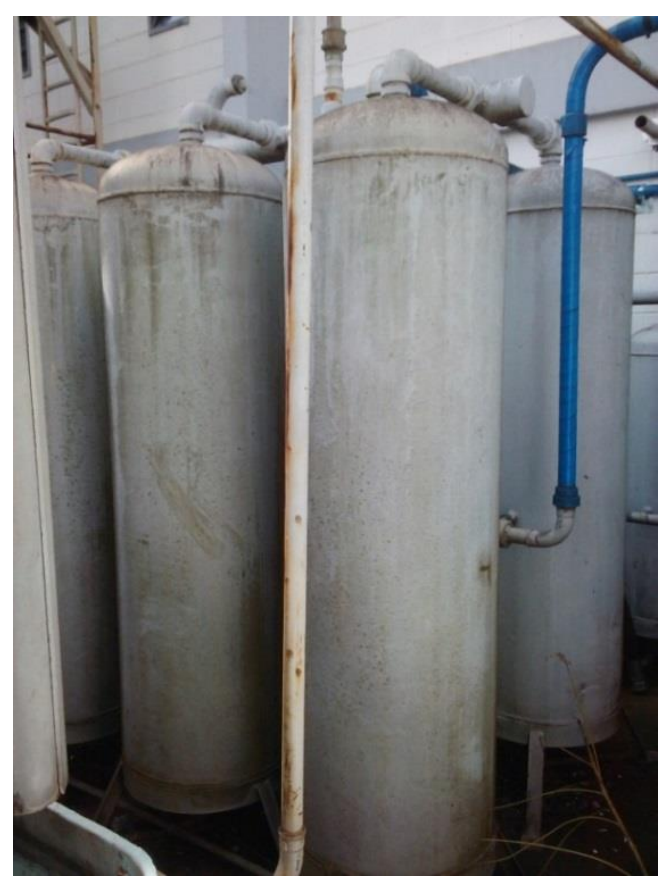

Figura 4.15 - Reservatório de ar do sistema pneumático.

Após ser filtrado por um conjunto de purgadores (V, Figura 4.1), o ar fornecido pelo compressor entra na linha experimental por uma válvula de agulha (X), controlada manualmente pelo operador do sistema.

\subsubsection{Eficiência de Separação de Gás}

A metodologia proposta por Ortiz-Vidal (2010) especifica que a eficiência de separação de gás deve ser medida através das vazões mássicas de gás na entrada e na saída do separador. Define-se a eficiência de separação por:

$$
\eta_{\text {shroud }}=\frac{\dot{m}_{j}}{\dot{m}_{m}}
$$

onde $\dot{m}$ é a vazão mássica do gás e os subscritos $m$ e $j$ representam, respectivamente, a montante e a jusante do separador. A fim de simplificar o processo de medição, assume-se que o gás tem comportamento ideal e que, assim, sua densidade pode ser calculada pela equação de estado dos gases perfeitos: 


$$
\begin{gathered}
\rho_{j}=\frac{P_{j}}{\bar{R} T_{j}} \\
\rho_{m}=\frac{P_{m}}{\bar{R} T_{m}}
\end{gathered}
$$

Com isto, obtermos a vazão mássica do gás pelo produto da sua vazão volumétrica pela sua densidade:

$$
\begin{gathered}
\dot{m}_{j}=\rho_{j} Q_{j}=\frac{P_{j} Q_{j}}{\bar{R} T_{j}} \\
\dot{m}_{m}=\rho_{m} Q_{m}=\frac{P_{m} Q_{m}}{\bar{R} T_{m}}
\end{gathered}
$$

Finalmente, substituindo as Equações (4.4) e (4.5) em (4.1) temos a Equação (4.6), que nos dá os parâmetros que precisam ser obtidos experimentalmente para que seja aferida a eficiência de separação do gás:

$$
\eta_{\text {shroud }}=\frac{P_{j} Q_{j} T_{m}}{P_{m} Q_{m} T_{j}}
$$

Para realizar as medições descritas se faz necessário um conjunto de medidores de vazão volumétrica, transdutores de pressão e termômetros. A primeira etapa deste trabalho, cujo foco foi a medição da eficiência de separação de gás em condições diversas de operação, exigiu o uso de duas linhas separadas de medição de vazão mássica de gás, à montante e à jusante da seção de testes.

À montante do separador-piloto, os sensores, indicados em 18 e 19 na Figura 4.1, medem a vazão volumétrica do gás. O medidor de engrenagens Oval GAL50 (Figura 4.16a) mede vazões de 1 a 20 1/min, enquanto o medidor de turbina Contech SVTG (Figura 4.16b) é usado para medir vazões de 22,8 a 228 1/min (1,37 a 13,7 m³/h). Assim como nas linhas de óleo e água, o uso de dois medidores com faixas de medição distintas ajuda a reduzir o erro total do sistema. Este conceito foi aplicado tanto aos medidores de vazão volumétrica quanto aos medidores de pressão. 


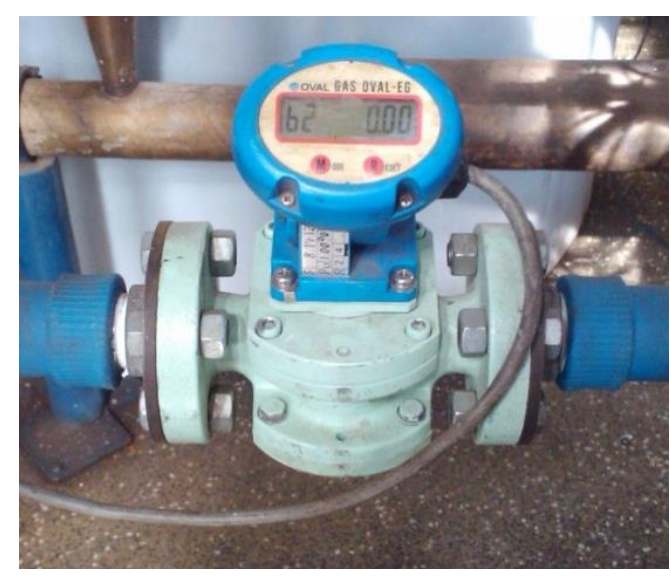

(a)

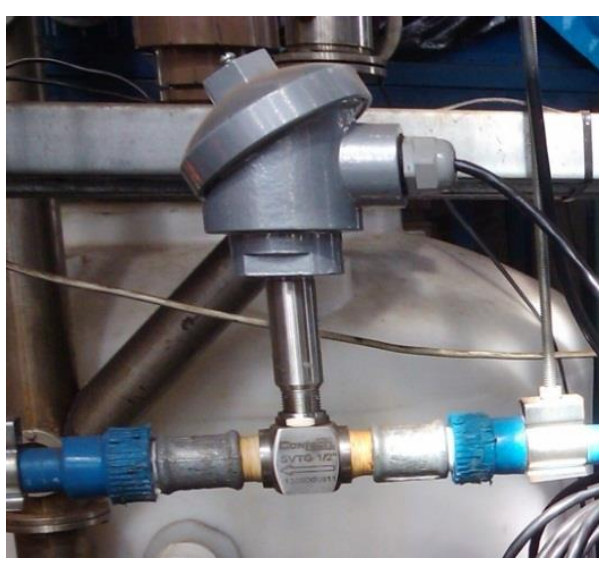

(a)

Figura 4.16 - Medidores de vazão volumétrica de ar, a) Oval GAL50 e b) Contech SVTG 1⁄2”,

Sensores de pressão relativa, indicados em 20 e 21 na Figura 4.1 e na Tabela 4.2, servem para mensurar a pressão do ar que passa pelos sensores de vazão volumétrica. Como a variável $P_{m}$ mostrada na Equação (4.6) é dada em termos de pressão absoluta, o barômetro de mercúrio Princo 453 indicado em 17 na Figura 4.1 foi utilizado para obter a pressão atmosférica que deve ser somada ao valor lido pelos transdutores de pressão relativa. Em testes com a mistura água-ar foi verificado que a leitura do transdutor de pressão Novus 961 (9) também pode ser utilizada para este fim, já que ela se iguala à pressão atmosférica.

A temperatura do ar, também necessária ao cálculo da vazão mássica, é medida à montante da linha de testes com um transmissor de temperatura IOPE TW-TC/2 conectado a um termopar tipo K (cromel-alumel) devidamente calibrado. 


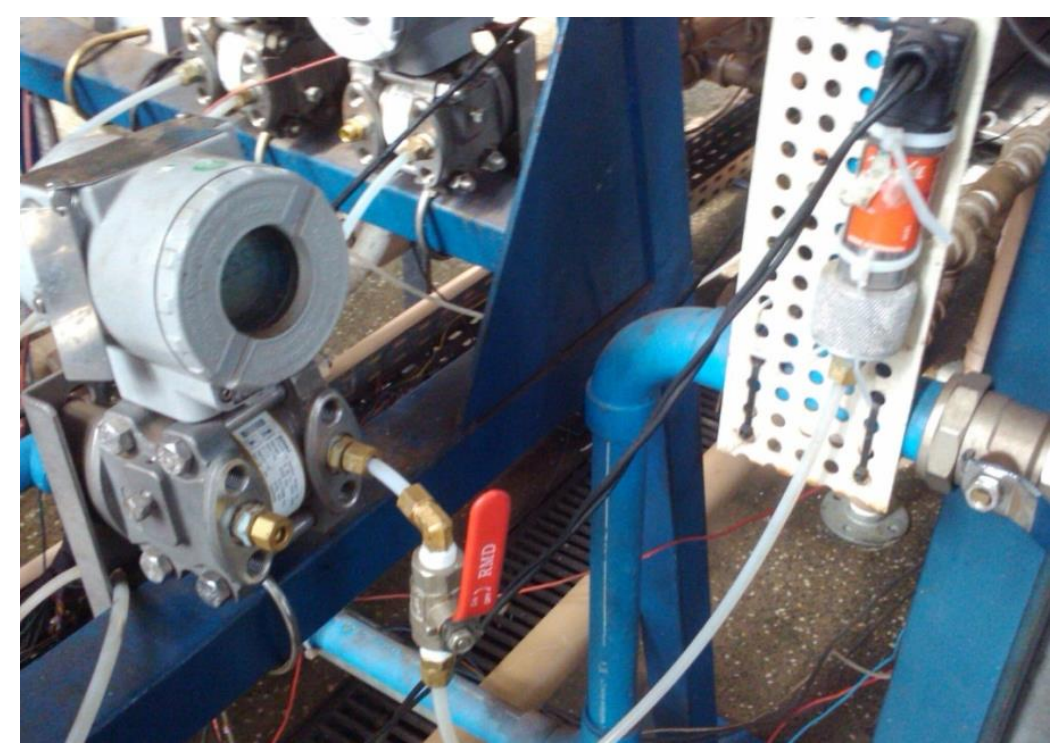

Figura 4.17 - Transdutores de pressão utilizados no cálculo da vazão mássica de ar à montante da seção de testes.

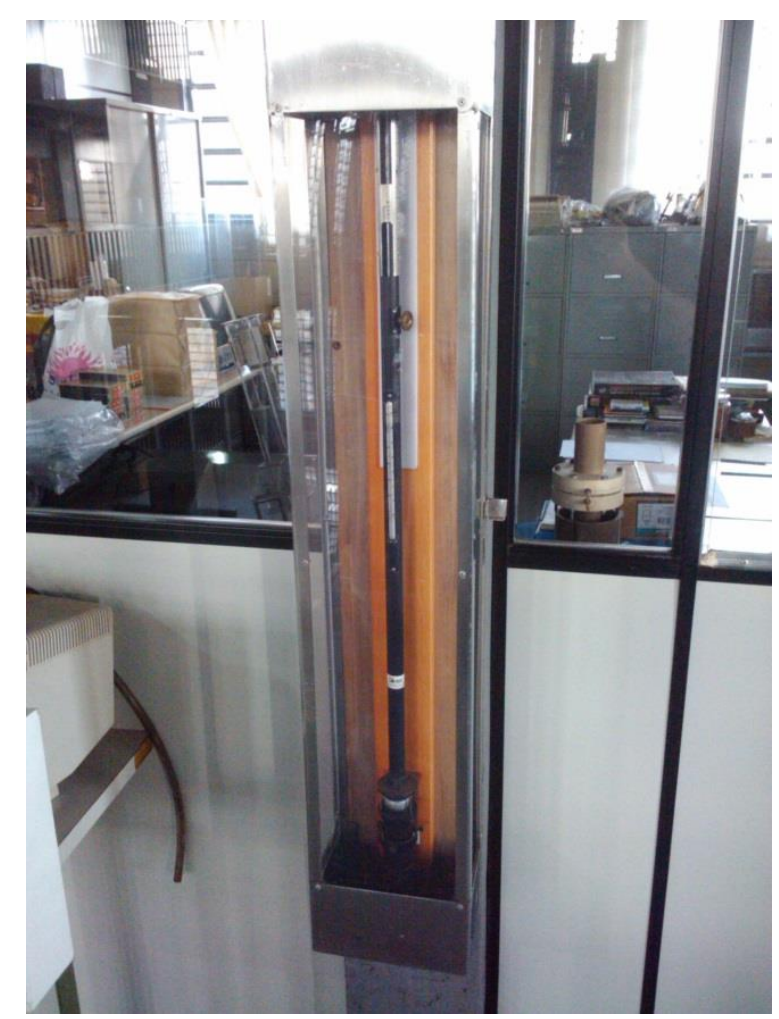

Figura 4.18 - Barômetro e termômetro de mercúrio Princo 453.

A medição da vazão mássica do ar à jusante do separador-piloto pode ser feita através de uma combinação de sensores de vazão volumétrica e de pressão relativa, indicados em 10, 
11 e 12 na Figura 4.1, ou através de um medidor de placa de orifício (14). O primeiro conjunto de instrumentos é utilizado para medir vazões baixas, enquanto o segundo é utilizado para vazões altas. A temperatura utilizada na medição foi considerada igual à temperatura atmosférica, medida pelo termômetro Princo 453 (16).

A Figura 4.19 mostra a placa de orifício utilizada no medidor de alta vazão de ar. Atuando como elemento primário de medição, a placa é instalada na linha de ar e causa uma restrição de fluxo que gera uma perda de carga localizada. Dois transdutores diferenciais de pressão Smar LD 301 (13 e 15), atuando como elementos secundários, medem a perda de carga para que a vazão mássica do ar possa ser calculada. Por ser um instrumento de calibração simples, a placa de orifício foi utilizada para verificar a leitura dos medidores de vazão volumétrica à montante do separador. A Figura 4.20 mostra o arranjo dos sensores utilizados.

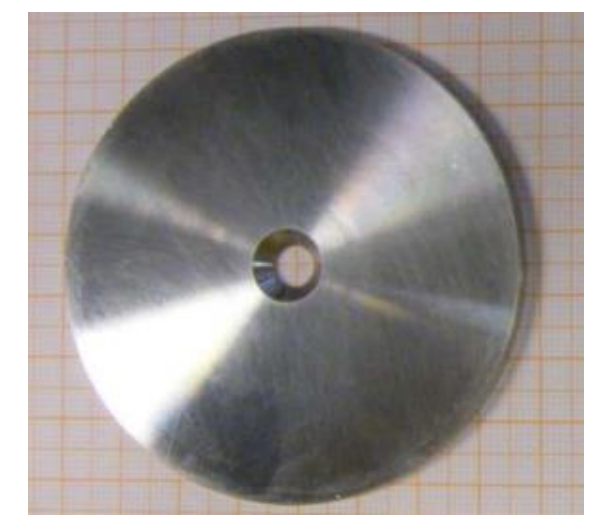

Figura 4.19 - Medidor de vazão do tipo placa de orifício com 6,6 mm de diâmetro de furo. 


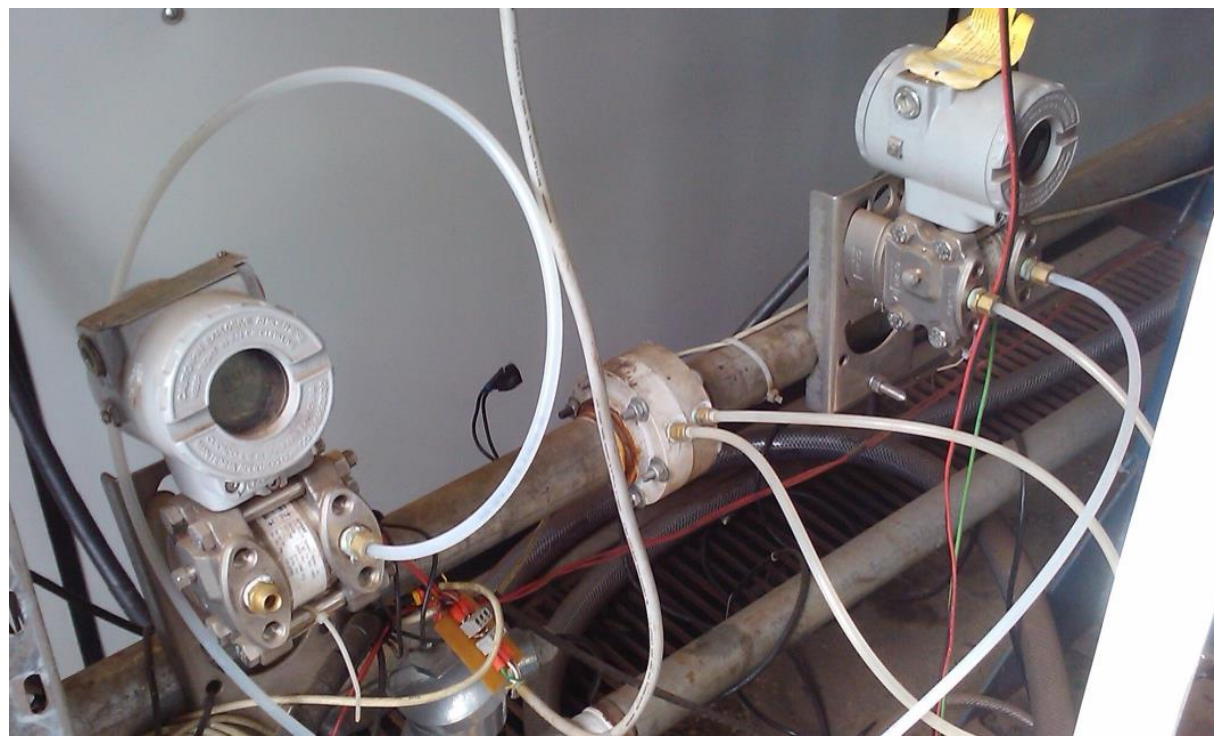

Figura 4.20 - Arranjo de transdutores de pressão diferencial Smar LD301 utilizados na medição de vazão através da placa de orifício.

A Figura 4.21 mostra o tanque de separação gás-líquido indicado em R (Tabela 4.1), instalado entre a seção de testes e os sensores de vazão mássica do ar à sua jusante. O tanque tem como função separar quaisquer rastros de líquido que possam ser arrastados com o ar para a linha, evitando que os medidores sejam danificados. 


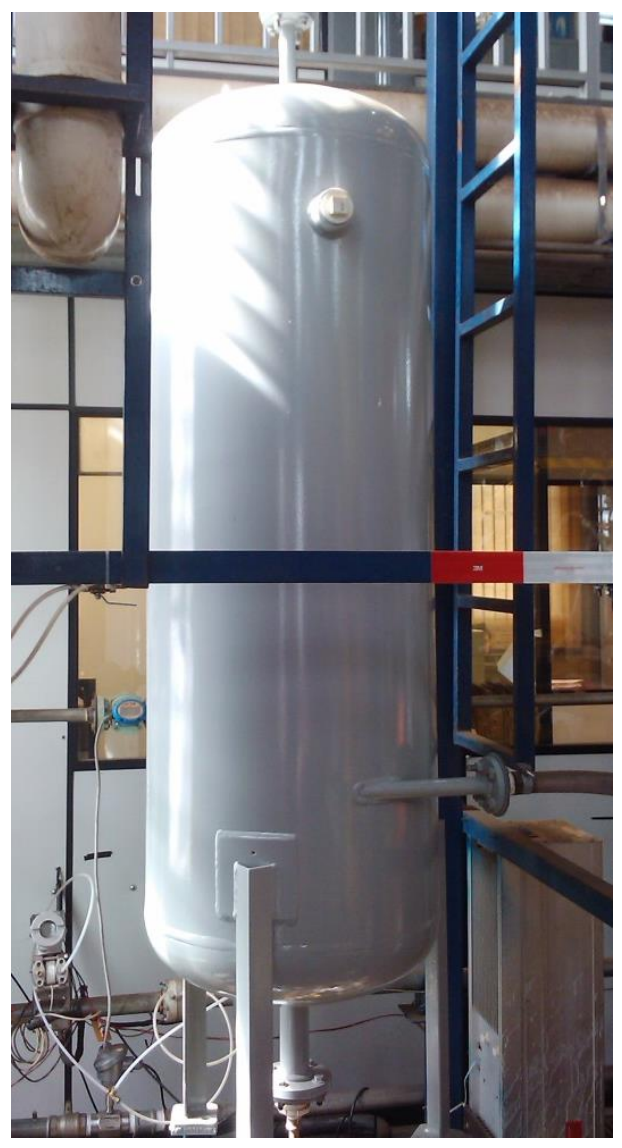

Figura 4.21 - Tanque de separação gás-líquido instalado à jusante da seção de testes.

\subsubsection{Aquisição de Dados}

O sistema de instrumentação descrito na Tabela 4.2 funciona em conjunto com um sistema de aquisição e controle que utiliza uma placa modelo NI PCI-6224 da National Instruments ${ }^{\circledR}$, ilustrada pela Figura 4.22. A placa tem 48 canais digitais e 32 canais analógicos, podendo adquirir sinais a uma frequência máxima de 5 mil amostras por segundo $(5 \mathrm{kHz})$ em cada canal. 


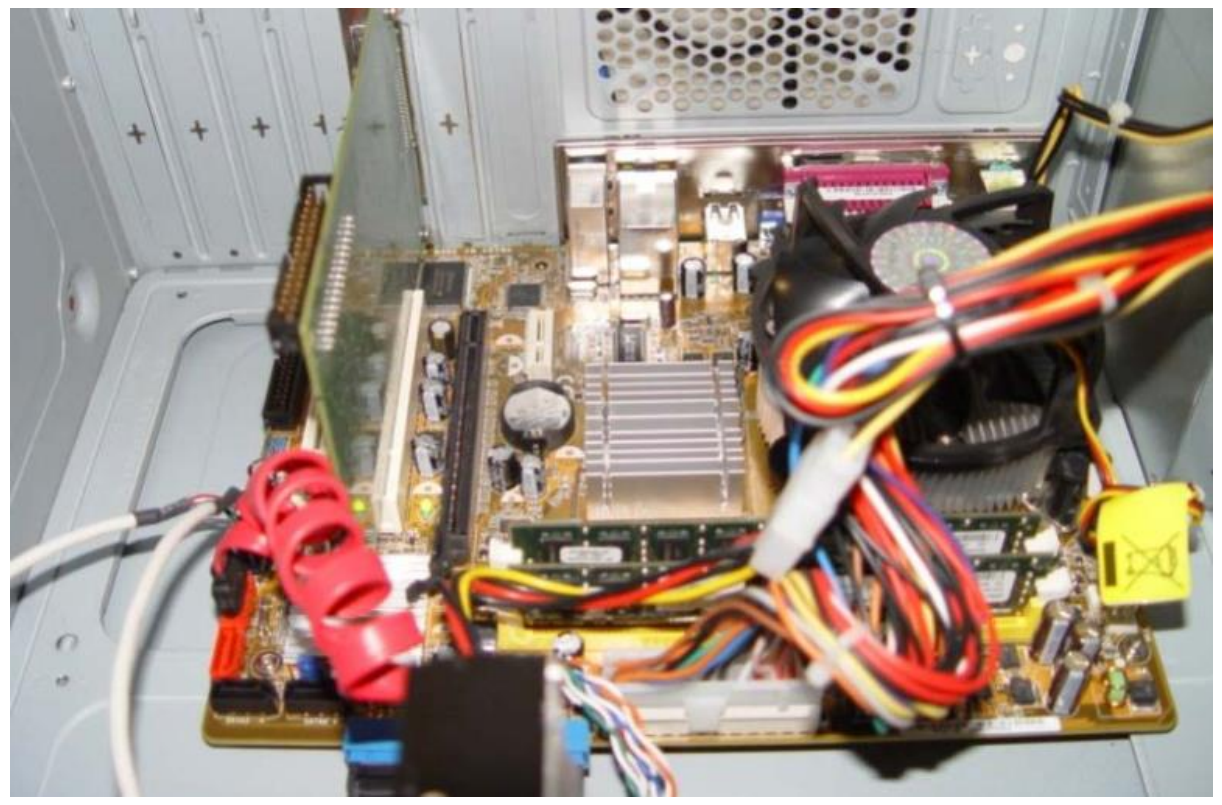

Figura 4.22 - Placa de aquisição NI PCI 6224.

Os sensores instalados no sistema de instrumentação possuem saídas analógicas padrão de 4-20 mA, exceto no caso dos sensores Oval GAL 50 (10 e 19, Tabela 2), que possuem uma saída em pulsos digitais de 1 e $5 \mathrm{~V}$. Medidores pertencentes ao primeiro grupo foram conectados a um bloco de conversão de sinais (Figura 4.23), em que resistores de 250 Ohm transformam o sinal de 4-20 mA em um sinal de 1 a $5 \mathrm{~V}$ que pode ser lido pela placa de aquisição.

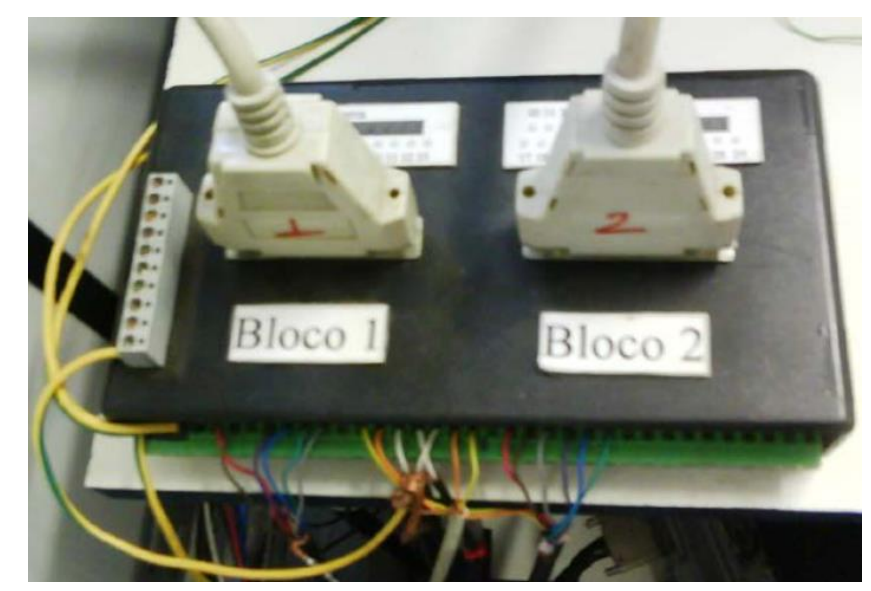

Figura 4.23 - Bloco conversor de sinais.

Um software desenvolvido na plataforma LabVIEW® 8.6, em conjunto com o engenheiro do LETeF Jorge Nicolau dos Santos, foi utilizado para realizar a aquisição automática dos sinais de todos os sensores. A fim de obedecer o critério de Nyquist, que diz 
que é necessário ter uma taxa de aquisição com no mínimo o dobro da frequência lida para evitar o aliasing na leitura dos sinais, foi escolhida a taxa de aquisição de $2500 \mathrm{~Hz}$. Um buffer cíclico foi implementado para evitar oscilações na leitura dos sensores de vazão por pulso, de forma que sempre fosse mostrada na interface uma média dos últimos 8 segundos de coleta de dados. A interface do software utilizado pode ser vista na Figura 4.24, enquanto o fluxograma completo (que atua na plataforma LabVIEW como uma linguagem de programação utilizada para criar o programa) pode ser visto no Apêndice D.

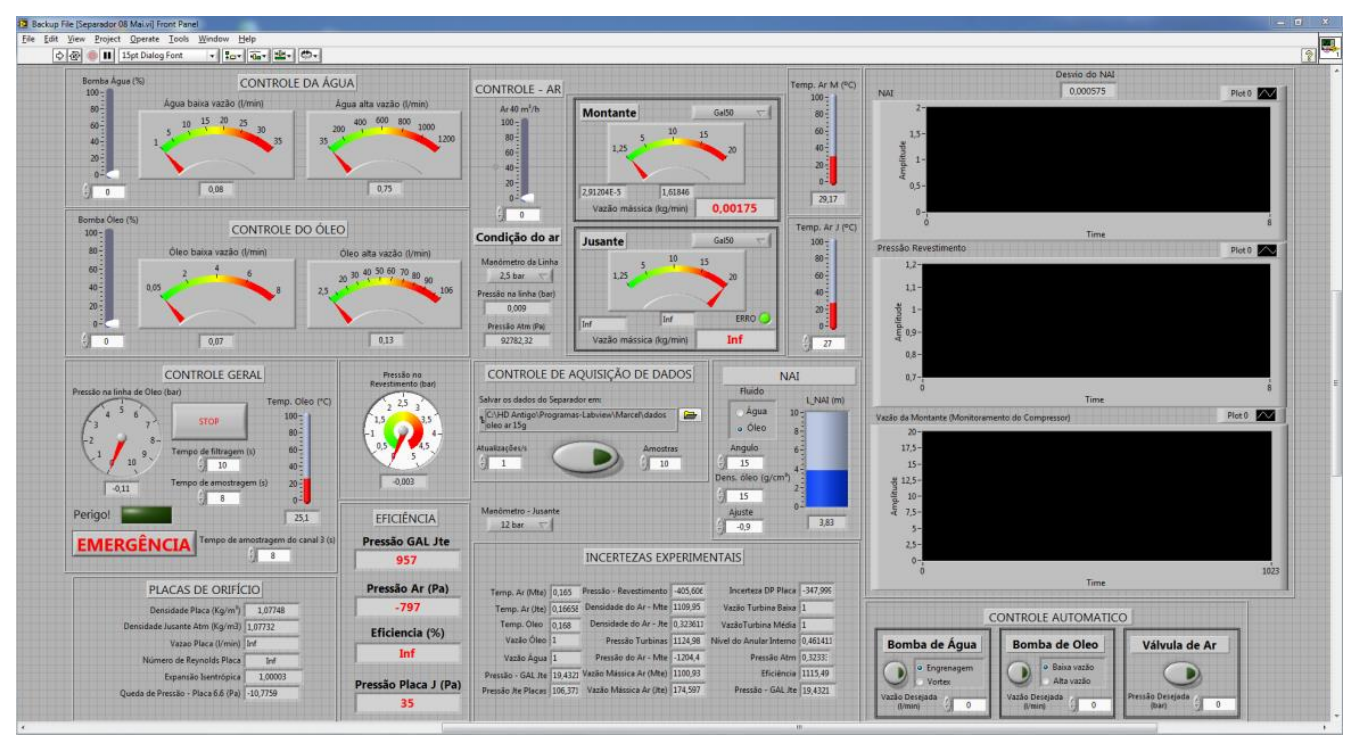

Figura 4.24 - Interface do software supervisório implementado em LabVIEW.

Todos os parâmetros relevantes ao projeto e à aquisição de dados experimentais são mostrados em tempo real ao usuário. Gráficos de parâmetros em função do tempo são também utilizados para que se possa verificar se o sistema está em regime permanente, situação necessária para a coleta de dados válidos. Além disso, incertezas experimentais relevantes são calculadas em tempo real para que se possa determinar o erro percentual da eficiência de separação do gás.

Ao mesmo tempo em que é feita a aquisição dos sinais, o programa é utilizado para controlar a potência que os variadores de frequência transferem às bombas helicoidais de água e óleo. Um sistema de controle via porta ethernet realiza a comunicação do sistema de bombas com a placa de aquisição. Um sistema de retroalimentação de sinais, implementado na interface LabVIEW®, lê um valor desejado de vazão da fase líquida (através dos sensores já mostrados) e ajusta a potência das bombas conforme necessário, executando controle em 
malha fechada. Com isto, resta ao operador apenas controlar o NAI na seção de testes para que se possa aferir os pontos experimentais desejados.

A fim de agilizar os testes, foi utilizado um computador portátil para acessar o computador de aquisição remotamente através do software TeamViewer®. Isto serviu para que o sistema pudesse ser controlado remotamente, de qualquer ponto do laboratório.

\subsubsection{Operação do aparato experimental}

Uma rotina experimental foi seguida para a execução dos ensaios de obtenção da eficiência de separação do gás. Inicialmente, deve-se definir o ângulo de inclinação e a faixa de vazões a serem utilizados na bateria de testes a ser realizada. Feito isto, é necessário ajustar o ângulo da seção de testes com o auxílio do sistema de içamento e do medidor de inclinação descritos anteriormente.

O estado das válvulas do sistema deve ser então verificado. Todas as válvulas da linha de ar devem ser abertas, exceto as válvulas de sensores que não serão utilizados, além da válvula de agulha que controla a entrada de ar no sistema. Todas as válvulas da linha do líquido a ser usado também devem estar abertas, exceto as válvulas dos medidores de vazão que não serão utilizados. Válvulas do líquido que não será utilizado devem sempre estar fechadas, a fim de evitar a presença de uma fase adicional na seção de testes.

O compressor é então acionado e espera-se que os tanques de ar atinjam pressão de trabalho. O sistema de purgadores é aberto temporariamente para drenar a água condensada acumulada, a fim de evitar danos aos medidores de vazão volumétrica de ar. O sistema de bombeamento e o computador de aquisição, além do computador que faz o acesso remoto, também são ligados.

Após a pressurização dos tanques de ar, é possível abrir a válvula de agulha que controla a entrada de ar na seção de testes. Ajusta-se a válvula até que seja obtida a vazão mássica desejada à montante do separador. Assim que uma pressão interna ao separador $\left(P_{\text {rev }}\right.$, ou pressão de revestimento) próxima a 0,5 bar é atingida, pode-se ligar a bomba de líquido sem que se corra o risco de o NAI subir demais (o que resultaria em uma entrada de líquidos na linha de ar). A pressão de revestimento, neste caso, atua em substituição a uma bomba centrífuga submersa, a qual atuaria em condições reais de uso de um separador gravitacional. 
O nível de líquido no anular interno do separador-piloto pode ser controlado através da pressão diferencial em seu interior, como evidenciam os trabalhos Ortiz-Vidal e Mendes. O controle da pressão interna do separador foi feito através de duas válvulas (T e Q, Figura 4.25) de escape do gás, localizadas à jusante da seção de testes.

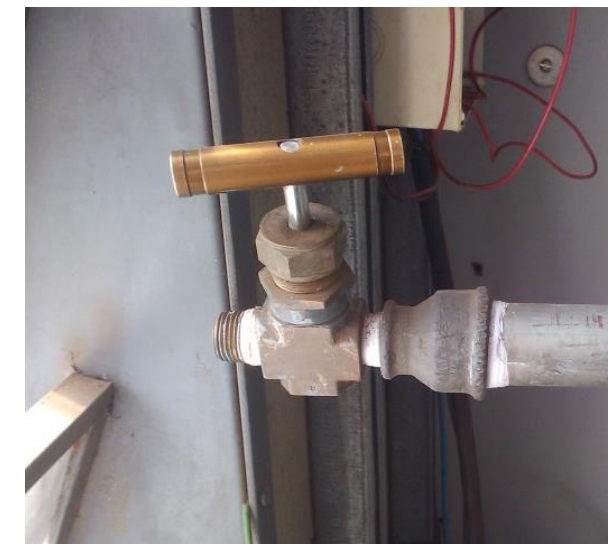

(a)

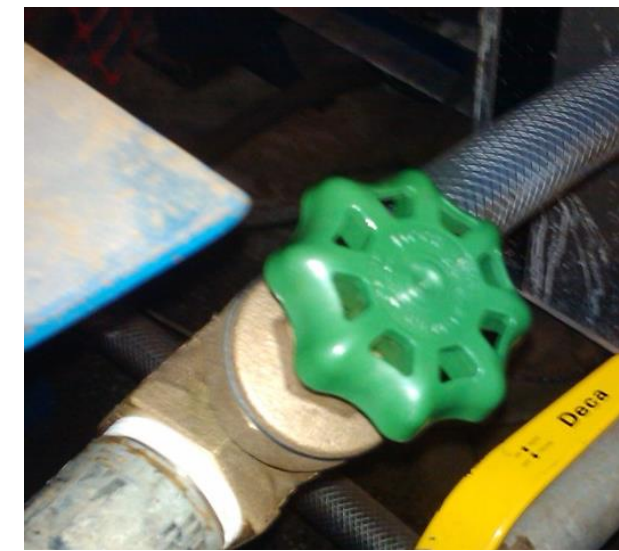

(a)

Figura 4.25 - Válvulas de controle da vazão de ar à jusante da linha de testes (a) Válvula de agulha indicada em T e (b) Válvula de gaveta indicada em Q.

Mantendo a vazão mássica do ar à montante do separador $\left(\dot{m}_{m}\right)$ e a vazão volumétrica do líquido $\left(Q_{L}\right)$ constantes (com a ajuda do controle automático.das bombas), torna-se necessário controlar apenas a vazão mássica do ar à jusante $\left(\dot{m}_{j}\right)$. Depois de posicionado o NAI na altura desejada, é necessário girar as válvulas T ou Q até que o programa LabVIEW mostre uma eficiência de aproximadamente 100\%. Durante a espera, necessária para que o sistema entre em regime permanente, é possível observar, em alguns casos, uma queda de pressão (e consequente aumento do NAI) constante com o tempo. Isto significa que o separador está em uma região de baixa eficiência de separação de gás, sendo assim necessário fechar levemente a válvula até que se chegue à eficiência verdadeira de separação. Esta eficiência é confirmada quando se observa o regime permanente, verificado quando a medida do gráfico da pressão de revestimento (à direita da Figura 4.24) no separador se torna estável.

\subsection{SEGUNDA ETAPA EXPERIMENTAL}

Na segunda etapa experimental foi utilizado o mesmo aparato descrito anteriormente, com mudanças na geometria da seção de testes e no sistema de medição de vazão mássica de 
gás. Nesta seção serão descritas brevemente as mudanças realizadas. Finalmente, se faz necessária também uma descrição detalhada da validação e do uso da sonda ORM (Optical Reflectance Measurement) utilizada para a aferição dos diâmetros de bolhas no anular interno da seção de testes.

\subsubsection{Alterações na seção de testes}

Entre as duas etapas experimentais descritas neste trabalho, houve um hiato no uso da seção de testes, possibilitando a realização de melhorias no sistema de medição. A montagem utilizada foi semelhante à utilizada nos trabalhos anteriores (Figura 4.26), em que o tubo externo (Revestimento do poço) tem o mesmo comprimento dos demais e a injeção de fluidos é feita através da luva inferior.

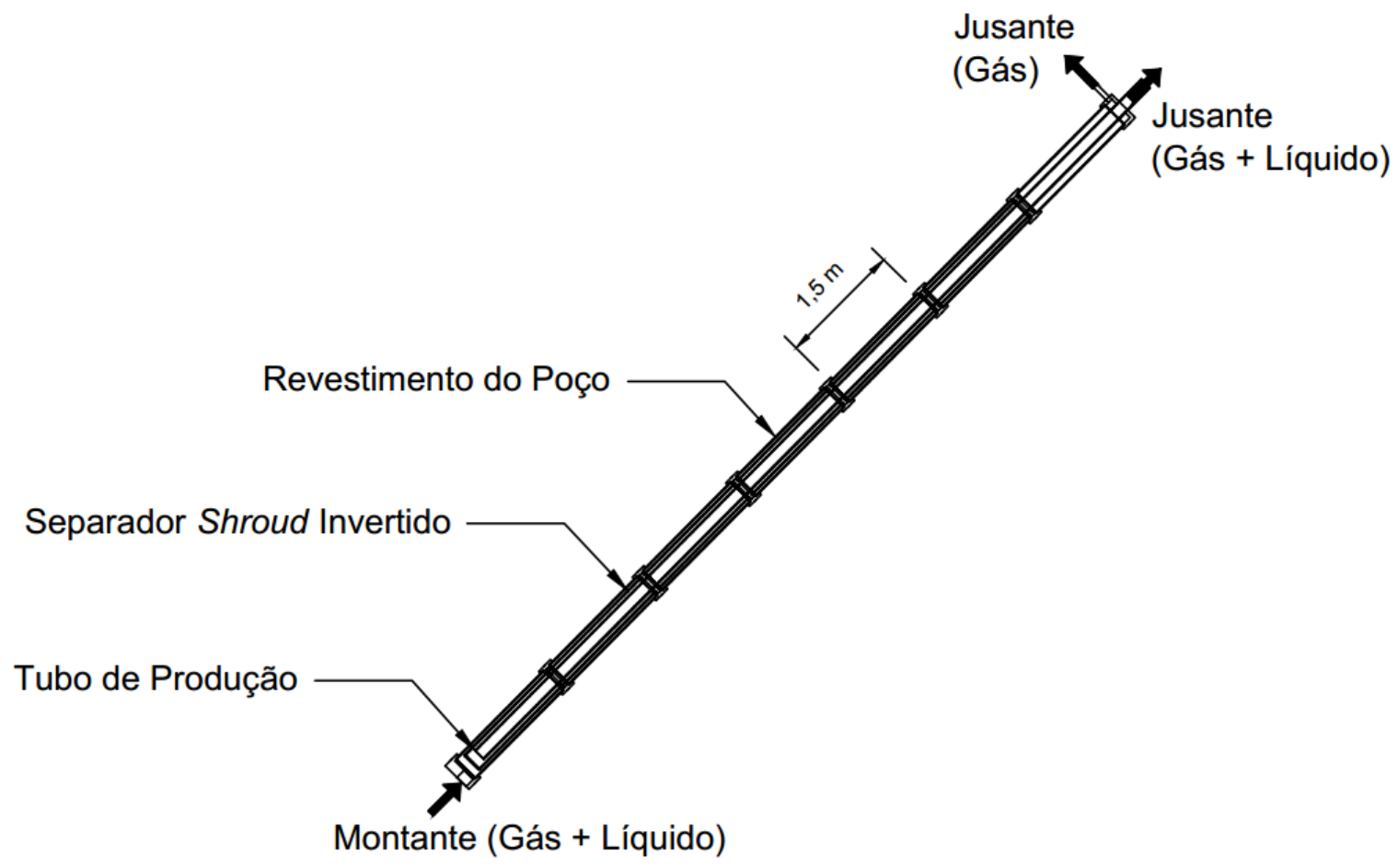

Figura 4.26 - Diagrama da segunda montagem da seção de testes.

A geometria, como detalhado na Tabela 4.3, foi alterada com o uso de novas luvas de PVC usinadas na própria oficina do laboratório. Uma peça especial (Figura 4.27), feita para a inserção da sonda ORM no duto anular interno (localizado entre o shroud e o tubo de produção) foi também usinada e instalada. Adicionalmente, foi necessária a instalação de um suporte para a sonda (Figura 4.28) devido à sua fragilidade. 


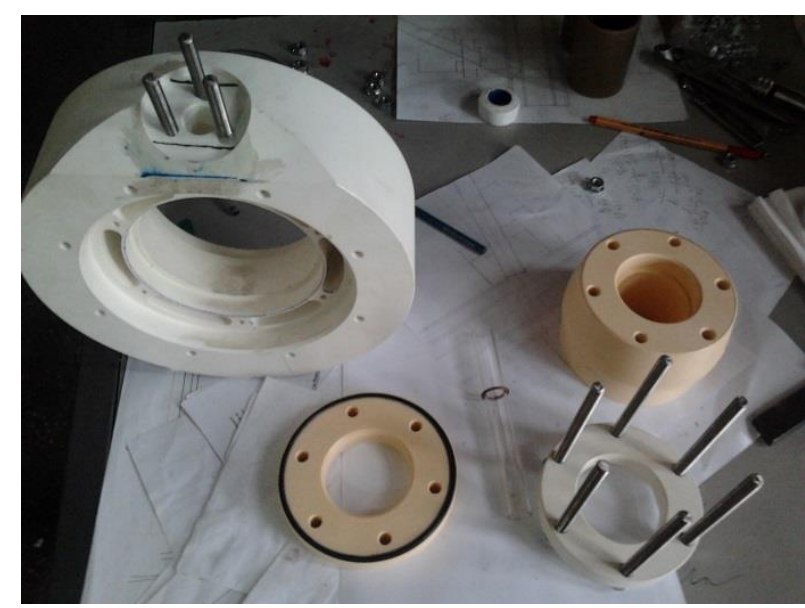

(a)

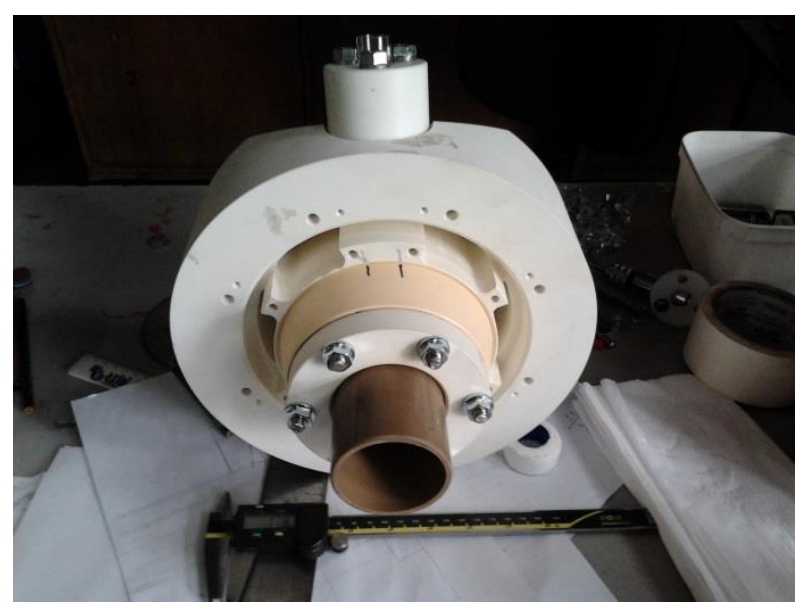

(a)

Figura 4.27 - Peça especial para acoplamento da sonda ORM na seção de testes. (a) Peça desmontada (b) Peça montada

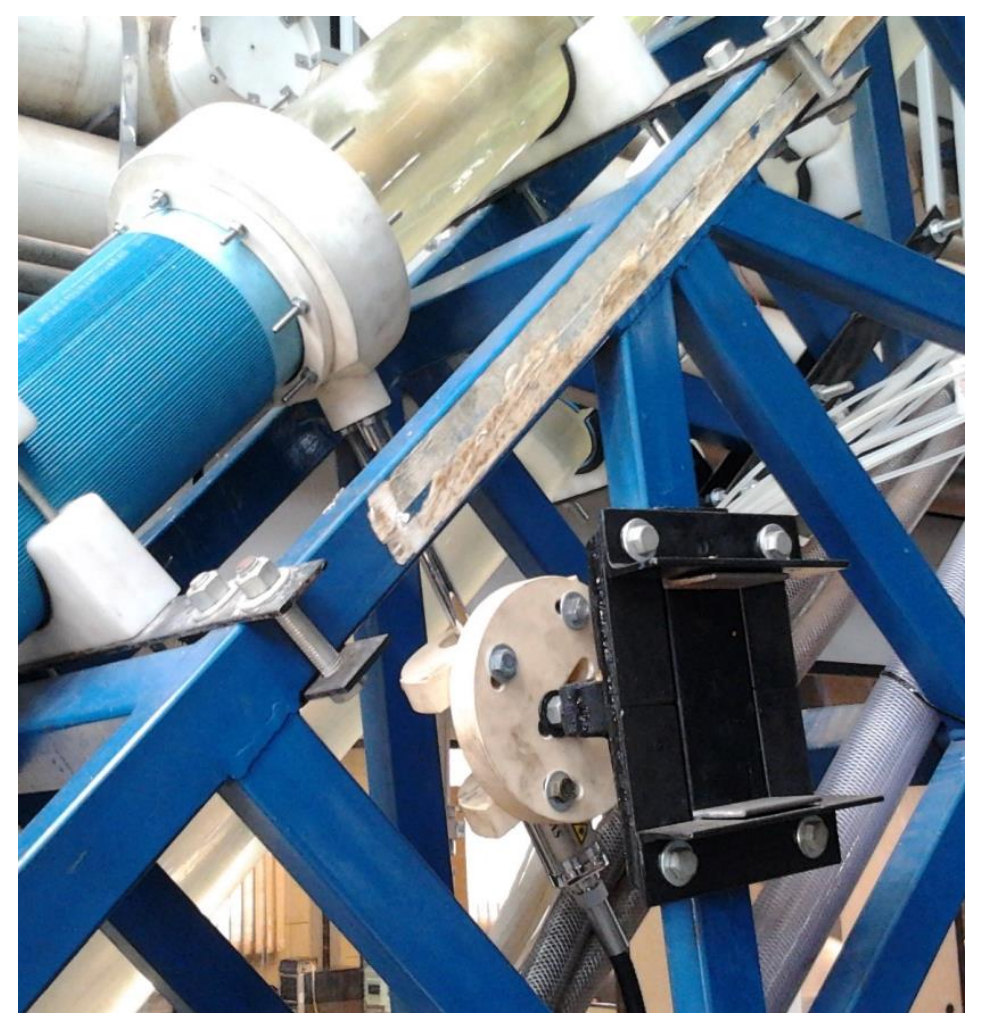

Figura 4.28 - Suporte para instalação da sonda

A haste da sonda foi posicionada com uma inclinação de $75^{\circ}$ em relação ao eixo. A lente da sonda ORM é inserida 0,7 metros acima (na direção do eixo central dos tubos da 
seção de testes) da entrada do tubo de produção. Sendo assim, o comprimento $L_{N A I}$ mínimo em que ainda se consegue medir a distribuição do diâmetro de bolhas é igual a esta distância.

\subsubsection{Alterações no sistema de alimentação de fluidos}

Um problema frequentemente observado na primeira etapa experimental é o acúmulo excessivo de pressão dentro do separador gravitacional. Para que seja mantido o escoamento do líquido na seção de testes, além do controle do NAI, é necessário que seja mantida nele uma diferença de pressão constante entre sua entrada (duto anular externo) e sua saída (tubo de produção). No entanto, após passar pelo tubo de produção, o escoamento passava por diversas singularidades até chegar ao separador de placas coalescentes (A, Tabela 4.1).

A fim de mitigar possíveis riscos associados à pressurização excessiva dentro de tubos de vidro, foi instalado um tanque intermediário (Y, Figura 4.2), aberto à atmosfera, para coletar o líquido à jusante da seção de testes. Uma bomba intermediária (Z), controlada por um variador de frequência (AA), retornava o líquido despejado no tanque para manter a circulação do líquido no aparato experimental. Assim, torna-se possível o uso da seção de testes com vazões mais elevadas, sem que seja comprometida a segurança do equipamento e do operador. A instalação pode ser vista na Figura 4.29. 


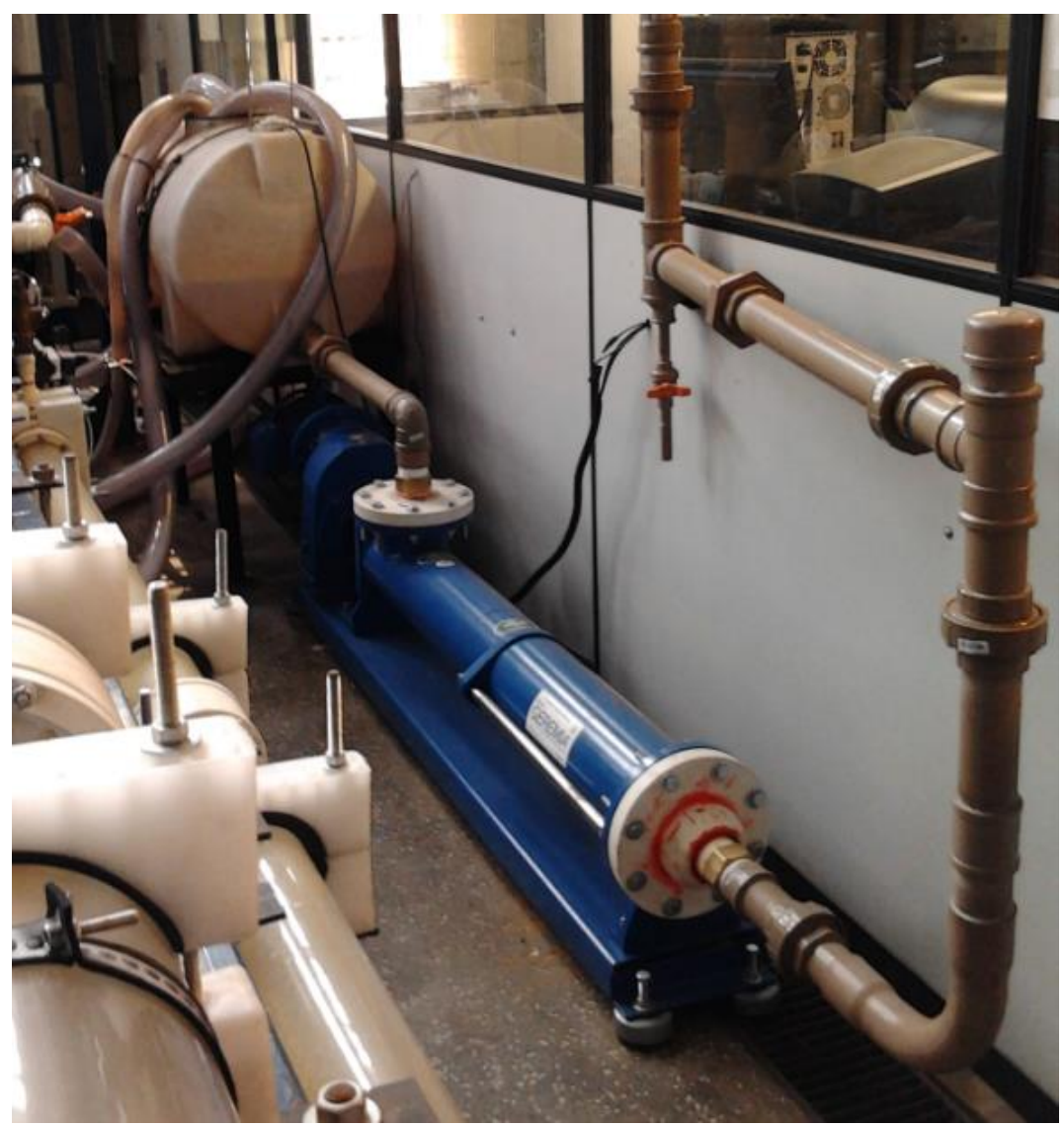

Figura 4.29 - Bomba e tanque utilizados à jusante da seção de testes.

\subsubsection{Alterações no sistema de instrumentação}

Durante o hiato entre as etapas experimentais, foi adquirida uma válvula de agulha acionada por motor de passo (AB, Figura 4.2), inserida onde antes havia uma válvula manual (X, Figura 4.1). Com o uso deste equipamento, foi possível controlar, através da interface em LabVIEW®, a vazão mássica de gás à montante da seção de testes, o que elimina parcialmente a necessidade de constantes ajustes manuais na válvula de agulha $\mathrm{T}$, como era antes necessário para o controle do NAI. O medidor Contech SVTG (18, Tabela 4.2) de vazão volumétrica de gás foi então instalado à jusante da seção de testes com sua saída aberta à atmosfera. O medidor Oval GAL50 (19, Tabela 4.2) foi mantido à montante do experimento e utilizado como anteriormente.

\subsubsection{Medição in situ do diâmetro de bolhas}

$\mathrm{Na}$ execução da segunda etapa do projeto, foi necessário o uso da medição in situ de bolhas no duto anular interno da seção de testes. Para este fim, foi adquirida e utilizada uma 
sonda (Figura 4.30) equipada com a tecnologia 3D ORM IDAS (In situ Droplet Aerosol Analysis System based on Optical Reflectance Measurement with spiral vertical moving selective focus), fabricada pela empresa alemã SEQUIP. O sistema não requer tratamento de dados, fornecendo diretamente as medições em formato de planilhas que podem ser analisadas e transformadas em histogramas. Este sensor, apesar de invasivo, consegue medir partículas com a precisão necessária ao estudo, como mostram as especificações do fabricante na Tabela 4.4 .

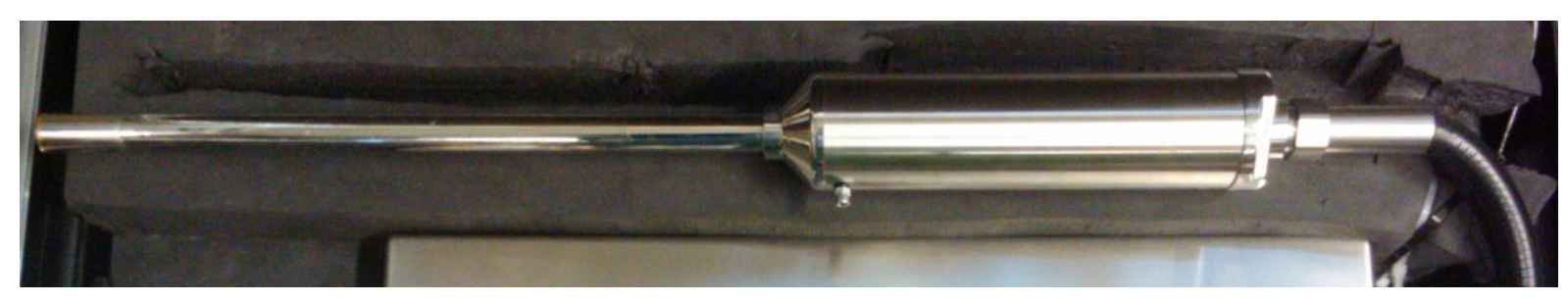

Figura 4.30 - Foto da sonda do sensor 3D ORM.

Tabela 4.4 - Especificações do sensor 3D ORM

Especificações

\section{1 a $3000 \mu \mathrm{m}$}

Faixa de medição

Incerteza

Intervalo de concentração de partículas

Potência do Laser
Até $1200 \mu \mathrm{m}$ : é feita a medição direta por multi-foco dinâmico seletivo 3D, considerando exclusivamente partículas no foco do Laser.

Acima de $1200 \mu \mathrm{m}$ : consideram-se, adicionalmente, partículas próximas ao foco do Laser

$\pm 0,25 \mu \mathrm{m}$

Até $80 \%$

1 a 5 mW, ajustável via software 
Uma investigação da gama de diâmetros de bolha prevista no aparato experimental, realizada com uma implementação da modelagem descrita no Capítulo 3 em plataforma Wolfram ${ }^{\circledR}$ Mathematica, mostra que o intervalo de medição do sensor 3D ORM é adequado aos objetivos do projeto.

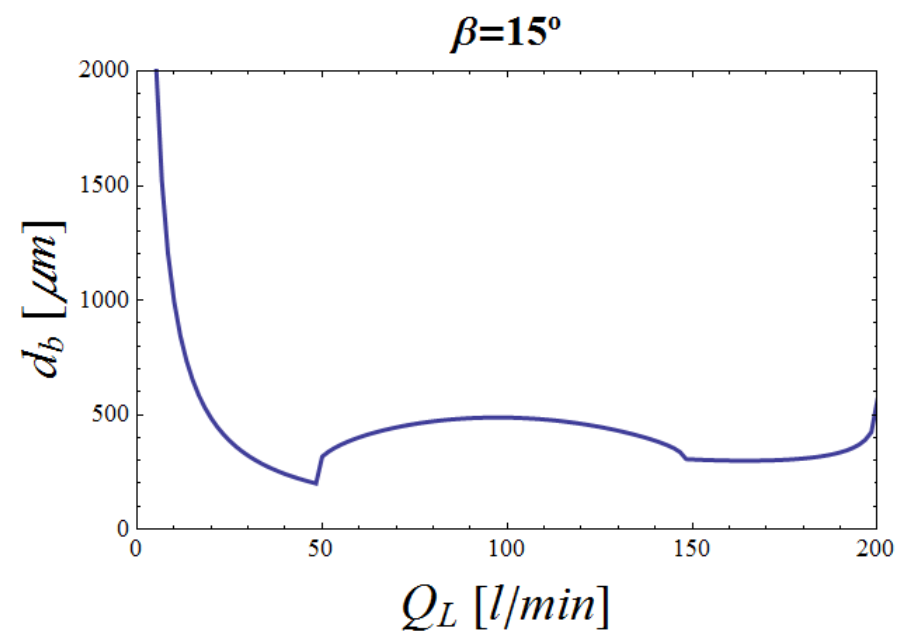

Figura 4.31 - Diâmetros de bolha esperados para a mistura ar-água a uma inclinação de 15 graus.

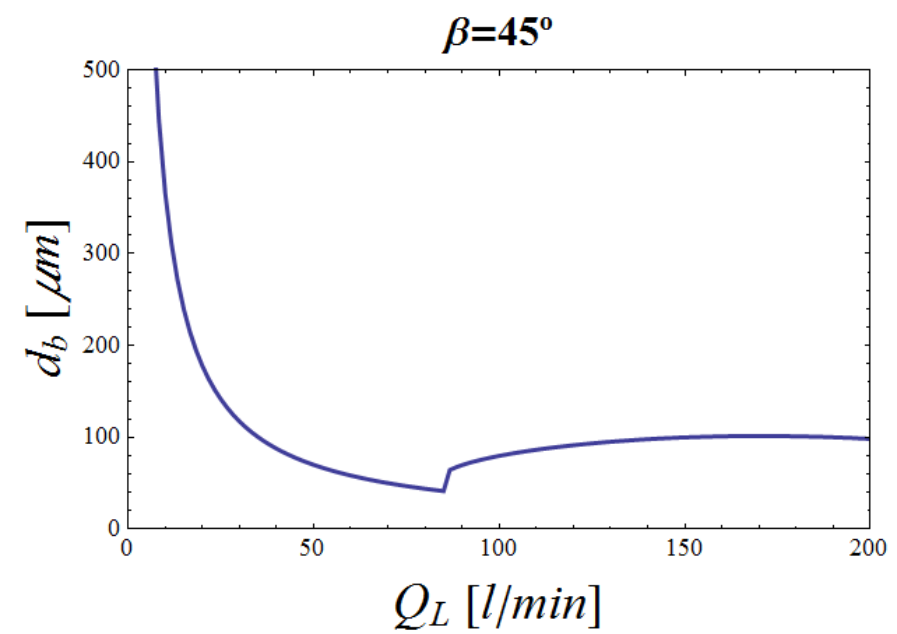

Figura 4.32 - Diâmetros de bolha esperados para a mistura ar-água a uma inclinação de 45 graus. 


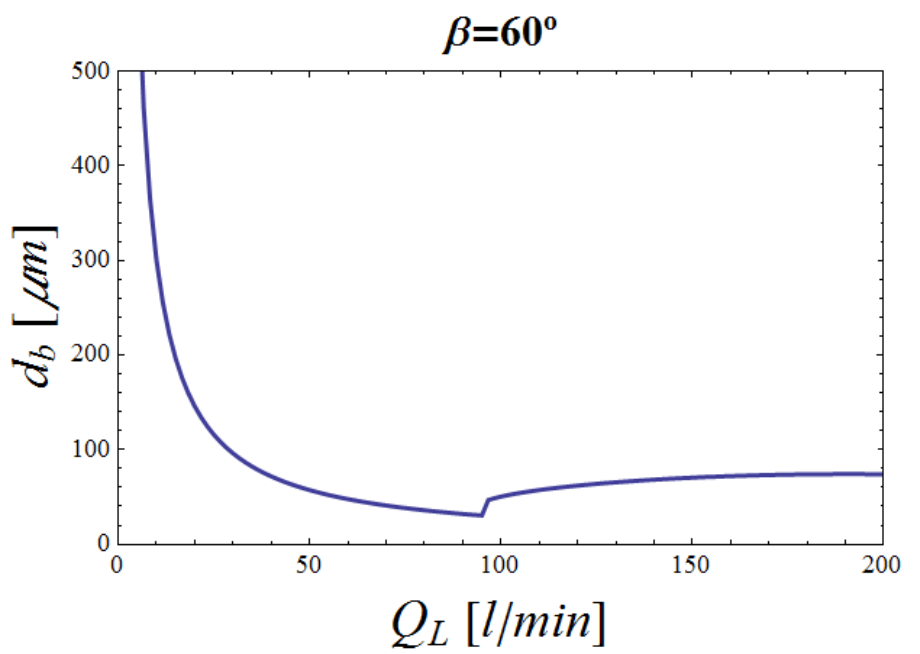

Figura 4.33 - Diâmetros de bolha esperados para a mistura ar-água a uma inclinação de 60 graus.

\section{É possível observar, da}

Figura 4.31 à Figura 4.33, o diâmetro de bolha máximo previsto pelo modelo para diferentes ângulos de inclinação. Na Figura 4.31, duas mudanças abruptas de tendência são observadas a determinadas vazões da fase líquida. A primeira mudança de tendência, observável nas vazões mais baixas, se refere à situação em que o nível do escoamento em superfície livre, $h_{L O_{A I}}$, atinge a superfície externa do tubo de produção. A segunda mudança de tendência se refere à situação em que a superfície externa do tubo de produção fica completamente submersa na fase líquida. As Equações (3.11) a (3.19) mostram uma mudança na dinâmica do escoamento em cada situação, justificando assim as mudanças de tendência.

\subsubsection{Validação da sonda ORM - Câmera de alta velocidade}

Para assegurar o bom funcionamento do sensor ORM na medição do diâmetro de bolhas, um teste foi projetado inicialmente usando a câmera de alta velocidade disponível no laboratório (Olympus® i-Speed). Um aquário de acrílico (Figura 4.34) foi conectado à linha de ar comprimido do laboratório através de um borbulhador, que foi utilizado para gerar bolhas mensuráveis, que pudessem ser analisadas com ambos os instrumentos. Os resultados foram comparados posteriormente com os histogramas gerados pela sonda ORM. 


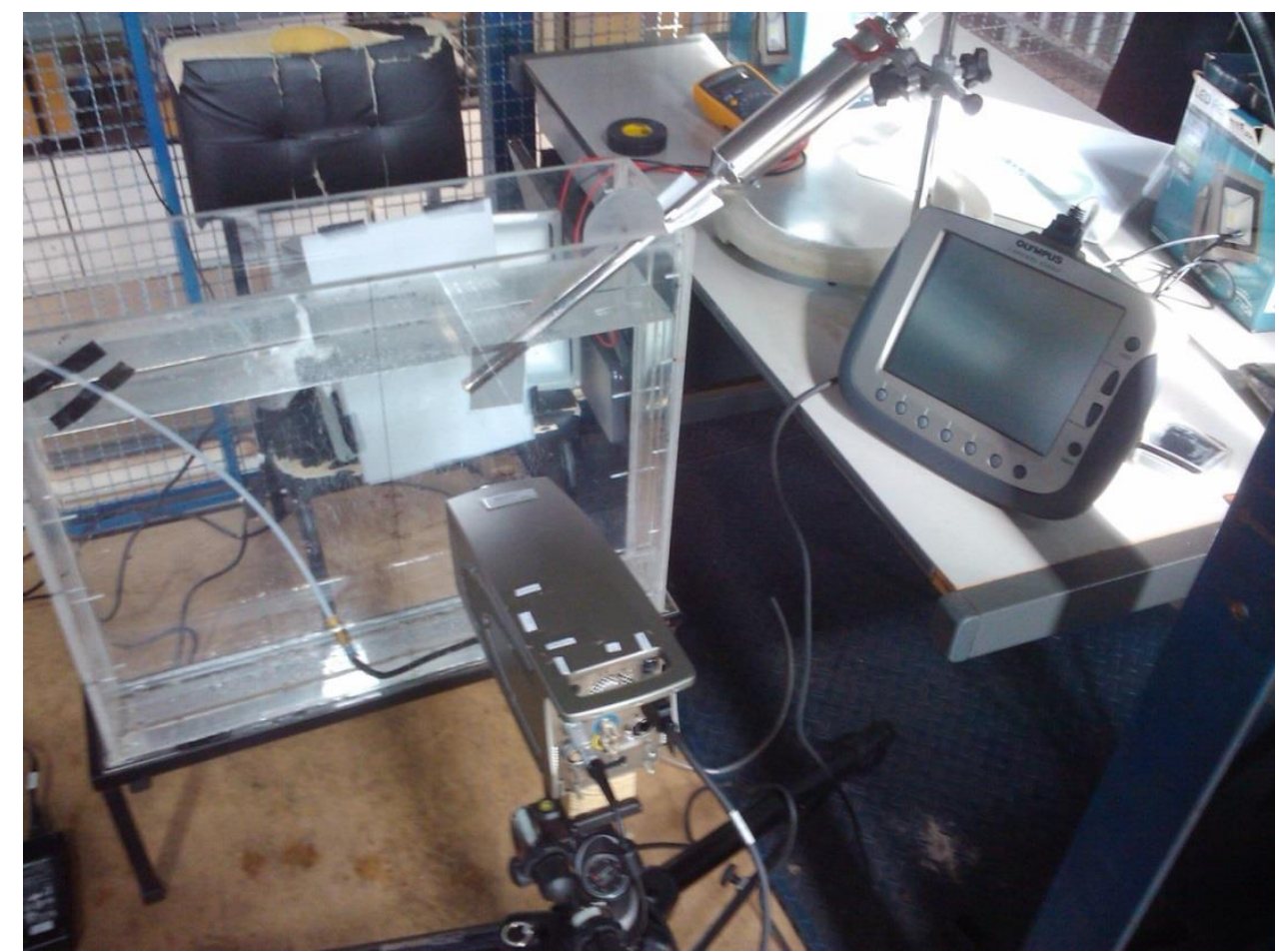

Figura 4.34 - Bancada usada para validação experimental do sensor ORM com câmera de alta velocidade.

A câmera foi usada em conjunto com um padrão milimetrado com resolução de 0,2 $\mathrm{mm}$, cujo comprimento foi convertido em pixels, juntamente com as imagens das bolhas que passavam pelo mesmo plano focal. Um software (Figura 4.35), desenvolvido em plataforma LabVIEW® pelo engenheiro Jorge Nicolau dos Santos, funcionário do laboratório, foi utilizado para automatizar esta tarefa. 


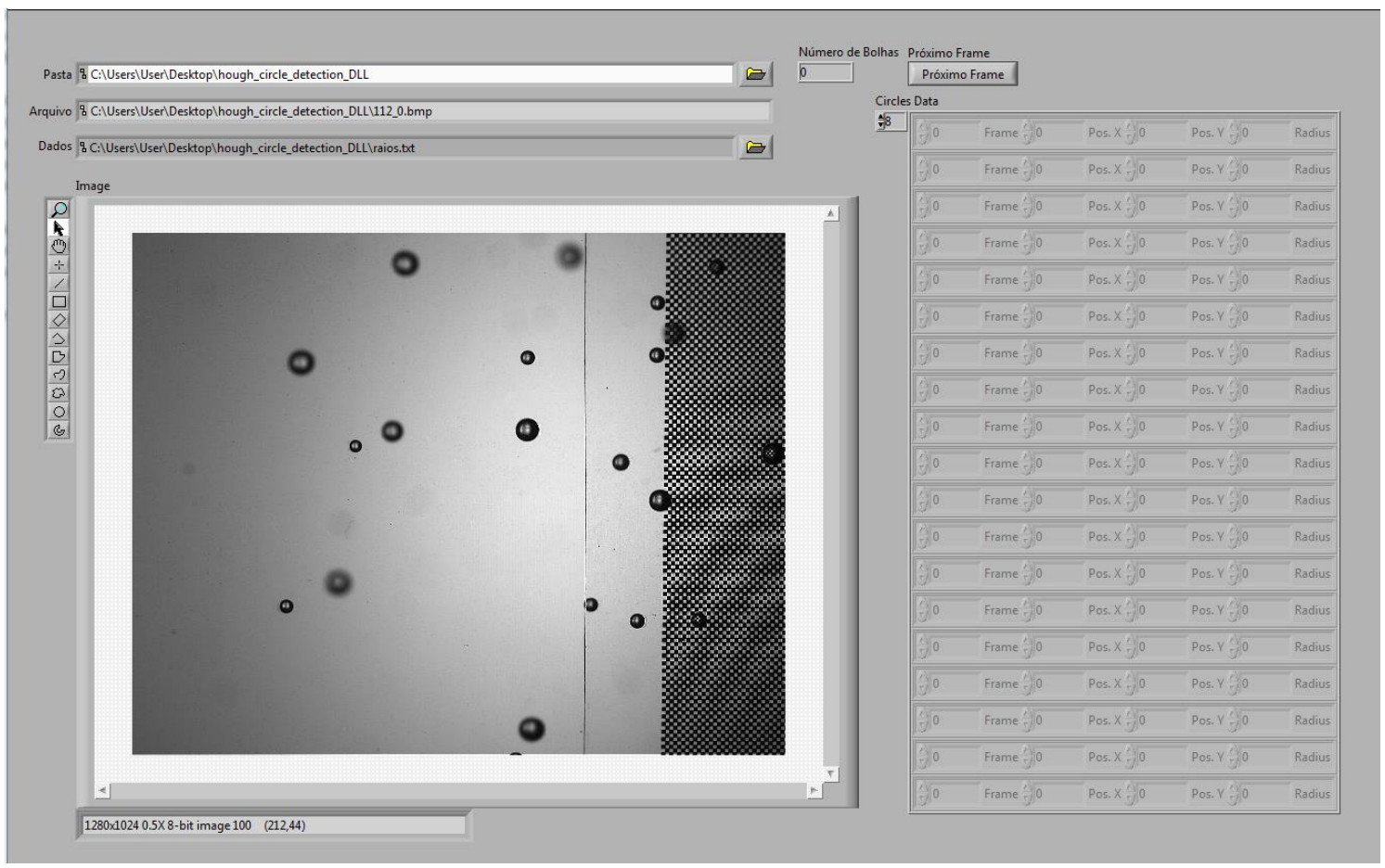

Figura 4.35 - Programa em plataforma LabVIEW® para análise do diâmetro de bolhas filmadas com câmera de alta velocidade.

No entanto, devido à distância entre os planos focais em que se encontravam o centro da lente do sensor e o padrão milimetrado (ou seja, distância igual a metade do diâmetro do tubo do sensor), não foram obtidos resultados consistentes. As bolhas que seriam efetivamente medidas pela sonda ficam desfocadas na imagem, gerando erros na medida de seu diâmetro quando comparadas ao padrão. Outros autores (BONGIOVANNI; CHEVAILLIER; FABRE, 1997) demonstraram anteriormente outras origens semelhantes de erro nesta forma de aquisição de diâmetros de bolhas, o que também sugere que este não seria o melhor método para validar o sensor.

\subsubsection{Validação da sonda ORM - Partículas de diâmetro conhecido}

Em uma segunda tentativa de validar o sensor ORM, foi feita a medição de partículas de diâmetro conhecido, cujo tamanho pudesse ser comparado diretamente com os valores aferidos pelo sensor. Para isto foram utilizadas microesferas ocas de vidro cujos diâmetros, de acordo com o fabricante, se situam em uma faixa de 8 a $11 \mu \mathrm{m}$.

Para a realização do teste foram necessários um béquer comum de $1000 \mathrm{ml} \mathrm{e} \mathrm{um}$ agitador magnético. Após a limpeza do béquer para eliminar partículas que gerariam ruído na 
medida, o recipiente foi preenchido com água destilada. A lente da sonda ORM foi posicionada dentro da água e, com isso, foi feita a primeira medida para verificar a presença de ruído. O software do ORM detectou a distribuição vista na Figura 4.36. O resultado representa um histograma dos dados adquiridos na forma de Diâmetro vs. Número de aquisições para cada diâmetro.

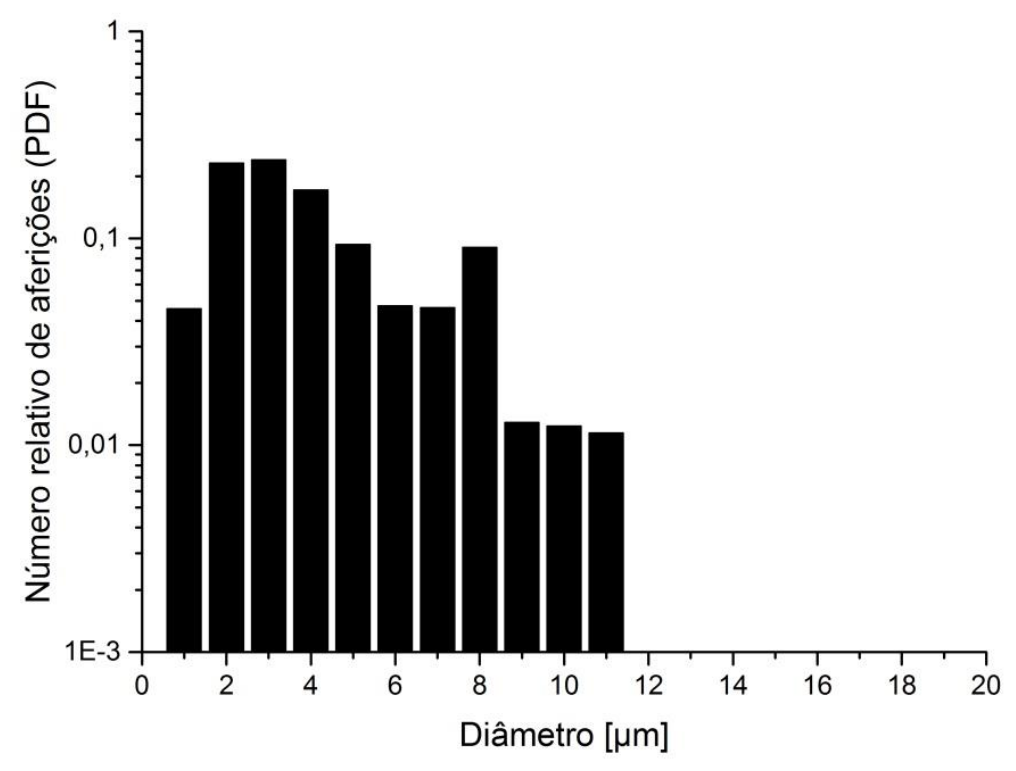

Figura 4.36 - Distribuição de diâmetros obtida antes da adição das microesferas de vidro, representando assim o ruído da medida.

Após este passo, o agitador foi ligado e as microesferas de vidro foram adicionadas à água até que se registrasse a leitura de partículas no software. O resultado obtido mostrou uma distribuição ligeiramente deslocada à esquerda. O resultado é mostrado na Figura 4.37. 


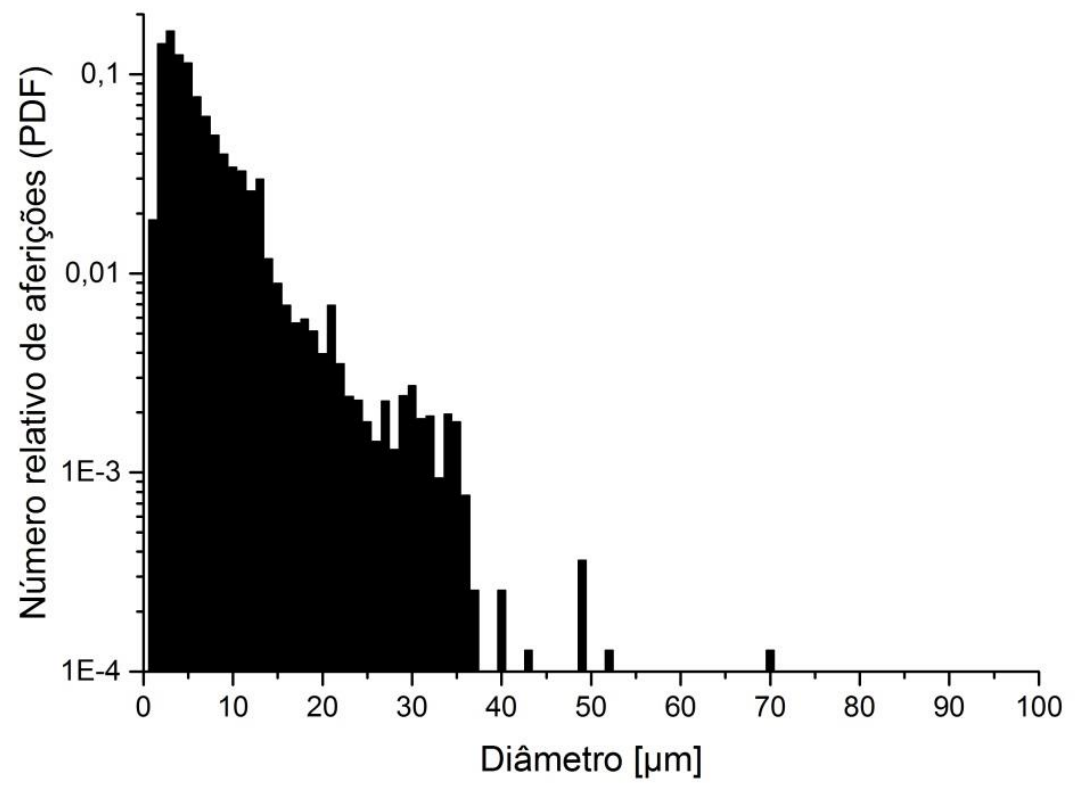

Figura 4.37 - Distribuição de diâmetros obtida na medição das microesferas de vidro.

Como a medida foi feita em ambos os casos durante um mesmo período de tempo, a quantia total de aquisições foi semelhante. Portanto, deve-se analisar as mudanças entre as duas medições para obter um resultado representativo das microesferas de vidro. A Figura 4.38 mostra as duas curvas PDF sobrepostas, sendo que a região que representa a amostra de água pura (sem microesferas de vidro) representa o ruído da medida. Com isto, obtemos um histograma representativo da medição das microesferas. Subtraindo o número relativo de aferições de partículas em água pura do número de aferições de partículas em água com microesferas, obtemos uma distribuição com $D_{\text {Sauter }}$ igual a $22 \mu \mathrm{m}$ e $D_{\text {médio }}$ igual a $13 \mu \mathrm{m}$. 


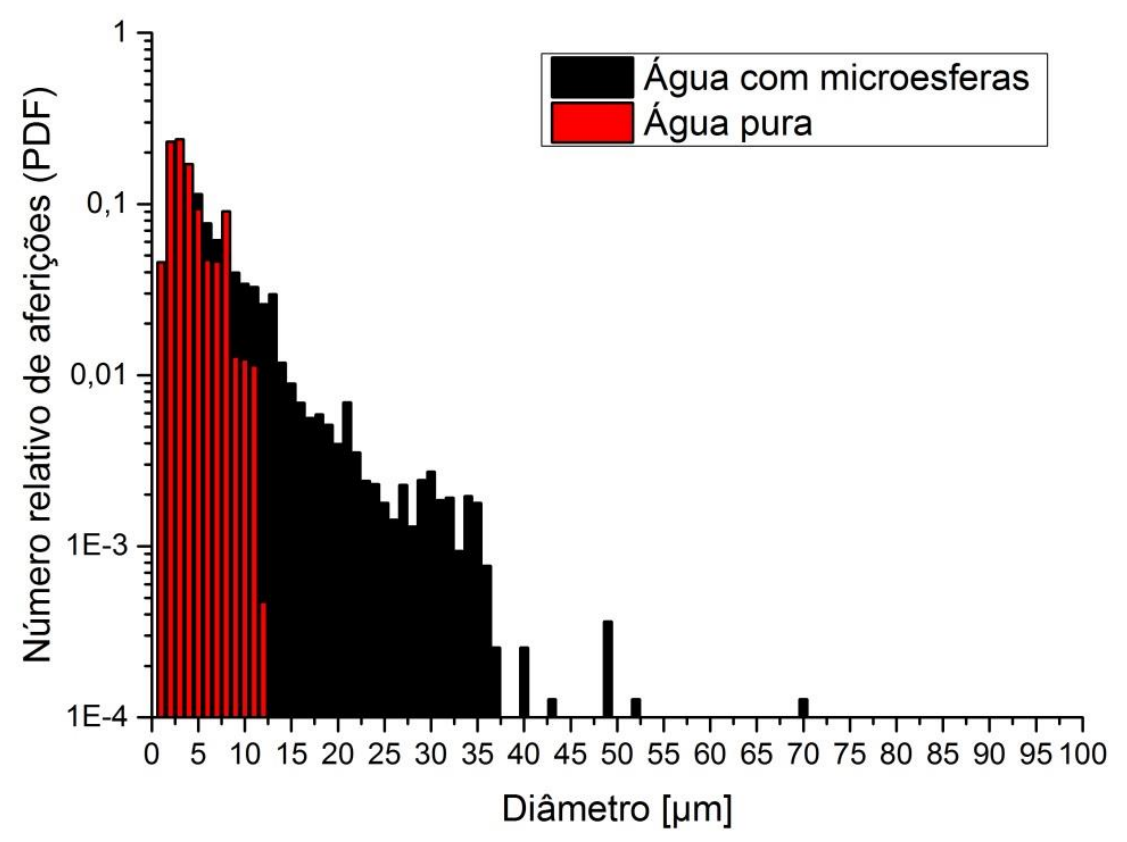

Figura 4.38 - Histograma comparativo da medição de partículas dispersas em água pura (em vermelho) e em água pura com microesferas de vidro (em preto).

O trabalho de validação do ORM sugere que um diâmetro representativo da amostra estaria situado entre o diâmetro médio e o diâmetro Sauter. Este estudo, no entanto, é aplicável apenas para diâmetros reduzidos, de até $50 \mu \mathrm{m}$. Será sugerida para trabalhos futuros a obtenção de partículas maiores para que seja realizado um estudo semelhante em uma faixa mais abrangente, por exemplo, de 8 a $2000 \mu \mathrm{m}$.

\subsection{ESTUDO DO FENÔMENO DE AFOGAMENTO}

Para testar a hipótese de Bohorquez et al. (2007), que sugeriu o uso de um tubo perfurado no shroud para evitar a ocorrência do fenômeno denominado "afogamento" por Mendes (2012), foi realizado um trabalho conjunto com Bulgarelli (2014) no aparato experimental descrito neste capítulo. Foi inicialmente aferida a vazão mínima para que fosse observado o fenômeno a $15^{\circ}$ de inclinação com a horizontal e utilizando a mistura bifásica água-ar. Um exemplo pode ser visto na Figura 4.39, em que a seção superior da linha de testes se encontra preenchida com água, enquanto o duto anular interno não está totalmente inundado. 


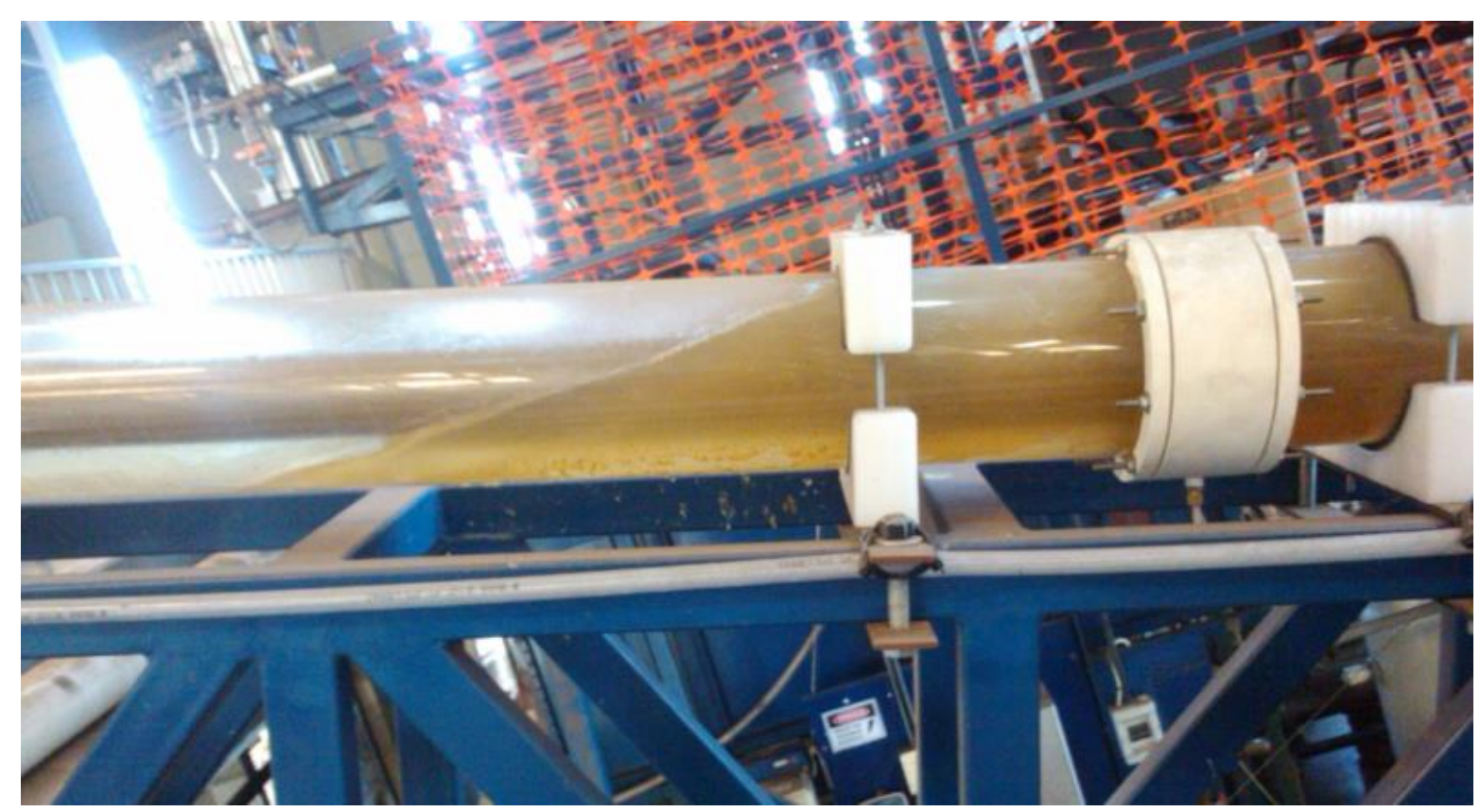

Figura 4.39 - Fenômeno de afogamento observado na linha de testes.

Bulgarelli (2014) calculou então o número mínimo de furos capaz de transmitir esta vazão no separador, supondo que os furos fossem feitos apenas na segunda e na terceira seções de tubos (a partir da extremidade superior) do shroud. Como resultado, foi determinado que seria necessário um total de 48 furos de $5 \mathrm{~mm}$ de diâmetro em cada seção perfurada. 

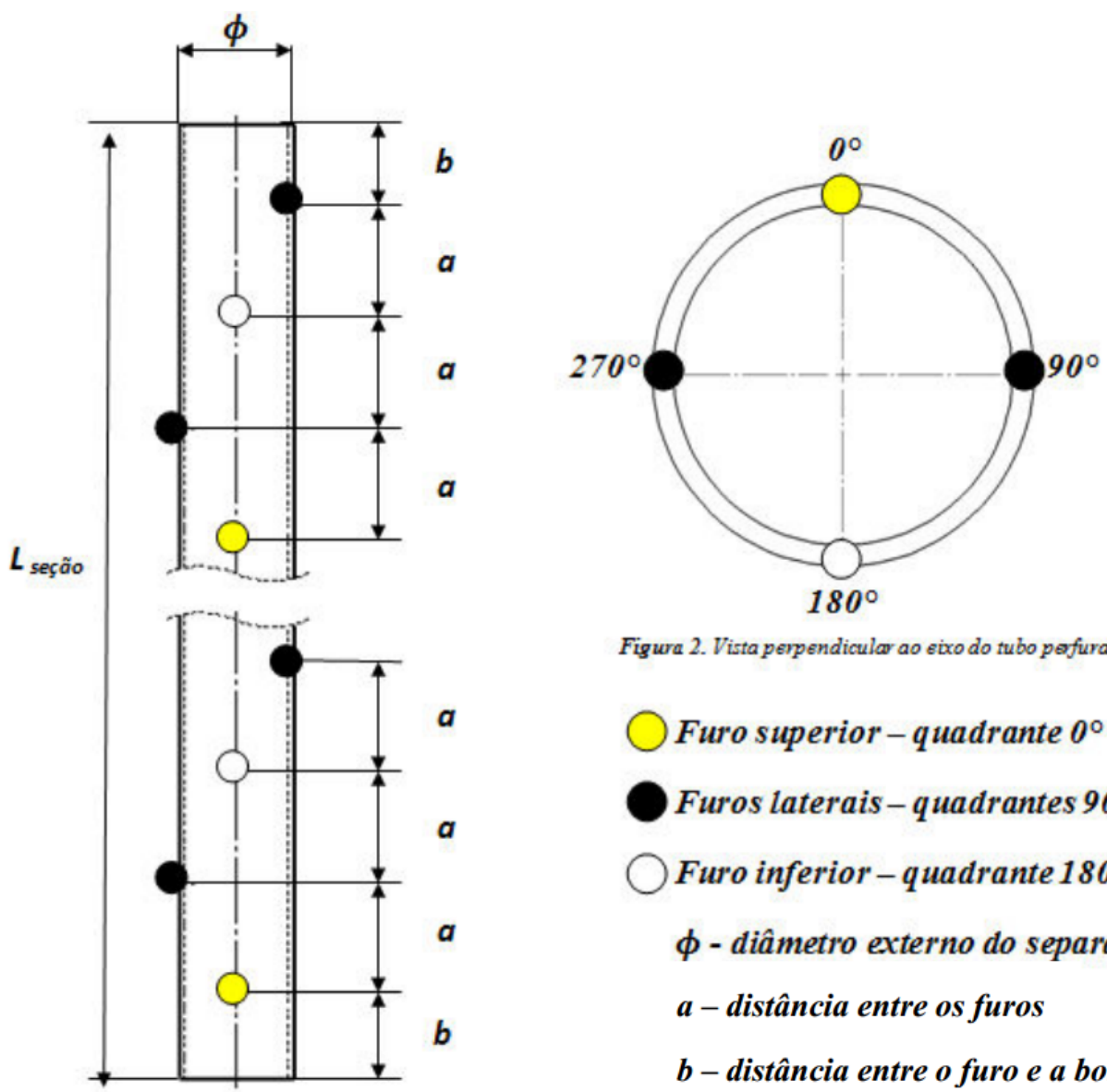

Figura 2. Vista penpendicular ao exixo do tubo peffurado.

Furo superior-quadrante $0^{\circ}$

Furos laterais-quadrantes $90^{\circ} e 270^{\circ}$

Furo inferior-quadrante $180^{\circ}$

$\phi$ - diâmetro externo do separador Shroud

$a$ - distância entre os furos

$b$ - distância entre o furo e a borda do tubo

Figura 4.40 - Vista frontal do tubo perfurado projetado por Bulgarelli (2014) .

Dois tubos de PVC de 1,5 m de comprimento e de geometria igual à dos tubos de vidro que compõem o shroud (em sua montagem na primeira etapa de testes, vide Tabela 4.3) foram então perfurados com o número sugerido de furos de forma igualmente espaçada, como pode ser visto na Figura 4.40. Testes comparativos de afogamento foram feitos com os tubos normais (sem furos) e com os tubos perfurados instalados no separador, a fim de observar diferenças na vazão mínima para que fosse observado o fenômeno em cada situação. 


\section{CAPÍTULO 5 RESULTADOS E DISCUSSÕES}

O presente capítulo, dividido em três seções principais, tem como objetivo apresentar os dados experimentais obtidos neste trabalho. Como feito no capítulo anterior, a primeira parte discutirá o estudo acerca da eficiência de separação de gás em condições diversas de vazão e comprimento do NAI. A segunda parte discutirá o estudo da distribuição do diâmetro de bolhas entranhadas por dissipação de energia cinética turbulente no separador. Finalmente, a terceira parte discutirá testes feitos com o uso de uma seção de tubo perfurado no separador, a fim de minimizar o fenômeno do afogamento, descrito anteriormente.

\subsection{ESTUDO DA SEPARAÇÃO DE GÁS}

Dados de eficiência de separação de gás em função da vazão de líquido foram comparados com a metodologia apresendada no Capítulo 3, a fim de validar o critério de separação de gás em separadores gravitacionais de shroud invertido proposto inicialmente por Ortiz-Vidal (2010) e estendido por Mendes (2012).

O modelo fenomenológico implementado em plataforma Wolfram Mathematica ${ }^{\circledR}$ é utilizado para plotar gráficos do NAI mínimo previsto em relação à vazão de líquido, sendo que foi feito um gráfico para cada inclinação $\left(15^{\circ}, 45^{\circ}\right.$ e $\left.60^{\circ}\right)$. Dados obtidos experimentalmente nas mesmas condições, implementadas no código, foram separados de acordo com a medição de eficiência de separação e plotados separadamente com símbolos distintos. Com isto, pode-se obter uma fronteira que separa as zonas de eficiência de separação. Os gráficos poderão ser comparados aos publicados por Ortiz-Vidal (2010) e Mendes (2012), de forma que se possa verificar se há discrepâncias nos resultados obtidos.

\subsubsection{Dados experimentais de eficiência de separação de gás}

Com a metodologia e o aparato experimental mostrados no Capítulo 4, um conjunto de 214 pontos experimentais foi obtido para as misturas bifásicas ar-água e ar-óleo, sendo que o tempo decorrido entre cada aferição era bastante longo (aproximadamente meia hora). A Tabela 5.1 mostra as baterias de testes realizadas neste trabalho. 
Tabela 5.1 - Pontos experimentais obtidos nas baterias de testes divididas por mistura bifásica e inclinação da seção de testes.

\begin{tabular}{cccc}
\hline \hline & Inclinação $(\beta)$ de $15^{\circ}$ & Inclinação $(\beta)$ de $45^{\circ}$ & Inclinação $(\beta)$ de $60^{\circ}$ \\
\hline \hline Mistura Ar-Água & 45 pontos & 43 pontos & 32 pontos \\
Mistura Ar-Óleo & 29 pontos & 33 pontos & 35 pontos \\
\hline \hline
\end{tabular}

O critério que separa os pontos experimentais referentes à separação total de gás dos pontos com perda de gás para o tubo de produção baseou-se na incerteza experimental desta variável, aferida em cada ponto. O software supervisório utilizado para operar a bancada experimental mede a incerteza total da eficiência de separação do gás através de cálculos de incerteza propagada, descritos no Apêndice A. Com esta variável, considera-se que um ponto apresenta separação de gás total se, e somente se, a eficiência medida ( $\left.\eta_{\text {medido }}\right)$ somada à incerteza da eficiência $\left(u_{\eta}\right)$ resultarem em um número maior ou igual que 100\%, como indicado nas Equações (5.1) e (5.2).

$$
\begin{aligned}
& \eta_{\text {medido }}+u_{\eta} \geq 100 \% \rightarrow \eta=100 \% \\
& \eta_{\text {medido }}+u_{\eta}<100 \% \rightarrow \eta<100 \%
\end{aligned}
$$

Com este critério, espera-se eliminar erros de medida devido a perturbações inerentes à seção de testes. Por exemplo, todos os dados foram obtidos em situações nas quais o aparato experimental se encontrava em regime permanente, mas fenômenos intermitentes como a geração de bolhas no misturador gás-líquido faziam com que houvesse constante oscilação na leitura dos medidores, como mostrado por Mendes (2012) em sua descrição dos experimentos.

\subsubsection{Ensaios com mistura ar-água}

A fim de otimizar a obtenção de dados, inicialmente foram plotados em plataforma Wolfram Mathematica ${ }^{\circledR}$ gráficos do $L_{N A I}$ previsto pelo modelo em função da vazão da fase líquida, $Q_{L}$, para cada inclinação a ser utilizada. A curva gerada é uma fronteira teórica que 
separa a região na qual há separação total de gás $(\eta=100 \%)$ da região na qual há separação parcial de gás $(\eta<100)$. Grosso modo, a primeira região se encontra no quadrante superior esquerdo e a segunda no quadrante inferior direito das Figuras 5.1 a 5.21. Com isto, foi planejada, em torno da curva teórica, a matriz de pontos experimentais a ser obtida. Para cada vazão $Q_{L}$ a ser analisada, foi tomado como ponto experimental inicial um valor de $L_{N A I}$ maior que o resultante da modelagem. Nos pontos seguintes era diminuído o valor de $L_{N A I}$, em pequenos decrementos, até que fossem observados valores claros de eficiência de separação parcial.

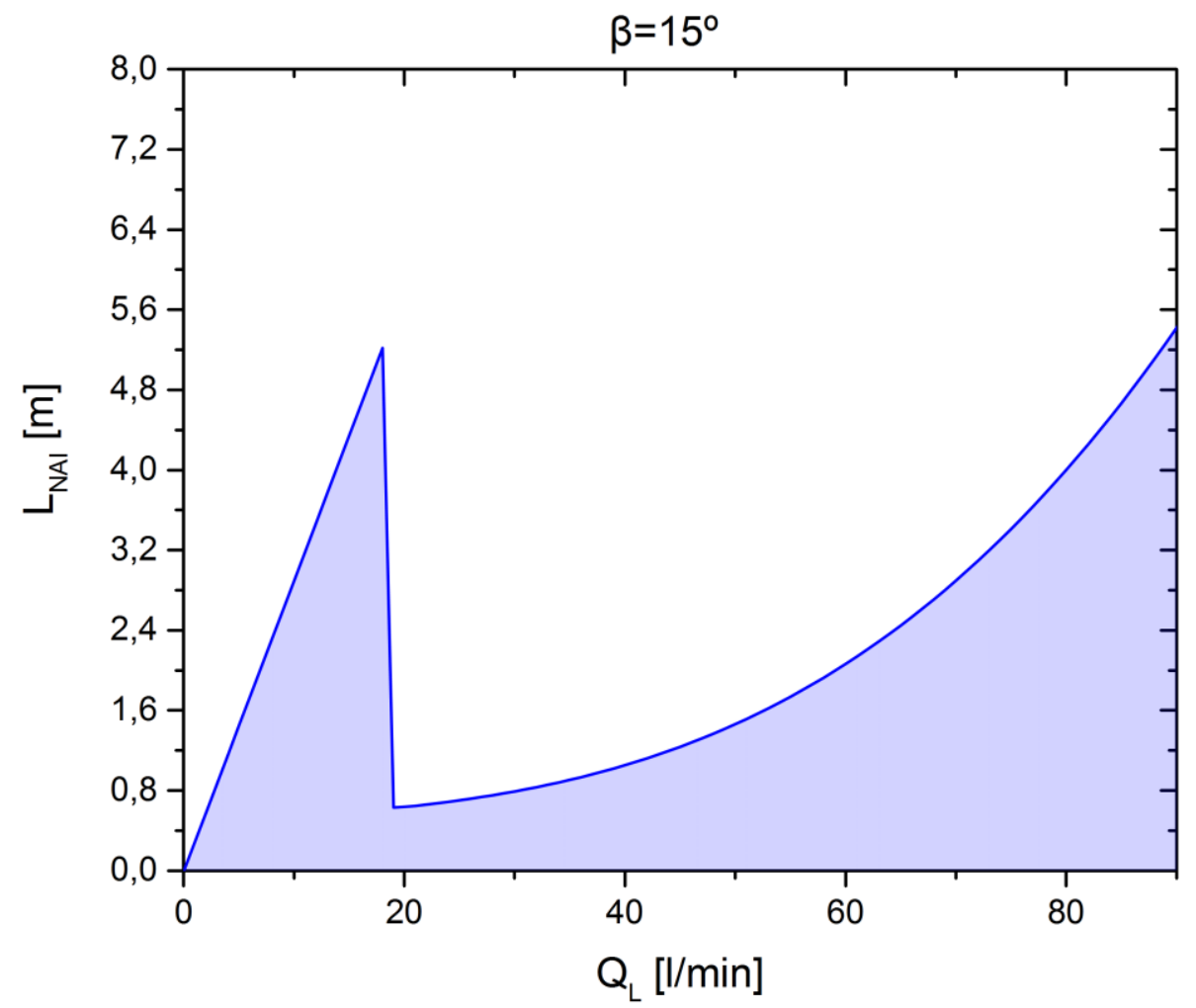

Figura 5.1 - Fronteira do comprimento $L_{N A I}$ em função da vazão de líquido $Q_{L}$ com o separador inclinado a $15^{\circ}$

A mudança abrupta na tendência do $L_{N A I}$ em função de $Q_{L}$ observada na Figura 5.1, não vista até então nos trabalhos anteriores, é atribuída à transição de regime laminar a turbulento no escoamento no shroud (na região C, Figura 3.1). Do ponto de vista do equacionamento, o comprimento de desenvolvimento do escoamento no anular interno $\left(L_{D E S}\right)$ é calculado através de diferentes equações para o escoamento turbulento e laminar, (3.3) e (3.4), respectivamente. Como resultado, o modelo prevê um comportamento da fronteira que separa as zonas de eficiência de separação que até então não havia sido observada nos 
trabalhos anteriores. Um conjunto maior de pontos foi obtido nesta região, para que se pudesse verificar experimentalmente a existência dessa mudança de tendência.

Adicionalmente, pode-se ver da Figura 5.1 à Figura 5.3 que a zona de transição se mantém nas diferentes inclinações, ocorrendo à mesma vazão. Isto se deve ao fato de que $L_{D E S}$ não varia com a inclinação da seção de testes.

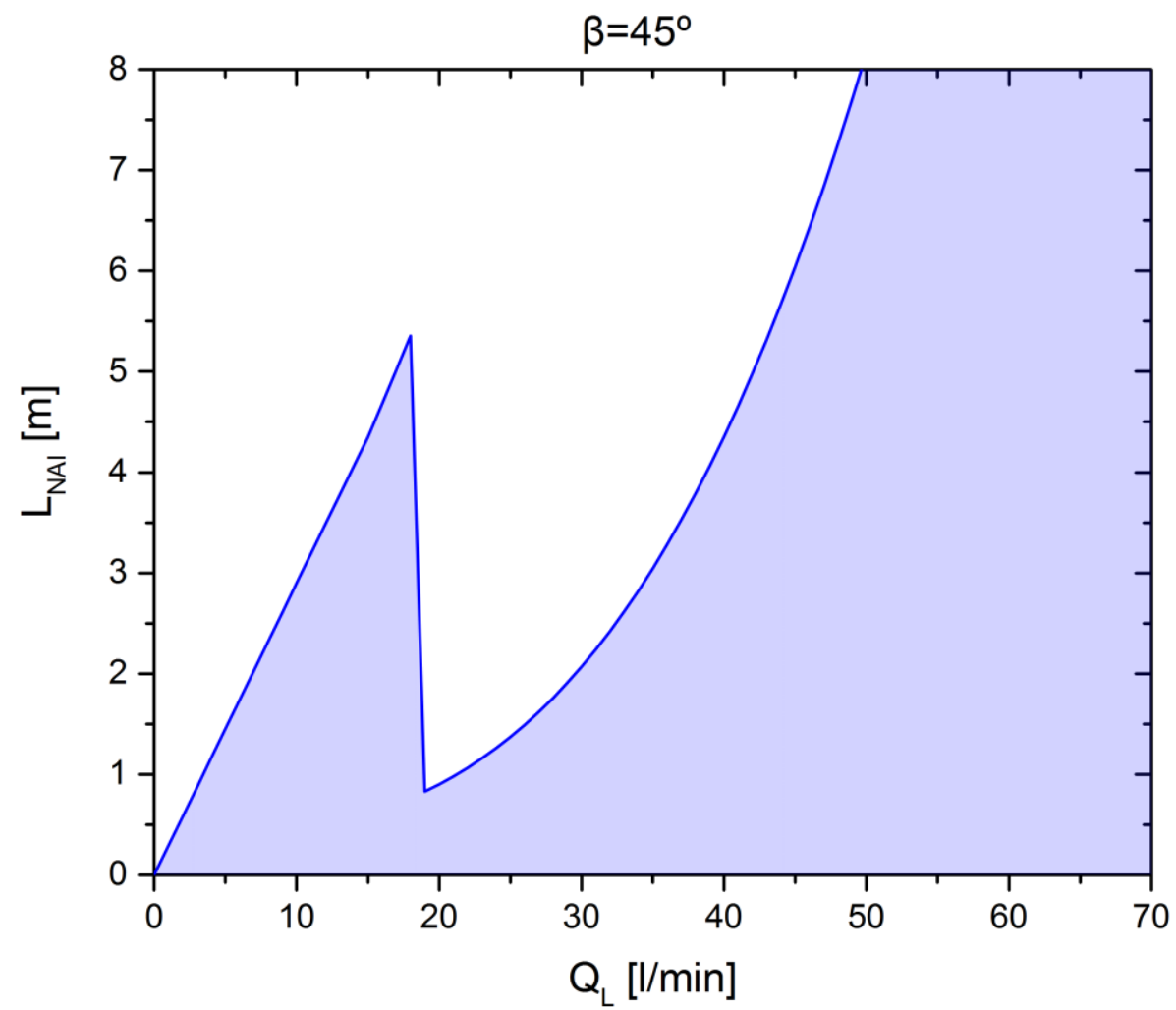

Figura 5.2 - Fronteira do comprimento $L_{N A I}$ em função da vazão de líquido $Q_{L}$ com o separador inclinado a $45^{\circ}$ 


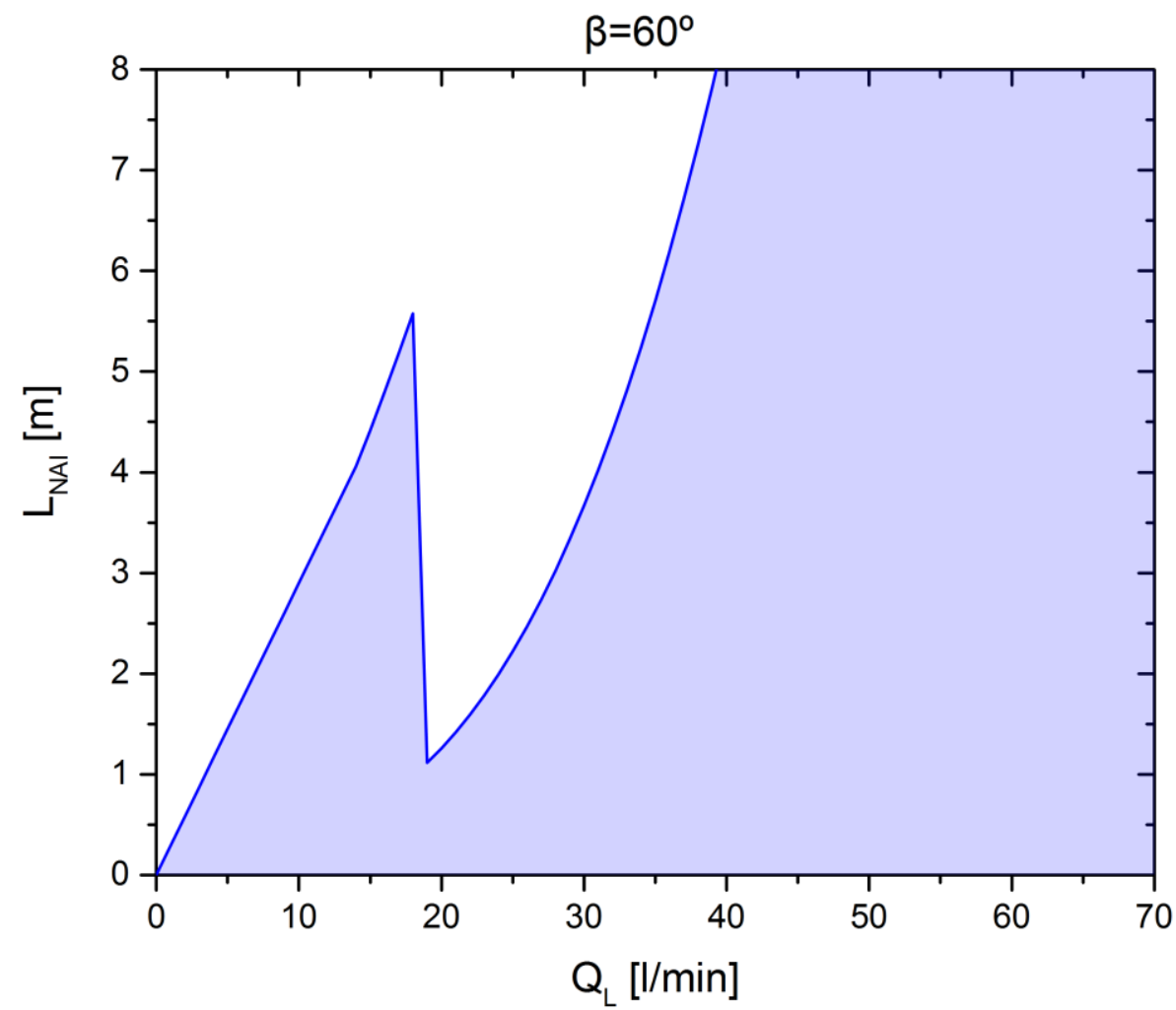

Figura 5.3 - Fronteira do comprimento $L_{N A I}$ em função da vazão de líquido $Q_{L}$ com o separador inclinado a $60^{\circ}$

Nas inclinações de $45^{\circ}$ e $60^{\circ}$ há uma forte limitação da nuvem de pontos experimentais devido ao comprimento da seção de testes. Vazões de líquido maiores que $50 \mathrm{l} / \mathrm{min}$, nestas inclinações, têm um comprimento mínimo do $L_{N A I}$ maior que 8,5 metros, i.e., todos os pontos que poderiam ser aferidos estão dentro da região de baixa eficiência prevista.

O conjunto de pontos aferidos está disposto em mapas de eficiência de separação, na forma de gráficos do $L_{N A I}$ previsto pelo modelo fenomenológico em função da vazão $Q_{L}$. Adicionando as fronteiras já mostradas ao gráfico de pontos experimentais, pode-se visualizar de maneira simples a validação do modelo. Para fins de comparação, adiciona-se também ao gráfico os pontos experimentais e o mapa de eficiência de separação dos estudos anteriores, de Ortiz-Vidal (2010) e Mendes (2012), como indicado nas legendas. 


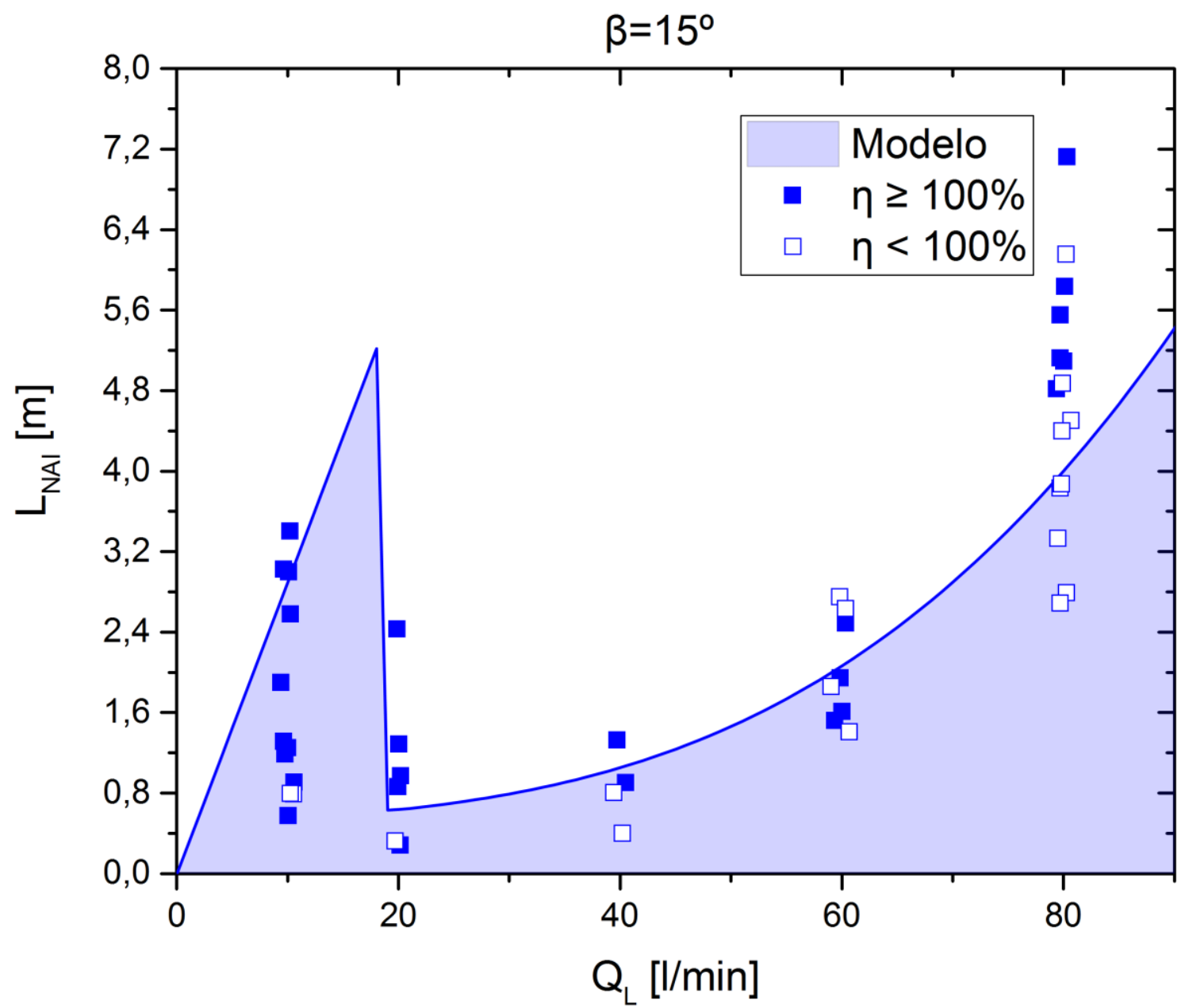

Figura 5.4 - Carta de eficiência de separação em termos do comprimento $L_{N A I}$ pela vazão de água, para a inclinação de $15^{\circ}$, com a nova nuvem de pontos experimentais sobreposta. 


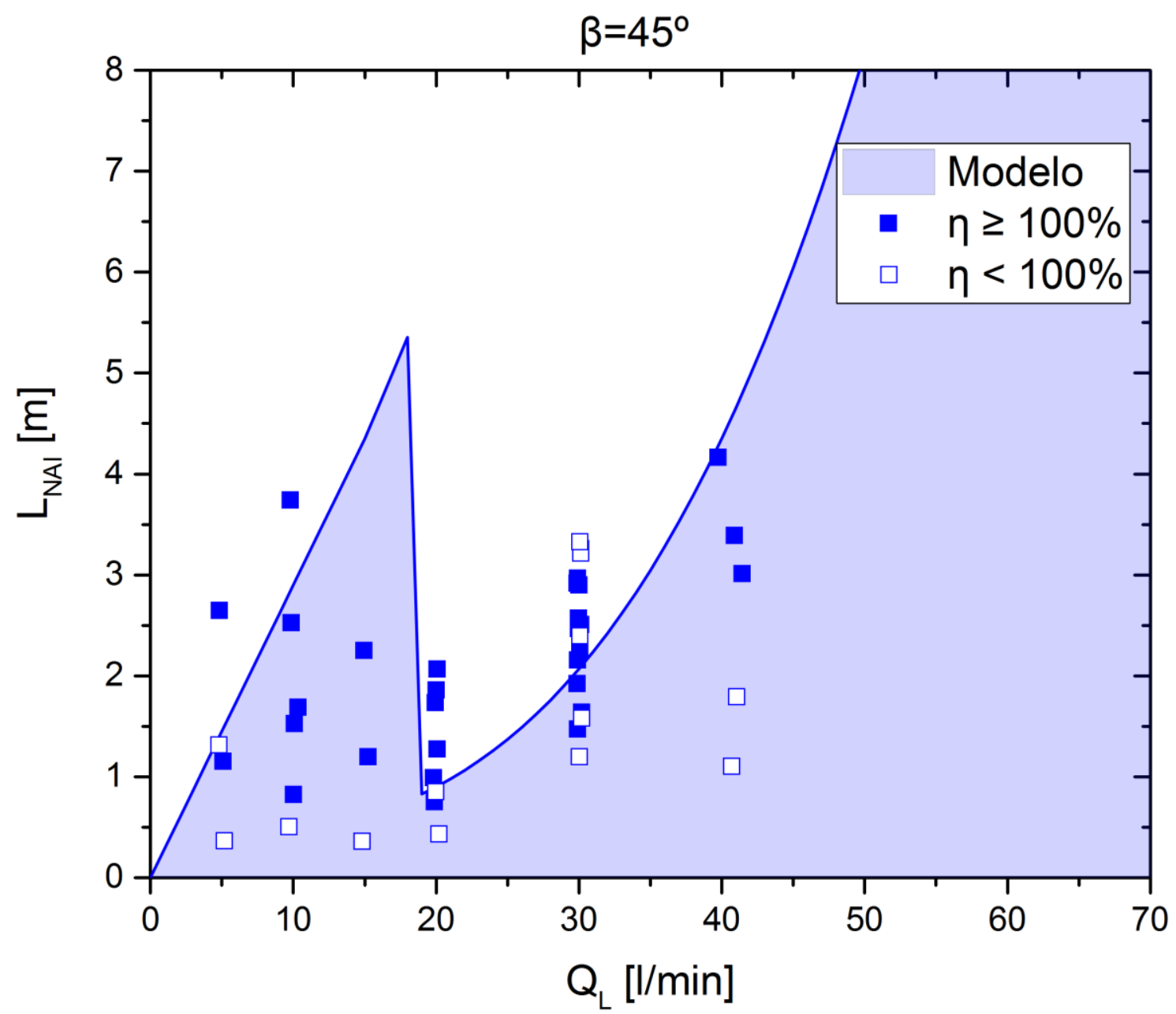

Figura 5.5 - Carta de eficiência de separação em termos do comprimento $L_{N A I}$ pela vazão de água, para a inclinação de $45^{\circ}$, com a nova nuvem de pontos experimentais sobreposta. 


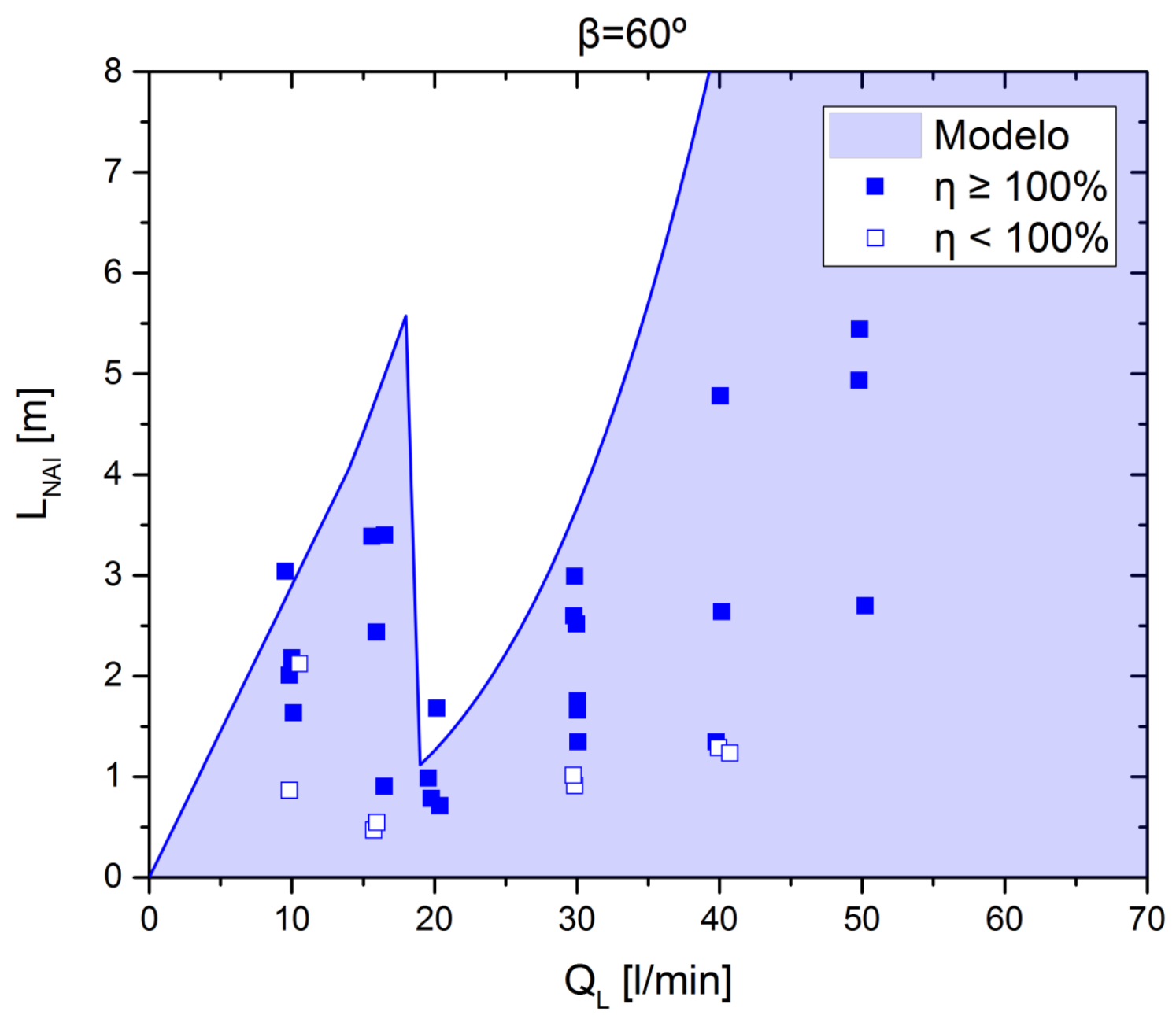

Figura 5.6 - Carta de eficiência de separação em termos do comprimento $L_{N A I}$ pela vazão de água, para a inclinação de $60^{\circ}$, com a nova nuvem de pontos experimentais sobreposta.

Como se pode ver, o modelo se comporta como esperado, deixando praticamente todos os pontos em que há perda de gás para o tubo de produção na região abaixo da fronteira. Alguns pontos de baixa eficiência de separação, no entanto, situam-se acima da fronteira, mas ainda assim apresentam valores de $\eta$ próximos a 90\%. Assim como nos estudos de OrtizVidal (2010) e Mendes (2012), pode-se perceber que há vários pontos com separação total de gás abaixo da fronteira. O modelo aparenta estar a favor da segurança, chegando em alguns casos a sobredimensionar o comprimento $L_{N A I}$ mínimo para o qual ocorre a separação total de gás.

Além disso, o modelo prevê dois modos diferentes de dissipação de energia cinética turbulenta, um decorrente do escoamento de superfície livre (na região B, Fig. 3.1) em regime laminar e outro em regime turbulento, como pode ser verificado através de inspeção das equações (3.8), (3.9) e (3.10). A fim de melhor analisar a equação (3.9) e seus parâmetros $m$ e 
$n$, que devem ser ajustados experimentalmente, os mesmos gráficos podem ser vistos com $L_{N A I_{A D}}$ em função do número de We ber modificado $W e^{*}$, sendo que:

$$
\begin{gathered}
L_{N A I_{A D}}=\frac{L_{N A I}}{D_{H_{A I}}} \\
W e^{*}=\frac{W e}{48} \\
L_{D I S_{A D}}=m\left(W e^{*}\right)^{-n}
\end{gathered}
$$

Os coeficientes propostos por Mendes (2012) para o caso turbulento $\left(R e_{S L}>2000\right)$ seriam $m=1500$ e $n=2$. Pode-se observar que o menor valor de $R e_{S L}$ (escoamento de superfície livre em duto anular inclinado) registrado para a mistura ar-água foi $R e_{S L}=9825$, com vazão de líquido $Q_{L}=4,8 \mathrm{l} / \mathrm{min}$ e inclinação $\beta=45^{\circ}$. Com isto, utilizou-se apenas o caso turbulento para esta mistura. 


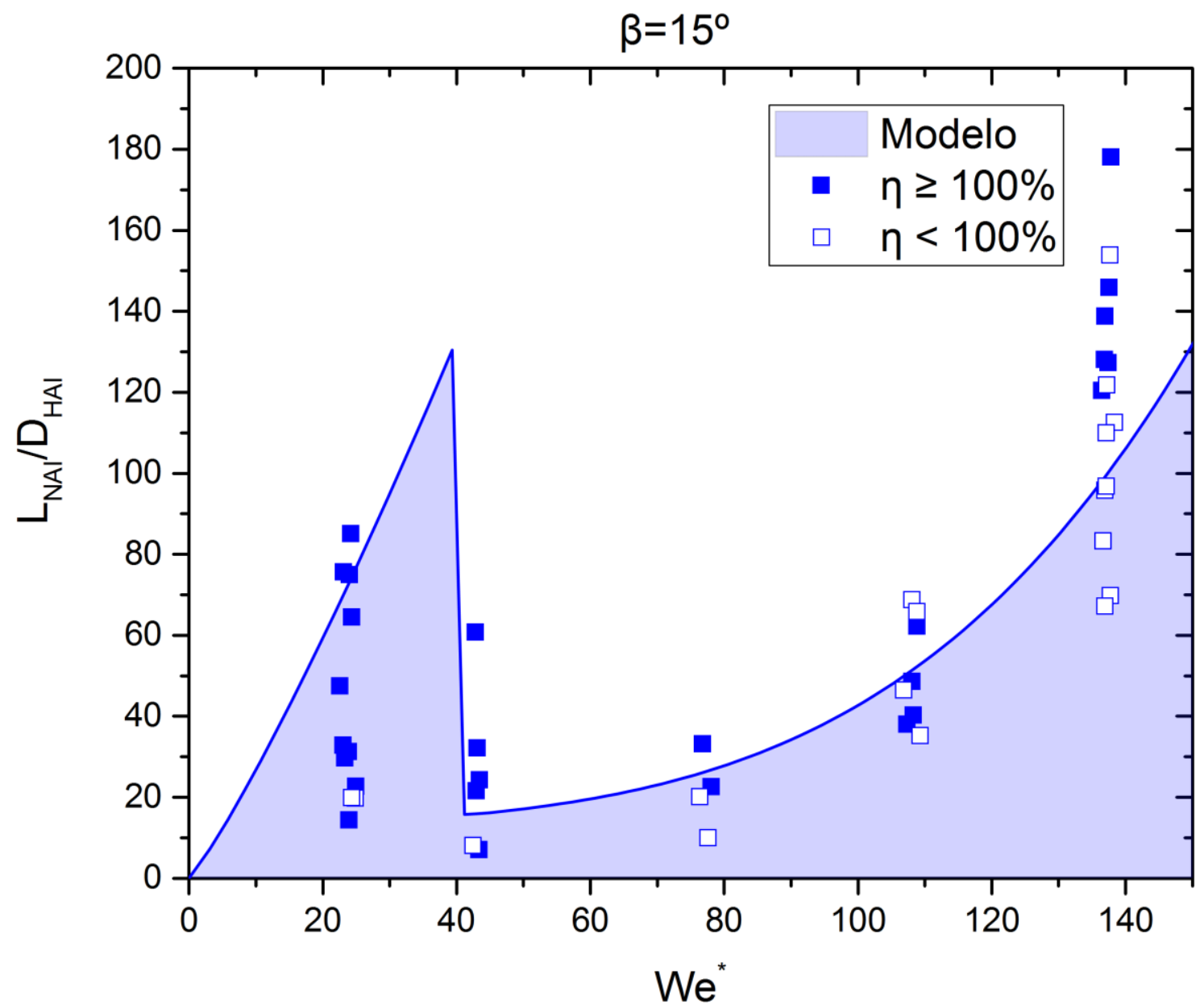

Figura 5.7 - Carta de eficiência de separação em termos do comprimento $L_{N A I}$ adimensional pelo número de Weber ajustado $\left(W e^{*}\right)$ do escoamento, para a inclinação de $15^{\circ}$, com a nova nuvem de pontos experimentais sobreposta 


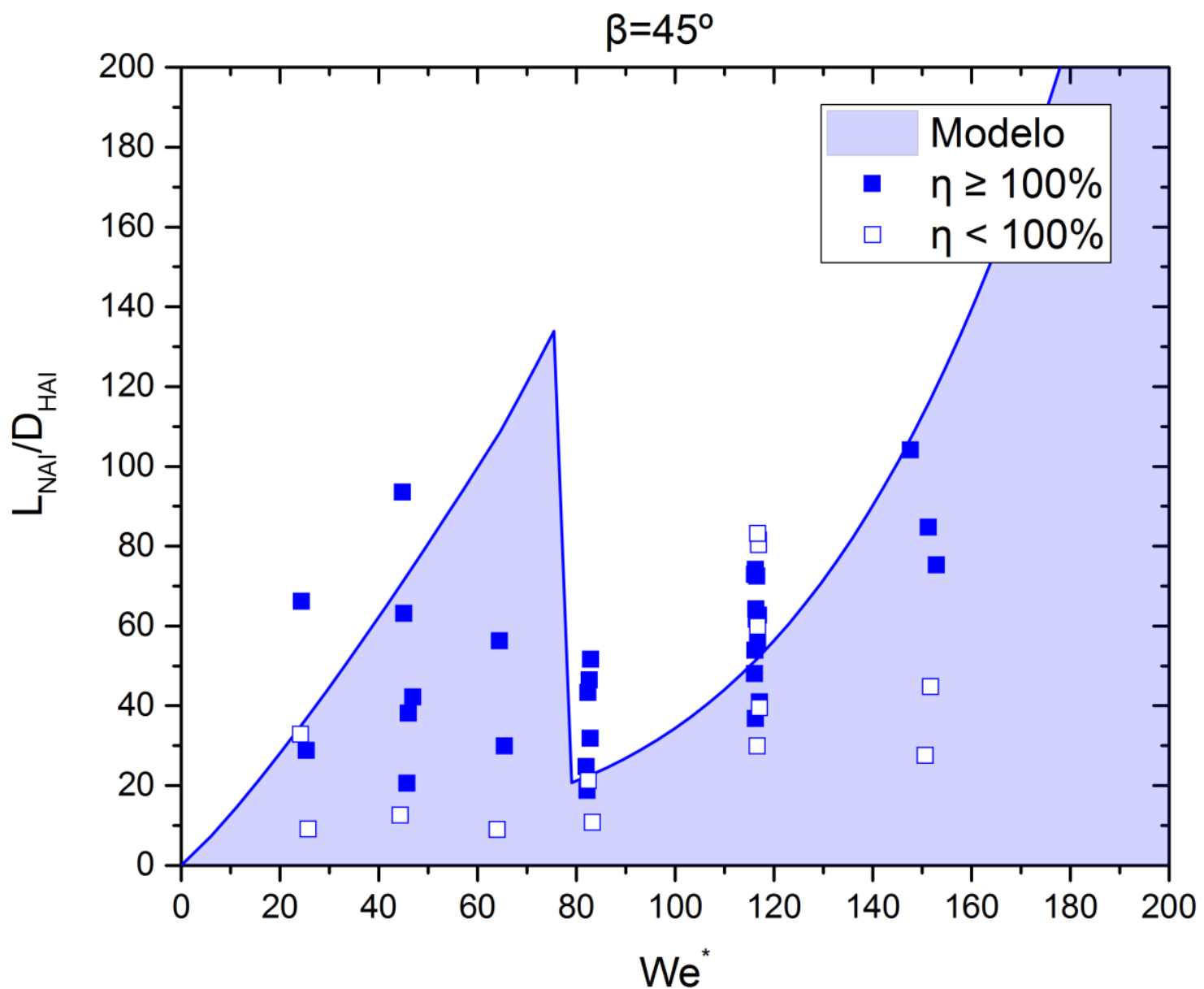

Figura 5.8 - Carta de eficiência de separação em termos do comprimento $L_{N A I}$ adimensional pelo número de Weber ajustado $\left(W e^{*}\right)$ do escoamento, para a inclinação de $45^{\circ}$, com a nova nuvem de pontos experimentais sobreposta 


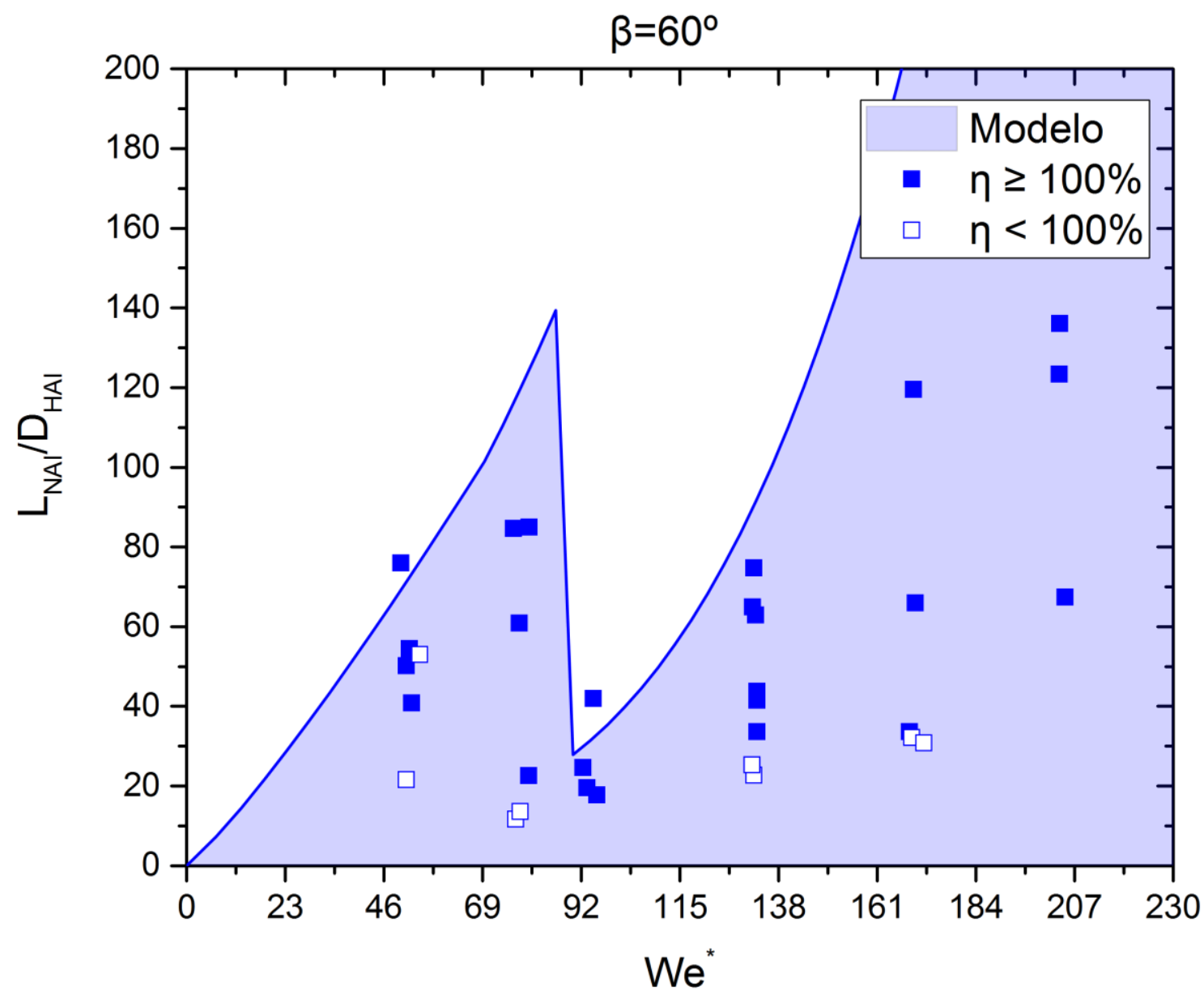

Figura 5.9 - Carta de eficiência de separação em termos do comprimento $L_{N A I}$ adimensional pelo número de Weber ajustado $\left(W e^{*}\right)$ do escoamento, para a inclinação de $60^{\circ}$, com a nova nuvem de pontos experimentais sobreposta

Novamente, o modelo se apresenta consistente. Os pontos experimentais de $L_{N A I}$ medidos em função da vazão $Q_{L}$ em que há eficiência de separação abaixo de $100 \%$ se apresentam na região abaixo da fronteira de separação prevista pelo modelo. Os pontos experimentais nos quais foi medida uma eficiência de separação de gás igual a $100 \%$, de acordo com o critério apresentado nas Equações (5.1) e (5.2), se encontram também em grande parte abaixo da fronteira de separação, o que mostra que o modelo pode superdimensionar o $L_{N A I}$ mínimo para cada vazão de líquido. As Figuras Figura 5.10 a Figura 5.12, que apresentam os dados experimentais do trabalho atual sobrepostos aos dados obtidos por Ortiz-Vidal (2010) e Mendes (2012), com as respectivas curvas de fronteiras de separação de gás geradas através do modelo, mostram que tal superdimensionamento também esteve presente nos trabalhos anteriores, principalmente nos testes em que a seção de testes foi inclinada a $60^{\circ}$ em relação à horizontal. 


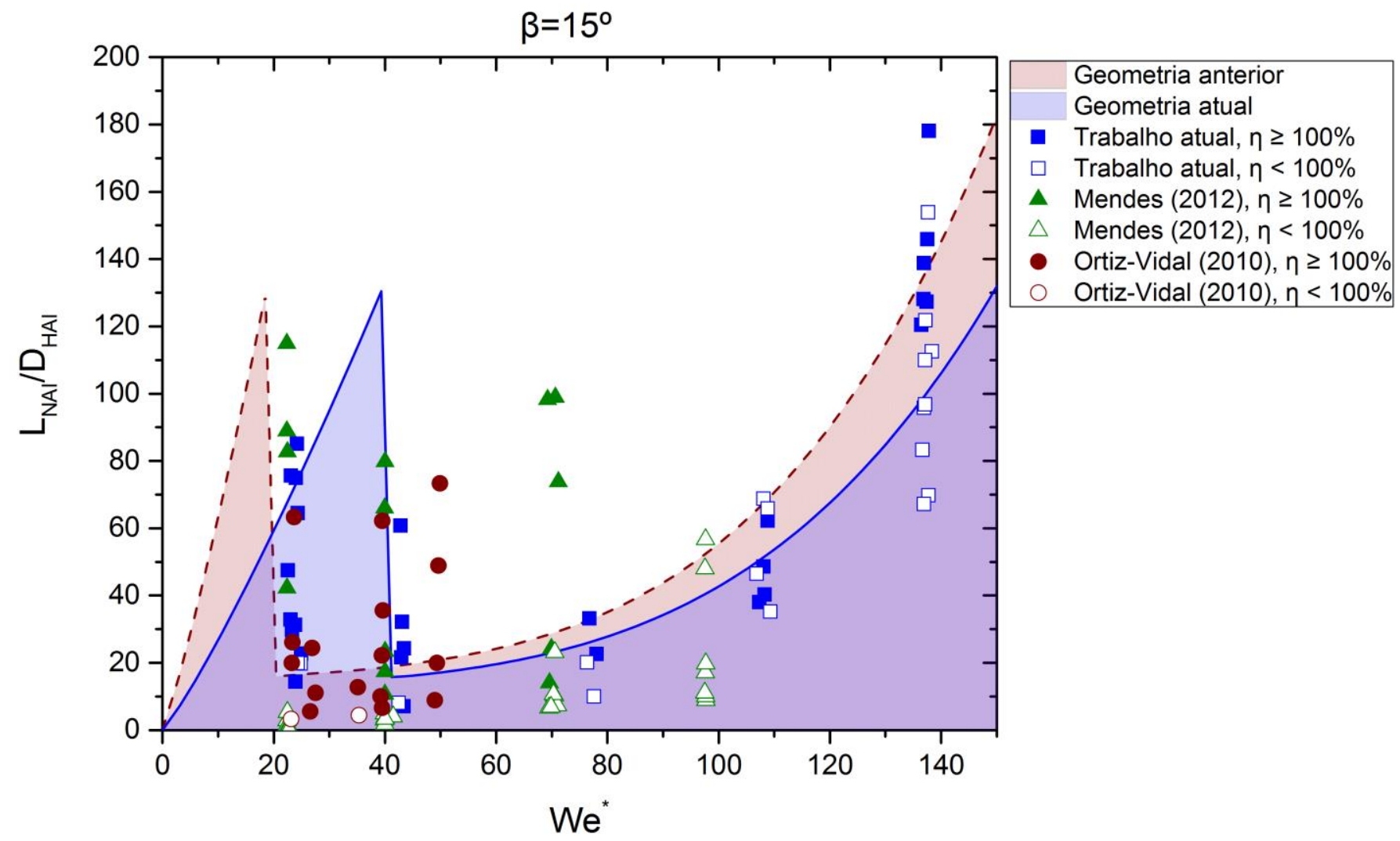

Figura 5.10 - Carta de eficiência de separação em termos do comprimento $L_{N A I}$ adimensional pelo número de Weber ajustado $\left(W e^{*}\right)$ do escoamento ar-água, para a inclinação de $15^{\circ}$, com os dados experimentais obtidos no trabalho atual e nos trabalhos de Ortiz-Vidal (2010) e

Mendes (2012) 


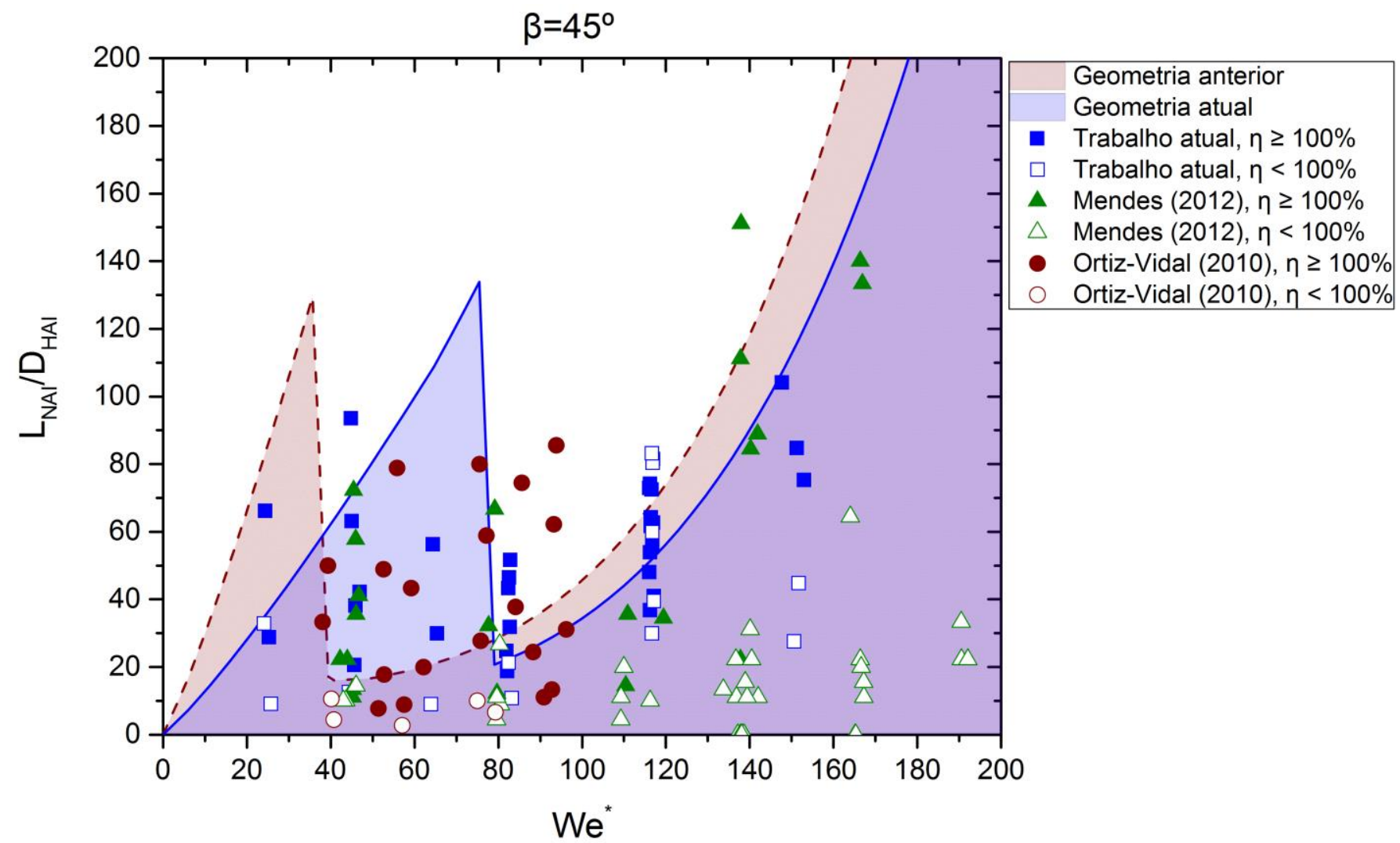

Figura 5.11 - Carta de eficiência de separação em termos do comprimento $L_{N A I}$ adimensional pelo número de Weber ajustado $\left(W e^{*}\right)$ do escoamento ar-água, para a inclinação de $45^{\circ}$, com os dados experimentais obtidos no trabalho atual e nos trabalhos de Ortiz-Vidal (2010) e Mendes (2012) 


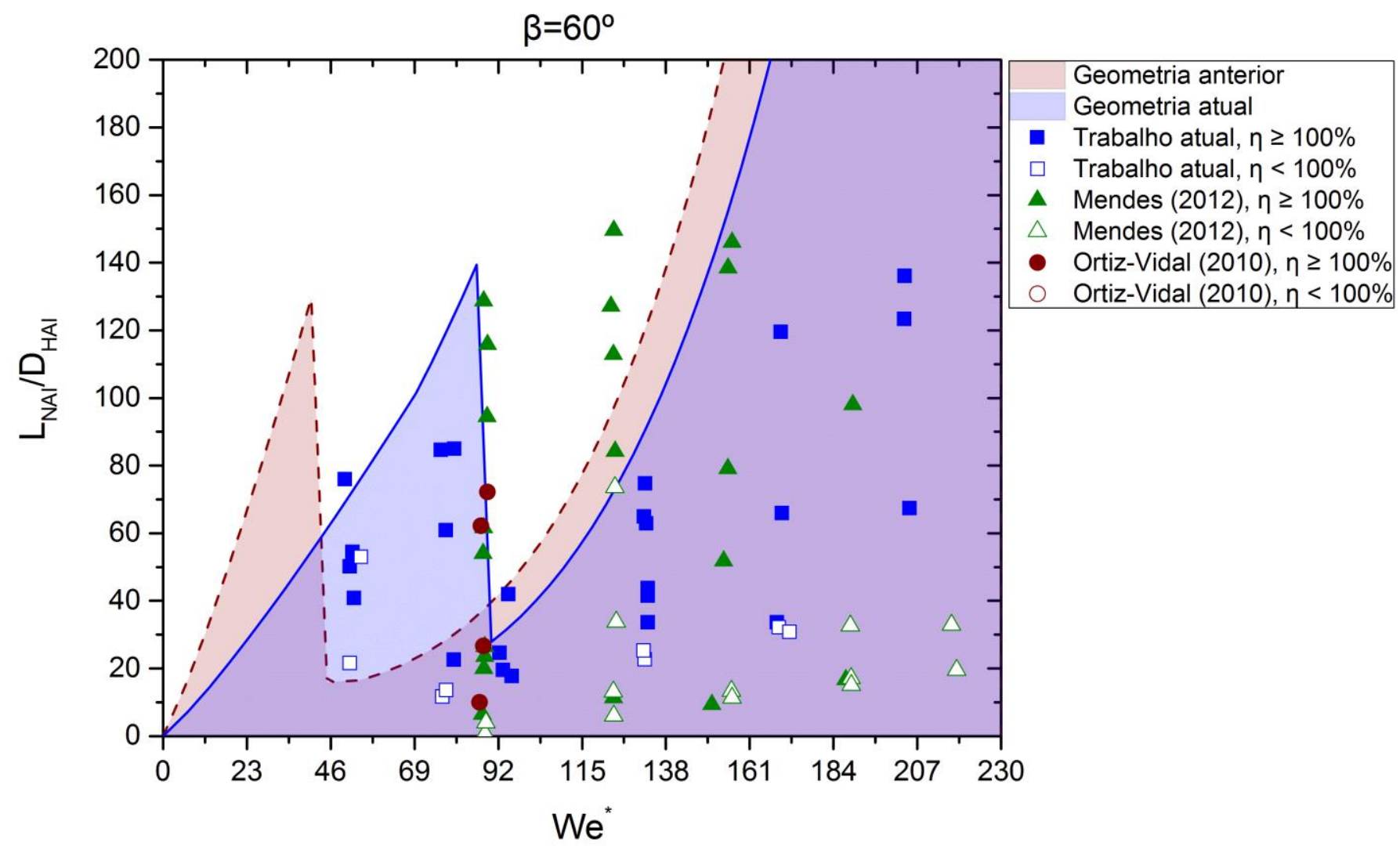

Figura 5.12 - Carta de eficiência de separação em termos do comprimento $L_{N A I}$ adimensional pelo número de Weber ajustado $\left(W e^{*}\right)$ do escoamento ar-água, para a inclinação de $60^{\circ}$, com

os dados experimentais obtidos no trabalho atual e nos trabalhos de Ortiz-Vidal (2010) e

Mendes (2012)

\subsubsection{Ensaios com mistura ar-óleo}

Para a mistura ar-óleo foram ensaiados escoamentos com as inclinações de $15^{\circ}, 45^{\circ} \mathrm{e}$ $60^{\circ}$. Assim, como foi mostrado para a mistura ar-água, temos a fronteira de $L_{N A I}$ em função da vazão de óleo $Q_{L}$ (Figura 5.13). Diferentemente do que é visto nas Figuras 5.1 a 5.3, a descontinuidade gerada pela transição laminar-turbulenta do escoamento não é vista, já que a vazão $Q_{L}$ necessária para isto é consideravelmente alta dada a maior viscosidade do óleo. 


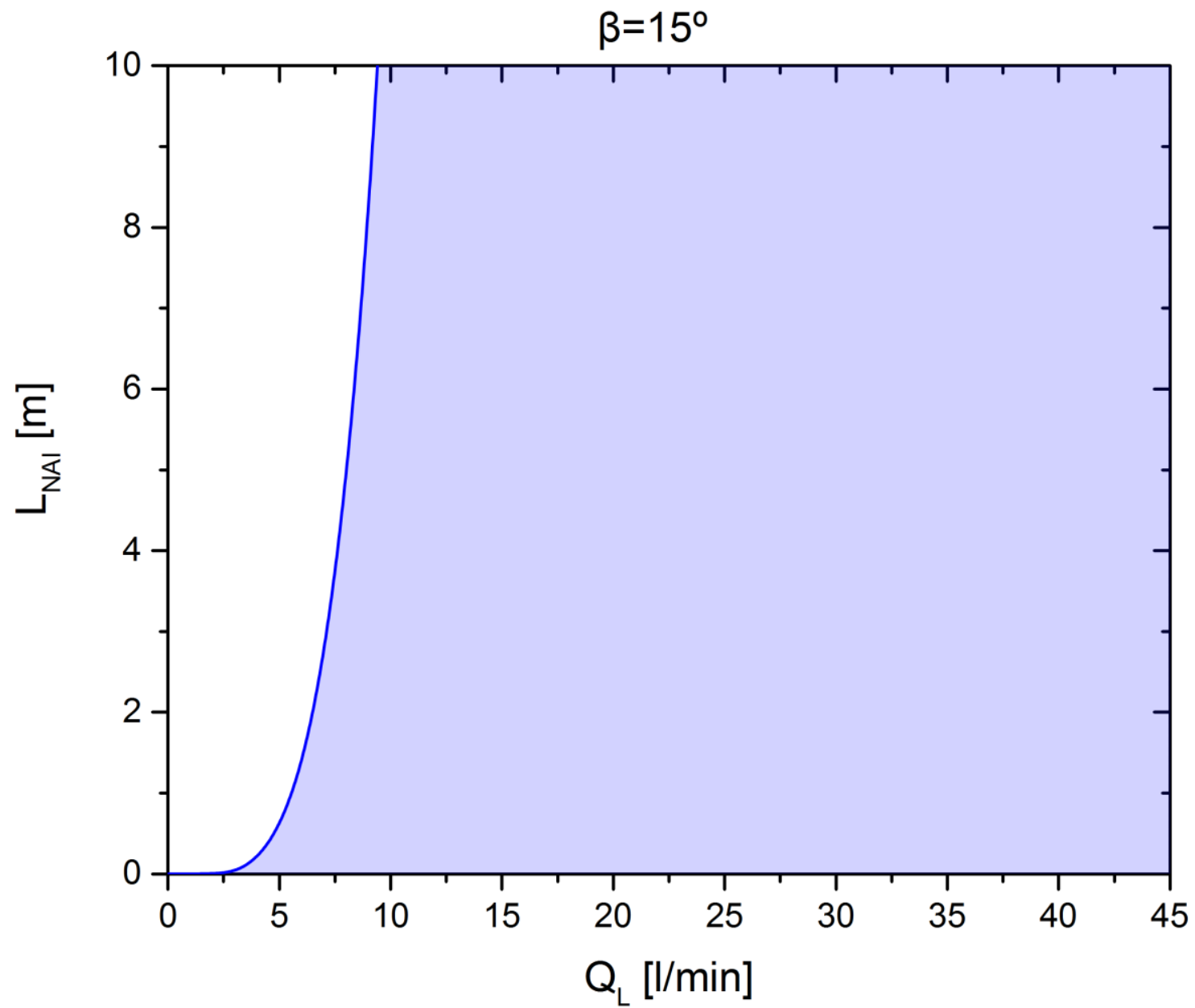

Figura 5.13 - Carta de eficiência de separação em termos do comprimento $L_{N A I}$ em função da vazão de óleo $Q_{L}$ para a inclinação de $15^{\circ}$.

Com os pontos aferidos na seção de testes, pode-se novamente confirmar a validade do modelo fenomenológico, como mostrado nas Figura 5.14 a Figura 5.16. 


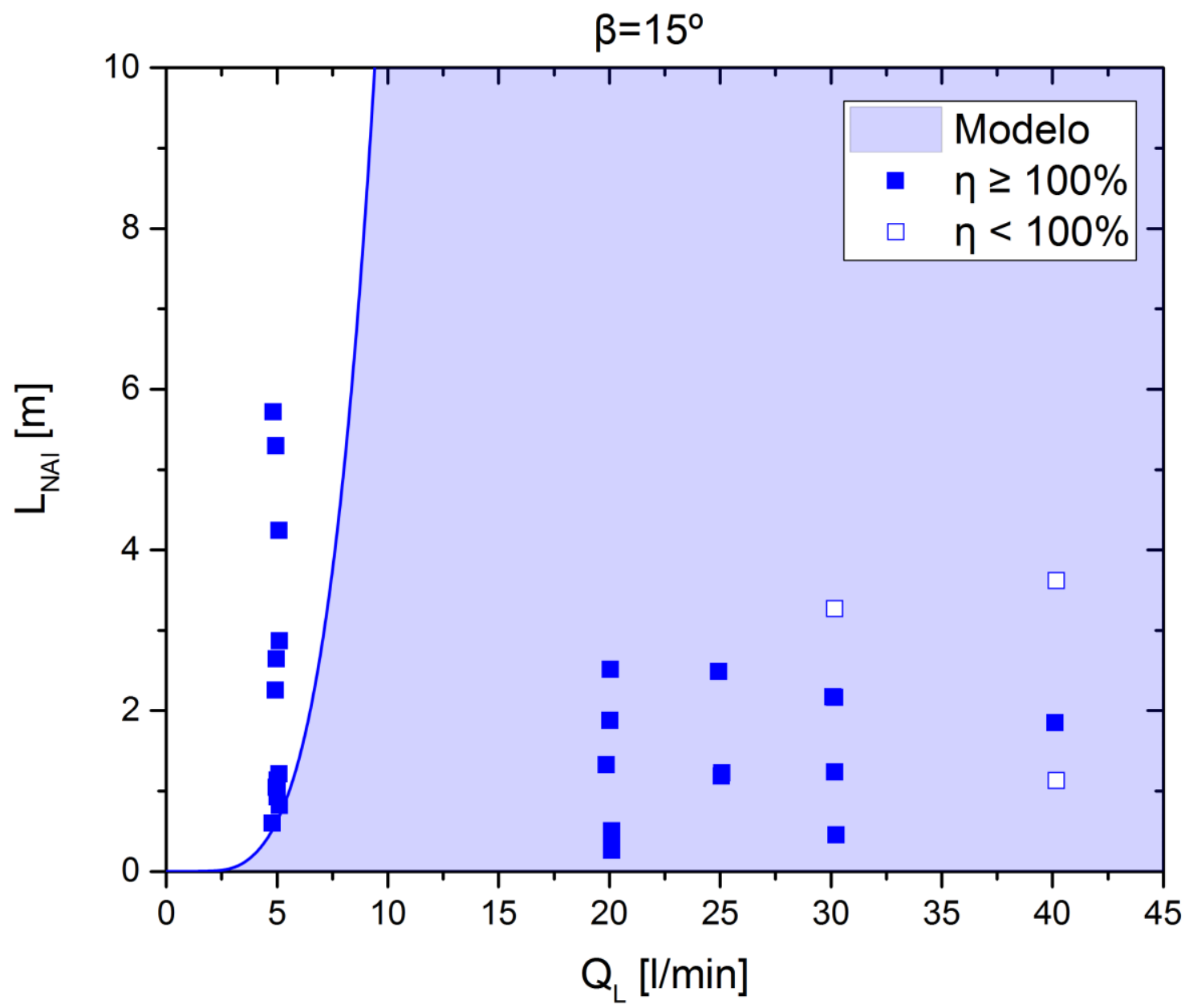

Figura 5.14 - Carta de eficiência de separação em termos do comprimento $L_{N A I}$ em função da vazão de óleo $Q_{L}$ com nova nuvem de pontos experimentais obtidos na inclinação de $15^{\circ}$ 


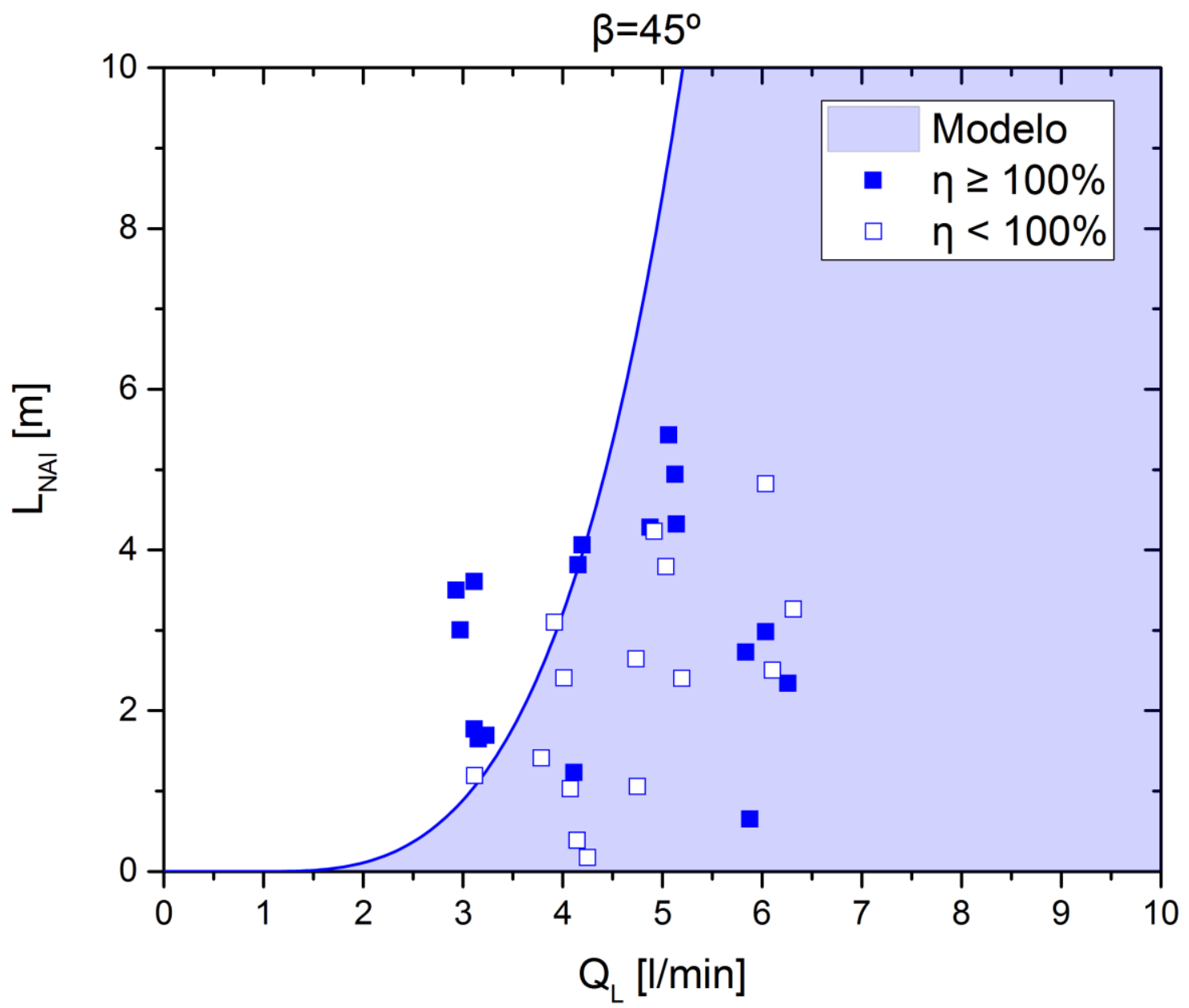

Figura 5.15 - Carta de eficiência de separação em termos do comprimento $L_{N A I}$ em função da vazão de óleo $Q_{L}$ com nova nuvem de pontos experimentais obtidos na inclinação de $45^{\circ}$ 


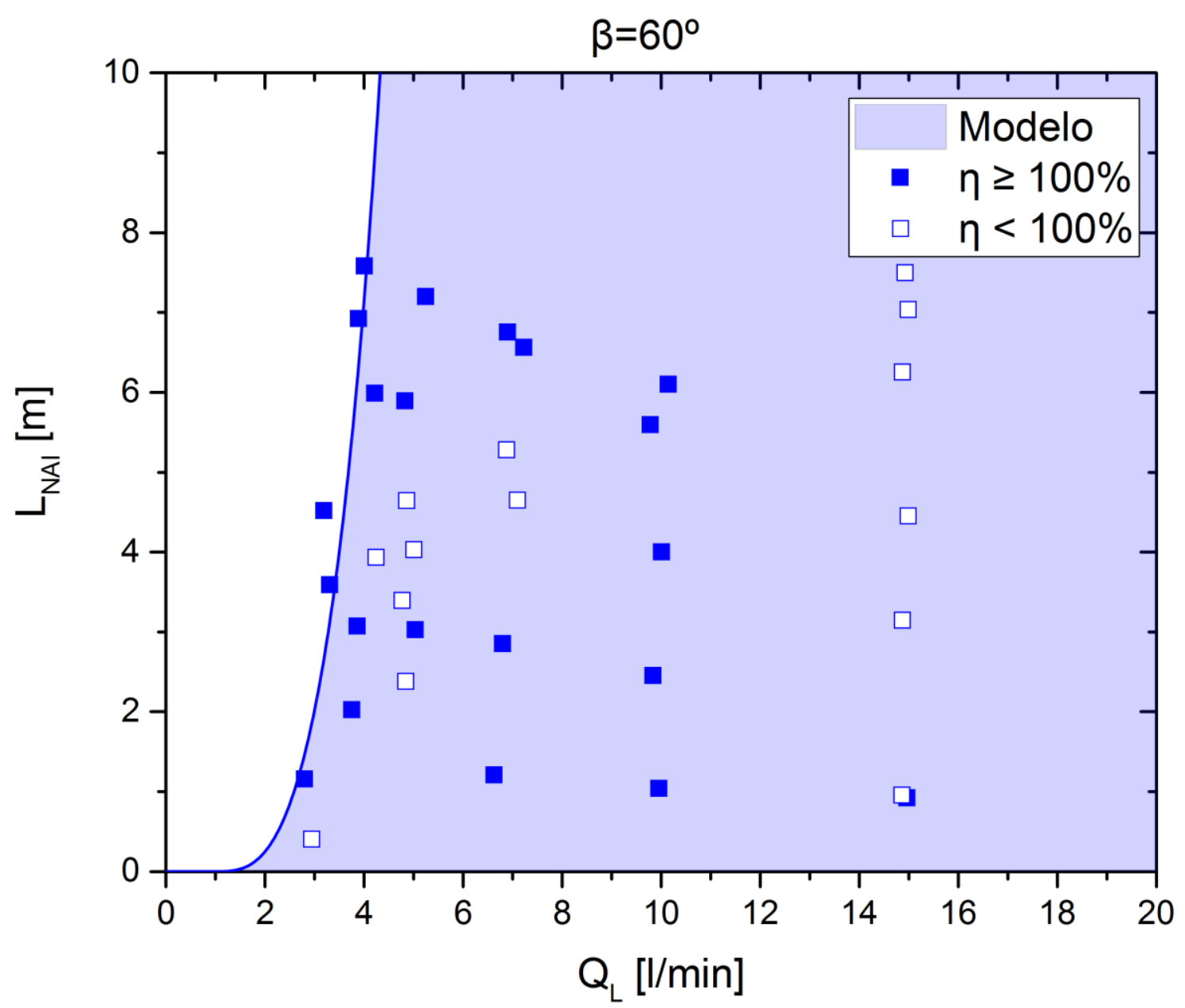

Figura 5.16 - Carta de eficiência de separação em termos do comprimento $L_{N A I}$ em função da vazão de óleo $Q_{L}$ com nova nuvem de pontos experimentais obtidos na inclinação de $60^{\circ}$

Adicionalmente, pôde-se gerar gráficos de $L_{N A I_{A D}}$ em função de $W e^{*}$, como feito anteriormente. Vale notar que, como o número de Weber depende da viscosidade da fase líquida, é possível calculá-lo individualmente para cada ponto experimental (baseado na temperatura do óleo, aferida em cada ponto) ou utilizar em todos os pontos a mesma viscosidade média usada para plotar a curva. Mendes (2012) utilizou o segundo método, como pode-se ver na Figura 5.17. Caso fosse utilizado o primeiro método, o gráfico de Mendes ficaria igual ao da Figura 5.18 (utilizando a mesma viscosidade média para plotar a curva, 215 cP, e a mesma densidade do óleo reportada por Mendes, igual a $824 \mathrm{~kg} / \mathrm{m}^{3}$ ). 


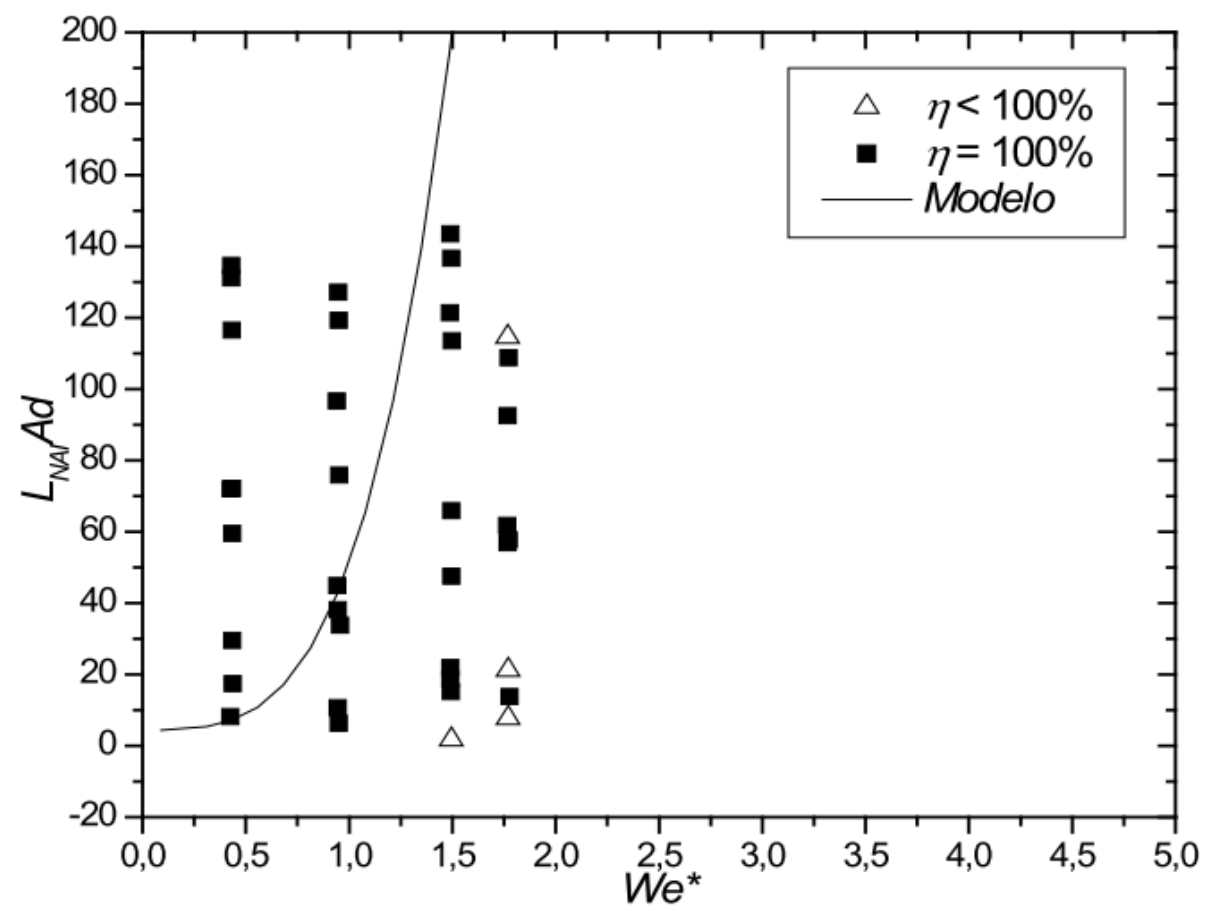

Figura 5.17 - Carta de eficiência de separação em termos do comprimento $L_{N A I}$ adimensional em função do número de Weber $W e^{*}$ para a inclinação de $15^{\circ}$, retidada de Mendes (2012).

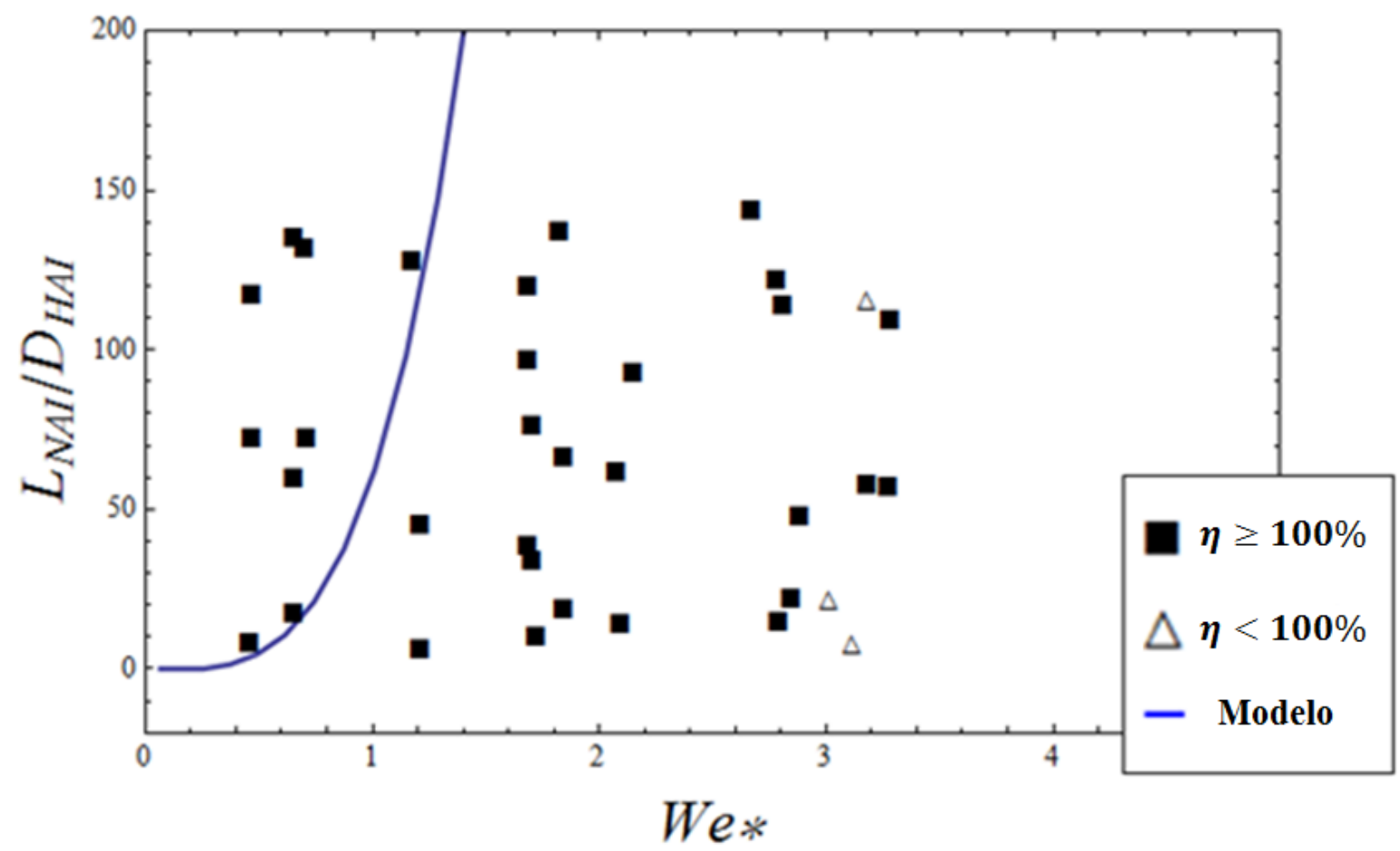

Figura 5.18 - Carta de eficiência de separação em termos do comprimento $L_{N A I}$ adimensional em função de $W e^{*}$ para a inclinação de $15^{\circ}$ com a nuvem de pontos obtida por Mendes (2012), levando em conta a viscosidade variável. 
Com o novo critério de viscosidade variável em mente, podem ser apresentados os gráficos dispostos nas Figuras 5.19 a 5.21, em que os pontos experimentais da nova base de dados são mostrados sobrepostos aos do estudo de Mendes (2012) em sua forma adimensional.

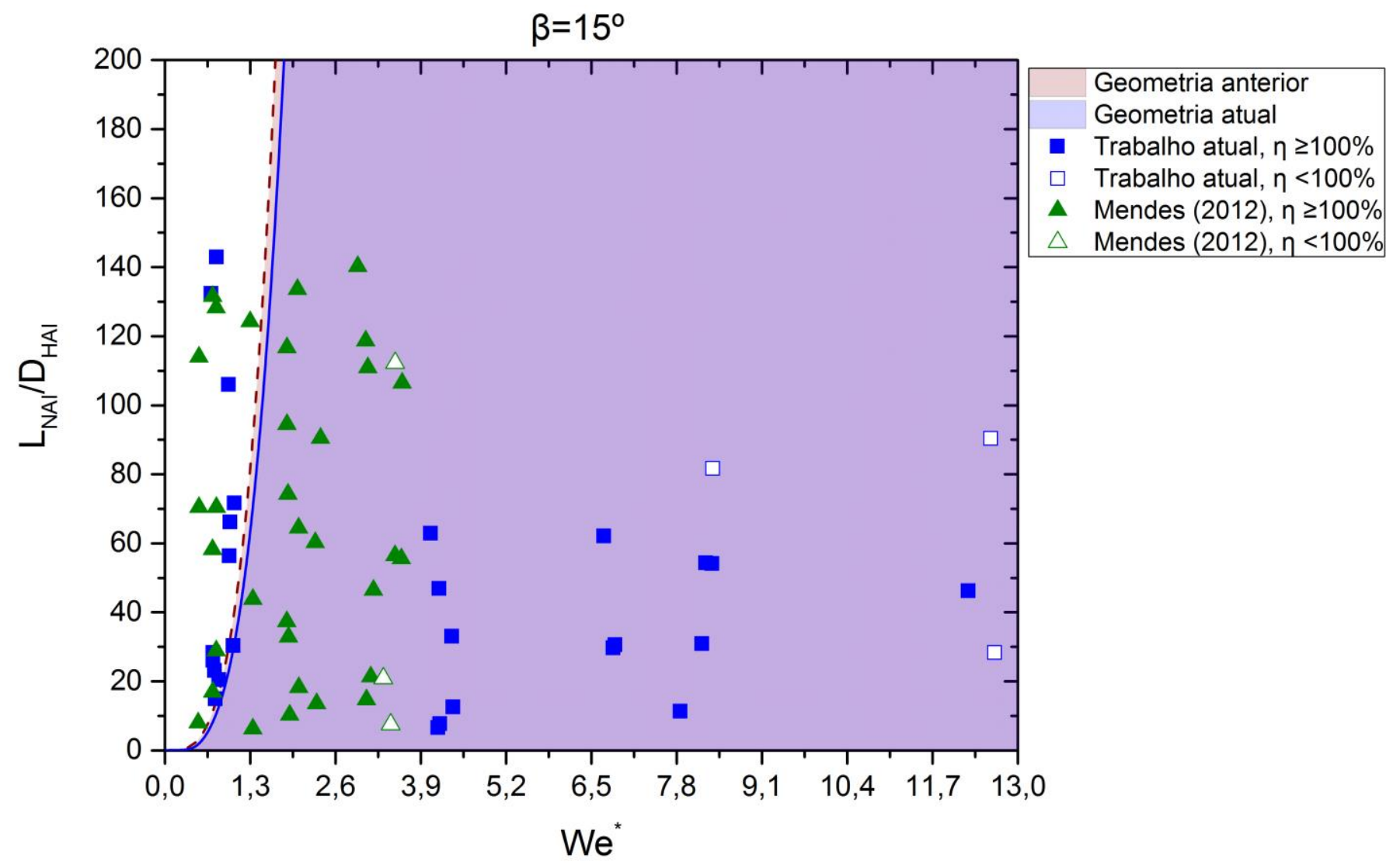

Figura 5.19 - Carta de eficiência de separação em termos do comprimento $L_{N A I}$ adimensional pelo número de Weber ajustado $\left(W e^{*}\right)$ do escoamento ar-óleo, para a inclinação de $15^{\circ}$, com os dados experimentais obtidos no trabalho atual e no trabalho de Mendes (2012). 


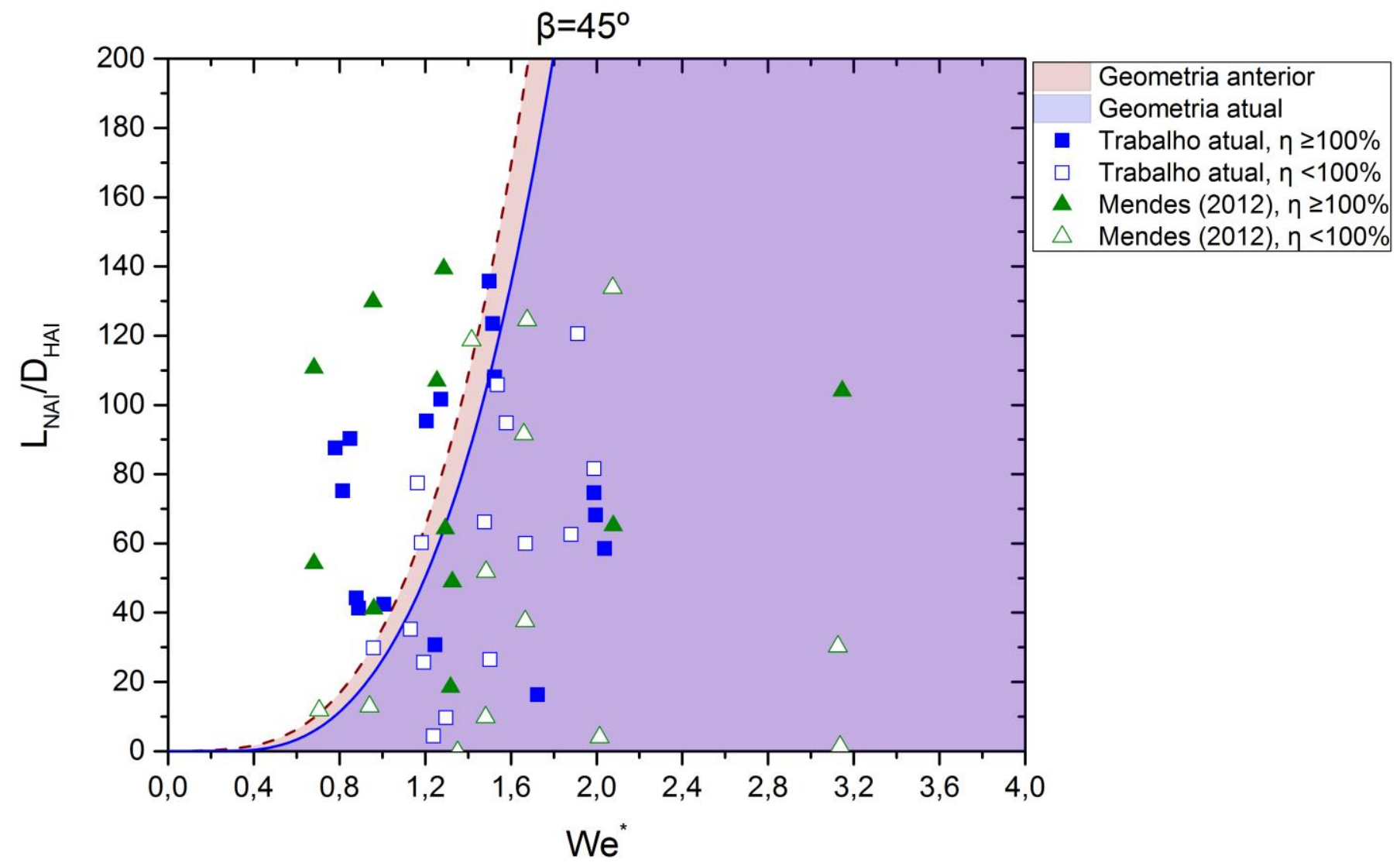

Figura 5.20 - Carta de eficiência de separação em termos do comprimento $L_{N A I}$ adimensional pelo número de Weber ajustado $\left(W e^{*}\right)$ do escoamento ar-óleo, para a inclinação de $45^{\circ}$, com os dados experimentais obtidos no trabalho atual e no trabalho de Mendes (2012). 


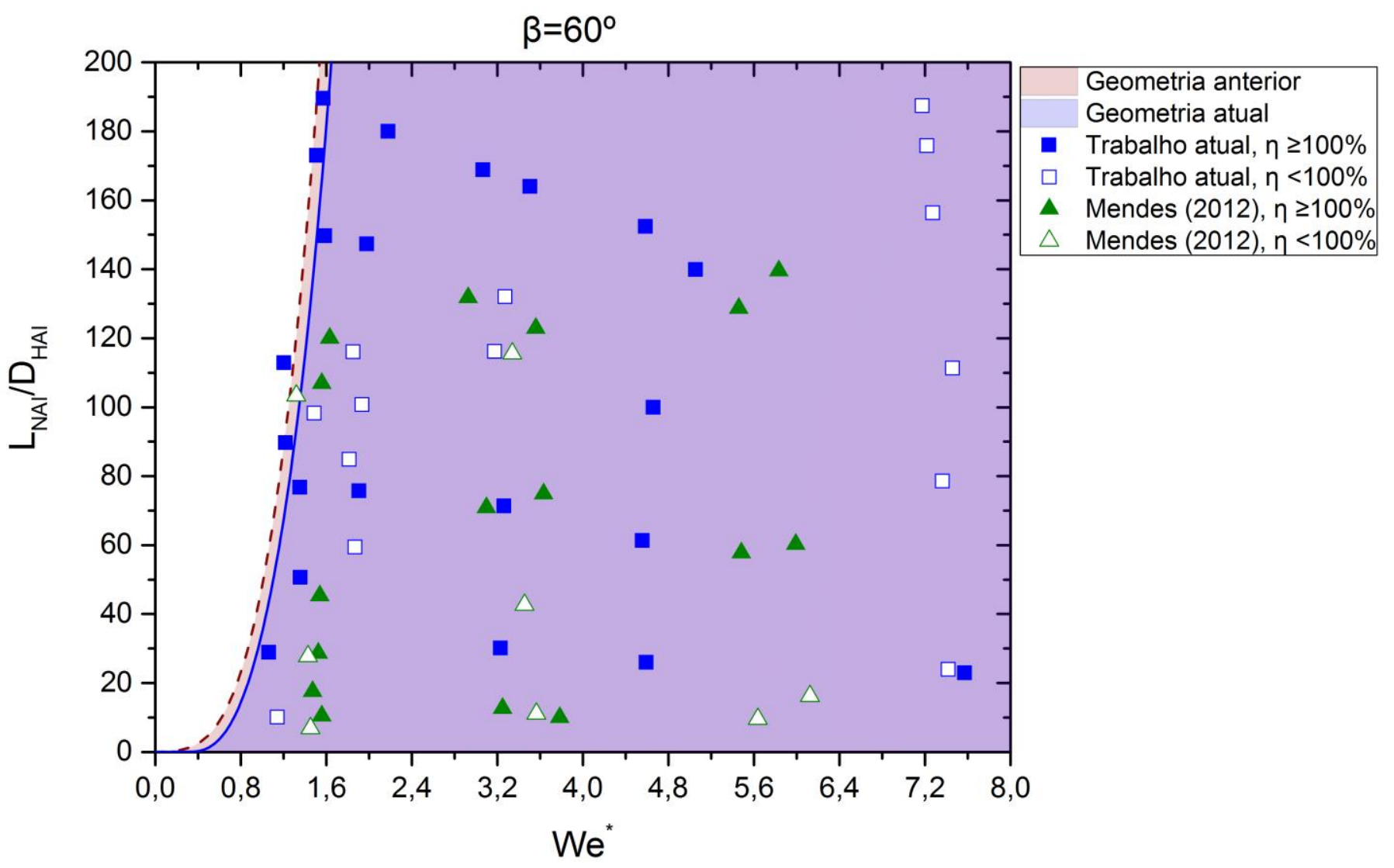

Figura 5.21 - Carta de eficiência de separação em termos do comprimento $L_{N A I}$ adimensional pelo número de Weber ajustado $\left(W e^{*}\right)$ do escoamento ar-óleo, para a inclinação de $60^{\circ}$, com os dados experimentais obtidos no trabalho atual e no trabalho de Mendes (2012).

\subsection{ESTUDO DA DISTRIBUIÇÃO DE DIÂMETROS DE BOLHA}

A seção de testes apresentada no Capítulo 4, com as alterações descritas na seção 4.3, foi utilizada para a aferição da distribuição de diâmetros de bolhas no duto anular interno, abaixo do $L_{N A I}$. Os dados foram obtidos em condições de regime permanente, realizando as mesmas medições dos dados de eficiência de separação de gás. Devido a restrições de tempo, foi possível obter apenas três pontos experimentais, utilizando a seção de testes a uma inclinação de $\beta=45^{\circ}$. A vazão $Q_{l}$ utilizada foi igual a $601 / \mathrm{min}$, suficiente para gerar bolhas com diâmetro de aproximadamente $58 \mu \mathrm{m}$, de acordo com o modelo fenomenológico (Figura 4.32).

A medição da distribuição do diâmetro médio de bolhas foi feita com três posições diferentes do $L_{N A I}$, obtendo-se assim três pontos experimentais distintos. As Figuras 5.22 a 
5.24 mostram três distribuições aferidas, separadas de acordo com a distância $L_{\text {lente }}$, entre a lente da sonda ORM e o ponto em que as bolhas são geradas, ou seja, o choque entre o escoamento em superfície livre e o líquido decantado. A distância é igual ao $L_{N A I}$ subtraído da distância fixa entre a luva de acoplamento do ORM e o fundo do tubo de produção, como mostrado na Equação (5.6).

$$
L_{\text {lente }}=L_{N A I}-0,70 \mathrm{~m}
$$

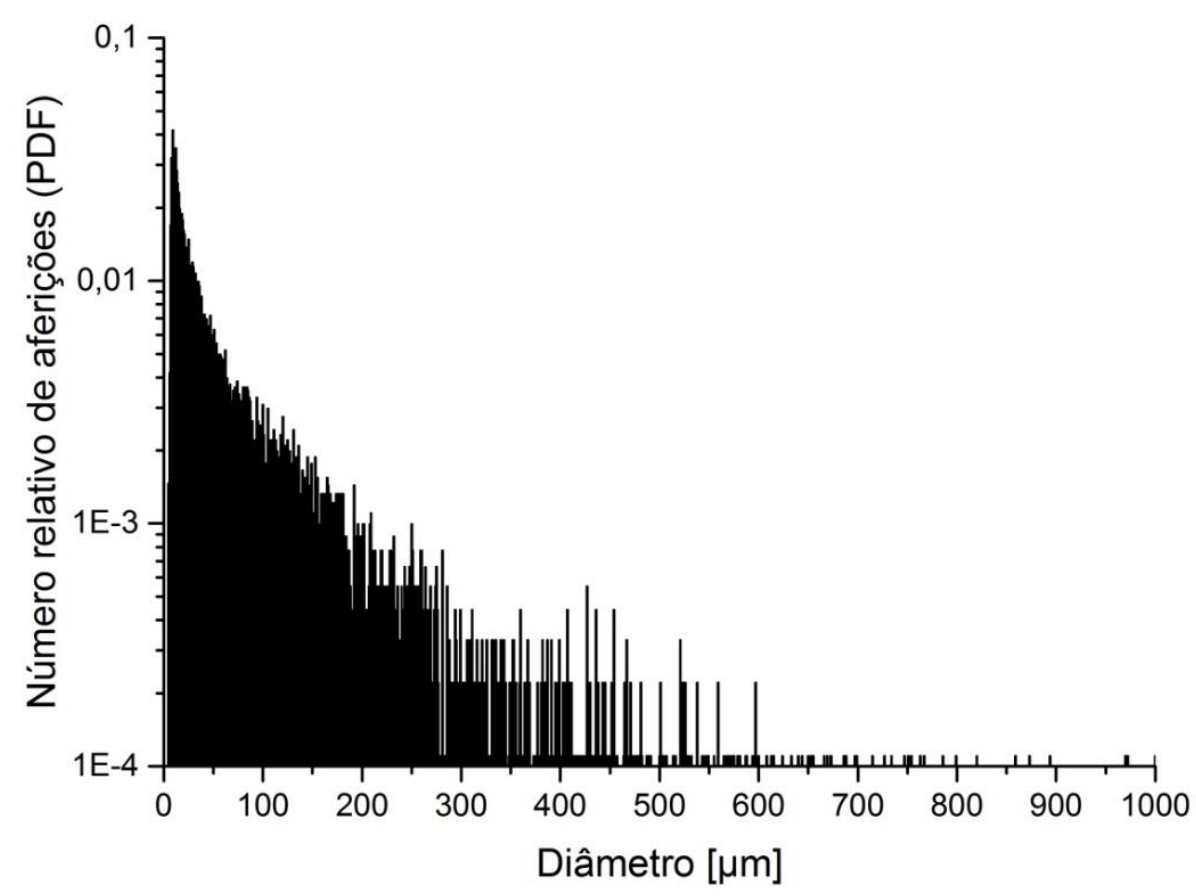

Figura 5.22 - Distribuição de diâmetros de bolhas com distância $L_{l e n t e}=2,92 \mathrm{~m}$. 


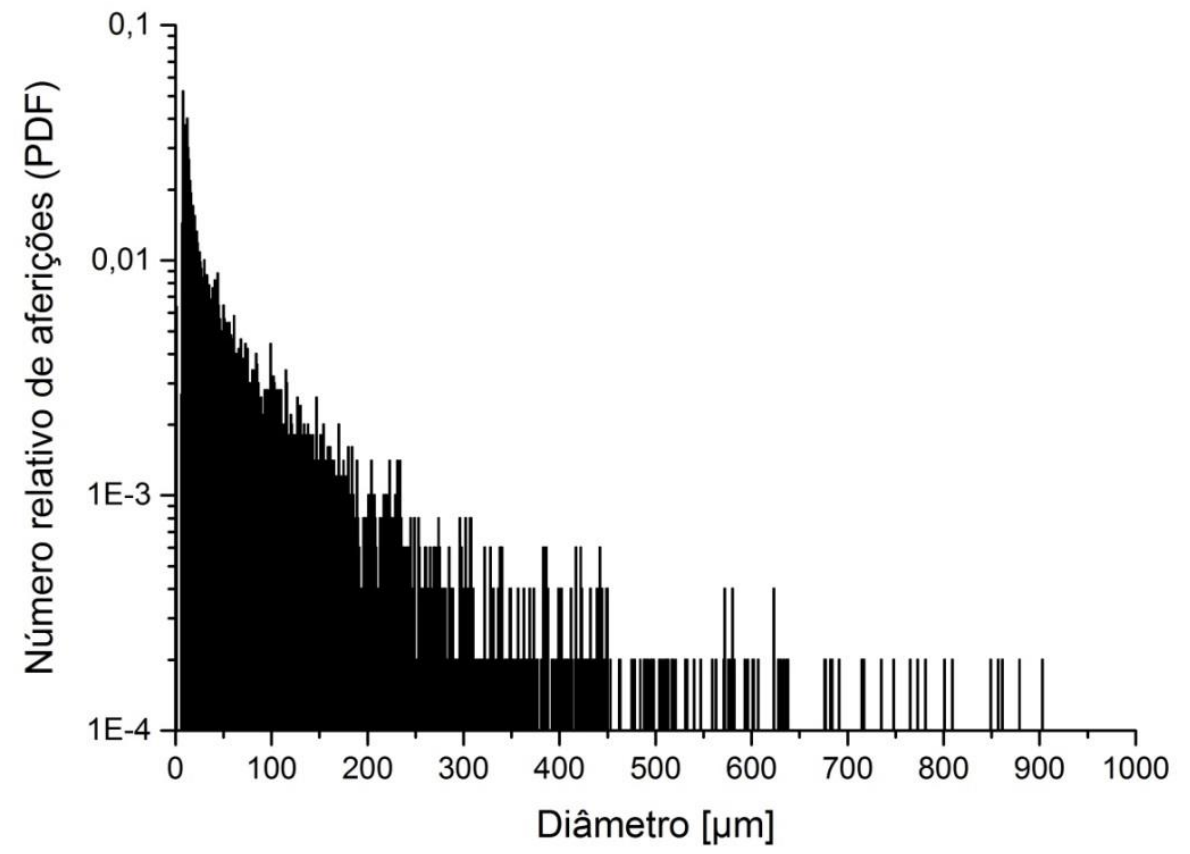

Figura 5.23 - Distribuição de diâmetros de bolhas com distância $L_{\text {lente }}=2,70 \mathrm{~m}$. 


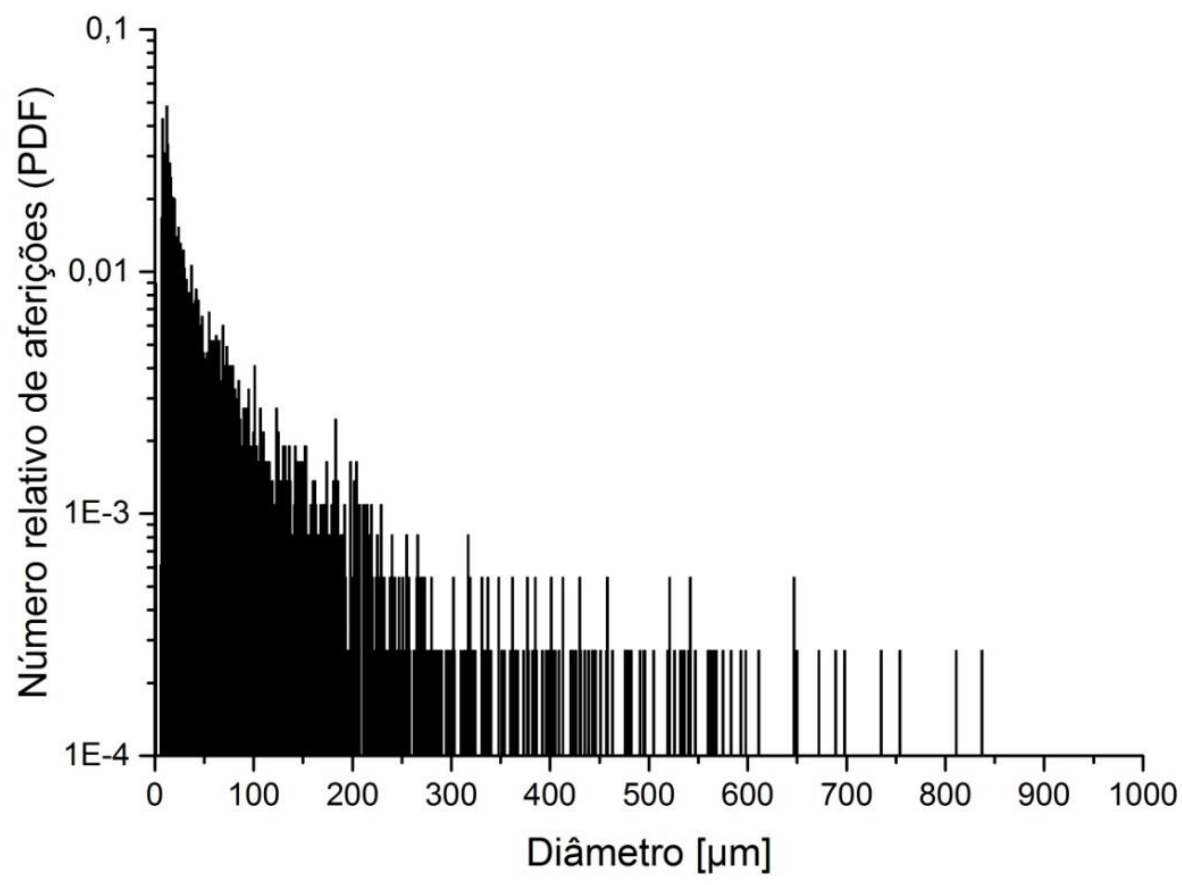

Figura 5.24 - Distribuição de diâmetros de bolhas com distância $L_{\text {lente }}=1,43 \mathrm{~m}$.

A partir dos dados pode-se utilizar três formas diferentes de calcular um diâmetro médio, que seja representativo das distribuições. O diâmetro Sauter, como já discutido, pode ser comparado com outros diâmetros sugeridos por Evans et al. (1992). Transformando os histogramas em gráficos da frequência cumulativa de aferições, podemos também aplicar o critério de diâmetro máximo (diâmetro maior que o de $99 \%$ das partículas da distribuição), como apresentado na Seção 2.3. Com isto, temos as Figuras 5.25 a 5.27. 


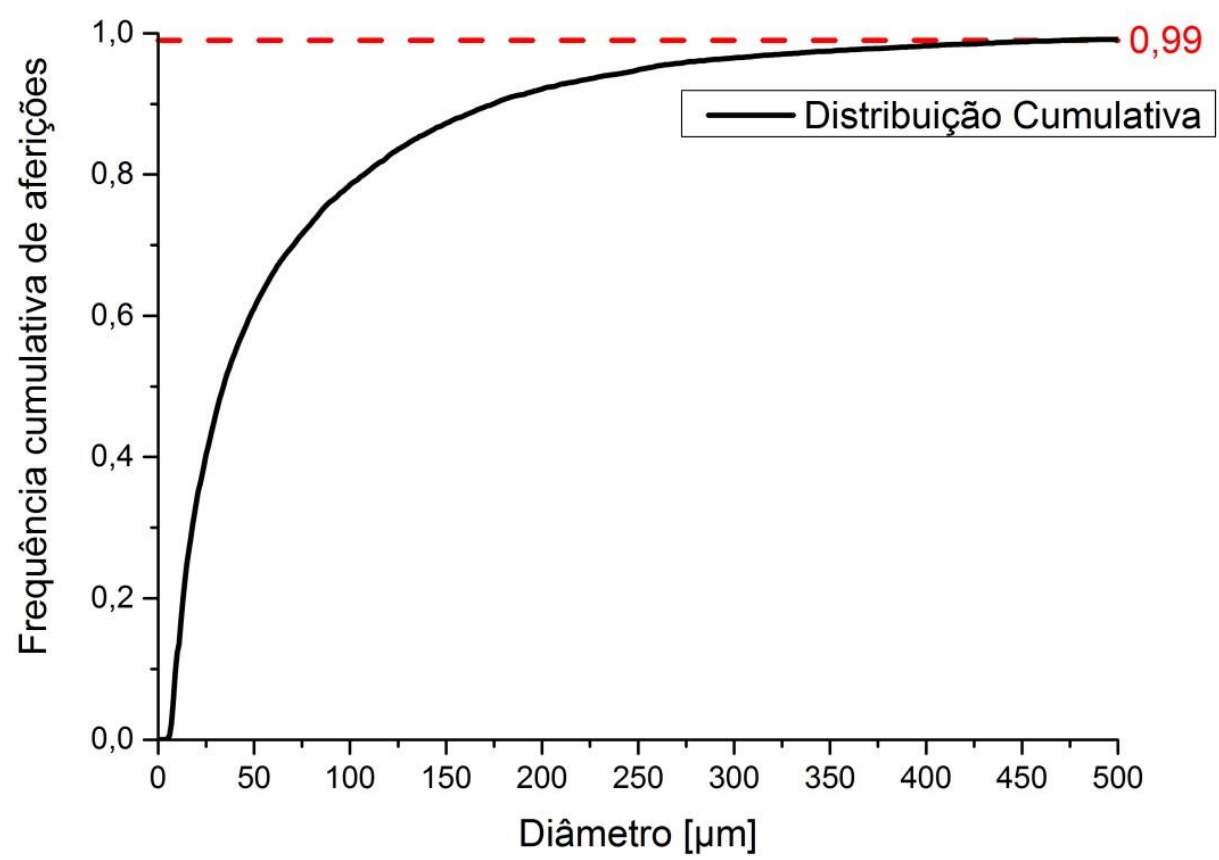

Figura 5.25 - Frequência cumulativa de aferições com $L_{\text {lente }}=2,92 \mathrm{~m}$.

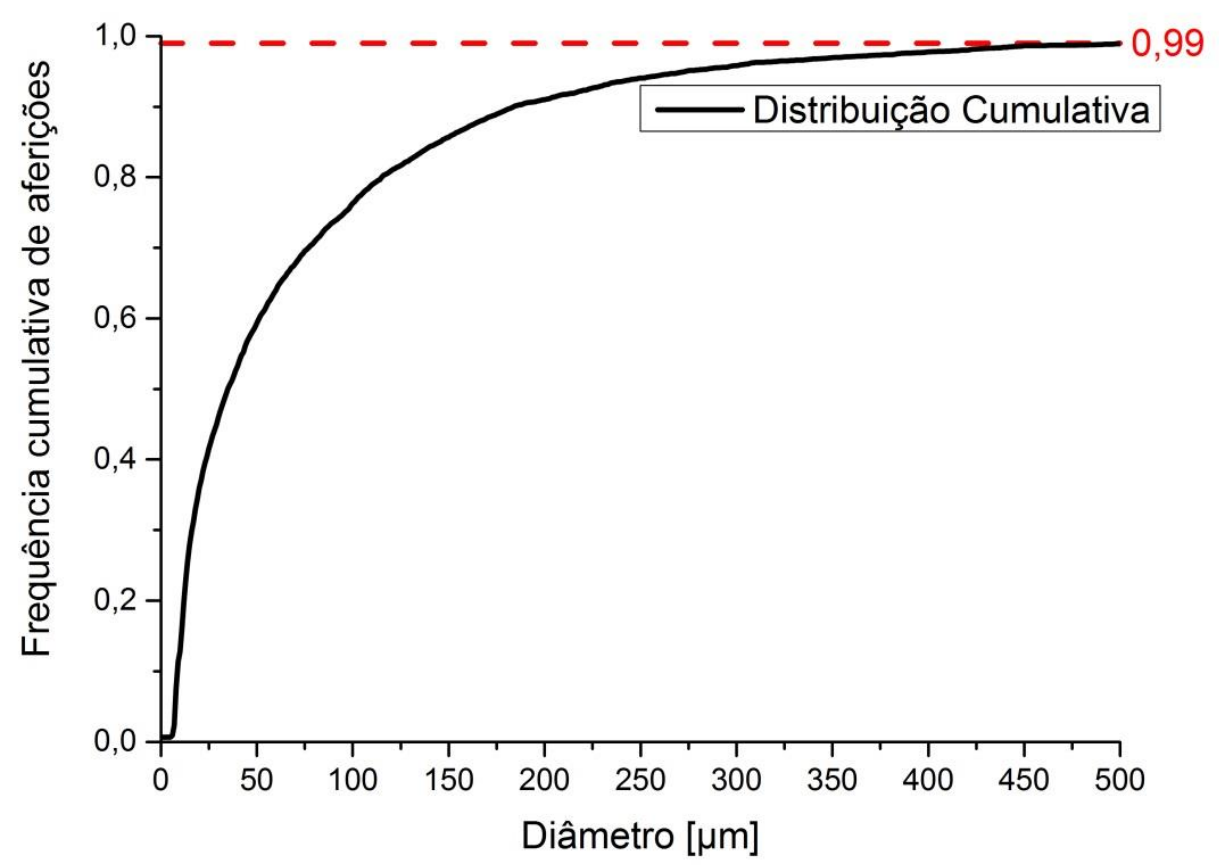

Figura 5.26 - Frequência cumulativa de aferições com $L_{\text {lente }}=2,70 \mathrm{~m}$. 


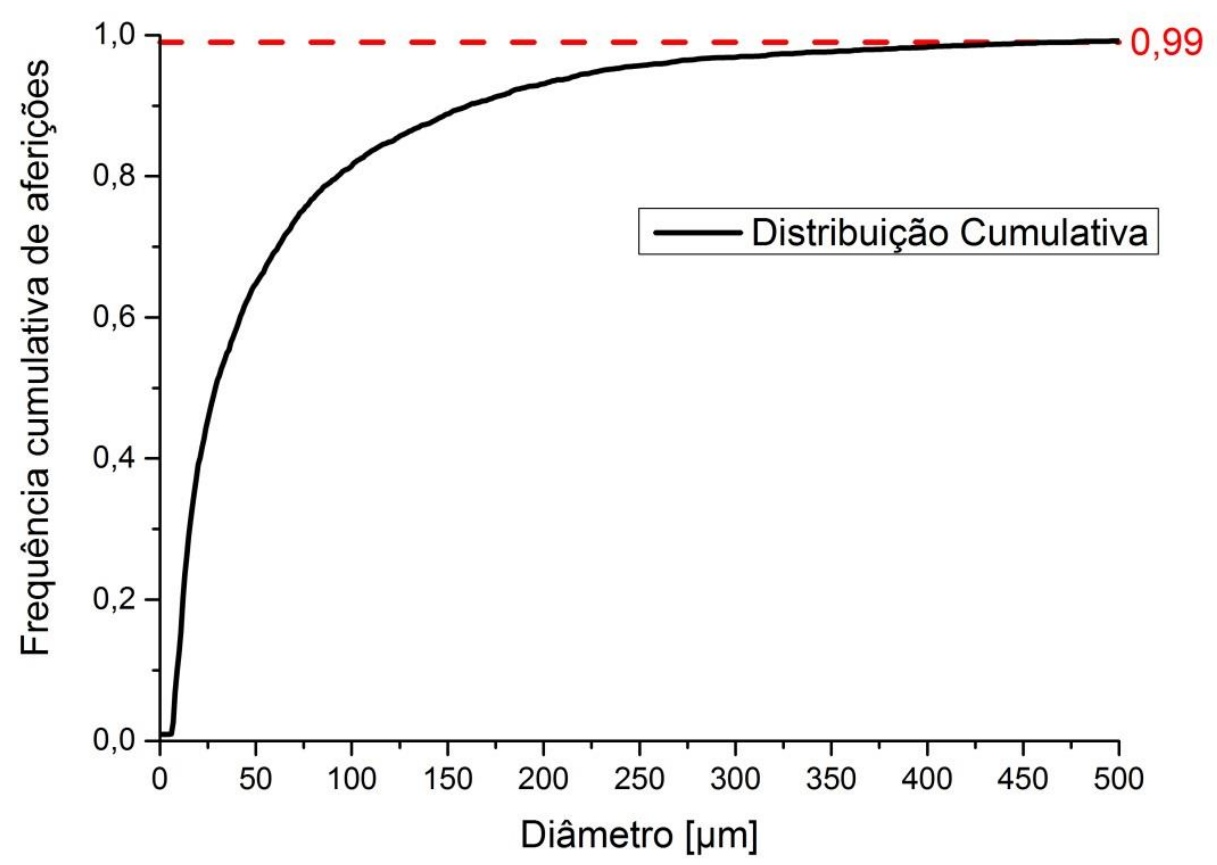

Figura 5.27 - Frequência cumulativa de aferições com $L_{\text {lente }}=1,43 \mathrm{~m}$.

Por fim, com os dados aferidos, temos a Tabela 5.2:

Tabela 5.2 - Dados obtidos através das distribuições de diâmetros de bolha

\begin{tabular}{cccccc}
\hline Teste & $\boldsymbol{L}_{\text {lente }}[\boldsymbol{m}]$ & $\boldsymbol{d}_{\text {médio }}[\boldsymbol{\mu m}]$ & $\boldsymbol{d}_{\text {Sauter }}[\boldsymbol{\mu m}]$ & $\boldsymbol{d}_{\text {máximo }}[\boldsymbol{\mu m}]$ & $\frac{\boldsymbol{d}_{\text {Sauter }}}{\boldsymbol{d}_{\text {máximo }}}$ \\
\hline \hline 01 & 2,92 & 70,43 & 382,37 & 471 & 0,81 \\
02 & 2,70 & 75,92 & 399,55 & 512 & 0,78 \\
03 & 1,43 & 64,70 & 349,23 & 476 & 0,73 \\
\hline \hline
\end{tabular}

Pode-se observar, à primeira vista, que o diâmetro máximo aferido se encontra muito acima do diâmetro máximo previsto de $58 \mu \mathrm{m}$ para esta vazão de líquido $\left(Q_{L}=60 \mathrm{l} / \mathrm{min}\right)$, obtido com o modelo fenomenológico pela Equação (3.6). Com isto se observa uma grande discrepância entre o diâmetro esperado e o que foi medido, o que sugere que esta parte da modelagem fenomenológica apresenta uma previsão incorreta e teria que ser reavaliada. $\mathrm{O}$ uso de correlações ajustadas experimentalmente, no entanto, permite que o modelo possa 
ainda assim ser utilizado no projeto de separadores gravitacionais. É importante ressaltar também que, nos testes apresentados, não foi observado um diâmetro único com o uso de vazão constante. Isto sugere que é necessário aferir o diâmetro de bolhas com uma variação grande do $L_{N A I}$ para uma mesma vazão, a fim de caracterizar o escoamento das bolhas. Tais informações serão úteis no aprimoramento da modelagem fenomenológica.

Não foi possível caracterizar o escoamento desta forma, até o presente momento, devido à falta de uma tendência observável na relação entre um diâmetro médio de bolha e a medida $L_{\text {lente }}$. Os resultados da razão entre $d_{\text {Sauter }}$ e $d_{\text {máximo }}$, no entanto, são congruentes com os resultados de Evans et al. (1992), que propuseram este fator adimensional para caracterizar um escoamento gás-líquido em que há geração de bolhas. É também possível notar que o diâmetro médio $d_{\text {médio }}$ aferido é semelhante ao valor esperado pelo modelo, ao contrário do valor $d_{\text {máximo }}$, como mostra a Figura 5.28 abaixo.

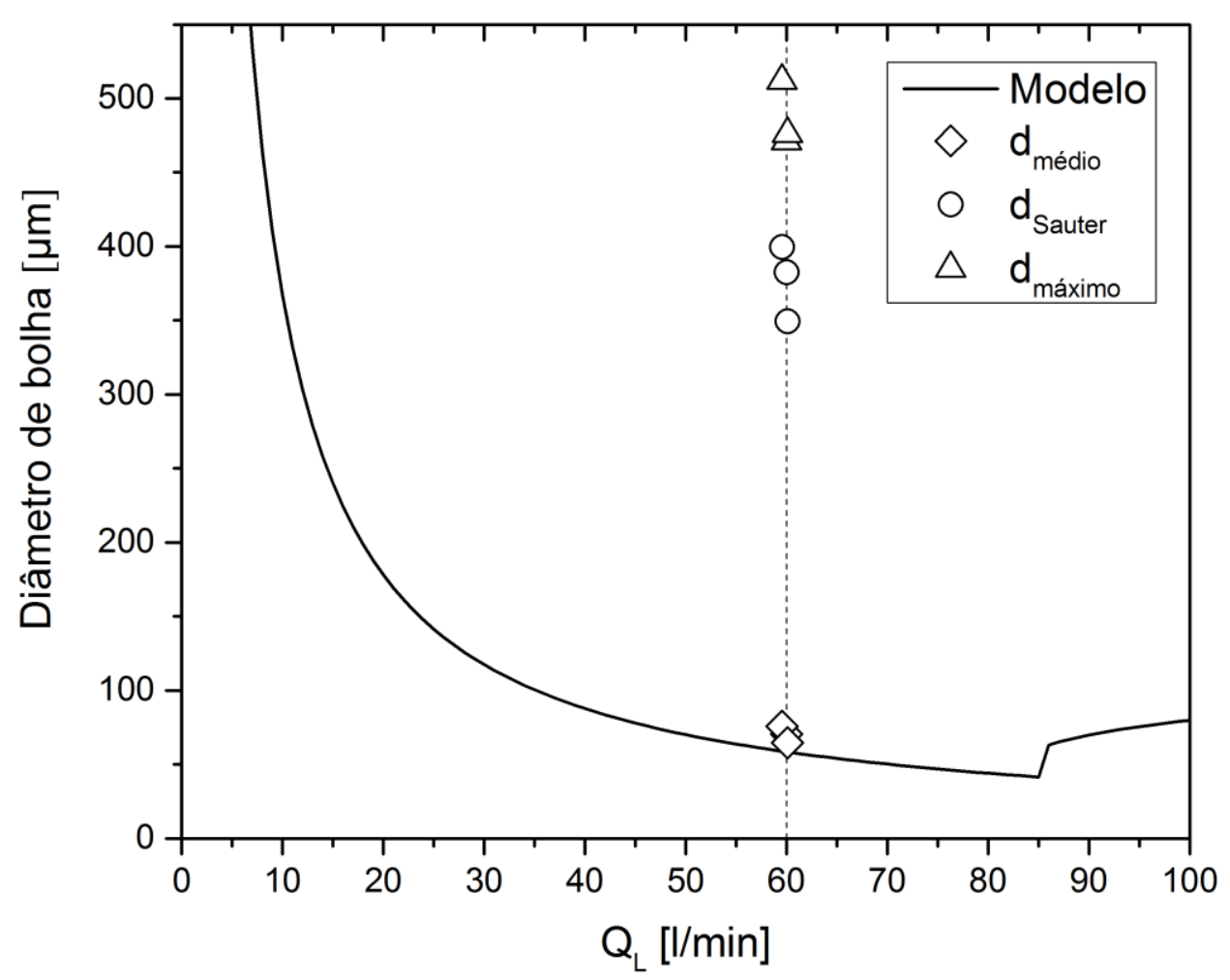

Figura 5.28 - Pontos experimentais sobrepostos à curva de diâmetros de bolha previstos pelo modelo fenomenológico. 


\subsection{ENSAIOS DE AFOGAMENTO (AR-ÁGUA)}

Dados experimentais para o estudo do fenômeno de afogamento foram obtidos com o mesmo procedimento utilizado nos estudos da eficiência de separação de gás, mas com vazões maiores que 200 1/min. Os dados estão dispostos na Figura 5.29 abaixo.

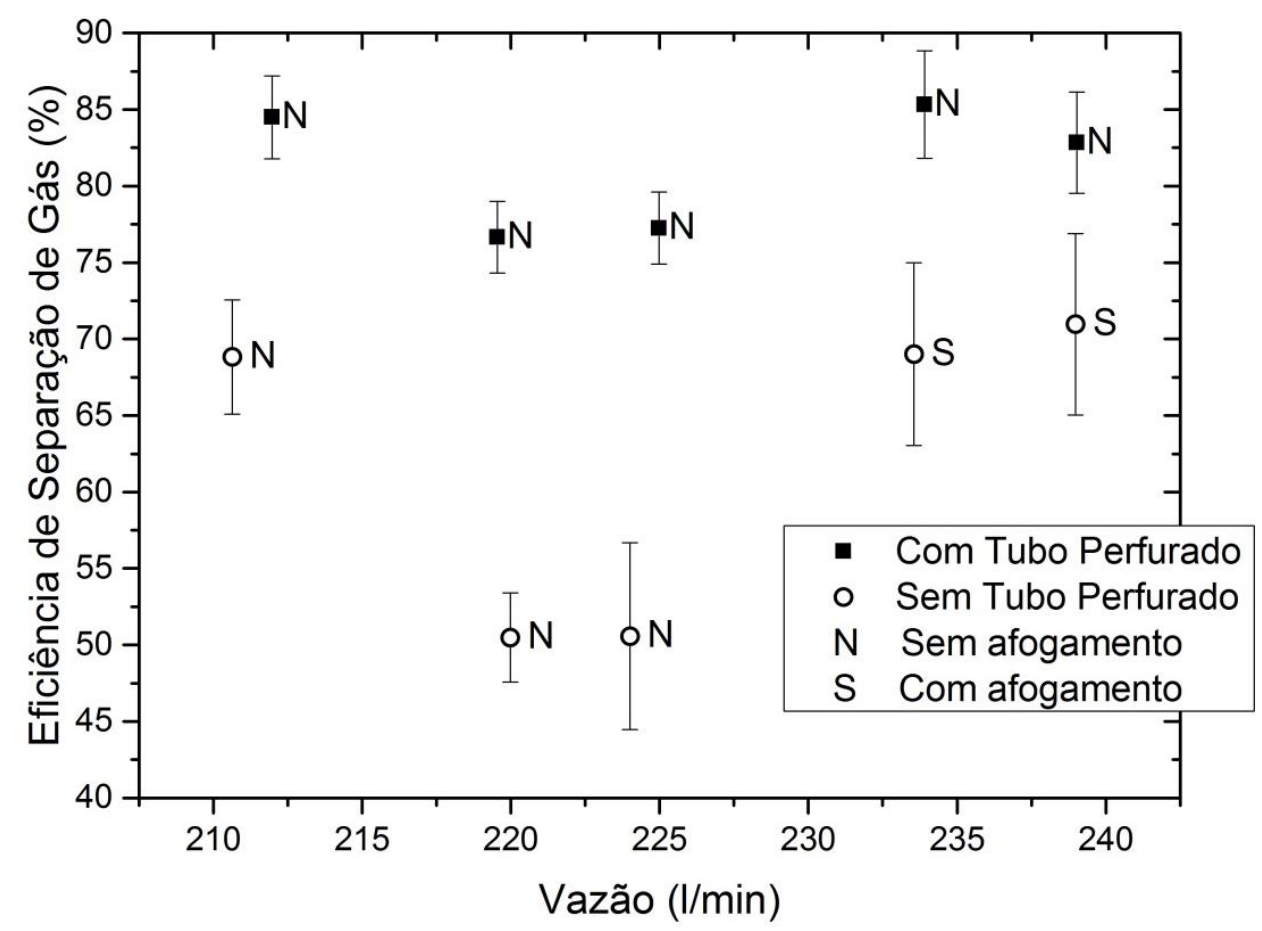

Figura 5.29 - Eficiências de separação de gás medidas em função das vazões nos testes de afogamento.

É possível observar visualmente durante o experimento que, na primeira geometria utilizada neste trabalho (Tabela 4.3), o fenômeno de afogamento começa a ocorrer em vazões próximas a 230 1/min. O mesmo fenômeno não foi observado após a inserção do tubo perfurado na seção de testes, corroborando a proposta de Bohorquez et al. (2007). Como buscou-se manter o mesmo NAI entre os mesmos conjuntos de pontos, é possível observar também uma tendência de aumento da eficiência de separação de gás após a instalação do tubo perfurado. 


\subsection{OBSERVAÇÕES QUALITATIVAS}

\subsubsection{Separação de Gás}

a. A viscosidade do óleo afeta os resultados experimentais de maneira significativa. As variações de temperatura ao longo do dia em que se realiza uma bateria de testes podem influenciar o estudo e devem ser levadas em conta, inclusive para o ajuste das constantes do modelo fenomenológico.

b. Houve alguma variação nas medidas de eficiência de separação de gás devido ao acionamento e desligamento do compressor, o que pode ter gerado erros aleatórios nas medidas. A interface em LabVIEW® foi configurada para registrar dados ao longo de um período grande de tempo (100 segundos), na tentativa de mitigar este efeito.

c. A medição do diâmetro de bolhas no separador teve resultados fora do esperado pelo modelo fenomenológico. No entanto, é de se esperar que o modelo tenha coerência com os dados de eficiência de separação, já que foi ajustado experimentalmente por Mendes (2012). Devido a restrições de tempo, não foi possível aprofundar o estudo, com medições do diâmetro de bolha em uma gama maior de inclinações, vazões e posições do NAI.

\subsubsection{Afogamento}

d. Na seção superior do shroud, em que ocorre o fenômeno de afogamento, pode-se observar a entrada do líquido em um perfil previsível conhecido como curva "S". Isto pode ser utilizado em um modelo fenomenológico para prever a vazão máxima antes que ocorra o afogamento.

e. Um aumento na eficiência de separação de gás pôde ser verificado nos dados coletados com o uso do tubo perfurado. Isto pode ser causado por uma redução na velocidade do escoamento em superfície livre. 


\section{CAPÍTULO 6 CONCLUSÕES E PERSPECTIVAS}

Neste trabalho foi estudado o separador gravitacional de fundo de poço tipo Shroud invertido. Após uma breve revisão da literatura, foi apresentado e analisado um modelo fenomenológico que pode ser utilizado para prever a eficiência de separação do aparato. Estudos experimentais foram realizados, descritos e discutidos, corroborando a potencialidade do uso de separadores gravitacionais em equipamentos de elevação de petróleo baseados em bombeamento centrífugo submerso (BCS). Nesta seção serão apresentadas as conclusões gerais, bem como algumas sugestões para trabalhos futuros.

\subsection{CONCLUSÕES:}

a. O modelo fenomenológico se comporta adequadamente quando considerada a necessidade de se estar a favor da segurança, mas poderia ser melhor ajustado para evitar superdimensionamento do separador.

b. A mudança de tendência da fronteira de eficiência de separação de gás prevista pelo modelo, devido à transição laminar-turbulenta do escoamento no duto anular (após o choque entre o escoamento em superfície livre e o líquido decantado), foi verificada por alguns pontos experimentais. Nos pontos vizinhos é observada a total separação de gás, o que mostra que esta região do modelo pode ter um $L_{N A I}$ mínimo consideravelmente superdimensionado.

c. O modelo fenomenológico apresenta falhas na previsão do diâmetro de bolhas geradas pelo choque turbulento no duto anular interno do separador. A equação utilizada para prever este diâmetro pode ser ajustada experimentalmente com o uso de dados semelhantes aos apresentados neste trabalho, porém obtidos em uma gama mais abrangente de condições operacionais.

d. O fenômeno de afogamento foi mitigado com sucesso nos testes realizados através do uso de um tubo perfurado devidamente projetado para esse fim. 


\subsection{ESTUDOS FUTUROS:}

a. Aferição de dados de eficiência de separação de gás (ESG) utilizando o separador na posição vertical. Trabalhos anteriores demonstram que a fenomenologia atual falha em prever o comportamento de separadores tipo shroud invertido nesta posição, altamente utilizada pela indústria de petróleo;

b. Aferição de dados de ESG utilizando um aquecedor de óleo, para variar sua viscosidade, a fim de ajustar as correlações experimentais atuais em situações mais diversas de viscosidade de óleo.

c. Validação do ORM com bolhas dispersas em um líquido claro, de maior viscosidade, como glicerina. Com bolhas paradas e isoladas seria possível realizar a medição do diâmetro de uma bolha por vez, utilizando várias técnicas diferentes. Outra solução possível seria o uso de partículas sólidas de vários diâmetros conhecidos;

d. Medição de bolhas com ORM ao longo de uma gama maior de comprimentos $L_{N A I}$ para verificar a distribuição do diâmetro de bolhas em diferentes pontos da seção de testes. Gráficos tridimensionais com tais dados ajudariam a compreender melhor o comportamento das bolhas arrastadas para o tubo de produção.

e. As técnicas utilizadas para medição de vazão mássica de gás à jusante e à montante da seção de testes geram incertezas experimentais significativas. Recomenda-se o uso de medidores Coriolis em testes futuros, conjuntamente com um compressor que funcione de forma contínua, para que seja mantido o regime permanente por mais tempo.

f. Medição de ESG em condições constantes de $L_{N A I}$ e $Q_{l}$, variando a vazão mássica de gás. Se a quantia de gás perdido é constante para um determinado valor destas variáveis, uma alteração na vazão mássica de gás poderia surtir mudanças na eficiência medida.

g. Obtenção de perfis de velocidade na zona de separação, após o choque entre a superfície livre e o líquido decantado, para melhor estudar a trajetória percorrida pelas bolhas entranhadas e melhor ajustar a equação de $L_{\text {STOKES }}$. 
h. Aferição de ESG utilizando mistura ar-óleo em vazões maiores, aproveitando as melhorias recentes no aparato experimental que permitem tais condições. 



\section{REFERÊNCIAS BIBLIOGRÁFICAS}

ALHANATI, F. J. S. Bottomhole gas separation efficiency in electrical submersible pump installations. Tulsa, OK: University of Tulsa, 1993.

AZZOPARDI, B. J. Sauter Mean Diameter. Disponível em: <http://dx.doi.org/10.1615/AtoZ.s.sauter_mean_diameter>. Acesso em: 20 set. 2015.

BARBOSA, F. P. Separação Gravitacional em Poços Direcionais: Estudo da Influência de Propriedades Físicas dos Fluidos, Geometria e Padrões de Escoamento. São Carlos SP: [s.n.].

BLANCO, C. P.; ALBIERI, T. F.; RODRIGUEZ, O. M. H. Revisão de modelos para transições de padrão de escoamento gás-liquido em duto anular vertical e horizontal BRAZILIAN CONGRESS OF THERMAL ENGINEERING AND SCIENCES. Anais... Belo Horizonte, MG: ABCM, 2008

BOHORQUEZ, R. et al. Laboratory Testing of Downhole Gas Separators Proceedings of SPE Annual Technical Conference and Exhibition. Anais...Society of Petroleum Engineers, nov. 2007 Disponível em: $<$ http://www.spe.org/ejournals/jsp/journalapp.jsp?pageType=Preview\&jid=EPF\&mid=SPE109532-PA\&pdfChronicleId=09014762801d1fcc >. Acesso em: 16 fev. 2013

BONGIOVANNI, C.; CHEVAILlIER, J. P.; FABRE, J. Sizing of bubbles by incoherent imaging: defocus bias. Experiments in Fluids, v. 23, n. 3, p. 209-216, 1997.

BULGARELLI, N. A. V. Perfuração do separador gravitacional shroud invertido para evitar o fenômeno de afogamento e melhorar o rendimento do separador. São Carlos SP: [s.n.].

CAETANO, E. F.; SHOHAM, O.; BRILL, J. P. Upward Vertical Two-Phase Flow Through an Annulus - Part I: Single-Phase Friction Factor, Taylor Bubble Rise Velocity, and Flow Pattern Prediction. Journal of Energy Resources Technology, v. 114, p. 1, 1992.

CARIOS, E. et al. Experimental Study of a Poor Boy Downhole Gas Separator Under Continuous Gas-Liquid Flow Proceedings of 2013 SPE Artificial Lift Conference Americas. Anais... Society of Petroleum Engineers, maio 2013 Disponível em: $<$ http://www.onepetro.org/mslib/servlet/onepetropreview?id=SPE-165033-MS\&soc=SPE $>$.

Acesso em: 21 jun. 2013

ÇEnGEL, Y. A.; CIMBALA, J. M. Fluids Mechanics - Fundaments and Applications. [s.l.] McGraw-Hill, 2006.

DELMÉE, G. J. Manual de Medição de Vazão. $3^{\text {a }}$ Edição ed.São Paulo: Edgard Blucher, 2003. 
EVANS, G. M.; JAMESON, G. J.; ATKINSON, B. W. Prediction of the bubble size generated by a plunging liquid jet bubble column. Chemical Engineering Science, v. 47, p. 3265-3272, 1992.

GULLIVER, J. S.; THENE, J. R.; RINDELS, A. J. Indexing gas transfer in self-aerated flows. Journal of Environmental Engineering, v. 116, n. 3, p. 503-523, 1990.

HARUN, A. F. et al. A simple model to predict natural gas separation efficiency in pumped wells. SPE Annual Technical Conference and Exhibition, 2000.

HARUN, A. F. et al. A Mechanistic Model To Predict Natural Gas Separation Efficiency in Inclined Pumping Wells. SPE Production and Operations Symposium, 2001.

HARUN, A. F. et al. A Simple Model To Predict Natural Gas Separation Efficiency in Pumped Wells. SPE Production \& Facilities, v.18, n.1, pp.5-12, 2003.

LACKNER, G. The effect of viscosity on downhole gas separation in a rotary gas separator. [s.1.] University of Tulsa, 1997.

LEA, J. F.; BEARDEN, J. L. Effect of gaseous fluids on submersible pump performance. J. Pet. Technol.; (United States), v. 34:12, 1982.

LIU, B.; PRADO, M. State-of-the-art: Literature Review on Natural SeparationTechnical Report TR-03, Artificial Lift Projects-TUALP. Tulsa, OK: [s.n.].

LIU, B.; PRADO, M. Use of Bubble Tracking Method for Modeling Natural Separation EfficiencyTechnical Report TR-08, Artificial Lift Projects-TUALP. Tulsa, OK: [s.n.].

LIU, B.; PRADO, M. Implementation of Bubble Tracking Method for Modeling Natural Separation EfficiencyTechnical Report TR-11, Artificial Lift Projects-TUALP. Tulsa, OK: [s.n.].

LOVICK, J. et al. Drop size distribution in highly concentrated liquid-liquid dispersions using a light back scattering method. Journal of Chemical Technology \& Biotechnology, v. 80, n. 5, p. 545-552, maio 2005.

MARQUEZ, R.; PRADO, M. Classification of the experimental natural separation data according to flow pattern regime TUALP Annual Advisory Board Meeting. Tulsa, OK: [s.n.].

MÁRQUEZ, R.; PRADO, M. Two-phase model for predicting downhole natural separation efficiency. Revista Tecnica de la Facultad de Ingenieria Universidade del Zuliaa, v. 30, p. 344-352, 2007.

MENDES, F. A. A. Estudo experimental, simulação numérica e modelagem fenomenológica da separação gravitacional de gás no fundo de poços direcionais. [s.l.] Universidade de São Paulo, 2012.

ORTIZ-VIDAL, L. E. Separação gravitacional de gás em um duto anular inclinado: estudo experimental e modelagem fenomenológica. [s.l.] Universidade de São Paulo, 2010. 
ORTIZ-VIDAL, L. E. et al. Experimental investigation of gravitational gas separation in an inclined annular channel. Experimental Thermal and Fluid Science, v. 39, n. 0, p. 17-25, 2012.

RONDY, P.; CHOLET, H. J.; FEDERER, I. Optimization of heavy oil and gas pumping in horizontal wells SPE Annual Technical Conference and Exhibition. Anais...1993

SAMBANGI, S. R. Gas Separation Efficiency in Electrical Submersible Pump Installations with Rotary Gas Separators. [s.l.] University of Tulsa, 1994.

SERRANO, J. C. Natural separation efficiency in electric submersible pump systems. [s.l.] University of Tulsa, 1999.

SOMMER, K. Sampling of powders and bulk materials. [s.1.] Springer Science \& Business Media, 2012.

SOUZA, R. DE O. et al. Separador de gás de fundo de poço de alta eficiência Seminario de elevação artificial, escoamento e medição. Anais... Rio de Janeiro, Brasil: PETROBRÁS Petróleo Brasileiro S.A., 2003

VOLKART, P. The mechanism of air bubble entrainment in self-aerated flow. International Journal of Multiphase Flow, 1980.

WESTENDE, J. M. C. V. Droplets in annular-dispersed gas-liquid pipe-flows. Delft: Technische Universiteit Delft, 2008. 



\section{APÊNDICE A INCERTEZAS EXPERIMENTAIS}

Erros aleatórios estão presentes em todos os componentes do sistema de instrumentação descrito no capítulo 4, gerando incertezas experimentais propagadas. A análise destas incertezas pode ajudar a melhorar a precisão dos métodos de medição.

Os mecanismos aqui descritos, retirados de Fox, McDonald e Pritchard (2006) e de Mendes (2012), foram implementados ao software supervisório em plataforma LabVIEW®, descrito anteriormente, para que incertezas excessivas fossem rapidamente percebidas e corrigidas. Neste apêndice será descrito o processo pelo qual foram calculadas as incertezas propagadas, enquanto que as incertezas particulares de cada medidor estão descritas na Tabela 4.2 .

A leitura de uma variável $X$, cuja incerteza conhecida é igual a $\delta X$, pode ser expressa por:

$$
X=X_{\text {medido }} \pm \delta X
$$

em que $X_{\text {medido }}$ é a leitura realizada por um instrumento. Tirando uma única amostra com o sensor em questão, sabe-se que a melhor estimativa de $X$ é $X_{\text {medido, }}$, sendo que a máxima diferença que se pode ter entre os dois valores é $\pm \delta X$.

A incerteza propagada de uma variável calculada pode ser estimada utilizando uma combinação dos efeitos das incertezas das variáveis que a compõem. Para uma variável $X$ composta por outras variáveis $X_{1}$ a $X_{N}$, temos:

$$
X=X_{1}^{a} X_{2}^{b} \ldots X_{N}^{m}
$$

Como mostrado por Mendes (2012), temos:

$$
\frac{\delta X}{X}=\left[\left(a \frac{\delta X_{1}}{X_{1}}\right)^{2}+\left(b \frac{\delta X_{2}}{X_{2}}\right)^{2}+\cdots+\left(m \frac{\delta X_{N}}{X_{N}}\right)^{2}\right]^{\frac{1}{2}}
$$

A fim de simplificar a expressão, temos em termos de incerteza relativa: 


$$
\frac{\delta X}{X}=u_{X}
$$

Logo:

$$
u_{X}=\left[\left(a u_{X_{1}}\right)^{2}+\left(b u_{X_{2}}\right)^{2}+\cdots+\left(m u_{X_{N}}\right)^{2}\right]^{\frac{1}{2}}
$$

A incerteza relativa dos sensores descritos na Tabela 4.2 pode ser determinada através dos valores descritos na última coluna da mesma. Ela é geralmente um valor dado em porcentagem associado ao fundo de escala do sensor (FE), ao valor lido (RD, i.e., Read Data) ou à sua faixa de medição (Span). Para o instrumento que mede a vazão de óleo $\left(Q_{o}\right)$, por exemplo, temos:

$$
u_{Q_{o}}=\frac{1 \% F E}{Q_{o}}=\left(\frac{0,08}{Q_{o}}\right) \%
$$

\section{A.1 Incerteza do medidor de vazão do tipo Placa de Orifício}

O sensor de placa de orifício utilizado na linha de ar à jusante da seção de testes é utilizado, através de cálculos implementados na plataforma LabVIEW®, para medir a vazão mássica de gás, $\dot{m}_{g_{j}}$. A incerteza deste elemento deprimogênio, descrita por Delmée (2003), é calculada através da A.7:

$u_{\dot{m}_{g_{j}}}= \pm \sqrt{u_{C}^{2}+\left(\frac{2 a}{1-a}\right)^{2}\left(u_{D}^{2}\right)+\left(\frac{2}{1-a}\right)^{2}\left(u_{d}^{2}\right)+u_{\varphi}^{2}+\frac{u_{\Delta P}^{2}}{4}+u_{\rho_{j}}^{2}}$

sendo:

$u_{\dot{m}_{g_{j}}}$ a incerteza relativa da medição da vazão mássica de gás;

$u_{C}$ a incerteza relativa sobre o coeficiente de descarga;

$u_{D}$ a incerteza relativa da medição do diâmetro interno do tubo;

$u_{d}$ a incerteza relativa da medição do diâmetro do furo da placa de orifício;

$u_{\varphi}$ a incerteza relativa da medição do fator isentrópico da placa; 
$u_{\Delta P}$ a incerteza relativa de medição da pressão diferencial na placa;

$u_{\rho_{j}}$ a incerteza da massa específica do gás ao passar pela placa de orifício;

$a$ a razão entre o diâmetro da placa de orifício e o diâmetro do tubo no qual a placa está instalada.

\section{A.1.1 Incerteza associada ao coeficiente de descarga}

Como demonstrado por Mendes (2012), para a placa de orifício de 6,6 mm de diâmetro instalada à jusante (que foi a única utilizada neste trabalho) da linha de testes, temos:

$$
u_{C}= \pm 0,43 \%
$$

\section{A.1.2 Incerteza associada ao diâmetro interno do tubo}

Utilizando um paquímetro digital com escala de 0,01-150 mm, Mendes (2012) realizou vinte medidas em posições diferentes do mesmo tubo utilizado neste trabalho. $\mathrm{O}$ desvio padrão obtido foi de $1,1 \times 10^{-4} \mathrm{~m}$, com a medida média do diâmetro igual a 41,39 mm. Com isto, temos:

$$
u_{D}= \pm \frac{2,2 \times 10^{-4}}{41,39 \times 10^{-3}}=0,53 \%
$$

\section{A.1.3 Incerteza associada ao diâmetro do furo da placa}

Através do mesmo procedimento utilizado para determinar a incerteza associada ao diâmetro interno do tubo em que está instalada a placa de orifício, Mendes (2012) determinou a incerteza do diâmetro do furo da placa:

$$
u_{d}= \pm 0,15 \%
$$

\section{A.1.4 Incerteza associada ao fator isoentrópico}

A incerteza do fator isoentrópico $\varphi$, como descrita por Delmée (2003), pode ser considerada igual a: 


$$
u_{\varphi}= \pm 4\left(\frac{\Delta P}{P}\right) \%
$$

em que $\Delta P$ é a pressão diferencial entre as faces da placa e $P$ é a pressão do ar que escoa através da mesma. Ambas as pressões são lidas por transmissores diferenciais de pressão Smar LD 301 com fundo de escala igual a $50 \mathrm{kPa}$, como descrito na Tabela 4.2 pelos itens 14 e 15 . $O$ valor de $P$ deve também ser acrescido do valor da pressão atmosférica, lido pelo barômetro de coluna de mercúrio Princo 453 (17, Tabela 4.2).

\section{A.1.5 Incerteza associada à pressão diferencial}

Como descrito na seção anterior, a pressão diferencial entre as faces da placa é medida pelo transmissor diferencial de pressão Smar LD 301, com faixa de medição entre 1,25 e 50 $\mathrm{kPa}$ como descrito na Tabela 4.2. Com isto, temos:

$$
u_{\Delta P}=\frac{(0,075 \% \text { Span })}{\Delta P}=\left(\frac{3,66}{\Delta P}\right) \%
$$

\section{A.2 Incerteza da vazão mássica de gás através da vazão volumétrica, pressão e temperatura}

Exceto pelo medidor de vazão do tipo placa de orifício, todas as malhas de medição de vazão mássica de gás $\left(\dot{m}_{g}\right)$ do aparato experimental descrito no capítulo 4 utilizam medidores de vazão volumétrica de gás em conjunto com medidores de pressão e temperatura. As leituras da temperatura do gás à jusante $\left(T_{j}\right)$ e à montante $\left(T_{m}\right)$ da linha, além da vazão volumétrica à jusante $\left(Q_{j}\right)$ contam com apenas um medidor para cada variável. Em contrapartida, a fim reduzir a incerteza experimental, as leituras da pressão do gás à jusante $\left(P_{j}\right)$ e à montante $\left(P_{m}\right)$ da linha, além da vazão volumétrica à montante $\left(Q_{m}\right)$ podem ser feitas com dois tipos de sensores para cada variável. Com isto, temos diversas combinações de medidores que podem ser usados para obter a vazão mássica do gás em cada lado da seção de testes. Uma generalização desta medição pode ser demonstrada por:

$$
\dot{m}_{m}=\rho_{m} Q_{m}
$$




$$
\begin{gathered}
\dot{m}_{j}=\rho_{j} Q_{j} \\
u_{\dot{m}_{m}}= \pm \sqrt{\left(\frac{\rho_{m} \delta \dot{m}_{m}}{\dot{m}_{m} \delta \rho_{m}} u_{\rho_{m}}\right)^{2}+\left(\frac{Q_{m} \delta \dot{m}_{m}}{\dot{m}_{m} \delta Q_{m}} u_{Q_{m}}\right)^{2}} \\
u_{\dot{m}_{j}}= \pm \sqrt{\left(\frac{\rho_{j} \delta \dot{m}_{j}}{\dot{m}_{j} \delta \rho_{j}} u_{\rho_{j}}\right)^{2}+\left(\frac{Q_{j} \delta \dot{m}_{j}}{\dot{m}_{j} \delta Q_{j}} u_{Q_{j}}\right)^{2}}
\end{gathered}
$$

Aplicando a derivada das Equações (A.13) e (A.14), temos:

$$
\begin{gathered}
u_{\dot{m}_{m}}= \pm \sqrt{\left(u_{\rho_{m}}\right)^{2}+\left(u_{Q_{m}}\right)^{2}} \\
u_{\dot{m}_{j}}= \pm \sqrt{\left(u_{\rho_{j}}\right)^{2}+\left(u_{Q_{j}}\right)^{2}}
\end{gathered}
$$

A.2.1 Incerteza das densidades do ar à montante e à jusante da linha

Para obter $u_{\rho_{m}}$ e $u_{\rho_{j}}$, temos através da hipótese de que o ar na linha se comporta como um gás ideal:

$$
\begin{gathered}
\rho_{m}=\frac{P_{m}}{R T_{a b s_{m}}} \\
\rho_{j}=\frac{P_{j}}{R T_{a b s_{j}}}
\end{gathered}
$$

em que $P, R$ e $T_{a b s}$ são, respectivamente, a pressão absoluta do ar, a constante do ar e a temperatura absoluta, cada uma com o subscrito $j$ ou $m$ que indica a montante ou a jusante da seção de testes. Em ambas as partes da linha, temos:

$$
P_{m}=P_{a b s}+P_{m a n_{m}}
$$




$$
P_{j}=P_{a b s}+P_{m a n_{j}}
$$

em que $P_{a b s}$ é a pressão absoluta medida através do barômetro Princo 453 ou pelo transmissor de pressão Novus 961 (para testes com água e para testes com óleo a $15^{\circ}$ ), enquanto $P_{\text {man }}$ e $P_{\text {man }_{j}}$ são as pressões medidas por manômetros localizados à montante e à jusante da seção de testes, respectivamente.

Com isto, temos:

$$
\begin{gathered}
\rho_{m}=\frac{P_{a b s}+P_{m a n_{m}}}{R\left(T_{m}+273,16\right)} \\
\rho_{j}=\frac{P_{a b s}+P_{m a n_{j}}}{R\left(T_{j}+273,16\right)}
\end{gathered}
$$

Finalmente, temos:

$$
\begin{gathered}
u_{\rho_{m}}=\sqrt{\left(\frac{P_{a b s}}{\rho_{m}} \frac{\delta \rho_{m}}{\delta P_{a b s}}\right)^{2} u_{P_{a b s}}^{2}+\left(\frac{P_{m_{m a n}}}{\rho_{m}} \frac{\delta \rho_{m}}{\delta P_{\text {man }_{m}}}\right)^{2} u_{P_{m a n_{m}}}^{2}+\left(\frac{T_{m}}{\rho_{m}} \frac{\delta \rho_{m}}{\delta T_{m}}\right)^{2} u_{T_{m}}^{2}} \\
u_{\rho_{j}}=\sqrt{\left(\frac{P_{a b s}}{\rho_{j}} \frac{\delta \rho_{j}}{\delta P_{a b s}}\right)^{2} u_{P_{a b s}}^{2}+\left(\frac{P_{m_{a n}}}{\rho_{j}} \frac{\delta \rho_{j}}{\delta P_{\text {man }_{j}}}\right)^{2} u_{P_{m a n_{j}}}^{2}+\left(\frac{T_{j}}{\rho_{j}} \frac{\delta \rho_{j}}{\delta T_{j}}\right)^{2} u_{T_{j}}^{2}}
\end{gathered}
$$

Derivando:

$$
\begin{aligned}
& u_{\rho_{m}} \\
& =\sqrt{\left(\frac{P_{a b s}}{P_{a b s}+P_{m_{m a n}}}\right)^{2} u_{P_{a b s}}^{2}+\left(\frac{P_{\text {man }_{m}}}{P_{a b s}+P_{m a n_{m}}}\right)^{2} u_{P_{m a n_{m}}}^{2}+\left(\frac{T_{m}}{273,16+T_{m}}\right)^{2} u_{T_{m}}^{2}}
\end{aligned}
$$




$$
u_{\rho_{j}}=\sqrt{\left(\frac{P_{a b s}}{P_{a b s}+P_{\text {man }_{j}}}\right)^{2} u_{P_{a b s}}^{2}+\left(\frac{P_{\text {man }_{j}}}{P_{a b s}+P_{\text {man }_{j}}}\right)^{2} u_{P_{m a n_{j}}}^{2}+\left(\frac{T_{j}}{273,16+T_{j}}\right)^{2} u_{T_{j}}^{2}}
$$

\section{A.3 Incerteza da eficiência de separação de gás}

Em posse de todas as equações que regem a incerteza das vazões mássicas de gás à montante e à jusante da seção de testes, temos finalmente para a eficiência de separação:

$$
\begin{gathered}
\eta=\frac{\dot{m}_{j}}{\dot{m}_{m}} \\
u_{\eta}= \pm \sqrt{\left(\frac{\dot{m}_{m}}{\eta} \frac{\delta \eta}{\delta \dot{m}_{m}} u_{\dot{m}_{m}}\right)^{2}+\left(\frac{\dot{m}_{j}}{\eta} \frac{\delta \eta}{\delta \dot{m}_{j}} u_{\left.\dot{m}_{j}\right)^{2}}^{2}\right.}
\end{gathered}
$$

Aplicando as devidas derivadas, como demonstrado por Ortiz-Vidal (2010):

$$
u_{\eta}= \pm \sqrt{u_{\dot{m}_{m}}^{2}+u_{\dot{m}_{j}}^{2}}
$$

Aplicando todas as substituições descritas neste apêndice, pode-se obter para qualquer combinação de medidores utilizada a incerteza experimental desejada. Este processo foi implementado no software supervisório do aparato experimental descrito no Capítulo 4, mostrando os resultados em tempo real. 



\section{APÊNDICE B PROPRIEDADES FÍSICAS DO ÓLEO}

O óleo Shell® Vitrea 100, presente no LETeF, foi utilizado em todos os experimentos com a mistura bifásica ar-óleo. Sua massa específica foi medida durante os experimentos com o uso de uma pipeta volumétrica de $50 \mathrm{ml}$ e uma balança cuja precisão é de 0,0005 g.

$$
\rho_{o}=903,6 \mathrm{~kg} / \mathrm{m}^{3}
$$

A viscosidade dinâmica do óleo foi medida com um Reômetro Brookfield® modelo LVDV-III. O aparelho utiliza um disco de superfície plana acoplado ao seu rotor, comprimindo um volume pequeno (aproximadamente $5 \mathrm{ml}$ ) de óleo com o disco contra uma superfície coplanar ao disco para que seja aplicado torque na fina camada de líquido. A temperatura do óleo foi variada de $10{ }^{\circ} \mathrm{C}$ a $45^{\circ} \mathrm{C}$ com o auxílio de um banho termostático acoplado ao reômetro.

Um conjunto de cinco pontos de viscosidade foi aferido a cada $5{ }^{\circ} \mathrm{C}$ de variação na temperatura, para que seja obtida a curva descrita na Figura B.1. Através de uma regressão de quarta ordem na nuvem de pontos, foi obtida uma curva de viscosidade (medida em $\mathrm{cP}$ ) em função da temperatura $T\left(\mathrm{em}^{\circ} \mathrm{C}\right)$ :

$$
\mu_{o}=1607,3 e^{\left(-\frac{T}{11,2}\right)}+39,2
$$




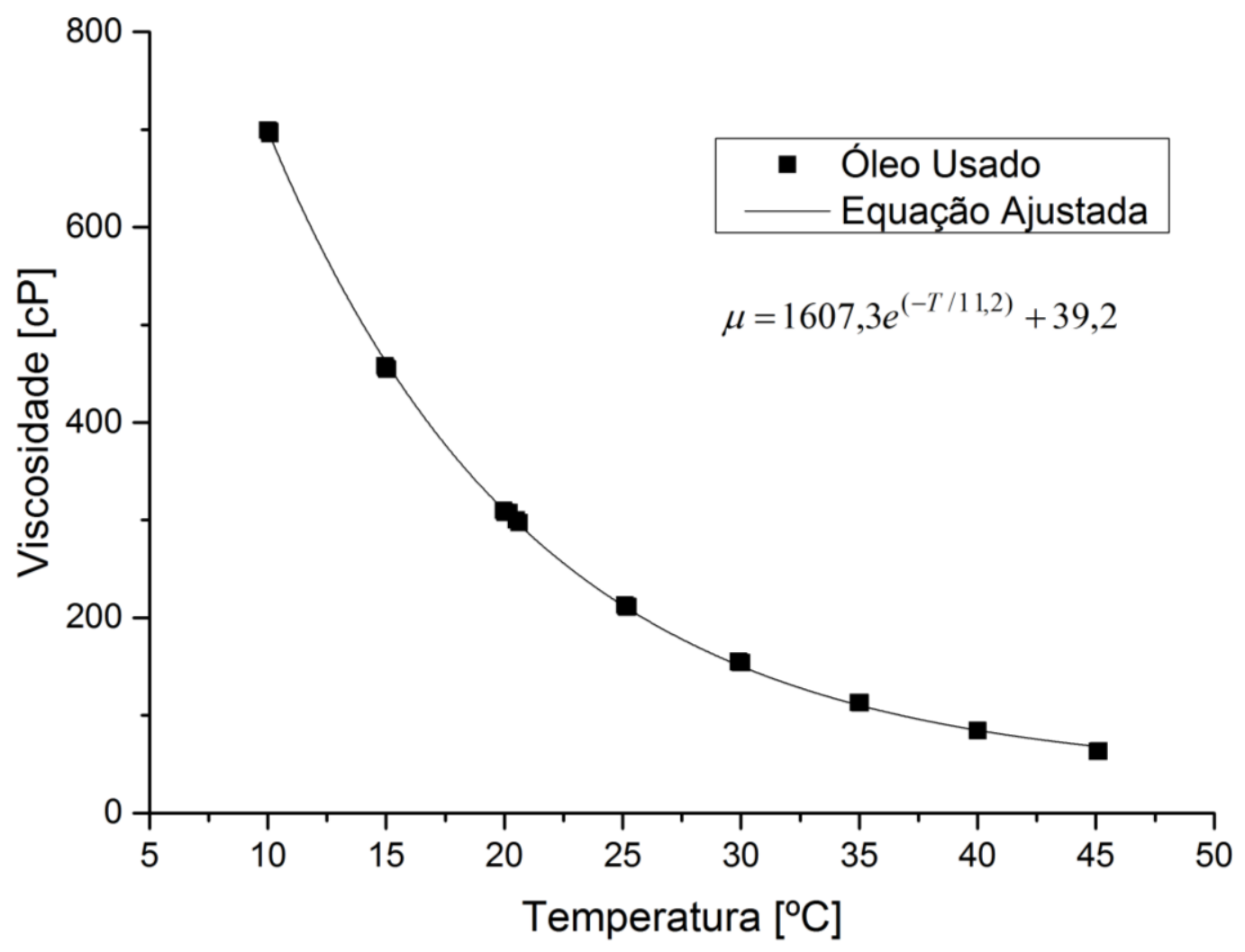

Figura B.1 - Curva de viscosidade dinâmica do óleo Shell Vitrea 100 utilizado vs. Temperatura. 


\section{APÊNDICE C DIAGRAMA DO SOFTWARE SUPERVISÓRIO}

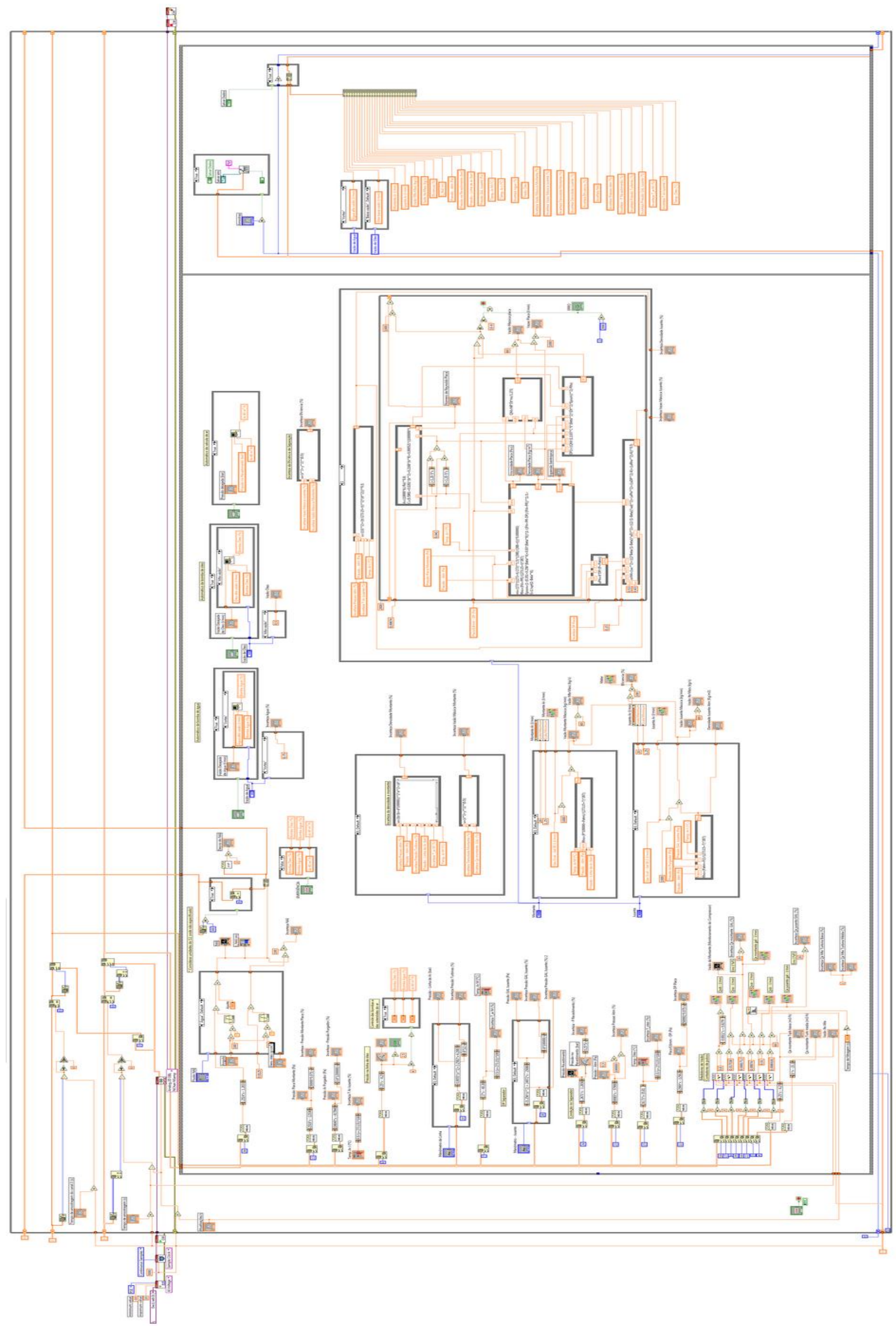

Figura C.1 - Diagrama do software supervisório utilizado para controle da bancada experimental. 



\section{APÊNDICE D DISCIPLINAS CONCLUÍDAS NO MESTRADO E PUBLICAÇÕES}

Tabela D.1 - Disciplinas concluídas durante o mestrado.

\begin{tabular}{|c|c|c|c|c|}
\hline Sigla & Nome da Disciplina & Início & Término & Conceito \\
\hline SEM5749-6/7 & $\begin{array}{l}\text { Mecânica dos } \\
\text { Fluidos }\end{array}$ & $11 / 03 / 2013$ & $23 / 06 / 2013$ & A \\
\hline SEM5740-5/4 & $\begin{array}{l}\text { Matemática para } \\
\text { Engenheiros }\end{array}$ & $14 / 03 / 2013$ & $26 / 06 / 2013$ & $\mathrm{~A}$ \\
\hline SEM5892-7/7 & $\begin{array}{l}\text { Metodologia e } \\
\text { Pesquisa } \\
\text { Bibliográfica }\end{array}$ & 20/03/2013 & 02/07/2013 & A \\
\hline SEM5872-2/3 & $\begin{array}{l}\text { Tópicos Avançados } \\
\text { em Mecânica dos } \\
\text { Fluídos }\end{array}$ & $14 / 08 / 2013$ & $26 / 11 / 2013$ & A \\
\hline SEM5863-9/5 & $\begin{array}{l}\text { Termodinâmica } \\
\text { Clássica }\end{array}$ & $16 / 08 / 2013$ & $28 / 11 / 2013$ & A \\
\hline
\end{tabular}

\section{D.1 Publicações em anais de congressos}

CHAVES, C., ORTIZ-VIDAL, L.E., BARBOSA, M.C., RODRIGUEZ, O.M.H., 2015. Frictional Pressure Drop Prediction in Bubbly Flow in an Annular Duct Using Driftflux Model, IV Journeys in Multiphase Flows (JEM 2015), Campinas - SP, Brasil, 2015.

BARBOSA, M.C., ORTIZ-VIDAL, L.E., RODRIGUEZ, O.M.H., ESTEVAM, V., LOPES, D., 2014. Investigation of Gas Separation in Inverted-Shroud Gravitational Separators of Different Geometries, 15th Brazilian Congress of Thermal Sciences and Engineering (ENCIT 2014), Belém - PA, Brasil 



\section{APÊNDICE E TRABALHO REALIZADO COM A INDÚSTRIA}

As instalações experimentais descritas neste trabalho foram financiadas pela petroleira brasileira PETROBRAS, detentora da patente de separadores gravitacionais de shroud invertido. Juntamente com os estudos experimentais e a modelagem fenomenológica, parte do trabalho se destinou à criação de ferramentas que pudessem auxiliar a PETROBRAS na instalação do separador gravitacional em campo.

De acordo com pedidos de funcionários da PETROBRAS, era necessária uma ferramenta de trabalho em que se pudesse usar os parâmetros do poço (como a geometria das tubulações e a vazão de produção) para obter dados como o comprimento mínimo do Lnai em um separador tipo shroud invertido, sem que fosse necessário conhecimento prévio do modelo fenomenológico. Com isto, foi elaborado um software in-house que pudesse atender a estas demandas.

\section{E.1 Wolfram Mathematica ${ }^{\circledR}$}

A primeira versão do software, desenvolvida em plataforma Wolfram Mathematica, utilizava como base o código que foi utilizado em todas as etapas deste trabalho para geração de gráficos de fronteiras de separação de gás e outros estudos da modelagem. A interface pode ser vista na Figura . 


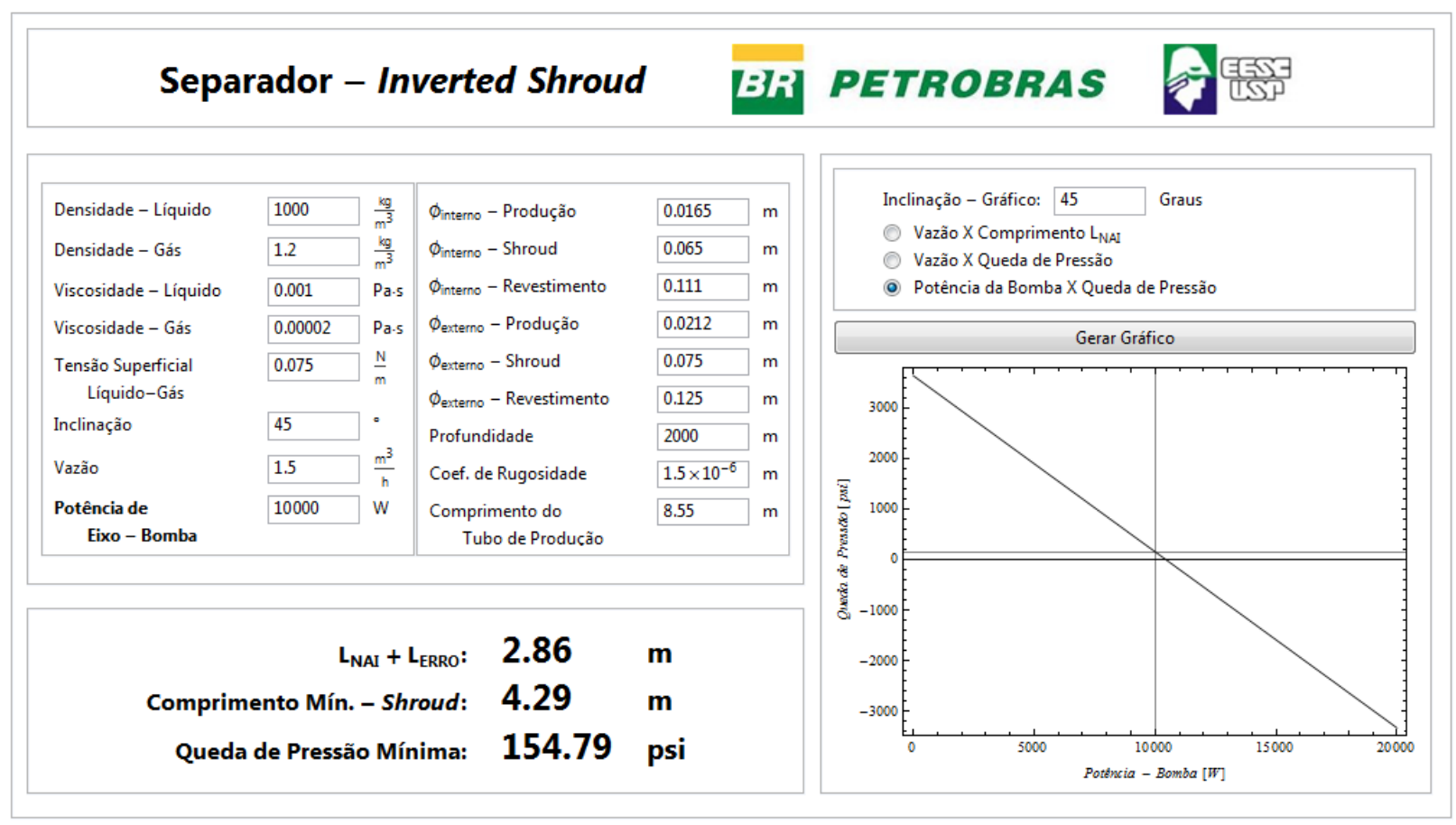

Figura E.1 - Interface do software entregue inicialmente à PETROBRAS.

No painel da esquerda é situada a seção em que o usuário insere todos os dados e condições de trabalho do poço. Abaixo e à direita ficam os dados de saída, calculados através dos dados de entrada, e um gráfico cujos eixos podem ser customizados (de acordo com os eixos acima do gráfico) para que o usuário possa alterar algum parâmetro na tentativa de obter uma condição de trabalho mais vantajosa.

Por usar uma plataforma proprietária (Wolfram Mathematica $\left.{ }^{\circledR}\right)$, cuja licença original deve ser comprada a preços consideráveis, funcionários da PETROBRAS pediram que a ferramenta fosse replicada em código aberto para que pudesse ser instalada em um número ilimitado de computadores. Além deste problema, a execução de um software programado em uma linguagem de alto nível como esta é bastante lenta e pouco robusta em comparação a um software programado em linguagens de baixo nível.

\section{E.2 C++}

Atendendo aos pedidos de funcionários da PETROBRAS, o programa foi replicado em linguagem $\mathrm{C}++$ com sua interface feita na plataforma $\mathrm{C}++$ Builder. A programação tomou como base a interface anterior, tendo sido desta vez programada por Barbosa Pola (2015). Sua interface pode ser vista na Figura . 


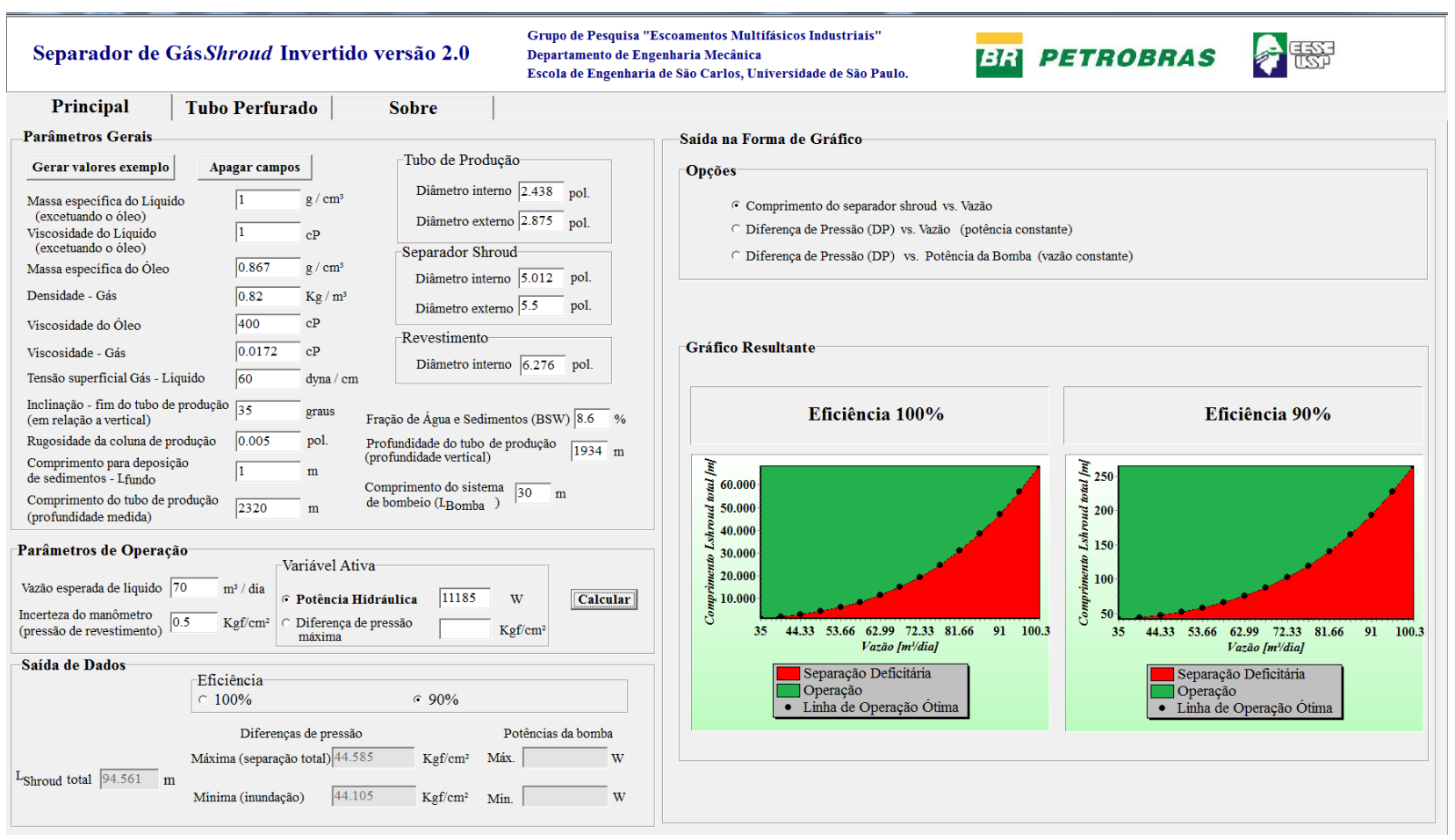

Figura E.2 - Interface da última versão do software entregue à PETROBRAS.

Após uma quantia de iterações no projeto, com ajuda da PETROBRAS, o software recebeu funcionalidades adicionais. Variáveis específicas à engenharia de petróleo, como o fator BSW (Basic Water and Sediments), foram adicionadas ao código para facilitar o trabalho do usuário final. Com isto torna-se possível inserir diretamente na interface do software os dados contidos em relatórios técnicos sem que sejam necessários cálculos adicionais. Após se verificar comprimentos excessivamente grandes do $L_{N A I}$ calculados pelo programa, outro pedido da PETROBRAS foi a adição de uma funcionalidade que permitisse a construção de um Shroud capaz de eficiências de separação de 90\%, valor máximo para que a integridade da BCS não seja comprometida. As curvas do modelo fenomenológico foram ajustadas novamente utilizando-se da mesma metodologia descrita neste trabalho, buscandose ajustar as curvas de todos os estudos experimentais até o presente momento para que ficassem acima dos pontos cuja eficiência de separação de gás ficasse abaixo de $90 \%$.

Adicionalmente, o trabalho de Bulgarelli (2014) gerou um novo modelo de projeto de tubos perfurados para separadores tipo shroud invertido. O modelo foi inserido em uma segunda aba do programa (Figura ), utilizando os dados inseridos na primeira aba além outros novos como a RGO (Razão Gás-Óleo) do poço. Isto possibilitou o cálculo da quantidade de 
furos necessários para reduzir o fenômeno de afogamento em poços com alta vazão de produção.

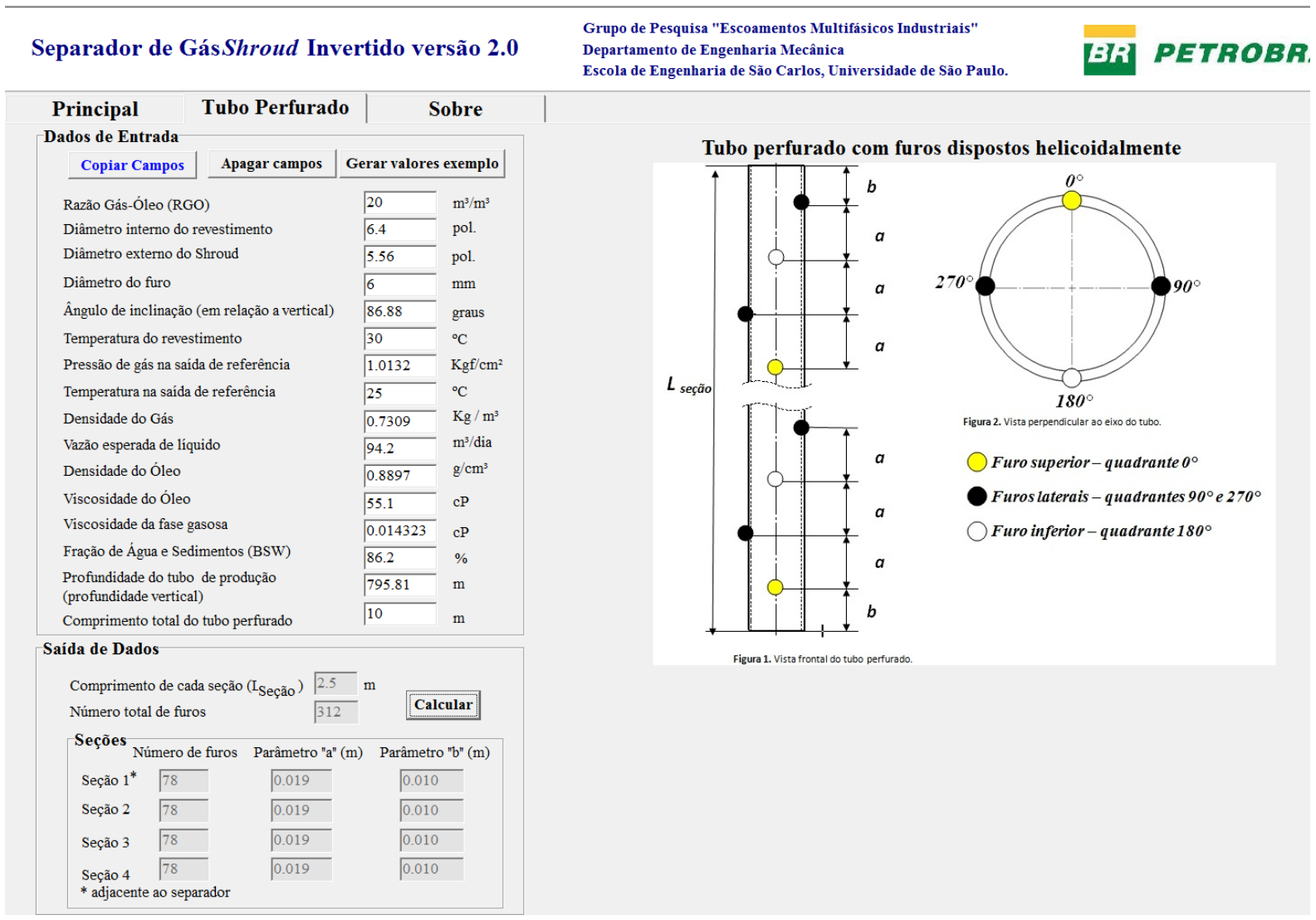

Figura E.3 - Interface da seção do software feita para calcular o número de furos em seções do shroud

Por fim, para facilitar o contato do usuário final com o software, foi elaborado um manual de instruções completo com fluxogramas de tomada de decisões (Figura ) e explicações a respeito de todas as funcionalidades disponíveis. 


\section{Diagrama de Tomada de Decisões - Software de} projeto de separadores tipo Shroud Invertido
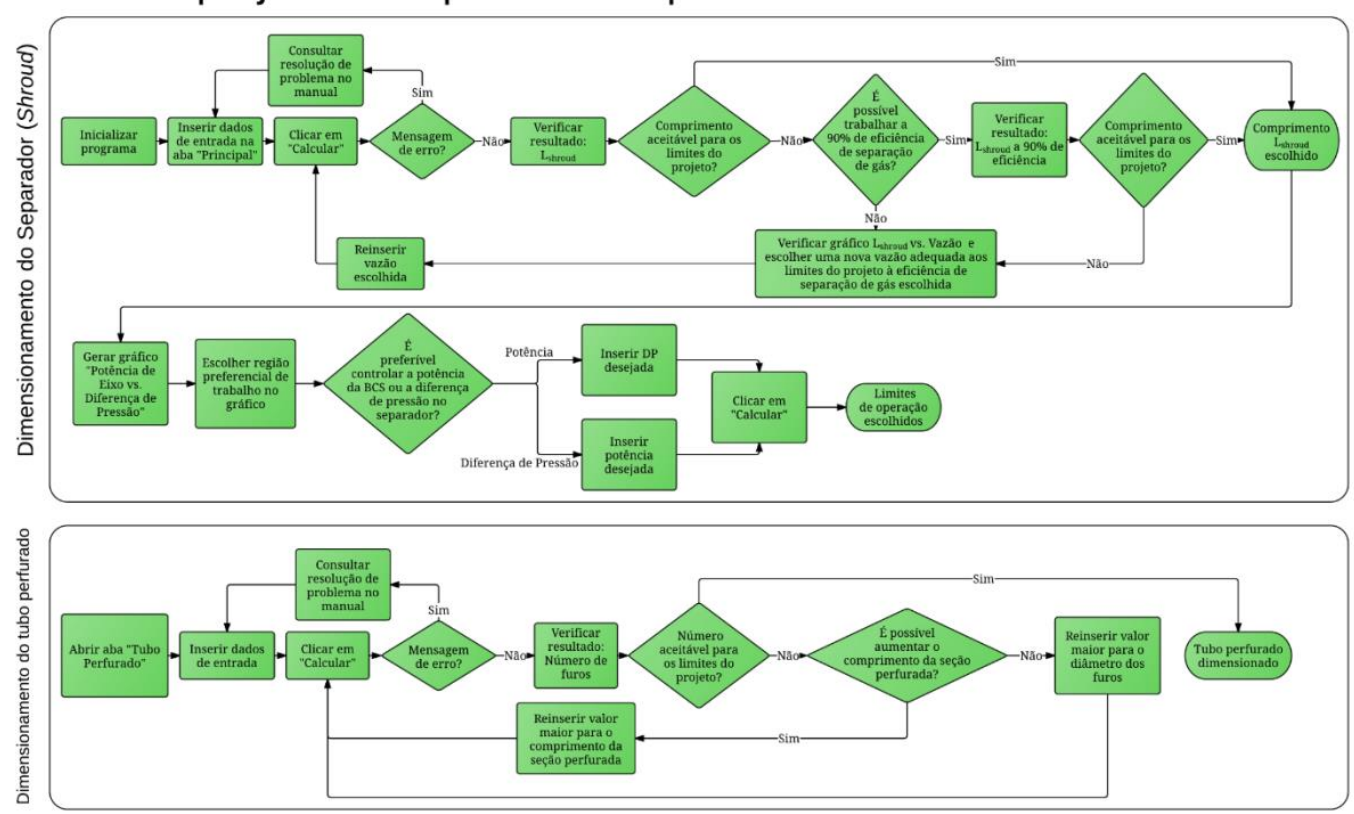

Figura E.4 - Fluxograma de tomada de decisões para orientação do usuário final do software de projeto de separadores tipo shroud invertido.

\section{E.3 Projeto de Separador para instalação em campo}

A fim de iniciar a fase de testes em campo, dois separadores foram projetados utilizando a modelagem atual e estão atualmente em fase de construção para posterior instalação no campo petrolífero de Serra, no Rio Grande do Norte - Brasil. Relatórios técnicos da PETROBRAS contendo todas as informações disponíveis sobre os poços foram disponibilizados para a realização deste projeto. Isto permitiu a identificação de possíveis melhorias no código e na modelagem, todos entregues na versão final do software. A Figura mostra parte do relatório enviado à empresa com os parâmetros de projeto necessários à construção dos separadores. 


\begin{tabular}{|c|c|c|c|}
\hline & $\begin{array}{l}\text { Parâmetros necessários para o projeto do } \\
\text { Separador Shroud }\end{array}$ & $\begin{array}{c}\text { Unidade } \\
*\end{array}$ & Observações \\
\hline \multirow{6}{*}{$\begin{array}{l}n \\
\frac{0}{0} \\
\frac{0}{0} \\
\frac{0}{0} \\
\frac{0}{0} \\
\frac{\pi}{3} \\
\frac{0}{2} \\
\frac{2}{4} \\
\frac{2}{0} \\
\frac{0}{2}\end{array}$} & Massa especifica de liquido (óleo) & adm. & \\
\hline & Densidade do gás & & não há unidade! \\
\hline & Viscosidade do liquido (óleo) & $\mathrm{cP}$ & \\
\hline & Viscosidade do gás & $\mathrm{cP}$ & obtido de simulação \\
\hline & Temperatura do gás no revestimento & ${ }^{\circ} \mathrm{C}$ & \\
\hline & Tensão superficial gás-liquido & Dyna/cm & dado não encontrado \\
\hline \multirow{10}{*}{ 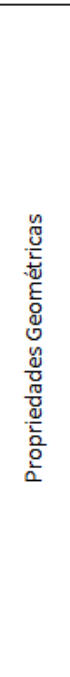 } & Diâmetro interno do revestimento do poço & inch & \\
\hline & Diâmetro externo do tubo de produção & inch & \\
\hline & Diâmetro interno do tubo de produção & inch & \\
\hline & Rugosidade Absoluta do tubo de produção & inch & Gr N80 tipo 1 \\
\hline & $\begin{array}{l}\text { Inclinação do tubo de produção no ponto de } \\
\text { instalação da bomba (com a vertical) }\end{array}$ & $\circ$ & $\begin{array}{l}\text { É onde o separador } \\
\text { será instalado }\end{array}$ \\
\hline & $\begin{array}{l}\text { Comprimento do tubo de produção até o ponto de } \\
\text { instalação da bomba }\end{array}$ & $\mathrm{m}$ & $\begin{array}{l}\text { Partindo da cota } \\
\text { superior (superfície) }\end{array}$ \\
\hline & $\begin{array}{l}\text { Posição vertical até o ponto de instalação do } \\
\text { separdor }\end{array}$ & $\mathrm{m}$ & $\begin{array}{l}\text { Extremidade inferior } \\
\text { do separador } \\
\text { (contando o } \\
\text { comprimento de } \\
\text { decantação) }\end{array}$ \\
\hline & Posição de instalação da bomba & $\mathrm{m}$ & \\
\hline & $\begin{array}{l}\text { Cota desde o nivel de referência (e.g. superficie) } \\
\text { até o inicio do tubo de produção }\end{array}$ & $\mathrm{m}$ & desconsiderar \\
\hline & $\begin{array}{l}\text { Comprimento entre a extremidade inferior do tubo } \\
\text { de produção e o fundo do Shroud (serve, por } \\
\text { exemplo, para acumulação de particulas sólidas) }\end{array}$ & $\mathrm{m}$ & Valores assumidos \\
\hline \multirow{7}{*}{ 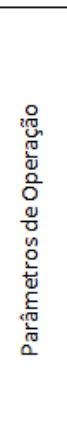 } & Vazão esperada de liquido & $\mathrm{m} 3 / \mathrm{d}$ & \\
\hline & Basic Sediments and Water (BSW) & $\%$ & \\
\hline & Razão Gás-Óleo (RGO) & $\mathrm{m} 3 / \mathrm{m} 3$ & $\begin{array}{l}\text { Calculado a condições } \\
\text { padrão }\end{array}$ \\
\hline & $\begin{array}{l}\text { Fundo de Escala do manômetro que medirá a } \\
\text { pressão de revestimento }\end{array}$ & & \\
\hline & $\begin{array}{l}\text { Precisão do manômetro que medirá a pressão de } \\
\text { revestimento }\end{array}$ & psi & \\
\hline & $\begin{array}{l}\text { Temperatura do gás recuperado (proveniente do } \\
\text { revestimento) }\end{array}$ & ${ }^{\circ} \mathrm{C}$ & $\begin{array}{l}\text { Temperatura } \\
\text { ambiente }\end{array}$ \\
\hline & Pressão do gás recuperado & bar & $\begin{array}{l}\text { Pressão ambiente } \\
\text { absoluta }\end{array}$ \\
\hline
\end{tabular}

Figura E.5 - Dados dispostos no relatório técnico entregue à PETROBRAS para a fabricação de um separador gravitacional tipo shroud invertido a ser utilizado em condições de campo. 


\section{APÊNDICE F DADOS EXPERIMENTAIS}

Tabela F.1 - Dados experimentais obtidos com a mistura bifásica ar-água nos estudos de eficiência de separação de gás.

\begin{tabular}{|c|c|c|c|c|c|c|c|}
\hline$\beta\left[^{0}\right]$ & $\begin{array}{c}Q_{L} \\
{[1 / \mathrm{min}]}\end{array}$ & $\begin{array}{c}\dot{m}_{m} \\
{[\mathrm{~kg} / \mathrm{s}]}\end{array}$ & $\begin{array}{c}\dot{m}_{j} \\
{[\mathrm{~kg} / \mathrm{s}]}\end{array}$ & $\begin{array}{r}L_{N A I} \\
{[\mathrm{~m}]}\end{array}$ & $\begin{array}{c}P_{\text {rev }} \\
{[\text { bar }]}\end{array}$ & $\begin{array}{c}\eta_{\text {shroud }} \\
{[\%]}\end{array}$ & $u_{\eta}[\%]$ \\
\hline 15 & 10,23 & 0,00030 & 0,00030 & 3,40 & $\bar{~} 0,491$ & 999,79 & 3,00 \\
\hline 15 & 10,28 & 0,00030 & 0,00029 & 2,58 & 0,516 & 97,67 & 3,05 \\
\hline 15 & 10,11 & 0,00029 & 0,00029 & 3,00 & 0,518 & 98,09 & 3,08 \\
\hline 15 & 9,68 & 0,00039 & 0,00038 & 3,02 & 0,601 & 97,68 & 2,47 \\
\hline 15 & 9,43 & 0,00039 & 0,00038 & 1,90 & 0,640 & 97,51 & 2,56 \\
\hline 15 & 9,77 & 0,00048 & 0,00047 & 1,19 & 0,742 & 98,43 & 2,17 \\
\hline 15 & 10,05 & 0,00048 & 0,00047 & 1,25 & 0,742 & 98,78 & 2,17 \\
\hline 15 & 9,66 & 0,00048 & 0,00047 & 1,31 & 0,754 & 98,15 & 2,18 \\
\hline 15 & 10,60 & 0,00046 & 0,00045 & 0,91 & 0,778 & 97,90 & 2,29 \\
\hline 15 & 10,08 & 0,00047 & 0,00047 & 0,57 & 0,804 & 99,04 & 2,27 \\
\hline 15 & 10,54 & 0,00047 & 0,00045 & 0,79 & 0,802 & 96,79 & 2,32 \\
\hline 15 & 10,27 & 0,00046 & 0,00045 & 0,80 & 0,804 & 97,65 & 2,33 \\
\hline 15 & 19,91 & 0,00045 & 0,00044 & 2,43 & 0,441 & 98,89 & 2,02 \\
\hline 15 & 20,05 & 0,00037 & 0,00036 & 1,29 & 0,464 & 98,99 & 2,45 \\
\hline 15 & 20,24 & 0,00035 & 0,00035 & 0,97 & 0,475 & 98,16 & 2,56 \\
\hline 15 & 19,98 & 0,00036 & 0,00035 & 0,86 & 0,477 & 97,67 & 2,54 \\
\hline 15 & 19,70 & 0,00035 & 0,00034 & 0,32 & 0,494 & 94,88 & 2,61 \\
\hline 15 & 20,20 & 0,00036 & 0,00035 & 0,28 & 0,497 & 97,50 & 2,52 \\
\hline 15 & 39,74 & 0,00035 & 0,00034 & 1,33 & 0,514 & 98,73 & 2,66 \\
\hline 15 & 40,52 & 0,00034 & 0,00034 & 0,90 & 0,525 & 98,36 & 2,73 \\
\hline 15 & 40,23 & 0,00035 & 0,00033 & 0,40 & 0,538 & 96,76 & 2,74 \\
\hline 15 & 39,45 & 0,00033 & 0,00032 & 0,80 & 0,530 & 96,55 & 2,82 \\
\hline 15 & 59,04 & 0,00033 & 0,00032 & 1,86 & 0,563 & 95,37 & 2,98 \\
\hline 15 & 60,38 & 0,00031 & 0,00031 & 2,49 & 0,541 & 97,79 & 3,08 \\
\hline 15 & 60,68 & 0,00032 & 0,00030 & 1,41 & 0,568 & 95,82 & 3,11 \\
\hline
\end{tabular}




\begin{tabular}{|c|c|c|c|c|c|c|c|}
\hline 15 & $\begin{array}{l}59,37 \\
\end{array}$ & 0,00031 & 0,00030 & 1,52 & 0,565 & 97,36 & 3,17 \\
\hline 15 & 60,03 & 0,00031 & 0,00031 & 1,61 & 0,562 & 97,07 & 3,10 \\
\hline 15 & 59,87 & 0,00031 & 0,00030 & 1,94 & 0,551 & 98,32 & 3,11 \\
\hline 15 & 79,48 & 0,00034 & 0,00033 & 3,33 & 0,701 & 96,02 & 3,12 \\
\hline 15 & 80,26 & 0,00042 & 0,00039 & 2,79 & 0,715 & 93,60 & 2,64 \\
\hline 15 & 79,70 & 0,00041 & 0,00039 & 2,69 & 0,717 & 95,57 & 2,67 \\
\hline 15 & 79,71 & 0,00040 & 0,00038 & 3,83 & 0,689 & 96,06 & 2,70 \\
\hline 15 & 79,82 & 0,00040 & 0,00038 & 3,87 & 0,689 & 95,25 & 2,69 \\
\hline 15 & 79,70 & 0,00035 & 0,00034 & 5,12 & 0,656 & 97,18 & 3,02 \\
\hline 15 & 80,05 & 0,00035 & 0,00034 & 5,09 & 0,655 & 97,76 & 3,03 \\
\hline 15 & 80,34 & 0,00034 & 0,00034 & 7,12 & 0,604 & 97,79 & 2,98 \\
\hline 15 & 80,15 & 0,00033 & 0,00032 & 5,83 & 0,634 & 97,96 & 3,17 \\
\hline 15 & 79,74 & 0,00033 & 0,00032 & 5,55 & 0,642 & 97,57 & 3,17 \\
\hline 15 & 79,39 & 0,00033 & 0,00032 & 4,81 & 0,659 & 97,52 & 3,16 \\
\hline 45 & 10,35 & 0,00412 & 0,00411 & 1,68 & 1,110 & 99,80 & 2,77 \\
\hline 45 & 9,81 & 0,00413 & 0,00416 & 3,74 & 1,012 & 100,76 & 2,77 \\
\hline 45 & 9,88 & 0,00415 & 0,00413 & 2,52 & 1,162 & 99,36 & 2,76 \\
\hline 45 & 10,10 & 0,00414 & 0,00411 & 1,52 & 1,174 & 99,30 & 2,78 \\
\hline 45 & 10,03 & 0,00418 & 0,00411 & 0,82 & 1,285 & 98,25 & 2,74 \\
\hline 45 & 9,69 & 0,00425 & 0,00403 & 0,51 & 1,123 & 94,99 & 2,72 \\
\hline 45 & 14,96 & 0,00426 & 0,00426 & 2,25 & 1,076 & 100,02 & 2,73 \\
\hline 45 & 15,24 & 0,00411 & 0,00413 & 1,20 & 1,151 & 100,45 & 2,80 \\
\hline 45 & 14,83 & 0,00433 & 0,00419 & 0,36 & 1,242 & 96,79 & 2,68 \\
\hline 45 & 20,02 & 0,00428 & 0,00422 & 1,86 & 0,350 & 98,77 & 2,77 \\
\hline 45 & 19,95 & 0,00431 & 0,00424 & 1,73 & 0,359 & 98,41 & 2,75 \\
\hline 45 & 19,97 & 0,00437 & 0,00417 & 0,85 & 0,434 & 95,59 & 2,72 \\
\hline 45 & 19,89 & 0,00428 & 0,00423 & 0,75 & 0,444 & 98,90 & 2,76 \\
\hline 45 & 19,84 & 0,00427 & 0,00424 & 0,99 & 0,435 & 99,20 & 2,77 \\
\hline 45 & 20,07 & 0,00415 & 0,00419 & 1,27 & 0,417 & 101,00 & 2,85 \\
\hline 45 & 20,19 & 0,00436 & 0,00417 & 0,43 & 0,540 & 95,60 & 2,72 \\
\hline 45 & 20,10 & 0,00435 & 0,00427 & 2,06 & 0,409 & 98,37 & 2,73 \\
\hline 45 & 30,18 & 0,00370 & 0,00355 & 1,58 & 0,412 & 96,13 & 3,28 \\
\hline 45 & 30,21 & 0,00364 & 0,00352 & 1,64 & 0,406 & 96,85 & 3,33 \\
\hline
\end{tabular}




\begin{tabular}{|c|c|c|c|c|c|c|c|}
\hline 45 & 30,04 & 0,00369 & 0,00352 & 1,20 & 0,439 & 95,17 & 3,28 \\
\hline 45 & 30,15 & 0,00362 & 0,00350 & 2,50 & 0,342 & 96,83 & 3,36 \\
\hline 45 & 30,14 & 0,00362 & 0,00351 & 3,26 & 0,286 & 96,96 & 3,35 \\
\hline 45 & 29,99 & 0,00374 & 0,00367 & 2,47 & 0,336 & 98,17 & 3,18 \\
\hline 45 & 29,89 & 0,00367 & 0,00363 & 1,92 & 0,375 & 98,75 & 3,22 \\
\hline 45 & 29,94 & 0,00375 & 0,00366 & 1,47 & 0,407 & 97,69 & 3,17 \\
\hline 45 & 30,09 & 0,00373 & 0,00368 & 2,25 & 0,352 & 98,53 & 3,18 \\
\hline 45 & 29,98 & 0,00379 & 0,00371 & 2,57 & 0,330 & 97,84 & 3,13 \\
\hline 45 & 29,88 & 0,00375 & 0,00369 & 2,91 & 0,302 & 98,33 & 3,16 \\
\hline 45 & 30,03 & 0,00380 & 0,00371 & 2,90 & 0,305 & 97,51 & 3,12 \\
\hline 45 & 29,93 & 0,00370 & 0,00365 & 2,97 & 0,297 & 98,63 & 3,21 \\
\hline 45 & 29,92 & 0,00372 & 0,00364 & 2,15 & 0,357 & 97,71 & 3,19 \\
\hline 45 & 5,09 & 0,00352 & 0,00343 & 1,15 & 0,709 & 97,25 & 3,37 \\
\hline 45 & 5,17 & 0,00353 & 0,00339 & 0,36 & 0,788 & 96,01 & 3,36 \\
\hline 45 & 4,86 & 0,00356 & 0,00347 & 2,64 & 0,666 & 97,31 & 3,37 \\
\hline 45 & 4,80 & 0,00362 & 0,00349 & 1,31 & 0,802 & 96,38 & 3,32 \\
\hline 45 & 41,46 & 0,00406 & 0,00404 & 3,01 & 0,351 & 99,45 & 2,89 \\
\hline 45 & 40,91 & 0,00408 & 0,00400 & 3,39 & 0,308 & 98,16 & 2,90 \\
\hline 45 & 41,05 & 0,00415 & 0,00398 & 1,79 & 0,420 & 95,82 & 2,86 \\
\hline 45 & 40,69 & 0,00415 & 0,00395 & 1,10 & 0,478 & 95,14 & 2,87 \\
\hline 45 & 39,76 & 0,00409 & 0,00399 & 4,16 & 0,246 & 97,48 & 2,92 \\
\hline 60 & 9,55 & 0,00058 & 0,00057 & 3,04 & 1,136 & 98,92 & 4,10 \\
\hline 60 & 10,01 & 0,00050 & 0,00048 & 2,18 & 1,304 & 97,82 & 4,35 \\
\hline 60 & 9,84 & 0,00086 & 0,00082 & 0,87 & 1,412 & 95,58 & 3,54 \\
\hline 60 & 10,12 & 0,00086 & 0,00086 & 1,63 & 1,350 & 100,44 & 3,56 \\
\hline 60 & 10,52 & 0,00079 & 0,00074 & 2,12 & 1,313 & 94,49 & 3,69 \\
\hline 60 & 9,85 & 0,00077 & 0,00074 & 2,00 & 1,327 & 96,97 & 3,70 \\
\hline 60 & 16,52 & 0,00057 & 0,00056 & 3,40 & 1,043 & 97,69 & 4,14 \\
\hline 60 & 16,49 & 0,00083 & 0,00082 & 0,90 & 1,290 & 98,95 & 3,62 \\
\hline 60 & 15,96 & 0,00076 & 0,00077 & 2,43 & 1,152 & 101,09 & 3,78 \\
\hline 60 & 15,74 & 0,00076 & 0,00072 & 0,47 & 1,338 & 94,74 & 3,70 \\
\hline 60 & 15,98 & 0,00089 & 0,00084 & 0,54 & 1,316 & 94,75 & 3,57 \\
\hline 60 & 15,64 & 0,00076 & 0,00074 & 3,38 & 1,078 & 97,70 & 3,86 \\
\hline
\end{tabular}




\begin{tabular}{llllllll}
\hline \hline 60 & 19,57 & 0,00046 & 0,00045 & 0,98 & 0,413 & 99,16 & 4,93 \\
60 & 20,18 & 0,00037 & 0,00037 & 1,68 & 0,354 & 99,25 & 5,23 \\
60 & 19,80 & 0,00036 & 0,00036 & 0,78 & 0,431 & 100,89 & 5,17 \\
60 & 20,40 & 0,00025 & 0,00026 & 0,71 & 0,457 & 101,27 & 4,09 \\
60 & 29,97 & 0,00032 & 0,00032 & 2,52 & 0,276 & 100,80 & 2,98 \\
60 & 30,06 & 0,00031 & 0,00031 & 1,75 & 0,349 & 100,55 & 3,17 \\
60 & 30,06 & 0,00031 & 0,00030 & 1,66 & 0,369 & 97,40 & 5,48 \\
60 & 30,07 & 0,00030 & 0,00030 & 1,34 & 0,397 & 100,14 & 3,26 \\
60 & 29,84 & 0,00032 & 0,00030 & 0,91 & 0,436 & 95,04 & 3,25 \\
60 & 29,78 & 0,00036 & 0,00035 & 2,59 & 0,288 & 97,99 & 2,66 \\
60 & 29,75 & 0,00031 & 0,00029 & 1,01 & 0,421 & 95,15 & 3,30 \\
60 & 29,87 & 0,00038 & 0,00038 & 2,99 & 0,242 & 100,28 & 2,45 \\
60 & 39,92 & 0,00039 & 0,00037 & 1,28 & 0,384 & 96,04 & 2,65 \\
60 & 40,17 & 0,00038 & 0,00038 & 2,63 & 0,252 & 99,01 & 2,49 \\
60 & 39,80 & 0,00038 & 0,00037 & 1,34 & 0,386 & 97,45 & 2,68 \\
60 & 40,74 & 0,00038 & 0,00037 & 1,23 & 0,422 & 95,72 & 2,71 \\
60 & 50,23 & 0,00038 & 0,00038 & 2,70 & 0,301 & 99,36 & 2,61 \\
60 & 49,82 & 0,00021 & 0,00022 & 4,93 & 0,100 & 101,42 & 4,02 \\
60 & 49,83 & 0,00021 & 0,00021 & 5,44 & 0,050 & 97,98 & 4,00 \\
60 & 40,07 & 0,00021 & 0,00020 & 4,78 & 0,048 & 97,62 & 3,98 \\
\hline \hline
\end{tabular}


Tabela F.2 - Dados experimentais obtidos com a mistura bifásica ar-óleo nos estudos de eficiência de separação de gás.

\begin{tabular}{|c|c|c|c|c|c|c|c|}
\hline $\boldsymbol{\beta}\left[{ }^{0}\right]$ & $\begin{array}{c}Q_{L} \\
{[1 / \mathbf{m i n}]}\end{array}$ & $\begin{array}{c}\dot{\boldsymbol{m}}_{m} \\
{[\mathrm{~kg} / \mathrm{s}]}\end{array}$ & $\dot{m}_{j}[\mathrm{~kg} / \mathrm{s}]$ & $L_{N A I}[\mathrm{~m}]$ & $\begin{array}{c}P_{\text {rev }} \\
\text { [bar] }\end{array}$ & $\begin{array}{c}\eta_{\text {shroud }} \\
{[\%]}\end{array}$ & $u_{\eta}[\%]$ \\
\hline 15 & 4,83 & 0,00037 & 0,00037 & $\begin{array}{l}5,71 \\
\end{array}$ & 0,134 & 100,35 & 2,04 \\
\hline 15 & 4,96 & 0,00035 & 0,00035 & 5,29 & 0,13 & 101,18 & 2,1 \\
\hline 15 & 5,09 & 0,00034 & 0,00034 & 4,24 & 0,152 & 100,45 & 2,16 \\
\hline 15 & 5,12 & 0,00033 & 0,00033 & 2,87 & 0,184 & 99,26 & 2,27 \\
\hline 15 & 4,99 & 0,00033 & 0,00033 & 2,64 & 0,189 & 100,13 & 2,28 \\
\hline 15 & 4,93 & 0,00032 & 0,00032 & 2,25 & 0,197 & 100,69 & 2,35 \\
\hline 15 & 5,1 & 0,0003 & 0,00031 & 1,21 & 0,224 & 100,55 & 2,47 \\
\hline 15 & 4,97 & 0,00029 & 0,00029 & 1,04 & 0,241 & 100,34 & 2,62 \\
\hline 15 & 5,02 & 0,0003 & 0,0003 & 1,13 & 0,241 & 99,61 & 2,55 \\
\hline 15 & 5,01 & 0,00029 & 0,00029 & 0,93 & 0,247 & 100,54 & 2,67 \\
\hline 15 & 5,12 & 0,00026 & 0,00027 & 0,82 & 0,245 & 100,96 & 2,87 \\
\hline 15 & 4,8 & 0,00025 & 0,00025 & 0,6 & 0,253 & 99,62 & 3,04 \\
\hline 15 & 40,12 & 0,00024 & 0,00022 & 1,85 & 0,61 & 95,25 & 4,83 \\
\hline 15 & 40,18 & 0,0005 & 0,00049 & 1,13 & 0,625 & 96,69 & 2,36 \\
\hline 15 & 40,18 & 0,00051 & 0,00049 & 3,62 & 0,568 & 96,26 & 2,28 \\
\hline 15 & 20,03 & 0,00032 & 0,00031 & 1,88 & 0,4 & 97,16 & 3,04 \\
\hline 15 & 20,05 & 0,00032 & 0,00032 & 2,51 & 0,382 & 101,15 & 2,95 \\
\hline 15 & 19,87 & 0,00041 & 0,00041 & 1,32 & 0,413 & 99,3 & 2,35 \\
\hline 15 & 20,12 & 0,0004 & 0,0004 & 0,5 & 0,433 & 99,03 & 2,45 \\
\hline 15 & 20,12 & 0,00039 & 0,00039 & 0,31 & 0,428 & 98,7 & 2,5 \\
\hline 15 & 20,11 & 0,00039 & 0,00038 & 0,26 & 0,428 & 99,21 & 2,51 \\
\hline 15 & 30,25 & 0,00038 & 0,00037 & 0,45 & 0,548 & 97,78 & 2,86 \\
\hline 15 & 30,19 & 0,00045 & 0,00045 & 1,23 & 0,518 & 100,28 & 2,38 \\
\hline 15 & 30,1 & 0,00045 & 0,00044 & 2,17 & 0,506 & 98,04 & 2,38 \\
\hline 15 & 30,17 & 0,00043 & 0,00042 & 2,16 & 0,506 & 97,54 & 2,48 \\
\hline 15 & 30,17 & 0,00042 & 0,00041 & 3,27 & 0,48 & 96,85 & 2,5 \\
\hline 15 & 24,94 & 0,00043 & 0,00043 & 2,48 & 0,399 & 100,05 & 2,26 \\
\hline 15 & 25,06 & 0,00041 & 0,0004 & 1,19 & 0,425 & 99,28 & 2,42 \\
\hline
\end{tabular}




\begin{tabular}{|c|c|c|c|c|c|c|c|}
\hline 15 & 25,1 & 0,0004 & 0,00039 & 1,22 & 0,425 & 998,79 & 2,46 \\
\hline 45 & 4,75 & 0,00047 & 0,00045 & 1,06 & 1,025 & 95,34 & 2,75 \\
\hline 45 & 5,20 & 0,00039 & 0,00037 & 2,40 & 0,922 & 95,64 & 3,17 \\
\hline 45 & 4,74 & 0,00041 & 0,00038 & 2,65 & 0,910 & 94,36 & 3,05 \\
\hline 45 & 5,04 & 0,00039 & 0,00037 & 3,79 & 0,870 & 94,53 & 3,09 \\
\hline 45 & 4,92 & 0,00040 & 0,00039 & 4,23 & 0,838 & 97,04 & 2,93 \\
\hline 45 & 4,88 & 0,00040 & 0,00039 & 4,28 & 0,836 & 97,38 & 2,94 \\
\hline 45 & 5,14 & 0,00038 & 0,00037 & 4,32 & 0,846 & 97,43 & 3,12 \\
\hline 45 & 5,13 & 0,00040 & 0,00039 & 4,94 & 0,790 & 97,60 & 2,89 \\
\hline 45 & 5,06 & 0,00040 & 0,00039 & 5,43 & 0,747 & 98,10 & 2,88 \\
\hline 45 & 4,25 & 0,00038 & 0,00037 & 0,17 & 1,049 & 96,31 & 3,40 \\
\hline 45 & 4,08 & 0,00040 & 0,00038 & 1,03 & 1,000 & 95,32 & 3,20 \\
\hline 45 & 6,04 & 0,00041 & 0,00040 & 2,98 & 1,024 & 96,87 & 3,15 \\
\hline 45 & 4,01 & 0,00046 & 0,00044 & 2,41 & 0,915 & 96,13 & 2,67 \\
\hline 45 & 3,92 & 0,00046 & 0,00044 & 3,10 & 0,876 & 96,36 & 2,64 \\
\hline 45 & 4,20 & 0,00039 & 0,00038 & 4,06 & 0,820 & 97,19 & 2,99 \\
\hline 45 & 5,88 & 0,00049 & 0,00047 & 0,65 & 1,204 & 97,35 & 2,89 \\
\hline 45 & 6,10 & 0,00041 & 0,00039 & 2,50 & 1,081 & 95,09 & 3,28 \\
\hline 45 & 6,31 & 0,00040 & 0,00038 & 3,26 & 1,031 & 94,92 & 3,31 \\
\hline 45 & 6,04 & 0,00040 & 0,00038 & 4,82 & 0,931 & 95,85 & 3,16 \\
\hline 45 & 2,97 & 0,00040 & 0,00039 & 3,00 & 0,916 & 97,65 & 3,06 \\
\hline 45 & 3,12 & 0,00040 & 0,00040 & 1,77 & 0,994 & 99,09 & 3,11 \\
\hline 45 & 3,16 & 0,00039 & 0,00038 & 1,65 & 1,018 & 98,87 & 3,24 \\
\hline 45 & 2,93 & 0,00028 & 0,00027 & 3,50 & 0,871 & 96,57 & 4,30 \\
\hline 45 & 3,12 & 0,00043 & 0,00042 & 3,61 & 0,864 & 98,81 & 2,78 \\
\hline 45 & 6,26 & 0,00043 & 0,00042 & 2,34 & 1,068 & 97,94 & 3,05 \\
\hline 45 & 5,84 & 0,00024 & 0,00023 & 2,73 & 1,040 & 95,01 & 5,47 \\
\hline 45 & 6,04 & 0,00041 & 0,00040 & 2,98 & 1,024 & 96,87 & 3,15 \\
\hline 45 & 3,24 & 0,00041 & 0,00040 & 1,69 & 0,990 & 97,54 & 3,00 \\
\hline 45 & 3,12 & 0,00042 & 0,00040 & 1,19 & 1,042 & 96,37 & 3,08 \\
\hline 45 & 4,16 & 0,00052 & 0,00051 & 3,81 & 0,941 & 98,44 & 2,36 \\
\hline 45 & 4,12 & 0,00052 & 0,00051 & 1,23 & 1,086 & 98,16 & 2,50 \\
\hline 45 & 3,79 & 0,00051 & 0,00050 & 1,41 & 1,083 & 97,19 & 2,54 \\
\hline
\end{tabular}




\begin{tabular}{|c|c|c|c|c|c|c|c|}
\hline 45 & 4,14 & 0,00051 & 0,00050 & 0,39 & 1,143 & 96,69 & 2,62 \\
\hline 60 & 2,80 & 0,00042 & 0,00041 & 1,15 & 1,237 & 98,60 & 3,02 \\
\hline 60 & 4,25 & 0,00048 & 0,00046 & 3,93 & 1,109 & 96,30 & 2,80 \\
\hline 60 & 2,95 & 0,00041 & 0,00039 & 0,41 & 1,323 & 95,91 & 3,25 \\
\hline 60 & 3,87 & 0,00049 & 0,00048 & 3,07 & 1,170 & 97,41 & 2,79 \\
\hline 60 & 3,76 & 0,00049 & 0,00048 & 2,02 & 1,244 & 97,32 & 2,85 \\
\hline 60 & 4,22 & 0,00041 & 0,00040 & 5,99 & 0,933 & 97,50 & 3,07 \\
\hline 60 & 4,84 & 0,00041 & 0,00039 & 2,38 & 1,243 & 93,77 & 3,43 \\
\hline 60 & 5,04 & 0,00049 & 0,00048 & 3,03 & 1,174 & 97,55 & 2,73 \\
\hline 60 & 4,77 & 0,00048 & 0,00046 & 3,39 & 1,158 & 96,47 & 2,81 \\
\hline 60 & 5,01 & 0,00048 & 0,00047 & 4,03 & 1,111 & 97,08 & 2,69 \\
\hline 60 & 4,87 & 0,00049 & 0,00047 & 4,64 & 1,089 & 96,80 & 2,65 \\
\hline 60 & 3,31 & 0,00040 & 0,00039 & 3,59 & 1,052 & 97,66 & 3,20 \\
\hline 60 & 3,20 & 0,00044 & 0,00043 & 4,51 & 0,989 & 98,00 & 2,77 \\
\hline 60 & 3,89 & 0,00044 & 0,00043 & 6,92 & 0,865 & 97,71 & 2,62 \\
\hline 60 & 4,01 & 0,00043 & 0,00042 & 7,58 & 0,817 & 98,08 & 2,63 \\
\hline 60 & 4,83 & 0,00045 & 0,00044 & 5,89 & 0,965 & 97,53 & 2,70 \\
\hline 60 & 5,25 & 0,00043 & 0,00042 & 7,20 & 0,866 & 98,36 & 2,71 \\
\hline 60 & 6,91 & 0,00045 & 0,00044 & 6,75 & 0,944 & 97,48 & 2,70 \\
\hline 60 & 7,10 & 0,00043 & 0,00041 & 4,65 & 1,106 & 95,56 & 3,04 \\
\hline 60 & 6,80 & 0,00046 & 0,00046 & 2,85 & 1,179 & 98,39 & 2,76 \\
\hline 60 & 6,63 & 0,00045 & 0,00044 & 1,20 & 1,305 & 97,48 & 2,98 \\
\hline 60 & 6,88 & 0,00045 & 0,00043 & 5,28 & 1,009 & 97,01 & 2,83 \\
\hline 60 & 7,23 & 0,00046 & 0,00045 & 6,56 & 0,916 & 97,92 & 2,63 \\
\hline 60 & 9,79 & 0,00047 & 0,00046 & 5,59 & 1,057 & 97,46 & 2,79 \\
\hline 60 & 9,96 & 0,00047 & 0,00045 & 1,04 & 1,205 & 97,06 & 2,99 \\
\hline 60 & 9,84 & 0,00047 & 0,00046 & 2,45 & 1,096 & 97,54 & 2,84 \\
\hline 60 & 10,01 & 0,00047 & 0,00046 & 4,00 & 0,976 & 97,64 & 2,66 \\
\hline 60 & 10,15 & 0,00047 & 0,00046 & 6,09 & 0,825 & 97,67 & 2,51 \\
\hline 60 & 14,97 & 0,00048 & 0,00046 & 0,92 & 1,383 & 95,10 & 5,63 \\
\hline 60 & 14,86 & 0,00050 & 0,00047 & 0,96 & 1,381 & 94,57 & 3,09 \\
\hline 60 & 14,88 & 0,00048 & 0,00045 & 3,14 & 1,216 & 94,17 & 3,07 \\
\hline 60 & 14,99 & 0,00050 & 0,00047 & 4,45 & 1,115 & 93,71 & 2,84 \\
\hline
\end{tabular}




\begin{tabular}{rlllllll}
\hline \hline 60 & 14,88 & 0,00049 & 0,00047 & 6,25 & 0,952 & 95,98 & 2,69 \\
60 & 14,99 & 0,00049 & 0,00046 & 7,03 & 0,875 & 95,61 & 2,63 \\
60 & 14,93 & 0,00048 & 0,00046 & 7,50 & 0,830 & 95,92 & 2,63 \\
\hline
\end{tabular}

Tabela F.3 - Dados experimentais obtidos com a mistura bifásica ar-água nos estudos de distribuições de diâmetros de bolhas.

\begin{tabular}{|c|c|c|c|c|c|c|c|c|c|c|c|}
\hline$\beta[0]$ & $\begin{array}{c}Q_{L} \\
{[1 / \mathrm{min}]}\end{array}$ & $\begin{array}{c}\dot{m}_{m} \\
{[\mathrm{~kg} / \mathrm{s}]}\end{array}$ & $\begin{array}{c}\dot{\boldsymbol{m}}_{\boldsymbol{j}} \\
{[\mathrm{kg} / \mathrm{s}]}\end{array}$ & $\begin{array}{r}L_{N A I} \\
{[\mathrm{~m}]}\end{array}$ & $\begin{array}{l}P_{\text {rev }} \\
\text { [bar] }\end{array}$ & $\begin{array}{c}\eta_{\text {shroud }} \\
{[\%]}\end{array}$ & $\begin{array}{c}u_{\eta} \\
{[\%]}\end{array}$ & $\begin{array}{c}L_{\text {lente }} \\
{[\mathrm{m}]}\end{array}$ & $\begin{array}{c}D_{\text {médio }} \\
{[\mu \mathrm{m}]}\end{array}$ & $\begin{array}{c}D_{\text {Sauter }} \\
{[\mu \mathrm{m}]}\end{array}$ & $\begin{array}{c}D_{\text {máximo }} \\
{[\mu \mathrm{m}]}\end{array}$ \\
\hline 45 & 60,01 & 0,00096 & 0,00083 & 3,62 & 0,264 & 86,79 & 3,46 & 2,92 & 70,43 & 382,37 & 471 \\
\hline 45 & 59,56 & 0,00095 & 0,00083 & 3,40 & 0,258 & 86,90 & 3,48 & 2,70 & 75,92 & 399,55 & 512 \\
\hline 45 & 60,11 & 0,00097 & 0,00075 & 2,13 & 0,419 & 76,76 & 3,37 & 1,43 & 64,70 & 349,23 & 476 \\
\hline
\end{tabular}

